\title{
$\operatorname{DOEFR} / 63037-1$
}

\section{The Effect of Government Actions on Environmental Technology Innovation: Applications to the Integrated Assessment of Carbon Sequestration Technologies}

\author{
A Final Report Submitted to \\ Dr. John C. Houghton \\ Office of Biological and Environmental Research \\ U.S. Department of Energy \\ Germantown, MD 20874
}

from

Edward S. Rubin, David A. Hounshell, Sonia Yeh, and Margaret Taylor Carnegie Mellon University

Pittsburgh, PA 15213

and

Leo Schrattenholzer, Keywan Riahi, Leonardo Barreto and Shilpa Rao International Institute for Applied Systems Analysis

A-2361 Laxenburg, Austria

DOE Patent Clearance Granted

January 2004

$\frac{\text { MDD worcull }}{\text { Mark P. Dvorscak }}$

Prepared for

DOE Chicago Operations Office

THE U. S. DEPARTMENT OF ENERGY

AWARD NO. DE-FG02-00ER63037 


\section{DISCLAIMER}

This report was prepared as an account of work sponsored by an agency of the United States Government. Neither the United States Government nor any agency Thereof, nor any of their employees, makes any warranty, express or implied, or assumes any legal liability or responsibility for the accuracy, completeness, or usefulness of any information, apparatus, product, or process disclosed, or represents that its use would not infringe privately owned rights. Reference herein to any specific commercial product, process, or service by trade name, trademark, manufacturer, or otherwise does not necessarily constitute or imply its endorsement, recommendation, or favoring by the United States Government or any agency thereof. The views and opinions of authors expressed herein do not necessarily state or reflect those of the United States Government or any agency thereof. 


\section{DISCLAIMER}

Portions of this document may be illegible in electronic image products. Images are produced from the best available original document. 


\section{Table of Contents}

EXECUTIVE SUMMARY

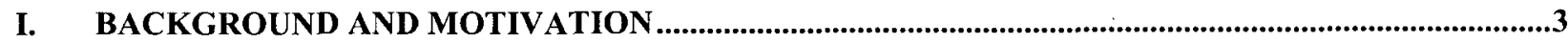

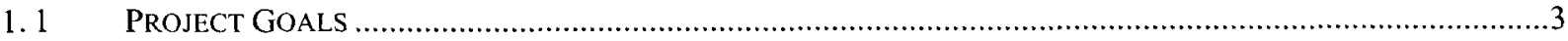

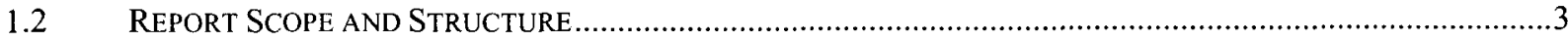

II. TECHNOLOGY INNOVATION IN SO $\mathrm{S}_{2}$ CONTROL .............................................................................5

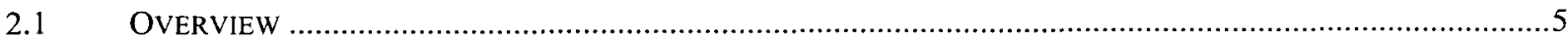

$2.2 \quad \mathrm{SO}_{2}$ REGULATION IN THE U.S.

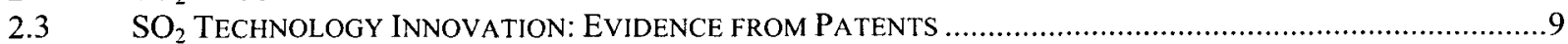

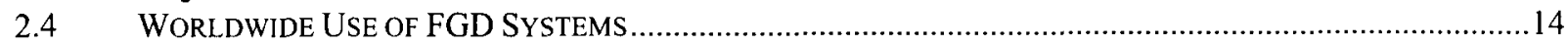

$2.5 \quad$ EXPERIENCE CURVES FOR FGD

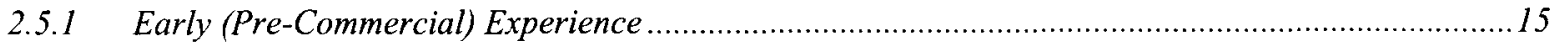

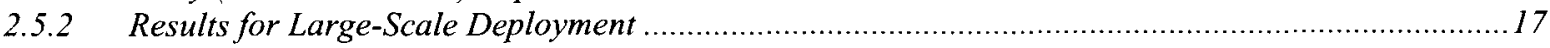

III. TECHNOLOGY INNOVATION IN NO ${ }_{\mathrm{x}}$ CONTROL............................................................................

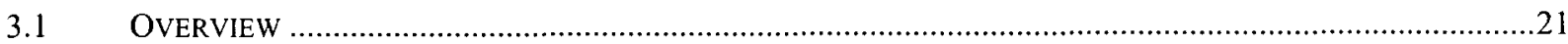

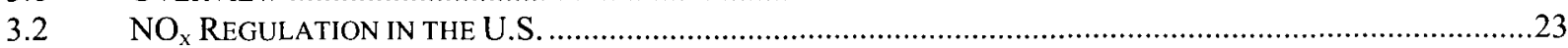

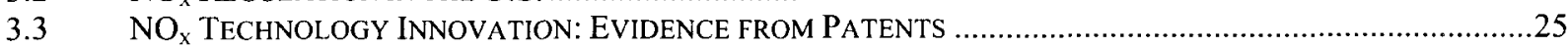

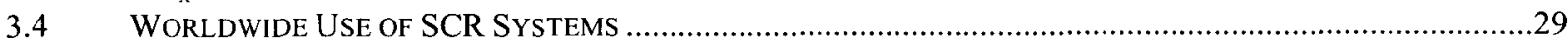

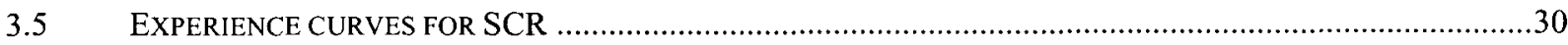

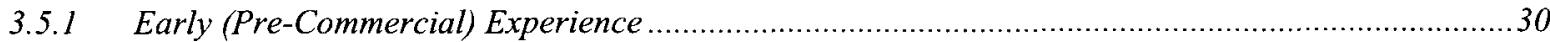

3.5.2 Results for Large-Scale Deployment ……..........................................................................

IV. TECHNOLOGY INNOVATION IN CO $\mathrm{CO}_{2}$ CONTROL ...........................................................................35

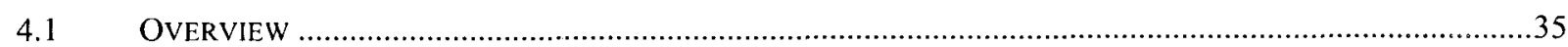

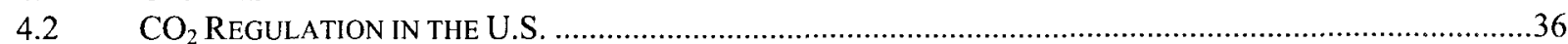

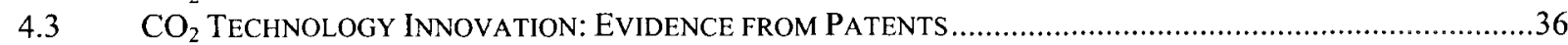

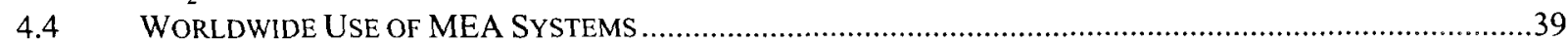

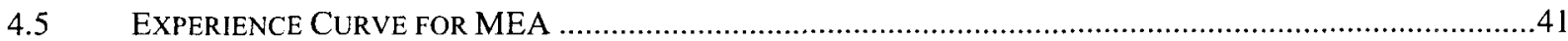

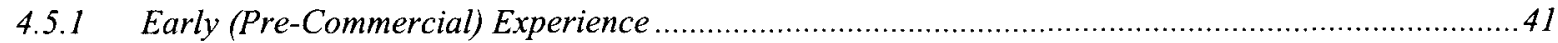

V. SUMMARY OF EXPERIENCE CURVES FOR ENVIRONMENTAL TECHNOLOGY ....................44

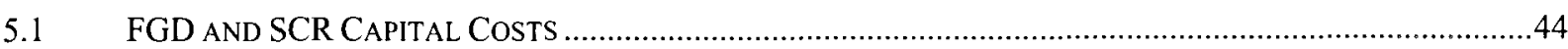

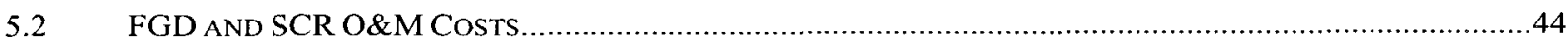

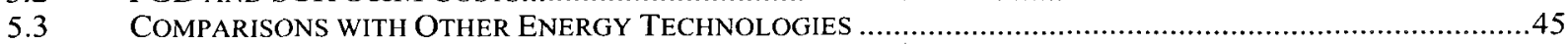

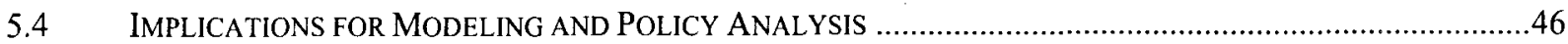

VI. APPLICATION OF EXPERIENCE CURVES TO INTEGRATED ASSESSMENT MODELS .........49

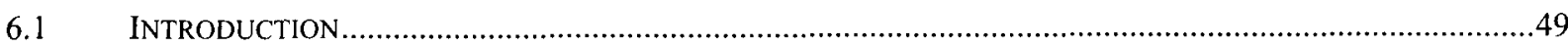

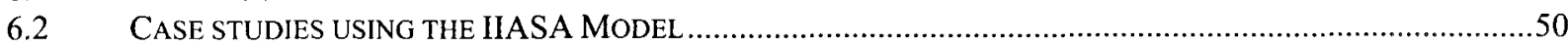

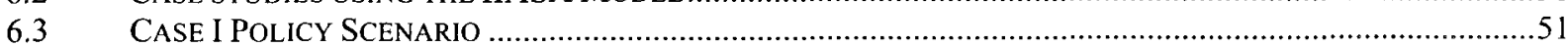

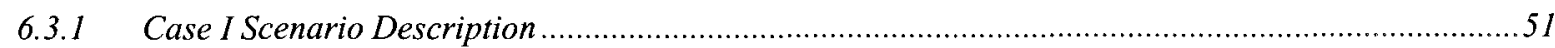

6.3.2 Results and Effects of Environmental Technology Learning …….................................................5I

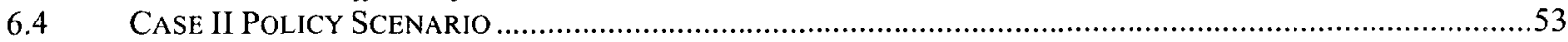

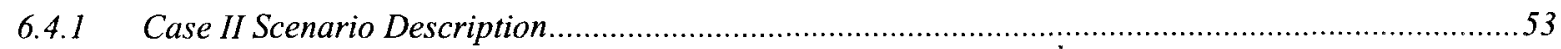

6.4.2 Results and Effects of Environmental Technology Learning …....................................................54

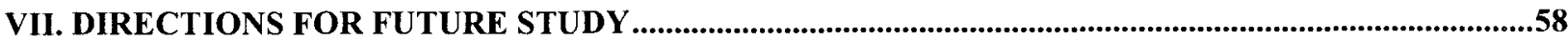

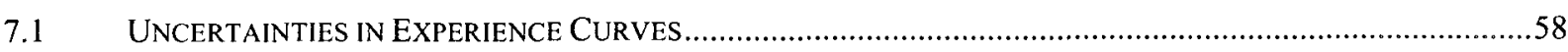

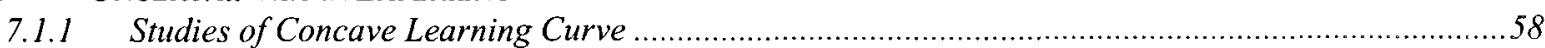

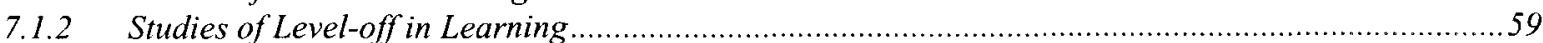

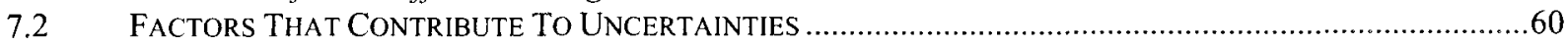




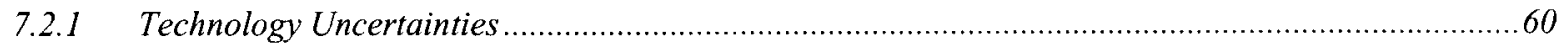

7.2.2 Market Structural Change, Forgetting and Other Social Factors .................................................61

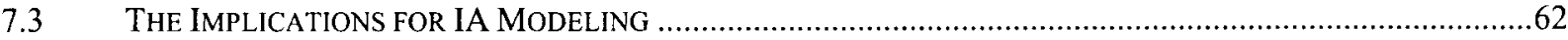

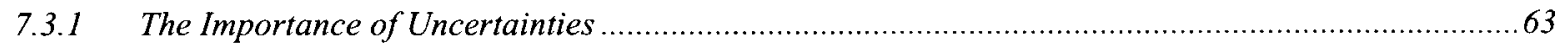

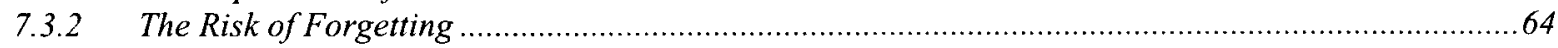

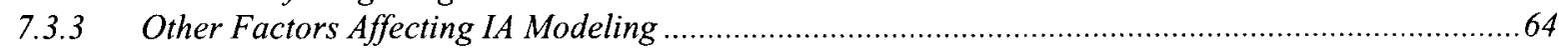

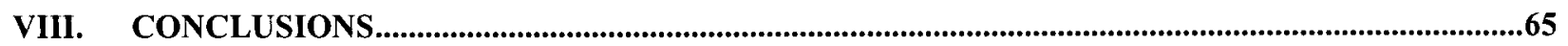

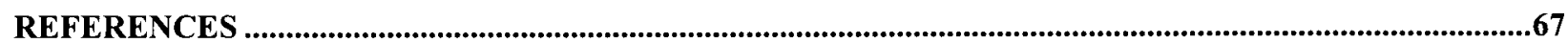

APPENDIX A. LIST OF PUBLICATIONS AND ACTIVITIES SPONSORED BY THE GRANT .................74

APPENDIX B. IIASA INTERIM REPORT …....................................................................................................76

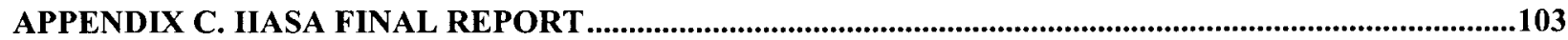




\section{Executive Summary}

The forecast of technology changes is one of the most important assumptions in most long-term energy, economic models. This project seeks to improve the ability of integrated assessment models (IA) to incorporate changes in technology, especially environmental technologies, cost and performance over time. In this reports, we presents results of research that examines past experience in controlling other major power plant emissions that might serve as a reasonable guide to future rates of technological progress in carbon capture and sequestration (CCS) systems. In particular, we focus on U.S. and worldwide experience with sulfur dioxide $\left(\mathrm{SO}_{2}\right)$ and nitrogen oxide $\left(\mathrm{NO}_{\mathrm{x}}\right)$ control technologies over the past 30 years, and derive empirical learning rates for these technologies. The patterns of technology innovation are captured by our analysis of patent activities and trends of cost reduction over time. Overall, we found learning rates of $11 \%$ for the capital costs of flue gas desulphurization (FGD) system for $\mathrm{SO}_{2}$ control, and $13 \%$ for selective catalytic reduction ( $\mathrm{SCR}$ ) systems for $\mathrm{NO}_{\mathrm{x}}$ control. We explore the key factors responsible for the observed trends, especially the development of regulatory policies for $\mathrm{SO}_{2}$ and $\mathrm{NO}_{\mathrm{x}}$ control, and their implications for environmental control technology innovation.

This report also discusses the relevance of these findings to other environmental issues of current interest, especially the outlook for technological progress in carbon capture and sequestration technologies applicable to fossil-fueled electric power plants. We examine the history of $\mathrm{CO}_{2}$ separation and capture technology that capture $\mathrm{CO}_{2}$ from the flue gas stream of electric power plants and other industrial processes and found significant learning in the past, and high learning potentials in the future.

This report also describes our collaboration efforts with the International Institute of Applied Systems Analysis (IIASA) in applying the observed learning rates to costs of CCS and other advanced energy technologies in a large-scale IA model. The results show that the costs of achieving a climate stabilization target are significantly lower relative to scenarios with no learning for CCS technologies. Similarly, the policy scenario that requires over time an increasing fraction of fossil-fueled power generation to incorporate CCS also found lower abatement costs and higher level of innovations when compared with scenarios of no learning. 
Lastly, issues remained to be addressed in the use of experience curves in long-term energy and environmental modeling are discussed in detail. Future research is needed for more understanding of the processes of technological innovation, and to incorporate more detailed models to improve the ability of IA models to represent the policy-related outcome of technology innovation. 


\section{Background and Motivation}

\section{1 Project Goals}

Assumptions about technological innovation and diffusion are among the most important uncertainties in integrated assessment (IA) models used to study global climate change and the impacts of climate policy options. Many integrated assessment models simply ignore technological innovation. Others use fairly simple metrics and methods to characterize changes in cost or performance overtime. For example, the cost of a technology or an energy carrier might be assumed to decrease over time in some exogenously-specified manner. Or the concept of autonomous energy efficiency might be invoked to predict reductions in future energy demand growth due to technological change. In some cases, assumptions about "backstop" technologies and technology "learning curves" are used to guide integrated assessment efforts and to estimate future technology costs and capabilities. A few models are beginning to incorporate more sophisticated methods that treat technological change endogenously.

Whatever the method used to model or characterize the role of technological innovation and diffusion, scenarios of future environmental change, and the predicted impacts of proposed policy measures, depend critically upon these assumptions. The purpose of the present project is to substantially improve the capability of IA models to represent the effects of technological innovations for an important new class of environmental technology: carbon capture and sequestration, especially as applied to fossil-fueled power plants. In particular, we seek quantitative representations of the changes in technology cost and performance over time as a function of pertinent variables then can be (or already are) incorporated in large-scale IA models. Understanding the effects of government actions on the introduction of environmental technological innovation is another important goal of this project.

\subsection{Report Scope and Structure}

This report summarizes the results of this research project, conducted from September 15, 2000 to November 15, 2003. The project involved four principal tasks: (1) extension and refinement of recently developed prediction and assessment methods to characterize technology innovations for sulfur dioxide control technologies; (2) application and further refinement of these methods to $\mathrm{NO}_{\mathrm{x}}$ controls, representing another class of environmental technology relevant to global change, but with different regulatory attributes; (3) preliminary application of the above methods to carbon capture and sequestration technologies; and (4) incorporation of the new technology change models in the IIASA models, to assess prospects for carbon sequestration technologies in an integrated assessment framework.

Section II of the report first presents our data and analysis of patterns of innovation in $\mathrm{SO}_{2}$ control technologies in the United States from 1887 to 1999. It shows how these patterns are correlated with the timing and stringency of regulations of the pollutant for electric power plants. The section further reports on the "experience curves" for the cost of commercial technologies developed to meet these regulations.

Section III next reports our findings of innovation patterns in $\mathrm{NO}_{\mathrm{x}}$ control technologies in the United States. Again we show how these patterns are correlated with the timing and stringency of regulations for electric power plants. U.S. $\mathrm{NO}_{\mathrm{x}}$ regulation differed significantly from $\mathrm{SO}_{2}$ 
regulation, and our analysis demonstrates how these differences yielded different patterns of innovation in the development of $\mathrm{NO}_{\mathrm{x}}$ control technologies. The section also reports on the experience curves of $\mathrm{NO}_{\mathrm{x}}$ control technologies for commercial electric power plants.

Section IV presents results of our screening of technology innovations in carbon capture and sequestration technologies using methods developed for analyzing innovation in $\mathrm{SO}_{2}$ and $\mathrm{NO}_{\mathrm{x}}$ control technologies. We also use a new screening method to correlate activities in research publications and the timing of international interests in the field of global climate change.

Section $\mathrm{V}$ compares the experience curves from the $\mathrm{SO}_{2}$ and $\mathrm{NO}_{\mathrm{x}}$ studies. The results are also compared with other studies of experience curves for energy technologies. We also discuss the implications of the findings for modeling and policy analysis.

Section VI describes the application of the $\mathrm{SO}_{2}$ experience curve to represent technical learning for carbon capture and sequestration technology (CCTs) (Policy Case I), and for both CCTs and other fossil-fueled power generation technologies (Policy Case II). It is shown that introducing cost trends for CCTs with technological learning increases their contributions to carbon mitigation strategies significantly. Secondly, the policy framework that requires over time an increasing fraction of fossil-fueled power generation to incorporate carbon capture technologies shows that the decarbonization of the electricity sector through carbon capture and sequestration would lead to significant technology innovations and $\mathrm{CO}_{2}$ emissions reductions.

Section VII discusses issues remain to be addressed in the use of experience curves in long-term energy and environmental modeling. The use of alternative functions to represent experience curves produces better fits to our data on the capital and O\&M costs of two above-mentioned power plant environmental control technologies. Experience curves of different shapes and uncertainties for learning rates will change the pace of cost reductions in large-scale energy models, which could change the outcomes of integrated assessment (IA) models.

Finally, Section VIII summarizes the results and presents the conclusions and policy implications from our analysis.

Supporting this work, a series of appendices are also included. Appendix A lists the publications resulting from this research. Appendices $B$ and $C$ present full details of the IA modeling work carried out in collaboration with the International Institute for Applied Systems Analysis (IIASA) as part of this project. 


\section{Technology Innovation in $\mathrm{SO}_{2}$ Control}

\subsection{Overview}

Sulfur dioxide $\left(\mathrm{SO}_{2}\right)$ is an air pollutant emitted to the atmosphere primarily through the burning of sulfur-containing materials, of which fossil fuels such as coal and oil are the most important examples. $\mathrm{SO}_{2}$ is, therefore, the byproduct of many long-standing economically productive processes. Although the importance of selected sources of $\mathrm{SO}_{2}$ emissions in the United States has changed over time, coal-fired electric power plants have been the primary source of these emissions since 1960. Public concern about $\mathrm{SO}_{2}$ pertains to its negative effects both on human health and on ecosystem well-being.

For over three decades, government actions in the United States have had a considerable influence on the development of $\mathrm{SO}_{2}$ control technologies. Innovation in these technologies (which includes the processes of invention, adoption, diffusion, and learning by doing) has been affected by organizational "actors" such as equipment vendors, electric utilities, and the government. " To first order, government is vital to innovation in $\mathrm{SO}_{2}$ control technologies because it defines, through such actions as legislation, executive orders, and litigation, the need and requirements for emission controls. Some government actions have also defined the manner in which emissions reductions should be achieved.

For example, $\mathrm{SO}_{2}$ legislation and its regulation have: proposed financial incentives for installing abatement equipment; set the stringency of emissions controls that must be met; defined the flexibility and time constraints for meeting abatement requirements; and defined - through their scope - the market size of equipment suppliers. In addition, government has funded research, training, and technical assistance programs including demonstration projects, grants to vendors, and technology transfer opportunities that directly affected the operation and design of equipment used to control $\mathrm{SO}_{2}$ emissions.

Environmental control strategies pertinent to $\mathrm{SO}_{2}$ emissions take one of three approaches: (1) use of naturally occurring lower-sulfur fuels, or technological removal of sulfur from fuels prior to combustion; (2) alternative power generation technologies such as fluidized bed combustion that remove sulfur during the combustion process; and (3) removal of $\mathrm{SO}_{2}$ from the postcombustion flue gas stream. ${ }^{2}$ Pre-combustion and post-combustion control methods and technologies have been most widely used by coal-fired power generation processes over the last

\footnotetext{
1 "Invention" refers to the development of a new technical idea. "Adoption" refers to the first commercial implementation of an invention. "Diffusion" refers to the process by which an adopted technology enters widespread use. Diffusion is often studied as a communication process. Finally, "learning by doing" refers to post-adoption innovative activities that result from knowledge gained from operating experience. Studies have shown that a considerable amount of innovative activity can be traced to operating personnel or to the contact of other researchers with operating personnel. See Schumpeter, J. A. (1942). Capitalism, Socialism and Democracy. New York, Harper Brothers, Cohen, W. and R. Levin (1989). Empirical studies of innovation and market structure. Handbook of Individual Organization. R. Schmalensee and R. D. Willig. Amsterdam, Elsevier. 2: 1059-1 107, Rosenberg, N. (1994). Exploring the Black Box: Technology, Economics, and History. Cambridge, UK, Cambridge University Press, Rogers, E. M. (1995). DIffusion of Innovations. New York, Free Press.

${ }^{2}$ Sub-bituminous and lignite coals, found primarily in easily surface-mined deposits in the western U.S., are typically lower in both heat and sulfur content. Bituminous and anthracite coals, found primarily in deposits that are deep-pit mined in the eastern U.S., are typically. higher in heat and sulfur content Laitos, J. G. and J. P. Tomain (1992). Energy Law in a Nutshell. St. Paul, MN, West Publishing..
} 
thirty years. ${ }^{3}$ Pre-combustion control technologies primarily involve physical removal processes such as crushing and grinding to remove inorganic sulfur in the form of pyrite from coal. More advanced chemical and biological pre-combustion technologies have been proposed that can also remove some of the organic sulfur from coal for a greater overall $\mathrm{SO}_{2}$ emission reduction, but these processes are very costly and none are yet commercial. None of these pre-combustion technologies, however, removes as much $\mathrm{SO}_{2}$ as post-combustion control technologies.

Post-combustion controls, which are now installed on roughly 90 gigawatts (or about one-third) of U.S. electrical capacity, are commonly referred to as flue gas desulfurization (FGD) systems or "scrubbing" technologies. FGD systems involve contacting the flue gas stream with a base reagent in order to remove $\mathrm{SO}_{2}$. These systems can be categorized as wet or dry processes. Wet FGD processes are the most common. They produce either a solid waste or gypsum by-product using reagents like limestone, lime, or dolomitic lime. Dry FGD technology mainly employs lime spray drying, but also includes direct sorbent injection into the furnace, or flue gas duct. Some FGD processes are "regenerable" using reagents such as sodium sulfite and magnesium oxide, to produce a useful byproduct rather than a solid waste, in some cases with combined sulfur oxide/nitrogen oxide removal. Figure 1 shows the distribution of installed post-combustion $\mathrm{SO}_{2}$ control technologies around the world.

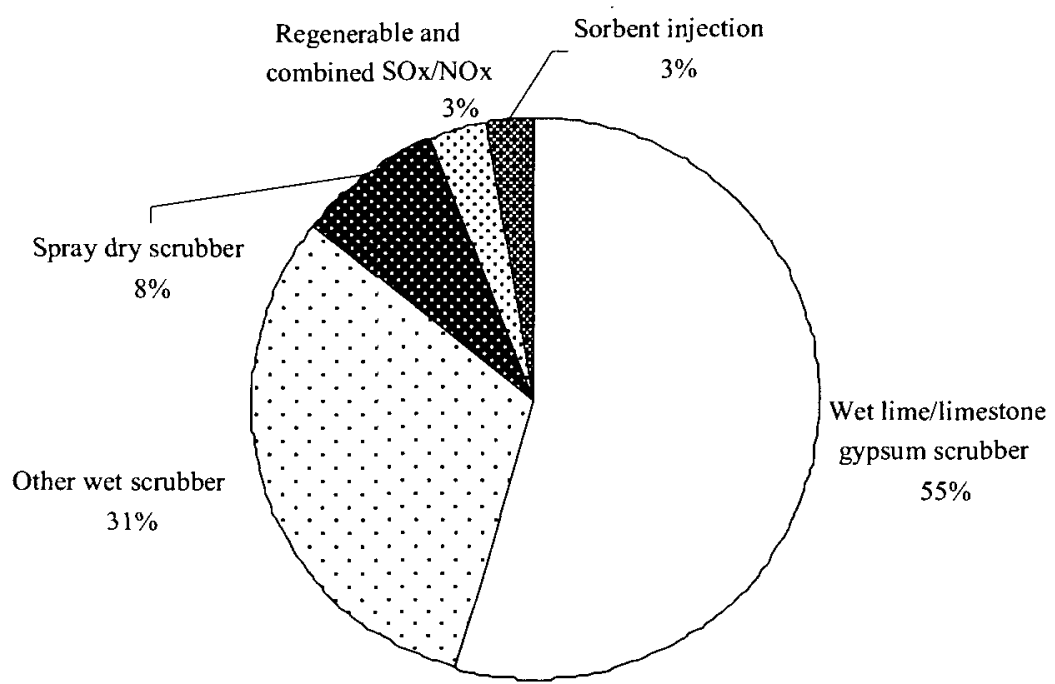

Figure 1. World market distribution of post-combustion $\mathrm{SO}_{2}$ control technologies in 1994, by type. Source: (Soud 1994)

The dominant wet FGD systems use limestone as the scrubbing reagent and today achieve reliable, $95 \%+\mathrm{SO}_{2}$ removal efficiencies. ${ }^{4}$ Figure 2 shows a simple schematic of a power plant using a wet limestone FGD system. In the wet scrubber, limestone slurry is contacted with flue gas. $\mathrm{SO}_{2}$ is absorbed, and either partially oxidized to a mixture of calcium sulfite and calcium sulfate, or (more commonly) fully oxidized (by the forced addition of air) to calcium sulfate

\footnotetext{
${ }^{3}$ Tall gas stacks that disperse $\mathrm{SO}_{2}$ from local areas were once promoted by the electric power industry as an effective method of controlling $\mathrm{SO}_{2}$ emissions from existing generation processes. These are no longer relevant because of regional concerns about $\mathrm{SO}_{2}$ and acid rain.

${ }^{4}$ Wet limestone scrubbing is dominant in the worldwide utility FGD market in part because limestone is inexpensive and widely available.
} 
(gypsum). ${ }^{5}$ Equation 1 displays the basic chemistry of the limestone $\mathrm{SO}_{2}$ absorption process with forced oxidation.

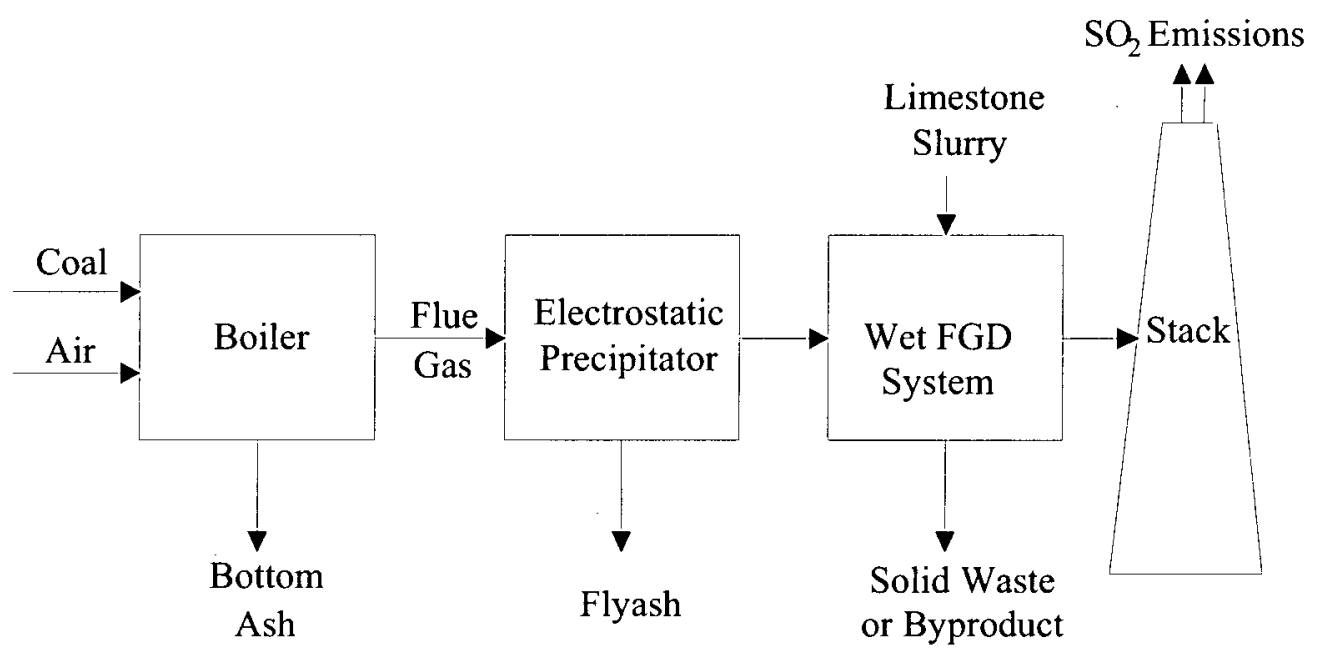

Figure 2. Schematic of a typical wet limestone FGD system at a coal-fired power plant.

Basic chemistry of the limestone $\mathrm{SO}_{2}$ absorption process.

$$
\mathrm{SO}_{2}+\mathrm{CaCO}_{3}+2 \mathrm{H}_{2} \mathrm{O}+\frac{1}{2} \mathrm{O}_{2} \rightarrow \mathrm{CO}_{2}+\mathrm{CaSO}_{4} \cdot 2 \mathrm{H}_{2} \mathrm{O} \quad \text { (Equation 1) }
$$

\section{$2.2 \mathrm{SO}_{2}$ Regulation in the U.S.}

Although the earliest applications of FGD at coal-burning power plants can be traced back to the early 1930s in England, the modern era of environmental controls dates from the late 1960s and early 1970s. In the United States, the 1970 Clean Air Act Amendments (CAAA) identified sulfur dioxide as one of five "criteria" air pollutants associated with adverse effects on human health and welfare. The principal sources of $\mathrm{SO}_{2}$ at that time were (and continue to be) coal-burning power plants. When burned, the sulfur in coal is converted primarily to $\mathrm{SO}_{2}$ and released to the atmosphere. The sulfur content of coals varies widely, from less than $0.5 \%$ to over $5 \%$ by weight, depending on coal type and source. In the early 1970s, the average sulfur content of coals burned at U.S. power plants was approximately $2.5 \%$.

In the U.S., environmental policies and regulations for controlling $\mathrm{SO}_{2}$ emissions (see Table 1) took two forms. For existing sources of $\mathrm{SO}_{2}$ (primarily power plants) individual states were required to limit emissions to a level that would achieve and maintain the national ambient air quality standards (NAAQS) for $\mathrm{SO}_{2}$ promulgated in 1971 by the newly created U.S. Environmental Protection Agency (EPA). These standards applied to ground-level pollution concentrations and were intended to protect human health and welfare. The resulting set of state and local emission regulations allowed some power plants to continue emitting $\mathrm{SO}_{2}$ with little or

\footnotetext{
${ }^{5}$ Absorber devices include packed towers, plate or tray columns, venturi scrubbers, and spray chambers Barbour, W. (1996). Gas absorbers. OAQPS control cost manual (EPA 453/B-96-001). W. M. Vatavuk. Research Triangle Park, NC, U.S. Environmental Protection Agency, Office of Air Quality Planning \& Standards.
} 
no emission controls, while at other locations moderate to severe restrictions were placed on $\mathrm{SO}_{2}$ emissions.

For new power plants, $\mathrm{SO}_{2}$ emission regulations were established directly by the EPA in the form of New Source Performance Standards (NSPS) requiring the use of "best available control technology" (BACT). The first NSPS for coal-fired power plants, established in 1971, defined $\mathrm{BACT}$ as a performance-based standard limiting $\mathrm{SO}_{2}$ emissions to 1.2 pounds per million Btu (lb/MBtu) of fuel energy input to the boiler. This emission standard corresponded to roughly a $75 \%$ reduction from the average emission rates at the time, but it allowed new plants to comply either by burning a sufficiently low-sulfur coal or by installing an FGD system while burning high-sulfur coals.

In 1979, a revised NSPS was promulgated that replaced the performance-based standard with a technology-based standard requiring all new coal-fired plants built after 1978 to employ a system of continuous emission reductions achieving between 70 and $90 \% \mathrm{SO}_{2}$ removal, with the percentage depending upon the sulfur content of the coal being burned. Given the set of pollution control technologies then available, this new standard effectively required the use of an FGD system on all new coal-fired plants. The lower removal efficiency limit applied to plants burning low-sulfur coals typical of those in the western U.S., while the higher limit of $90 \%$ removal applied to plants burning higher sulfur coals characteristic of the Midwest and Eastern U.S. then the dominant fuel sources for electric power generation.

Table 1 also lists the more recent $\mathrm{SO}_{2}$ control requirements stemming from the 1990 amendments to the Clean Air Act. To address the problem of acid deposition, EPA established a national emissions cap for $\mathrm{SO}_{2}$ at a level of 9.8 million tons/yr, to be achieved by the year 2000 . To achieve this limit, existing power plants were required to further reduce their $\mathrm{SO}_{2}$ emissions by roughly $40 \%$ below their 1990 levels. Power plants could comply either by switching to cleaner (low-sulfur) fuels, by installing an FGD system, by purchasing emission credits under a newly created emissions trading scheme, or by some combination of these approaches. 
Table 1. Major U.S. regulations for $\mathrm{SO}_{2}$ emissions from electric power plants.

\begin{tabular}{|c|c|c|}
\hline Year & Regulation & Content \\
\hline 1970 & $\begin{array}{l}\text { Clean Air Act } \\
\text { Amendments }\end{array}$ & $\begin{array}{l}\text { Established national ambient air quality standards (NAAQS) for } \mathrm{SO}_{2} \text {, } \\
\text { affecting emissions from existing sources, and New Source Performance } \\
\text { Standards (NSPS) for new plants }>73 \mathrm{MWe} \text {. Emission limits were } 1.2 \mathrm{lb} \\
\mathrm{SO}_{2} / \mathrm{MBtu} \text { of fuel burned for coal units and } 0.8 \mathrm{lb} / \mathrm{MBtu} \text { for oil-fired units. }\end{array}$ \\
\hline 1977 & $\begin{array}{l}\text { Clean Air Act } \\
\text { Amendments }\end{array}$ & $\begin{array}{l}\text { NSPS revised for coal-fired plants. Units built after } 1978 \text { must remove } 70 \% \\
\text { to } 90 \% \text { of potential } \mathrm{SO}_{2} \text { emissions if actual emissions do not exceed } 0.6 \mathrm{lb} \\
\mathrm{SO}_{2} / \mathrm{MBtu} \text {, or }>90 \% \text { removal with no more than } 1.2 \mathrm{lb} \mathrm{SO}_{2} / \mathrm{MBtu} \text {. }\end{array}$ \\
\hline 1990 & $\begin{array}{l}\text { Clean Air Act } \\
\text { Amendments: } \\
\text { Title IV, Acid } \\
\text { Rain Program }\end{array}$ & $\begin{array}{l}\text { Reduce annual } \mathrm{SO}_{2} \text { emissions by } 9.8 \text { million tons/yr }(\mathrm{Mt} / \mathrm{y}) \text { below } 1980 \\
\text { levels in two phases. Phase I ( } 1995-2000) \text { : required } 263 \text { high-emitting units in } \\
21 \text { eastern and midwestern states to reduce total emissions by roughly } 3.5 \\
\mathrm{Mt} / \mathrm{y} \text { beginning in } 1995 \text {. Phase II ( } 2000 \text { and beyond) tightened these annual } \\
\text { emissions limits and set restrictions on smaller, lower-emitting plants fired by } \\
\text { coal, oil, and gas. The program affects all new utility units and all existing } \\
\text { generators with an output capacity of }>25 \mathrm{MW} \text {. The Act established an } \\
\text { emission allowance trading system with allowances allocated annually } \\
\text { beginning in } 1995 \text { (one allowance }=1 \text { ton } \mathrm{SO}_{2} / \mathrm{yr} \text { ). The Act also set a } \\
\text { permanent ceiling (or cap) of } 8.95 \text { million allowances/yr for allocation } \\
\text { beginning January } 1,2000 \text {. Banking provisions and other incentives for early } \\
\text { emission reductions also were established. }\end{array}$ \\
\hline
\end{tabular}

Outside the U.S., the most stringent controls on $\mathrm{SO}_{2}$ emissions appeared in Japan and Germany. The first modern commercial-scale FGD systems were installed on Japanese power plants in the late 1960s. These units served as benchmarks for early FGD adoptions in the United States. In 1984, in response to growing concerns about the destruction of German forests from acid rain, Germany enacted stringent new regulations requiring the installation of FGD systems on all large coal-fired plants already in service. Subsequently, other European nations also adopted regulations requiring FGD on coal-fired power plants.

\section{3 $\mathrm{SO}_{2}$ Technology Innovation: Evidence from Patents}

Researchers have long used patents as a measure and descriptive indicator of inventive activity (Griliches 1990). Patents provide detailed and publicly accessible technical and organizational information for inventions over a long period of time. In addition, studies have shown that patenting activity parallels R\&D expenditures by firms; this relationship is particularly useful when detailed R\&D information for an industry is unavailable. In addition, studies have shown that patenting activity can be linked to events external to a firm. This attribute of patents also is especially useful for studying the effects of $\mathrm{SO}_{2}$-related government actions on inventive activity in $\mathrm{SO}_{2}$ control technology.

Our patent activity analysis drew on four main sources of data: the U.S. Patent and Trademark Office (USPTO) patent database from 1887-1997, an interview with the primary USPTO examiner of FGD technologies (Straub 1999), International Energy Agency (IEA) data on the world FGD market (Soud 1994) and patent lists obtained from three companies that together supplied nearly $40 \%$ of the U.S. FGD capacity in 1973-93. First, the USPTO classes used to develop prior art - earlier patents whose claims are legally determined by the patent examiner to be closely related to the claims in the citing patent - were elicited from the patent examiner, then used to generate a time-series of 2,681 patents issued from 1887-1997 relevant to $\mathrm{SO}_{2}$ 
control. This "class-based" patent dataset was consistent for over 100 years and thus could be used to relate patenting trends to the timing of past government actions related to $\mathrm{SO}_{2}$ control.

Patent classes are a relatively broad method for identifying specific technologies, however. Thus, a second dataset of 1,593 patents was generated based on an electronic search for relevant keywords in the abstracts of all patents granted from 1976-1996. These dates were used because systematic electronic keyword searching is only possible for USPTO patents granted after 1975. Content analysis was then performed on this "abstract-based" dataset by reading each abstract to eliminate irrelevant patents. The final yield was 1,237 relevant patents. Patent activity in this dataset was later analyzed in the context of various government actions through econometric analysis and the interpretation of experts, as discussed later in the paper.

To check the commercial relevance of both the class-based and abstract-based datasets, the patent lists obtained from prominent FGD vendors were compared to those in each dataset to see if the screening had identified them. Both datasets included a high percentage of these commercially relevant patents, with the abstract-based dataset showing better overall performance.

Figure 3 shows the level of inventive activity in $\mathrm{SO}_{2}$ control technology as reflected by patenting activity over more than 100 years using the class-based dataset. Patenting levels can be portrayed as a step-function dividing two time periods. Prior to the late $1960 \mathrm{~s}$, there was little or no activity (no more than four patents per year), despite government legislation dating back to 1955 that authorized research into air pollution abatement methods (see Table 1). The onset of $\mathrm{SO}_{2}$-related patenting activity is seen to coincide with adoption of the 1970 Clean Air Act Amendments (CAAA) and the 1971 New Source Performance Standards (NSPS), which effectively established a national market for FGD technology in the United States. After 1970, patenting activity never fell below 76 per year. Thus, the patenting trend in Figure 3 suggests that the adoption of stringent national regulations for $\mathrm{SO}_{2}$ emissions control stimulated inventive activity more than government-sponsored research support alone. This indication that national regulation was a more effective stimulant of inventive activity than federal research funding alone is supported by other veins of evidence in our research, notably the technical content analysis of the $\mathrm{SO}_{2}$ Symposium and the testimony of experts interviewed. It is also consistent with findings from case studies of other environmental technologies (Ashford, Ayers et al. 1985). 


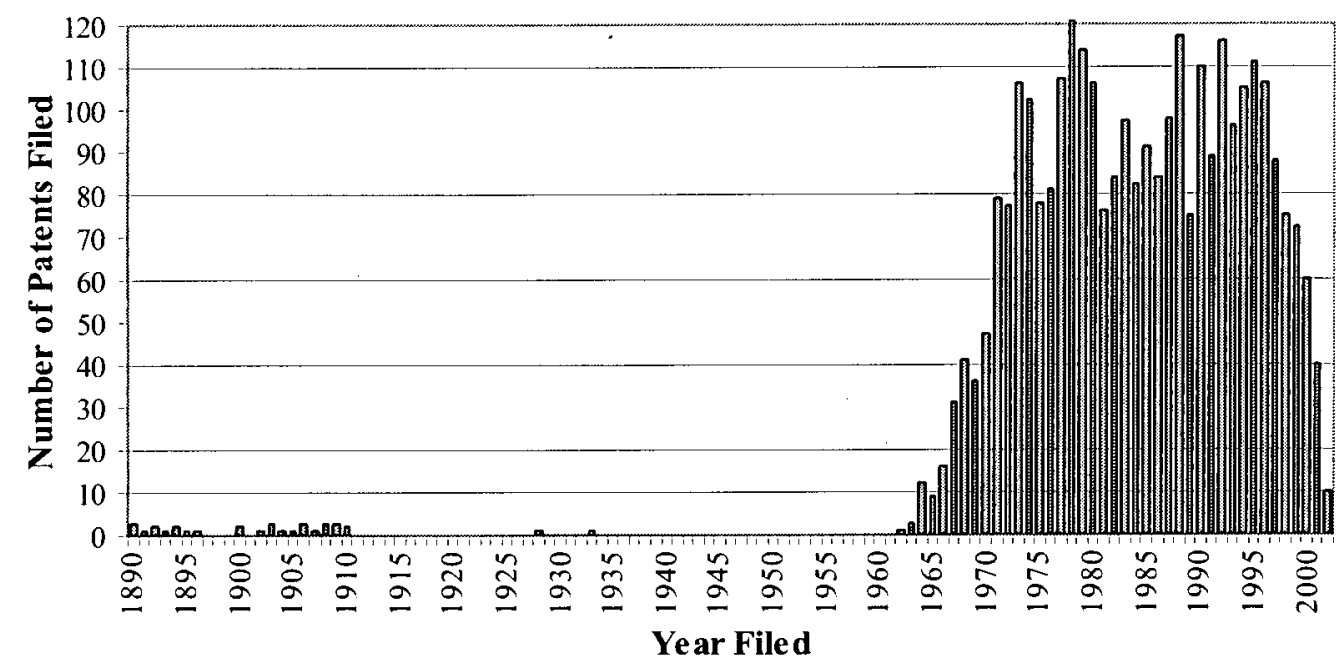

Figure 3. U.S. patents relevant to $\mathrm{SO}_{2}$ control technology (based on the patent class dataset).

The anticipation of government regulation also appears to have spurred inventive activity as reflected by patent filings. Trends in the abstract-based patent dataset (Figure 4), together with expert testimony, support this hypothesis (see (Taylor, Rubin et al. 2003) for details). The data in Figure 4 (as well as the class-based dataset in Figure 3) shows "bursts" of patent filing activity in $1978,1979,1988$, and 1992 that are indicative of changes in external events relevant to the technology (Griliches 1990). The experts also believed that the pattern of peaks observed in Figure 4 was due to contemporary national legislative and regulatory events identified in Table 1. For example, as an explanation for the 1988 peak, nearly all the experts mentioned a heightened public and legislative awareness of acid rain in the mid- to late-1980s and the anticipation of legislation that would have overhauled the Clean Air Act. The result of that anticipation, they explained, was an intensification of research, technology demonstrations, and testing of moderate-removal $\mathrm{SO}_{2}$ control technologies that would have fit contemporaneous Congressional proposals (see Table 1), but ultimately did not get enacted. The idea that anticipated regulation has the ability to drive innovation is not new to this study; Ashford, Ayers, and Stone (Ashford, Ayers et al. 1985), for example, drew a similar conclusion from studies of other industries. This study shows, however, that the direction and nature of innovative activity can be affected significantly by the anticipated and actual requirements of environmental regulations. 


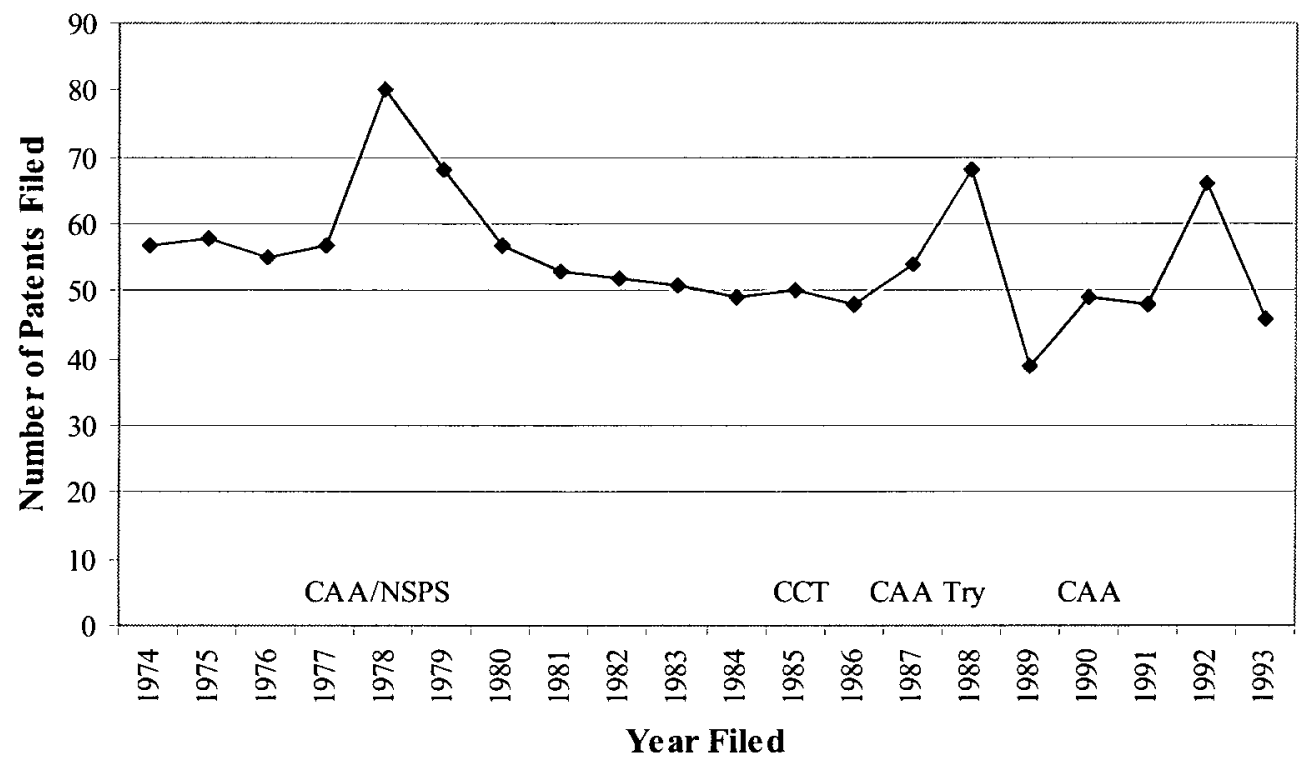

Figure 4. Trend in U.S. patents relevant to $\mathrm{SO}_{2}$ control technology as identified in the abstractbased dataset. (See Table 1 for descriptions of the government actions shown on the $\mathrm{x}$-axis at different points in time.)

Evidence that regulatory stringency directs the focus of inventive activity is seen in Figure 5, which shows patenting activity in pre-combustion $\mathrm{SO}_{2}$ control technologies, which are primarily coal cleaning processes. Although these technologies were not dominant in the overall patent datasets, in the early 1970s patenting activity in this area grew significantly. At that time, $\mathrm{SO}_{2}$ emission standards allowed low-sulfur coals to play a prominent role as a compliance strategy for both new and existing sources, and pre-combustion sulfur removal was of significant interest. However, after the 1977 CAAA required New Source Performance Standards to be tightened (based on the technological capabilities of both wet and dry FGD systems), patenting activity in coal cleaning technologies dropped precipitously. Both statistical analysis and expert elicitation support the conclusion that the stringency of the 1979 NSPS (requiring 70 to $90 \%$ sulfur removal) curtailed inventive activity in pre-combustion technologies, as these technologies were no longer as central an option in $\mathrm{SO}_{2}$ control for new plants as the post-combustion control technologies. 


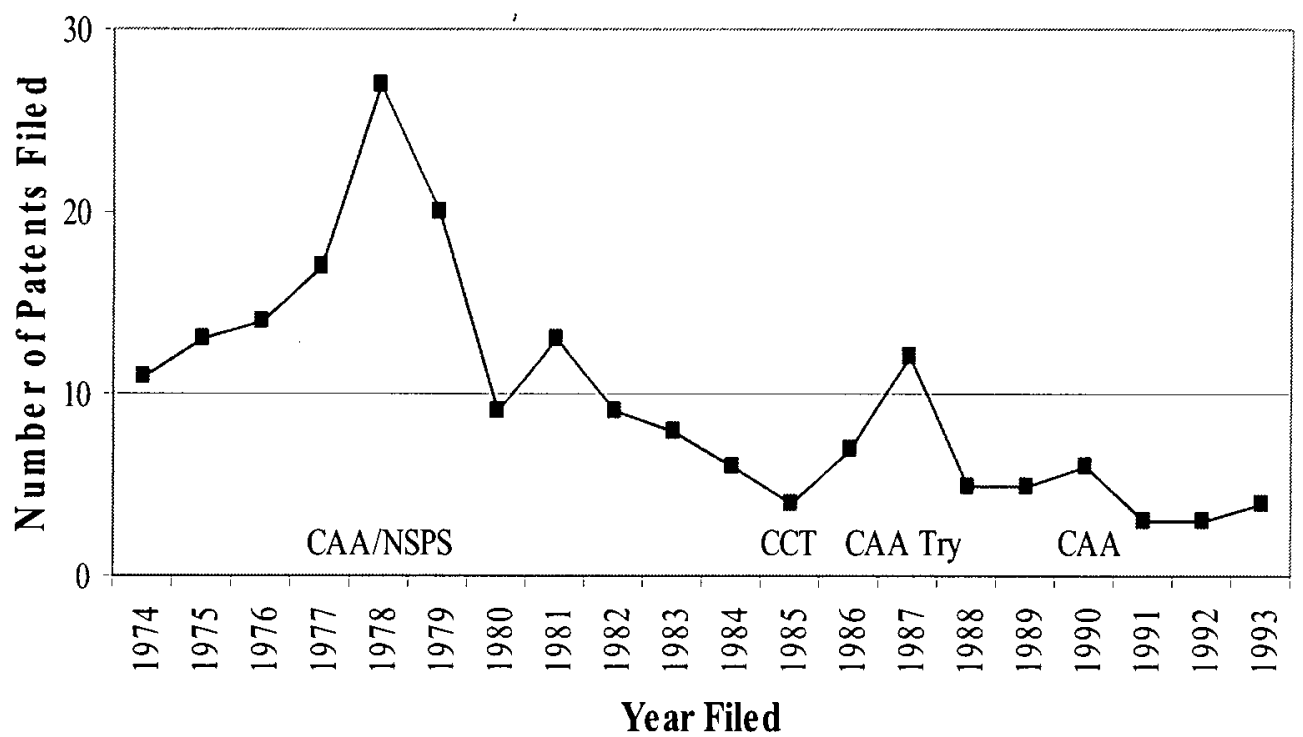

Figure 5. Trend in pre-combustion $\mathrm{SO}_{2}$ control technology patents identified in the abstract-based dataset.

Conversely, the stringency of the 1979 NSPS for low-sulfur coals was an important driver of innovation in dry FGD technology in the 1980s, according to both expert interviews and the content analysis of papers presented at the national $\mathrm{SO}_{2}$ Symposium (Taylor, Rubin et al. 2001). Dry FGD technology was the basis for the 70\% removal floor of the 1979 NSPS, and the technology matured and diffused quite rapidly in the utility FGD market as a result. The 1990 CAAA, however, although initially predicted to increase demand for FGD systems, eroded the market potential for both dry and wet FGD system applications at existing power plants when the $\mathrm{SO}_{2}$ allowance trading market returned low-sulfur coal to its importance in $\mathrm{SO}_{2}$ control. ${ }^{6}$ As a result, research in dry FGD technology declined significantly (Taylor, Rubin et al. 2001). In this case, the flexibility provided by the 1990 acid rain regulations discouraged inventive activity in technologies that might have had broader markets under the traditional command-and-control regimes in place prior to 1990 .

Overall, our results regarding the effects of regulatory stringency and market scope on environmental technology innovation are consistent with one of the strong conclusions of the mainstream innovation literature, namely that the demand for a technology is a major driver of innovation (Mowery and Rosenberg 1982). In the context of environmental technologies, the demand for various types of pollution control equipment is almost inseparable from the details of environmental legislation (Kemp 1997).

\footnotetext{
${ }^{6}$ Of those plants specifically required to participate in Phase I of the 1990 CAAA, $62 \%$ chose fuel switching and blending as a compliance option while only $10 \%$ chose FGD Zipper, C. E. and L. Gilroy (1998). "Sulfur dioxide emissions and market effects under the Clean Air Act Acid Rain Program." J. Air Waste Manage. Assoc. 48: 82937.
} 


\subsection{Worldwide Use of FGD Systems}

FGD systems (also known as scrubbers) encompass a variety of technologies that have been extensively described and discussed in the literature (Soud 1994). By far the most prevalent technology, accounting for approximately $86 \%$ of current world capacity, are so-called "wet" FGD systems employing limestone or lime as a chemical reagent. These systems can achieve the highest $\mathrm{SO}_{2}$ removal efficiencies (historically around $90 \%$, but today as high as 98 to $99 \%$ ). However, the process generates a solid residue that must either be transformed into a useful byproduct (such as gypsum) or disposed of as solid waste.

So-called "dry" FGD systems typically use lime $(\mathrm{CaO})$ as the reagent in a spray dryer system that typically achieves lower $\mathrm{SO}_{2}$ removal rates than a wet FGD system (historically about 70$80 \%$, but today as high as $94 \%$ ). Such systems were typically used to meet the less restrictive $\mathrm{SO}_{2}$ removal requirements for low-sulfur coals allowed by the NSPS. Because of their limited applicability, lime spray dryers and other forms of dry $\mathrm{SO}_{2}$ removal account for less than $8 \%$ of the total FGD market (Soud 1994).

Figure 6 depicts the worldwide growth in FGD installations over the past three decades. The yaxis measures the total electrical capacity of power plants whose flue gases are treated with wet lime or limestone scrubbers. The onset of FGD use in each country corresponds to the time at which regulations were adopted that were sufficiently stringent so as to require or encourage the use of FGD as an emissions control strategy. Figure 6 also shows that the United States has dominated in the deployment of this technology. Today, approximately $30 \%(90 \mathrm{GW})$ of U.S. coal-fired capacity is equipped with FGD systems, most of them wet limestone scrubbers.

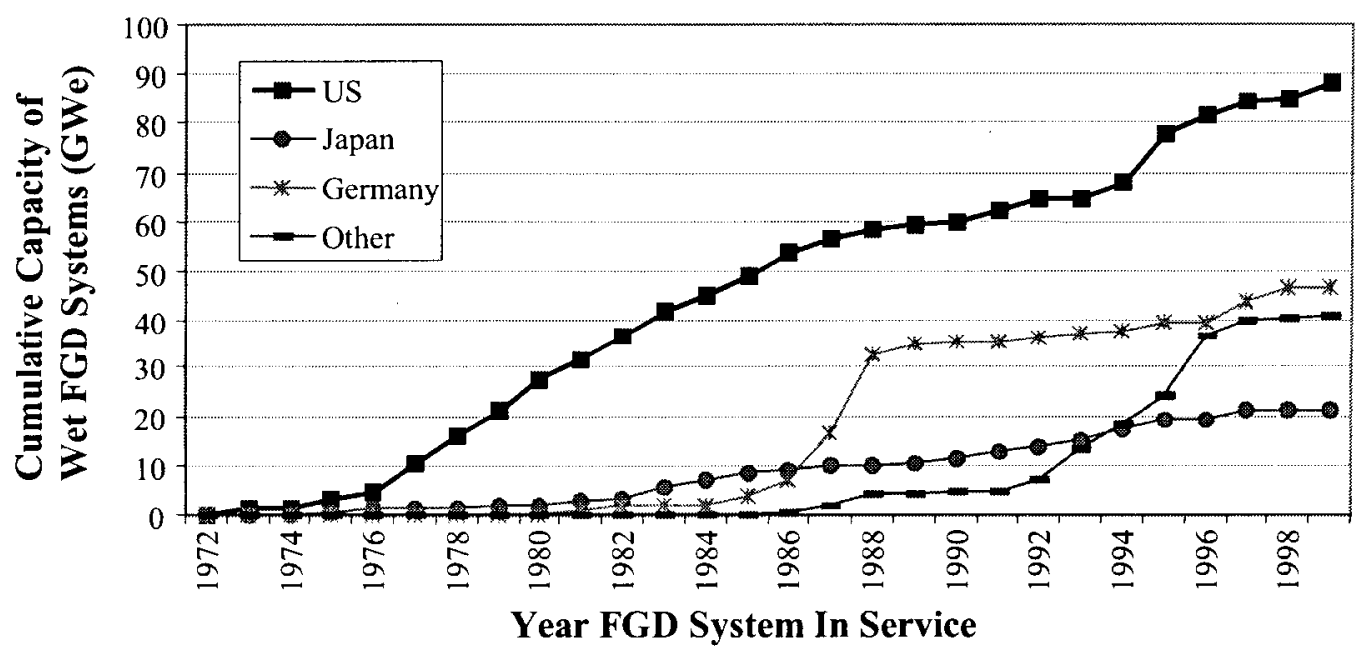

Figure 6. Cumulative installed capacity of wet lime/limestone FGD systems in different countries. Source: (Soud 1994)

\subsection{Experience Curves for FGD}

A seminal paper by T.P. Wright (Wright 1936) introduced the concept of a "progress curve" to describe his finding that the average direct man-hours required to manufacture a given model of a Boeing aircraft dropped systematically with each unit produced. This phenomenon of "learning by doing" has subsequently been studied and generalized to a wide variety of applications. 
Systematic reviews of this extensive literature can be found elsewhere (see, e.g., (Arrow 1962; Rapping 1965; Yelle 1979; Dutton and Thomas 1984)). Mathematically, most studies have used the simple non-linear function first proposed by Wright to describe the reduction in cost associated with increases in production:

$$
y_{i}=a x_{i}^{-b}
$$

(Equation 2)

where,

$$
\begin{aligned}
& y_{i}=\text { time or cost to produce } i^{\text {th }} \text { unit } \\
& x_{i}=\text { cumulative production through period } i \\
& a=\text { coefficient (constant) } \\
& b=\text { learning rate exponent }
\end{aligned}
$$

According to this equation, each doubling of cumulative production results in a time or cost savings of $\left(1-2^{-b}\right)$. The latter quantity is defined as the learning rate, while the quantity $2^{-b}$ is defined as the progress ratio.

This concept of a learning curve has been extended to characterize the reductions in capital cost associated with the continued development and deployment of a wide variety of technologies, including energy technologies (Grubler, Nakicenovic et al. 1999). Known more generally as "experience curves," the observed cost decreases in this case reflect not only the benefits of learning by doing, but also the benefits derived from financial investments in research and development to improve the technology and its production. These investments are the key factor leading to new generations of a given technology that are not only lower in cost but often improved in other ways as well (e.g., more efficient or reliable than earlier models). Recent reviews of the literature on experience curves for energy-related technologies (Grubler, Nakicenovic et al. 1999; McDonald and Schrattenholzer 2002) found a range of learning rates varying from $-14 \%$ to $34 \%$, with most values between $4 \%$ and $30 \%$ and a median value of $16 \%$. This is consistent with values reported earlier for many non-energy technologies (Boston Consulting Group 1968). Past studies, however, have focused mainly on products and technologies for which there are natural demands in a market economy, such as demands for lower-cost power generation systems. Little attention has been given to what we call environmental technologies, such as FGD and SCR systems, for which there are no significant demands in the absence of government actions requiring their use for environmental protection of the public at large. The development of experience curves for environmental technologies is thus the major focus of this research.

\subsubsection{Early (Pre-Commercial) Experience}

Under the provisions of the Clean Air Act of 1967 and its 1970 amendments, the Federal EPA funded research and development on $\mathrm{SO}_{2}$ removal processes from power plant stack gases including several conceptual design and cost studies. It was estimated that from 1966 to 1972 the R\&D expenditures probably exceeded $\$ 100$ million for industry and government combined (Anon 1972). Despite that, there was considerable controversy over what it is practical to do to control $\mathrm{SO}_{\mathrm{x}}$ in the flue gas then and in the immediate future. Earlier efforts of cost evaluation for those technologies involved many necessary design assumptions and cost estimate accuracy were questionable since technology was in design state and available technical data were limited. Equipment costs were sketchy since most vendors had yet to fabricate and erect the large gas 
scrubbing devices required for full-scale systems. Furthermore, very little corrosion data were available to predict materials of construction for the services involved. In many cases, optimism of the process developers tended to maximize process potential and to minimize problem areas such as corrosion, scaling, solids disposal, sulfite oxidation, mist elimination, gas reheat, operational turndown, and $\mathrm{pH}$ control. The cost data in the early $1970 \mathrm{~s}$ were subject to uncertainties in scale-up factors and incomplete commercial data and operational experience. Data were largely based on experimental and prototype installations. A basis for more accurately assessing full-scale performance and installation and operating costs were not yet established. In 1975 , probably the two questions uppermost in the minds of the utility industry regarding stack gas $\mathrm{SO}_{2}$ removal processes were system reliability and cost. It was noted that $\mathrm{SO}_{2}$ removal systems have a history of increasing costs as more is learned and better process definition is established. Cost estimates of the late 1960's were considerably lower than recent projections due to the early optimistic view of the investigators that the system unknowns would be controlled, and inexpensive materials of construction could be utilized (Skopp 1969; The M. W. Kellogg Company 1971). As time passed and pilot-plant results became known, the magnitude of the estimates increased and much higher costs was later then expected (Spaite 1972; 1973; Battelle Columbus Laboratory 1973).

Based on early learning-by-using, costs continued to increase as designs were modified to achieve high system reliability and to comply with regulatory requirements. After a decade of experience and learning, costs finally began to decline in the 1980s. Figure 7 shows the FGD installations in the US market for the past 30 years from 1969-1999. Figure 8 shows the historical trends of early economic evaluations for FGD (a) capital, and (b) operating and maintenance $(\mathrm{O} \& \mathrm{M})$ costs.

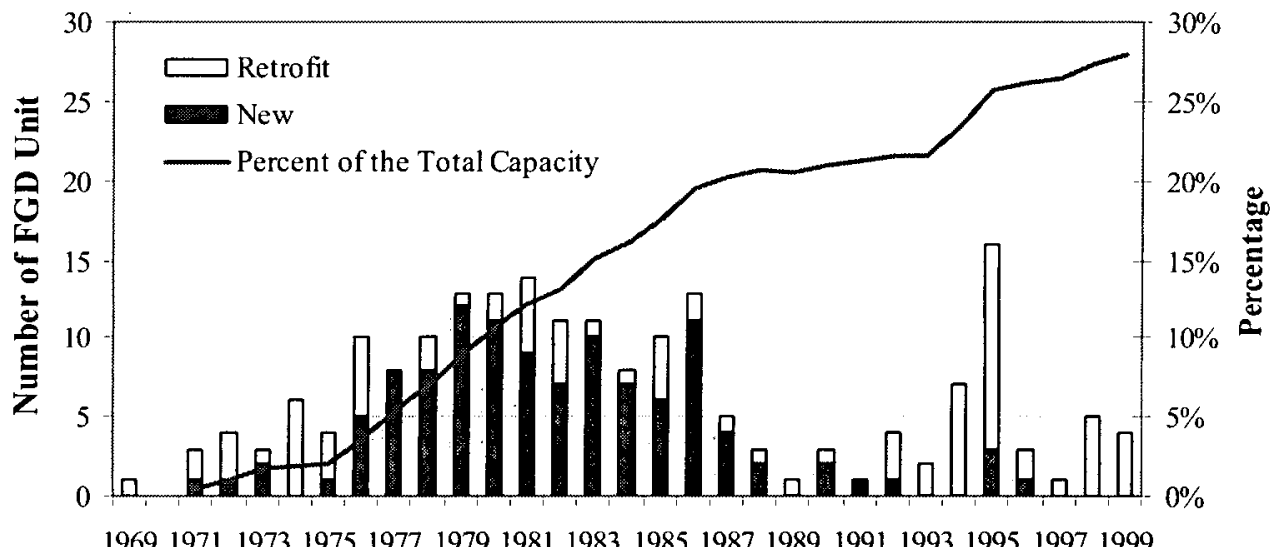

FGD In Service Date

Figure 7. FGD installations from 1969-1999, separated by new/retrofit unit. Also shown is the percent of FGD cumulative installed capacity (MW) to the total US coal-fired capacity (MW). 
(a).

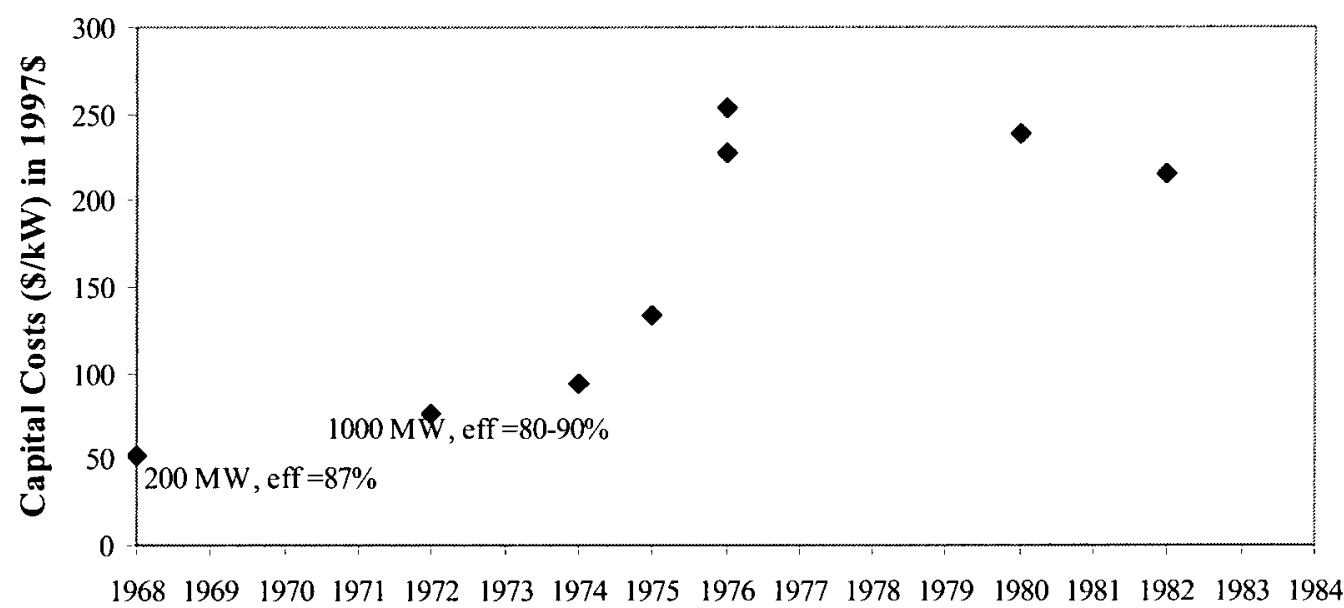

FGD Technology Year

(b).

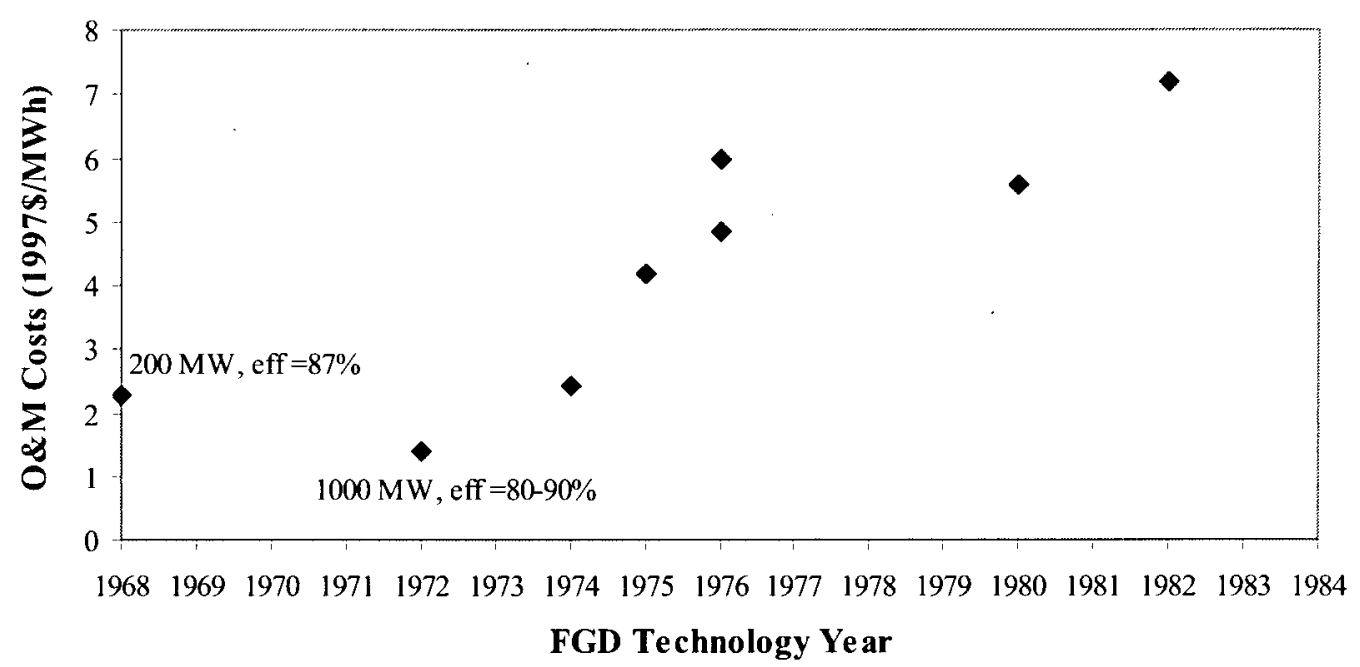

Figure 8. Capital and annualized operating and maintenance $(O \& M)$ costs of a wet limestone FGD system for a standard new coal-fired power plant. Except where specified otherwise, a standard plant is sized $500 \mathrm{MWe}$, burning $3.5 \%$ sulfur coal, and achieve $90 \% \mathrm{SO}_{2}$ removal efficiency. The earliest plants, however, did not achieve the high levels of availability and reliability required for utility operations, leading to more costly designs in later years.

\subsubsection{Results for Large-Scale Deployment}

The deployment of FGD systems over the past several decades has been accompanied by measurable improvements in performance and reductions in the cost of this technology for a given application. The development of an experience curve to characterize FGD cost trends is not straightforward, however, because the cost of an FGD system depends on many site-specific power plant factors (such as plant size, age, emission limits, and fuel properties) that are not directly related to improvements in FGD technology, per se. Thus, to obtain a more accurate picture of real FGD cost reductions, we used a series of historical cost studies performed over a period of years by the same organizations using a consistent set of design premises as the basis for FGD cost estimates. This allows us to characterize the cost of doing the same "job" at different points in time. Systematic studies of FGD cost were performed by the Tennessee Valley Authority (TVA) during the 1970s and 1980s when FGD systems were first being installed at 
U.S. coal-fired power plants (Torstrick, Henson et al. 1978; McGlamery, O'Brien et al. 1980). Beginning in the mid-1980s, the Electric Power Research Institute (EPRI) conducted a similar series of studies for a variety of FGD processes (Keeth, Ireland et al. 1986; Keeth, Ireland et al. 1990; Keeth, Ireland et al. 1991; Keeth, Ireland et al. 1995). Both the TVA and EPRI studies reflected contemporaneous designs and costs of FGD systems being installed at U.S. power plants, and both organizations were highly regarded as authoritative sources in the $\mathrm{SO}_{2}$ control industry (Taylor 2001).

Figure 9 shows the trend in FGD capital cost, adjusted for inflation using the Chemical Engineering construction cost index. All values are based on a standardized case of a wet limestone $\mathrm{FGD}$ system achieving $90 \% \mathrm{SO}_{2}$ removal at a $500 \mathrm{MW}$ power plant burning a highsulfur coal $(3.5 \% \mathrm{~S})$. To account for small changes in the design premises used in more recent studies (e.g., small changes in fuel sulfur content and plant size), reported cost results were also adjusted using a power plant computer model to account for the influence of these factors (Rubin, Kalagnanam et al. 1995; Rubin, Kalagnanam et al. 1997). To develop an experience curve, the cumulative installed FGD capacity corresponding to each data point was taken to be the technology year of each cost study in which the FGD technology was evaluated. The technology year is typically 1-3 years prior to the publication date and reflects the typical time lag between data collection and the presentation of results (typically at a widely attended industry conference). The $\mathrm{x}$-axis values in Figure 9 reflect worldwide installations of FGD systems (primarily in the U.S., Germany, and Japan) in recognition of the international nature of markets and technology innovations in FGD systems (Taylor 2001).

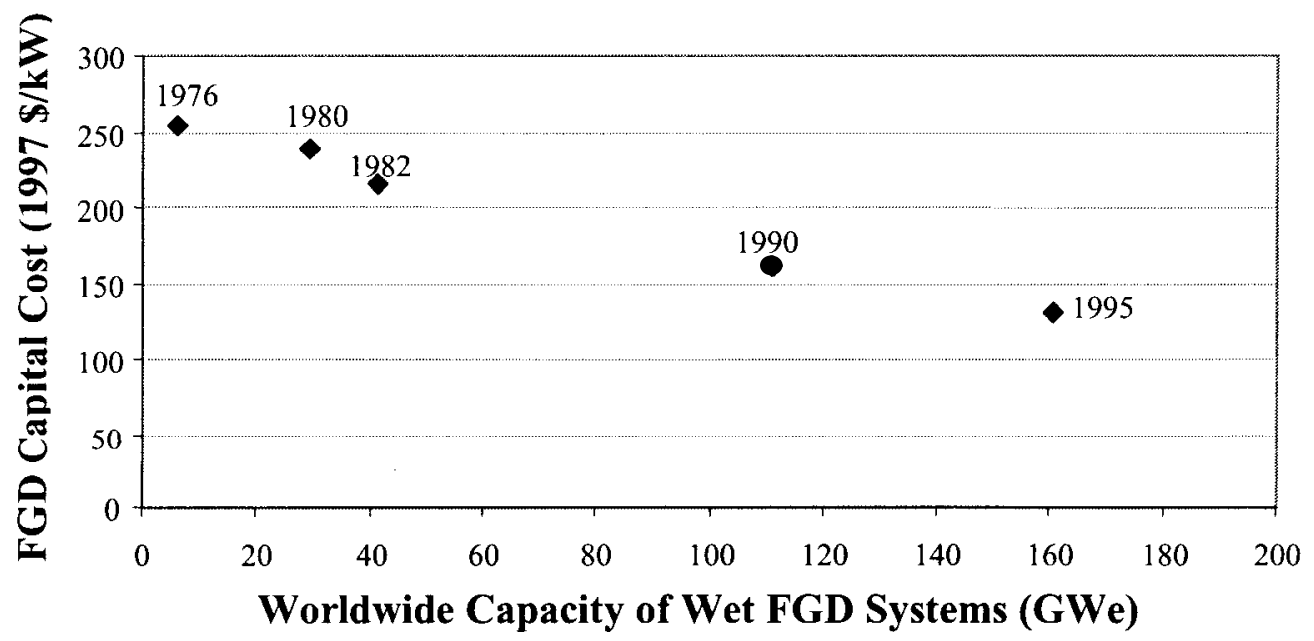

Figure 9. Capital cost of a new wet limestone FGD system for a standardized coal-fired power plant (500 MWe, $3.5 \%$ sulfur coal, $90 \% \mathrm{SO} 2$ removal) as a function of cumulative worldwide capacity of FGD installations. Based on data from (Torstrick, Henson et al. 1978; McGlamery, O'Brien et al. 1980; Keeth, Ireland et al. 1986; Keeth, Ireland et al. 1991; Soud 1994; Keeth, Ireland et al. 1995).

FGD capital costs exhibit significant declines over time as cumulative capacity increases. Many of the process improvements that contributed to lower costs (especially improved understanding and control of process chemistry, improved materials of construction, simplified absorber designs, and other factors that improved reliability) were the result of sustained R\&D programs and inventive activity, as documented and described elsewhere (Taylor 2001). Increased 
competition among FGD vendors also may have been a contributing factor. Such influences are difficult to discern in most studies of experience curves because the available data typically represent the costs to technology users (i.e., technology prices) rather than the cost to technology developers. In this study, however, a careful examination of the underlying technological changes over several decades (Taylor 2001) convinces us that the FGD cost reductions shown here primarily reflect the fruits of technology innovation. Later in Section $V$, we recast the data in Figure 9 into a conventional experience curve equation and compare it to results for SCR systems.

There is clear evidence that FGD operating and maintenance (O\&M) costs also have been reduced as a result of technology innovation and learning by doing. A systematic approach to quantifying such trends would require a retrospective study of each major element of O\&M costs, including FGD reagent use, energy use, labor costs, maintenance costs, and byproduct disposal costs. Most of the studies used in this paper to determine FGD capital cost also reported expected O\&M costs, though in different degrees of detail. But unlike capital cost estimates, which can be (and were) verified against the actual cost of plants built at different points in time, projected O\&M costs over the operating life of a system (typically several decades) cannot be readily verified until many years later. Thus, systematic design studies of the type used here reflect the trend in expected O\&M costs for new plant designs, as opposed to actual experience. Nonetheless, such trends can be useful indicators of technological change since they do reflect and incorporate contemporaneous improvements in technology design as well as experience from learning by doing based on earlier designs.

Figure 10 shows the total projected O\&M costs for several of the FGD design studies used earlier to quantify capital costs. An overall cost reduction of $40 \%$ is seen over a 13 -year period. Many factors contributed to this reduction, including various process improvements (leading to reductions in reagent consumption, associated solid waste quantities, and process energy use), as well as reductions in operating labor and maintenance expenses. A companion analysis by Taylor showed that labor costs alone exhibited a $20 \%$ learning rate at U.S. power plants operating an FGD system for 12 years or more (Taylor 2001). While the relative importance of different O\&M cost elements varies with plant design and operating conditions, reductions in such costs have clearly accompanied reductions in capital cost. The data in Figure 10 is used later to provide a rough estimate of the learning rate for O\&M costs in the absence of more complete empirical data on changes in actual O\&M costs for a given FGD application. 


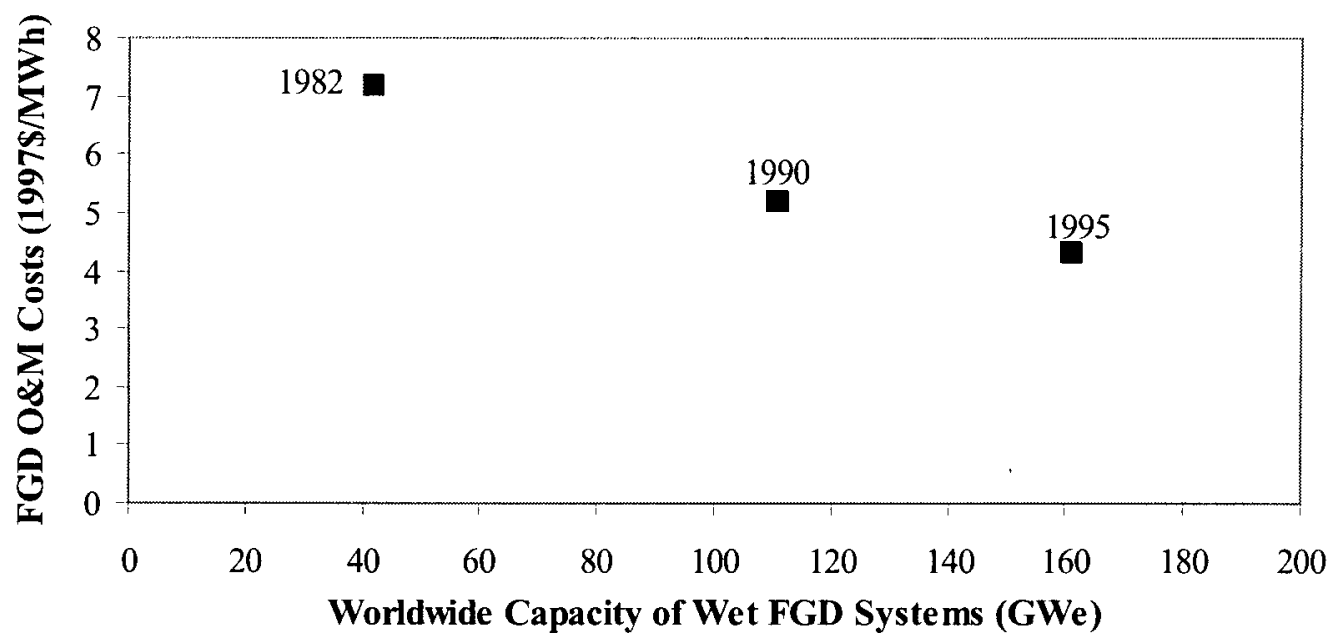

Figure 10. Annualized operating and maintenance (O\&M) cost of a new wet limestone FGD system for a standardized coal-fired power plant $\left(500 \mathrm{MWe}, 3.5 \%\right.$ sulfur coal, $90 \% \mathrm{SO}_{2}$ removal, $65 \%$ capacity factor) as a function of cumulative worldwide capacity of FGD installations. Based on data from (Keeth, Ireland et al. 1986; Keeth, Ireland et al. 1991; Keeth, Ireland et al. 1995)

In summary, the $\mathrm{SO}_{2}$ control technology case study provides evidence that links the technology innovation process to government actions, in particular, the imposition of regulations and standards that require or incentivize the use of environmental technology to achieve emission reductions. The study also quantifies the reductions in capital costs and performance improvements resulting from the innovation process including the adoption and diffusion of improved technology. For purposes of integrated assessment modeling, these results are reflected in "experience curves" that quantify the impacts of technology innovation as a function of the cumulative installed capacity or operation of the technology in question (in this case, $\mathrm{SO}_{2}$ scrubbers). This formulation implicitly incorporates the many factors that contribute to technology innovation and the adoption of an environmental technology. In the context of IA models, it represents a significant improvement in the current state of the art for representing the cost and performance impacts of technical change for environmental control systems. 


\section{Technology Innovation in $\mathrm{NO}_{\mathrm{x}}$ Control}

\subsection{Overview}

$\mathrm{NO}_{\mathrm{x}}$ emissions have been associated with a wide variety of health and environmental impacts including an increase in ground-level ozone, the formation of fine particles in the atmosphere, acid rain and the acidification of aquatic systems, and more recently, global warming effects. Such concerns have led to a series of government actions to reduce $\mathrm{NO}_{\mathrm{x}}$ emissions from fossilfueled, stationary combustion sources as well as from mobile sources.

As in the case of $\mathrm{SO}_{2}$, environmental control strategies pertinent to control $\mathrm{NO}_{\mathrm{x}}$ emissions can generally be divided into two categories: primary measures involving combustion modifications, and post-combustion $\mathrm{NO}_{\mathrm{x}}$ flue gas treatment processes. Primary measures for $\mathrm{NO}_{\mathrm{x}}$ control, such as burner optimization, air staging (over-fired air or two-stage combustion), flue gas circulation, fuel staging, and low $\mathrm{NO}_{\mathrm{x}}$ burners, generally require relatively little capital investment and do not entail the use of chemical additives or reagents. Post-combustion $\mathrm{NO}_{\mathrm{x}}$ processes reduce the $\mathrm{NO}_{\mathrm{x}}$ in the flue gas to nitrogen and water downstream of the furnace, using reagents such as ammonia or urea in selective catalytic reduction (SCR) or selective non-catalytic reduction (SNCR) technologies. The reduction capabilities of $\mathrm{NO}_{\mathrm{x}}$ control range from $30 \%$ to $60 \%$ for primary measures, $30 \%$ to $50 \%$ for SNCR and $70-90 \%$ removal efficiency for SCR systems.

In response to government regulations, $\mathrm{NO}_{\mathrm{x}}$ control technology has been passing through various phases as the regulatory and commercial climate has changed since the early 1970s. During the decade of the ' $70 \mathrm{~s}$, boiler manufactures focused on developing and field-demonstrating $\mathrm{NO}_{\mathrm{x}}$ control technologies to meet the New Source Performance Standards of 1971 and 1979. In the 1980 s, with the reduced need for new utility generating capacity, emphasis shifted to retrofittable technologies to meet acid rain control legislation. In the 1990s, more rigorous reductions in $\mathrm{NO}_{\mathrm{x}}$ emissions were required for both new and existing source. Until recently, federal and state requirements for $\mathrm{NO}_{\mathrm{x}}$ emission reductions from power plants have been quite modest, and standards such as the Title IV Acid Rain $\mathrm{NO}_{\mathrm{x}}$ program could generally be met by low-cost combustion modification technologies (Figure 11). Only in response to recent ozone attainment requirements has the more expensive option of post-combustion $\mathrm{NO}_{x}$ control technology been introduced into the U.S. power generation market. Still greater $\mathrm{NO}_{\mathrm{x}}$ reductions will be needed for the third phase of the Ozone Transport Commission (OTC) emission trading program, $\mathrm{NO}_{\mathrm{x}}$ State Implementation Plan (SIP) Call, and Section 126 regulations of the Clean Air Act. This will require the use of advanced $\mathrm{NO}_{\mathrm{x}}$ control technologies, especially selective catalytic reduction (SCR), to achieve 75 to 90 percent of the total reductions needed (STAPPA\&ALAPCO 1994; Krolewski and Mingst 2000; NESCAUM 2001). ${ }^{7}$

\footnotetext{
${ }^{7}$ EPA regulatory impact analyses predicted that SCR retrofits would be installed at 142 utility units, representing approximately $72,900 \mathrm{MW}$ in order to achieve overall $\mathrm{NO}_{\mathrm{x}}$ SIP call/Section 126 compliances U.S. EPA (1999). Regulatory Impact Analysis for the NOx SIP Call, FIP, and Section 126 Petitions. Washington DC, Environmental Protection Agency, Office of Air and Radiation.. Another study by DOE estimated that to achieve the required reduction in $\mathrm{NO}_{x}$ emissions in SIP call area, it is projected that SCR would be selected for about 500 fossil-fired boilers, totaling about $180 \mathrm{GWe}$, and SNCR would be selected for about 200-300 units, totaling about 20-35 GWe. Of these, $98 \%$ of the $\mathrm{NO}_{\mathrm{x}}$ removal is from coal-fired units, and $93-98 \%$ of all $\mathrm{NO}_{\mathrm{x}}$ removal is achieved by SCR U.S. DOE (1999). Demonstration of Selective Catalytic Reduction Technology to Control Nitrogen Oxide Emissions
} 


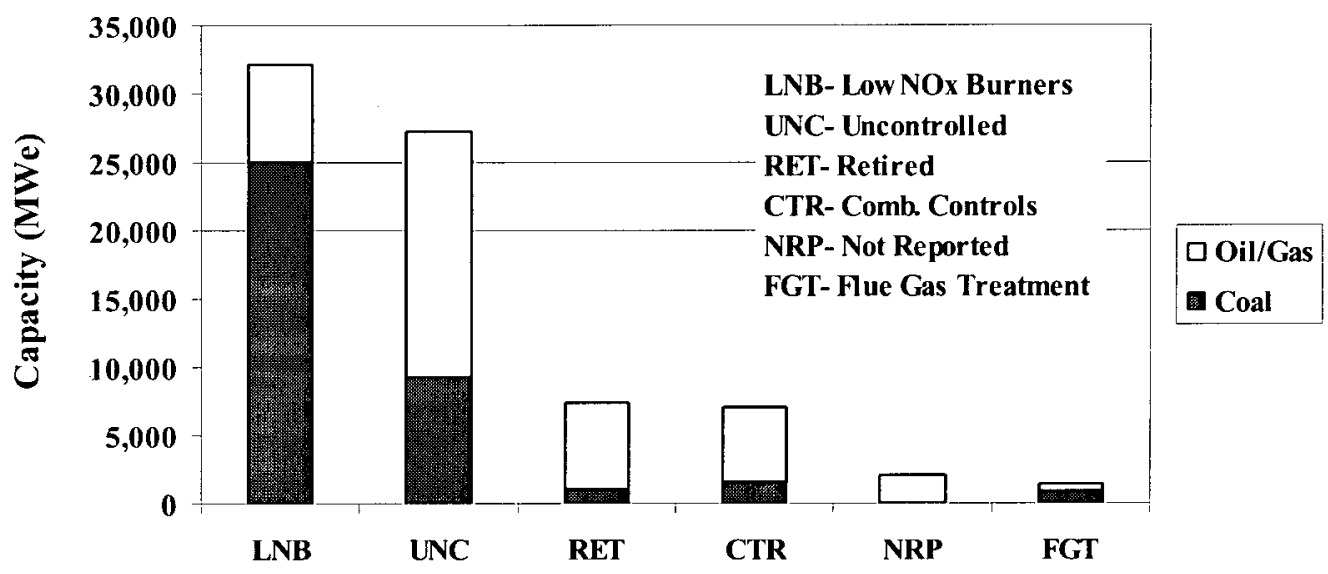

Applied Control Technology

Figure 11. Total utility boiler capacity (coal and oil/gas) using $\mathrm{NO}_{\mathrm{x}}$ control technology in the 1996 Ozone Transport Region (OTR). Source: (NESCAUM 2001).

Furthermore, several $\mathrm{NO}_{\mathrm{x}}$ trading programs are expected to provide flexible, yet stringent incentives to achieve lower $\mathrm{NO}_{\mathrm{x}}$ emissions. Evidence suggests that these $\mathrm{NO}_{\mathrm{x}}$ trading programs will provide economic incentives (selling $\mathrm{NO}_{\mathrm{x}}$ allowances) for a unit to go well beyond its required annual emission limit. Recent experience has also provided a better indicator of what post-combustion control technologies are capable of achieving beyond present regulations (Krolewski and Mingst 2000; NESCAUM 2001).

The early history of $\mathrm{NO}_{\mathrm{x}}$ control in stationary power plants is an example of a relatively weak technological response to initially weak regulatory demands in the U.S. The creation of the OTC in 1994, and subsequently more stringent $\mathrm{NO}_{\mathrm{x}}$ regulations, elicited a stronger technology response, mainly advanced post-combustion technologies. This achieved a doubling of the $\mathrm{NO}_{\mathrm{x}}$ reduction levels compared to the two decades before 1995 (NESCAUM 2001).

Like FGD systems, SCR is a post-combustion technology that employs a chemical reagent to remove $\mathrm{NO}_{x}$ from the flue gas stream. In this case, the reagent is ammonia $\left(\mathrm{NH}_{3}\right)$ injected into the flue gas stream exiting the boiler. $\mathrm{NO}_{\mathrm{x}}$ is reduced to molecular nitrogen via two overall reactions:

$$
\begin{aligned}
& 4 \mathrm{NO}+4 \mathrm{NH}_{3}+\mathrm{O}_{2} \rightarrow 4 \mathrm{~N}_{2}+6 \mathrm{H}_{2} \mathrm{O} \\
& 2 \mathrm{NO}_{2}+4 \mathrm{NH}_{3}+\mathrm{O}_{2} \rightarrow 3 \mathrm{~N}_{2}+6 \mathrm{H}_{2} \mathrm{O}
\end{aligned}
$$

To achieve high ( 80 to $90 \%) \mathrm{NO}_{\mathrm{x}}$ removal, a catalyst operating at high temperature is required. For this reason, an SCR system is typically located at the boiler exit upstream of the power plant's air preheater (Figure 12). The control of ammonia slip (excess $\mathrm{NH}_{3}$ in the flue gas) is a secondary environmental impact of concern in SCR system design.

From High-Sulfur, Coal-Fired Boilers: A DOE Assessment. Morgantown, PA, U.S. Department of Energy, Office of Fossil Energy, Federal Energy Technology Center.. 


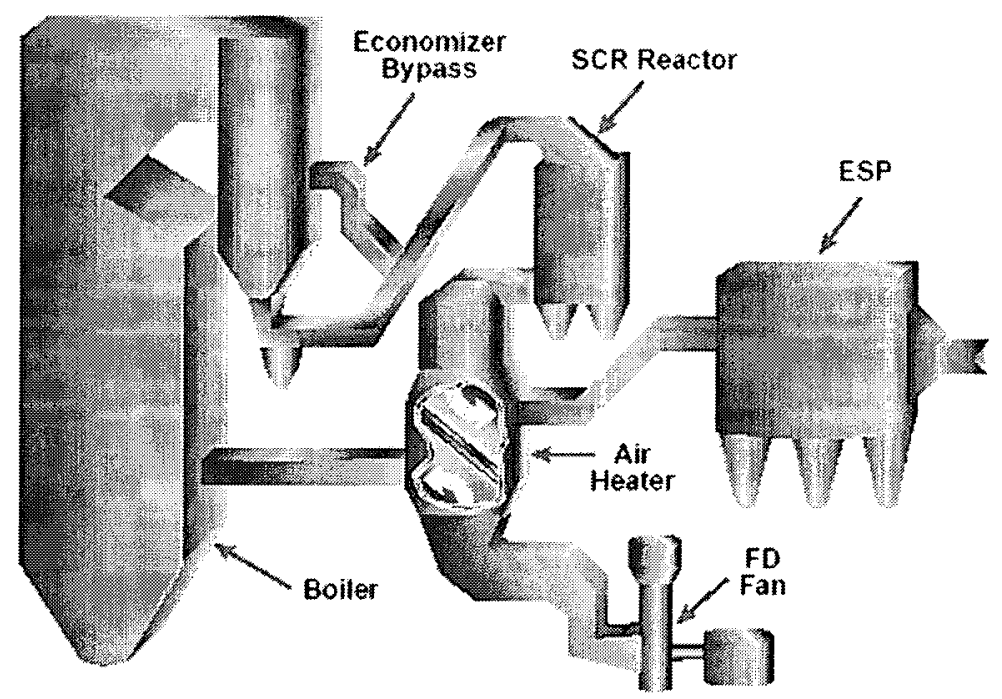

Figure 12. Schematic flow diagram of a typical high-dust SCR system. Source: (U.S. DOE 1997)

Innovation in $\mathrm{NO}_{\mathrm{x}}$ control technologies stimulated by government regulations is again verified in this study. We show that in the case of Japan, Germany, and U.S., innovations in $\mathrm{NO}_{\mathrm{x}}$ control technologies, as measured by the number of new patents related to $\mathrm{NO}_{\mathrm{x}}$ control technologies, did not occur until stringent government regulations were in place, thus "forcing" innovation. We also demonstrate that reductions in the cost of new generations of SCR equipment are consistently associated with the increasing adoption of the control technology as measured by the world total installed capacity. As with FGD systems for $\mathrm{SO}_{2}$ control, the observed changes in SCR technology reflect the impact of technological advancements as well as other factors such as market competition and investments in R\&D.

\subsection{NO $\mathrm{N}_{\mathrm{x}}$ Regulation in the U.S.}

In addition to $\mathrm{SO}_{2}$, the 1970 CAAA also identified nitrogen dioxide $\left(\mathrm{NO}_{2}\right)$ and ground-level ozone $\left(\mathrm{O}_{3}\right)$ as criteria air pollutants linked to adverse human health effects. Both pollutants are formed by chemical reactions that occur in the atmosphere, although some $\mathrm{NO}_{2}$ is also emitted directly from high-temperature combustion processes such as occur at power plants. Nitric oxide (NO) is formed in much greater quantities during combustion and is gradually oxidized to $\mathrm{NO}_{2}$ once emitted to the atmosphere. The combination of $\mathrm{NO}$ and $\mathrm{NO}_{2}-$ referred to as $\mathrm{NO}_{\mathrm{x}}$ - also contributes to acid rain and (together with volatile organic compounds) the formation of groundlevel ozone.

In the United States, the control of $\mathrm{NO}_{\mathrm{x}}$ emissions from power plants initially followed the same timetable and regulatory approach as for $\mathrm{SO}_{2}$ (see Table 2). The key difference was the stringency of applicable requirements. Under the 1970 CAAA, existing power plants were largely unaffected by state-level requirements to achieve the $\mathrm{NO}_{\mathrm{x}}$ air quality standards. For new plants, the EPA New Source Performance Standards imposed only modest requirements that could be met at low cost using improved low- $\mathrm{NO}_{\mathrm{x}}$ burners (LNB) for combustion. During the 1970s and 1980s, as $\mathrm{SO}_{2}$ emission restrictions grew more stringent (and more costly), $\mathrm{NO}_{\mathrm{x}}$ emission requirements for coal plants changed only slightly as LNB technology improved. 
Table 2. Major U.S. regulations for $\mathrm{NO}_{\mathrm{x}}$ emissions from electric power plants.

\begin{tabular}{|c|c|c|}
\hline Year & Regulation & Content \\
\hline 1970 & $\begin{array}{l}\text { Clean Air Act } \\
\text { Amendments }\end{array}$ & $\begin{array}{l}\text { Established national ambient air quality standards for } \mathrm{NO}_{2} \text { and New Source } \\
\text { Performance Standards (NSPS) for new plants }>73 \mathrm{MWe} \mathrm{NO}_{\mathrm{x}} \text { limits were } 0.7 \\
\mathrm{lb} \mathrm{NO} / \mathrm{MBtu} \text { of fuel burned for coal units, } 0.3 \mathrm{lb} / \mathrm{MBtu} \text { for oil-fired units and } \\
0.2 \mathrm{lb} / \mathrm{MBtu} \text { for gas-fired units. }\end{array}$ \\
\hline 1977 & $\begin{array}{l}\text { Clean Air Act } \\
\text { Amendments }\end{array}$ & $\begin{array}{l}\text { NSPS revised for coal-fired plants. New } \mathrm{NO}_{\mathrm{x}} \text { emission limits for units built } \\
\text { after } 1978 \text { are } 0.6 \mathrm{lb} \mathrm{NO} / \mathrm{MBtu} \text { (bituminous coal) and } 0.5 \mathrm{lb} / \mathrm{MBtu} \\
\text { (subbituminous coal). }\end{array}$ \\
\hline 1990 & $\begin{array}{l}\text { Clean Air Act } \\
\text { Amendments }\end{array}$ & $\begin{array}{l}\text { Two major portions of the CAA affecting power plant } \mathrm{NO}_{\mathrm{x}} \text { control are Title I } \\
\text { (National Ambient Air Quality Standards), and Title IV (Acid Rain Control). } \\
\text { Regulations stemming from } 1990 \text { amendments are discussed below. }\end{array}$ \\
\hline 1994 & $\begin{array}{l}\text { Title I: Ozone } \\
\text { Transport } \\
\text { Commission } \\
\text { (OTC) } \mathrm{NO}_{\mathrm{x}} \\
\text { Budget } \\
\text { Program } \\
\end{array}$ & $\begin{array}{l}\text { A regional } \mathrm{NO}_{\mathrm{x}} \text { emissions control program in } 12 \text { Northeastern states to help } \\
\text { attain the health-related NAAQS for ground-level ozone. These reductions are } \\
\text { in addition to previous state requirements that included the installation of } \\
\text { reasonably. available control technology. States committed to developing and } \\
\text { adopting regulations to reduce region-wide } \mathrm{NO}_{\mathrm{x}} \text { emissions by } 1999 \text { with } \\
\text { further reductions by } 2003 \text {. }\end{array}$ \\
\hline 1995 & $\begin{array}{l}\text { Title IV: U.S. } \\
\text { Acid Rain } \\
\text { Control } \\
\text { Program }\end{array}$ & $\begin{array}{l}\text { A two-phased reduction in } \mathrm{NO}_{\mathrm{x}} \text { emissions from coal-fired power plants to } \\
\text { control acid deposition. Phase } \mathrm{I} \text {, finalized in } 1995 \text {, sought to reduce } \mathrm{NO}_{\mathrm{x}} \\
\text { emissions by over } 400,000 \text { tons/yr between } 1996 \text { and } 1999 \text { by requiring } \\
\text { Reasonably Available Control Technology (RACT), as defined by USEPA for } \\
\text { different types of boilers. Phase II tightened and extended these requirements } \\
\text { to reduce } \mathrm{NO}_{\mathrm{x}} \text { emissions by over } 2 \mathrm{Mt} / \mathrm{yr} \text { beginning in } 2000 \text {. The average } \\
\text { RACT requirement was approximately } 0.55 \mathrm{lb} \mathrm{NO}_{2} / \mathrm{MBtu} \text {. }\end{array}$ \\
\hline 1998 & $\begin{array}{l}\text { Title I: } \mathrm{NO}_{\mathrm{x}} \\
\text { State } \\
\text { Implementation } \\
\text { Plan (SIP) Call }\end{array}$ & $\begin{array}{l}\text { EPA issues a rule requiring } 22 \text { states to revise their State Implementation Plan } \\
\text { to further reduce } \mathrm{NO}_{\mathrm{x}} \text { emissions by } 1.2 \mathrm{Mt} / \mathrm{yr} \text { by } 2007 \text {. The rule gives each } \\
\text { affected state a } \mathrm{NO}_{\mathrm{x}} \text { emission budget. States have flexibility to determine how } \\
\text { to reduce emissions to achieve the specified target. }\end{array}$ \\
\hline 1999 & $\begin{array}{l}\text { Title I: Section } \\
126 \text { Federal } \\
\mathrm{NO}_{\mathrm{x}} \text { Budget } \\
\text { Trading } \\
\text { Program }\end{array}$ & $\begin{array}{l}\text { For states opting to meet the } \mathrm{NO}_{\mathrm{x}} \text { SIP Call requirements through a cap and } \\
\text { trade program, EPA developed a model } \mathrm{NO}_{\mathrm{x}} \text { Budget Trading Program rule to } \\
\text { facilitate cost-effective } \mathrm{NO}_{\mathrm{x}} \text { emissions reductions from large stationary } \\
\text { sources. The model rule includes provisions for applicability, allocations, } \\
\text { monitoring, banking, penalties, trading protocols and program administration. } \\
\text { States can modify certain provisions of the model rule. The allowance trading } \\
\text { component provides incentives for units to over-control if the cost is less than } \\
\text { the market price of } \mathrm{NO}_{\mathrm{x}} \text { allowances. }\end{array}$ \\
\hline
\end{tabular}

Because $\mathrm{NO}_{\mathrm{x}}$ also contributes to acidic deposition, the acid rain provisions of the 1990 CAAA required many existing coal-fired plants to install "reasonably available control technology" in the form of LNB and other combustion modifications. In 1994, however, EPA established much more stringent $\mathrm{NO}_{\mathrm{x}}$ emission reduction requirements for existing power plants as part of a comprehensive regional strategy to attain the health-related NAAQS for ground-level ozone. These new requirements called for $\mathrm{NO}_{\mathrm{x}}$ reductions averaging about $85 \%$. An emissions trading program akin to that for $\mathrm{SO}_{2}$ also was established to help reduce compliance costs. Nonetheless, achieving these stringent $\mathrm{NO}_{\mathrm{x}}$ reductions has required retrofitting many existing power plants with post-combustion SCR systems as well as LNB. A massive expansion in SCR installations is now underway in the United States to meet the compliance deadline of 2004. A recent 1997 
revision to the Federal NSPS for coal-burning plants also now requires a low level of $\mathrm{NO}_{\mathrm{x}}$ emission currently achievable only with SCR systems in most cases.

In contrast to the U.S. situation, the use of SCR in other industrialized countries began many years earlier in response to stricter $\mathrm{NO}_{\mathrm{x}}$ emission limits. Japan first enacted strict requirements in the 1970s and pioneered the development of SCR technology for power plant applications. In the mid-1980s, Germany required the use of SCR systems on large coal-fired power plants as part of its acid rain control program. Subsequently other European countries also began to adopt this technology. SCR systems also have been deployed at some power plants burning oil or natural gas, including gas turbine plants used for peak power generation.

\subsection{NO $\mathrm{N}_{\mathrm{x}}$ Technology Innovation: Evidence from Patents}

We use an iterative process to conduct patent analysis that link inventive activity in $\mathrm{NO}_{\mathrm{x}}$ control technologies to government actions. The first step was an exploration of a few highly relevant $\mathrm{NO}_{\mathrm{x}}$ control technology patents based on iteratively conducted, small-scale patent searches that are relevant to technical solutions to $\mathrm{NO}_{\mathrm{x}}$ emissions from stationary sources. For the " $\mathrm{NO}_{\mathrm{x}}$-class based dataset," a list of potential class/subclass combinations was developed from these preliminary searches, and interviews were conducted with the various patent examiners responsible for these classes.

A second, abstract-based patent dataset was developed next in order to better identify relevant patents. The preliminary searches conducted earlier were analyzed for frequently occurring keywords within the patents' titles and abstracts, and the resulting keywords and their likely variations were used to run further searches on patents in a limited number of years (dispersed over time). These search results were then analyzed for relevant keywords. The process was repeated until the combination of keywords selected appeared to maximize the number of relevant patents and minimize the number of irrelevant patents that were captured with each search. These keywords were then used to search the entire USPTO database for patents granted after January 1, 1976 (since only patents granted after this date are electronically coded for the abstract field that the searches were run on). A detailed description of these two search methods (class-based and abstract-based) can be found in (Taylor, Rubin et al. 2001). In this research, however, we combine the two methods by examining the class/subclass in the abstract-based database, compare it with the list of class/subclass that we previously recorded, and keep those classes that have high frequencies in the abstract-based database and remove those that are highly infrequent. The resulting class/subclass combinations that emerged from this method are displayed in Table 3. This list is used to search the entire USPTO database from 1790 to July 2003. The dataset that resulted from searching these class/subclass combinations over time encompassed 5,071 patents. 
Table 3. U.S. patent classes and subclasses that comprise the $\mathrm{NO}_{\mathrm{x}}$ patent dataset (U.S. Patent and Trademark Office 2003).

\begin{tabular}{|l|l|}
\hline $\begin{array}{c}\text { USPC Class/ } \\
\text { Subclasses }\end{array}$ & \multicolumn{1}{c|}{ Definition of USPC Class/Subclasses } \\
\hline $423 / 235,239.1$ & $\begin{array}{l}\text { Class 423, the "chemistry of inorganic compounds," includes these subclasses } \\
\text { representing (235) the modification or removal of nitrogen or nitrogenous } \\
\text { components of a normally gaseous mixture, (239.1) including through use of a } \\
\text { solid sorbent, catalyst, or reactant. }\end{array}$ \\
\hline $122 / 4 \mathrm{D}$ & $\begin{array}{l}\text { Class 122, "liquid heaters and vaporizers," includes this subclass for miscellaneous } \\
\text { boilers and boiler parts that are not otherwise classifiable. }\end{array}$ \\
\hline $110 / 345,347$ & $\begin{array}{l}\text { Class 110, "furnaces," includes these subclasses representing (345) processes to } \\
\text { treat combustion exhaust gases, for example, in order to control pollution and (347) } \\
\text { processes related to the burning of pulverized fuel. }\end{array}$ \\
\hline $431 / 4,8-10$ & $\begin{array}{l}\text { Class 431, "combustion" includes these subclasses representing a combustion } \\
\text { process or burner operation that includes (4) feeding an additive to a flame in order } \\
\text { to give it a special characteristic; (8) flame shaping or distributing components in a } \\
\text { combustion zone; (9) whirling, recycling, or reversing flow in an enclosed flame } \\
\text { zone; (10) supplying a distinct stream of an oxidzer to a region of incomplete } \\
\text { combustion. }\end{array}$ \\
\hline
\end{tabular}

Figure 13 displays the full $\mathrm{NO}_{\mathrm{x}}$ patenting activities by the date they were filed over time. The patenting activities increase substantially after 1970, and appear to occur in stages. Before 1970, patenting activity averaged about 10 patents per year since the early 1900s. Between 1971 and 1984, patenting activity averaged 100 patents per year - a ten-fold increase over the pre-1970 level. From 1985 to 2000 , patenting activity continued to rise to an average of 165 patents per year. The falloff in the last few years is largely an artifact of "truncation effects" in the dataset due to the lag time between file dates and grant dates, ${ }^{8}$ and thus data in the years of 2001 and 2002 will not be included in the analyses that follow. We attribute the initial rise in post-1970 patenting activity as a response to the emission regulations of $\mathrm{NO}_{\mathrm{x}}$ stationary sources in Japan, the Clean Air Act Amendments, and the 1971 NSPS. A second rise in the patenting activities around 1985 can be attributed to the new $\mathrm{NO}_{\mathrm{x}}$ regulations in Germany, and the subsequent US regulations of Title I and Title VI in the 1990s.

\footnotetext{
${ }^{8}$ In this database, the average lag time between a patent's file date and grant date is 2.1 years, ranging from 3 months to 20 years.
} 


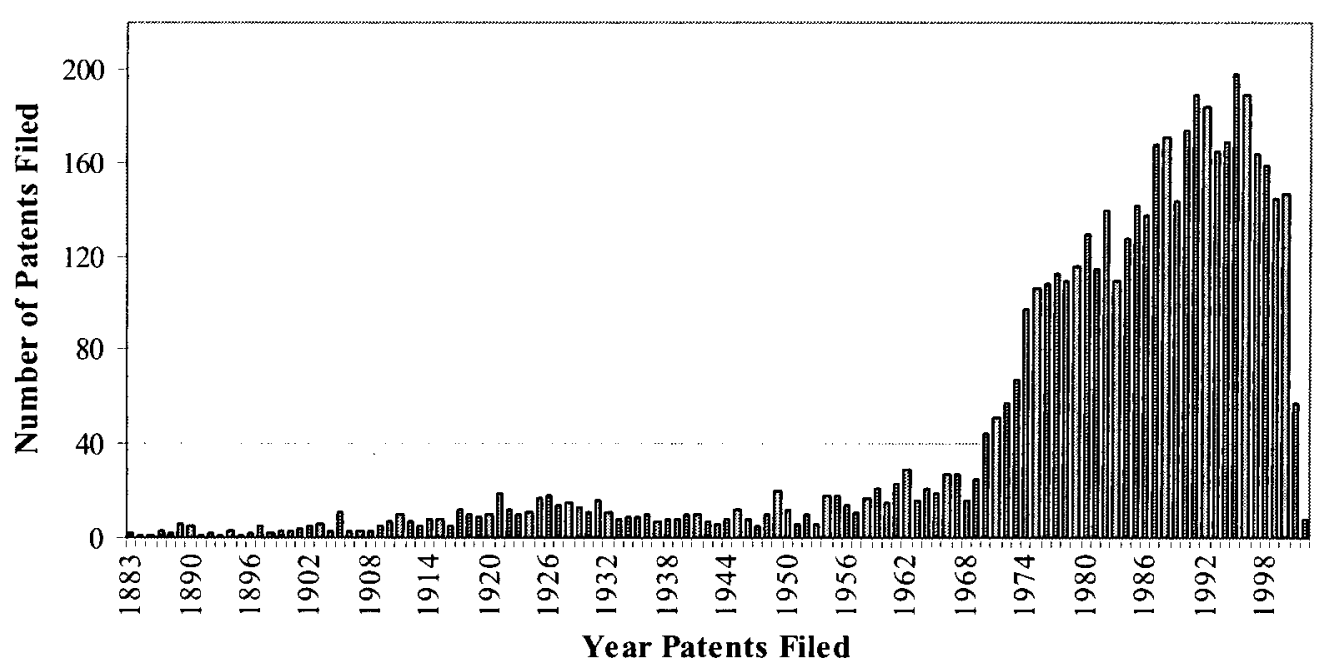

Figure 13. Patenting trends for technologies to control $\mathrm{NO}_{\mathrm{x}}$ from stationary power sources.

Most of the patents filed prior to 1970 dealt with low to moderate levels of $\mathrm{NO}_{\mathrm{x}}$ control via combustion modifications (consistent with NSPS requirements), while higher-efficiency chemical removal systems are prevalent after 1970. This activity is seen more clearly in Figure 14, which depicts patenting activity in the class/subclass combinations of 423/235 and $423 / 239.1$. These two class/subclasses were noted by patent examiners as particularly pertinent to SCR and SNCR technology (see Table 3 for a more detailed description). Patenting activity in these two subclasses increased in the beginning of 1970 s, then rose sharply again in the mid1980 s, and was sustained through the 1990s.

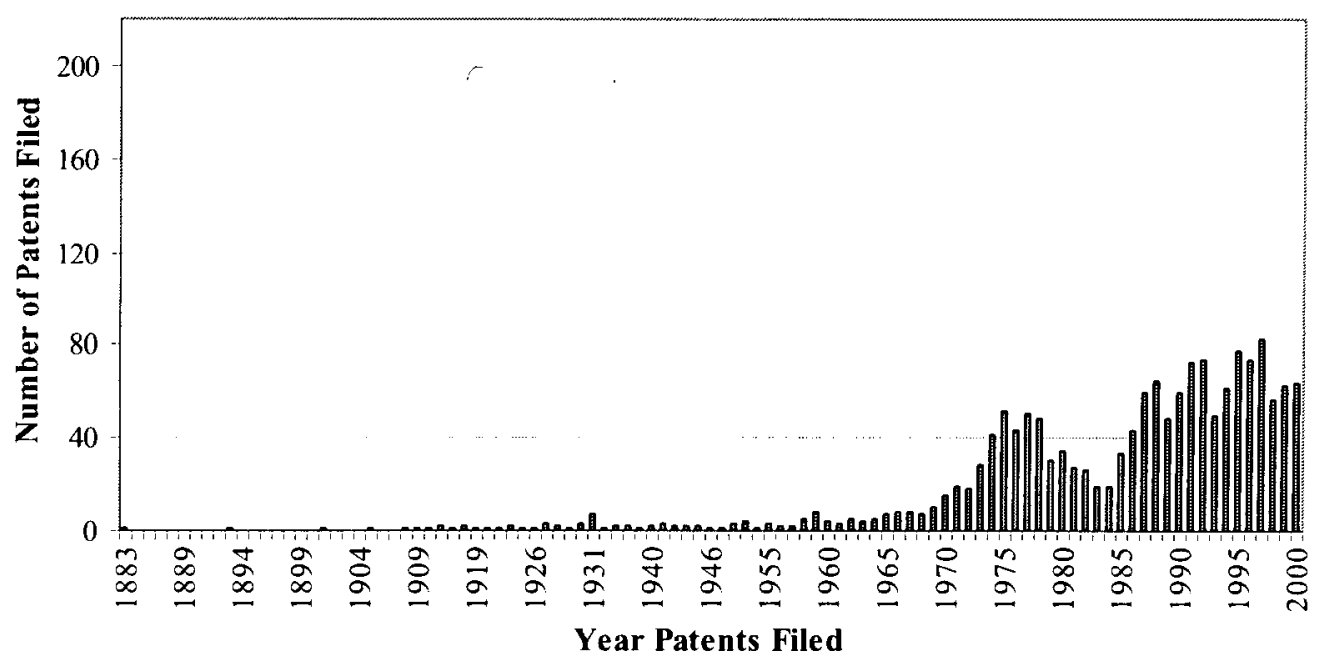

Figure 14. $\mathrm{NO}_{\mathrm{x}}$ patents in the main post-combustion control technology: class/subclass combinations of $423 / 235$ and $423 / 239.1$.

The importance of other nations in the $\mathrm{NO}_{\mathrm{x}}$ innovation story is evident in Figures 15-17. On average from 1963-1995, the US-based inventors held $62 \%$ of all US patents, while Japan and Germany held approximately $13 \%$ and $8 \%$, respectively. Figure 15 shows that US held only 
about $56 \%$ of all patents in $\mathrm{NO}_{\mathrm{x}}$ control, while Japan and Germany held greater proportions than the averages of their portfolio in all US patents.

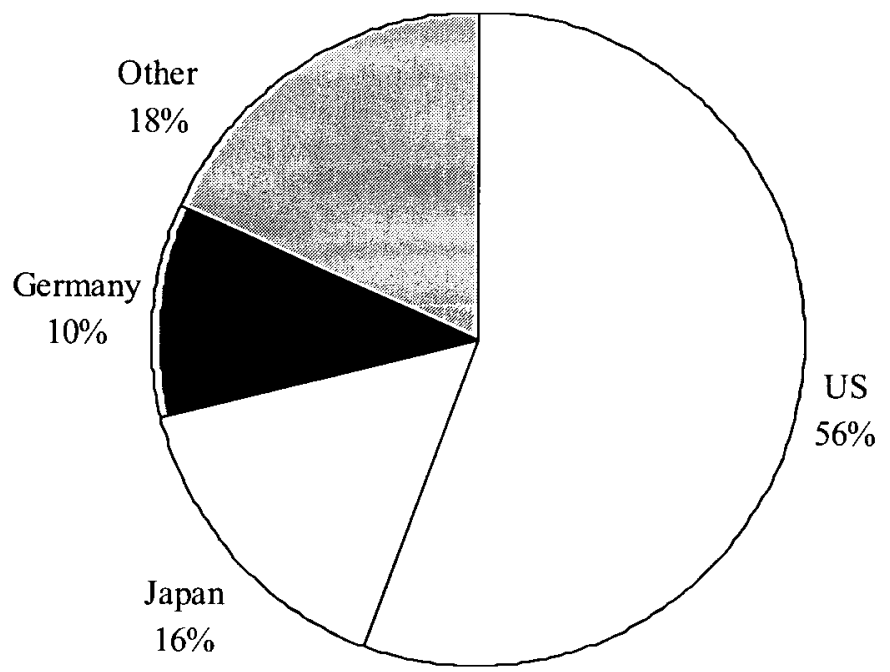

Figure 15. $\mathrm{NO}_{\mathrm{x}}$ patents by inventor nation of origin.

Figure 16 shows the ratio of a country's patents in $\mathrm{NO}_{\mathrm{x}}$ control to their annual total national patent portfolio in the U.S. (i.e. its patent activity index). The US patent activity in $\mathrm{NO}_{\mathrm{x}}$ control roughly tracks the nation's overall patenting level. More significant is the importance of Japanese patenting in $\mathrm{NO}_{\mathrm{x}}$ control technologies from 1972 to 1980, and Germany's proportion of $\mathrm{NO}_{\mathrm{x}}$ patents in the years 1982-1992.

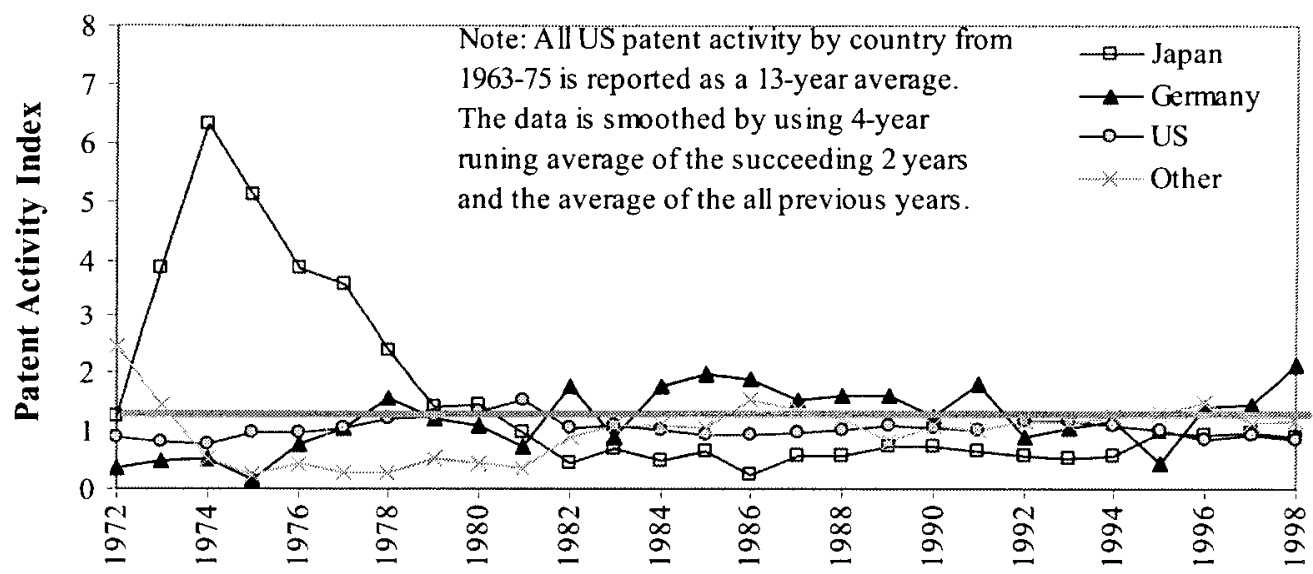

Year Patent Filed

Figure 16. Patent activity indices for the overall $\mathrm{NO}_{\mathrm{x}}$ dataset.

This activity is seen more clearly in Figure 17, which depicts patenting activity in the class/subclass combinations of $423 / 235$ and $423 / 239.1$. The pattern of patenting activity in postcombustion technologies is consistent with the earlier adoption and development of these systems in Japan (in the mid-to-late 1970s) and Germany (in the mid-to-late 1980s) and the lack of sufficiently stringent standards in the U.S. For both Germany and Japan, it is clear that the SCR and SNCR patent classes accentuate the trend seen earlier in the overall $\mathrm{NO}_{\mathrm{x}}$ dataset. 


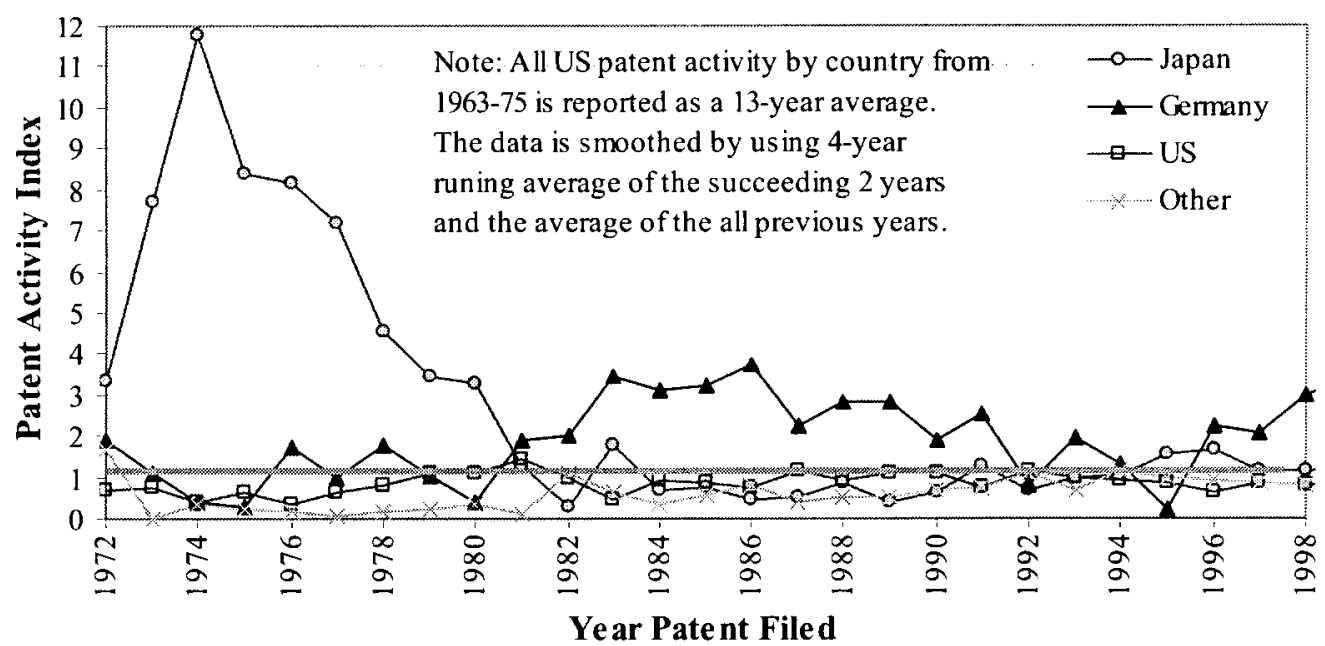

Figure 17. Patent activity indices for patents in the main post-combustion control technology classes $(423 / 235$ and $423 / 239.1)$.

Interestingly, there is a lack of high patenting activity for post-combustion $\mathrm{NO}_{\mathrm{x}}$ control technology by US inventors after imposition of stringent $\mathrm{NO}_{\mathrm{x}}$ control requirements in the mid1990s. A possible explanation is that the US chose to meet the stringent regulations by importing mature high-efficiency technologies (such as SCR), or licensing patents on these technologies from Japan and Germany. The fact that Japan is a very important licensor of SCR technology supports this hypothesis. It remains to be seen, however, whether there will be a new burst of U.S. patenting activity in the post- 2000 period, where most retrofits of U.S. plants will occur.

\subsection{Worldwide Use of SCR Systems}

SCR was first developed and commercialized in Japan in the 1970s and later in Germany in 1980s. Even as late as the 1980s, SCR had not found commercial acceptance in the United States. The principal reasons were the lack of stringent regulatory requirements, as well as projected high cost and potential technical problems with U.S. high-sulfur coal (Damon, Ireland et al. 1987). In spite of these concerns, interest in SCR technology grew because of the low $\mathrm{NO}_{\mathrm{x}}$ emissions achievable by this technology. Recent U.S. experience has benefited in large degree from the prior generations of designs in Japan and Germany.

Figure 18 shows the historical trend in the worldwide growth of SCR capacity. As with FGD systems, the onset of growth reflects the stringency and timetable for $\mathrm{NO}_{\mathrm{x}}$ reductions in different countries. The earliest use of SCR at coal-fired power plants is seen in Japan beginning in 1980, ${ }^{9}$ followed by widespread adoption in Germany in the mid-1980s. The U.S. has been the laggard in SCR use, with the first units on coal-fired plants installed only in 1993. However, U.S. capacity of SCR systems is now expected to grow to at least $100 \mathrm{GW}$ by 2004 (U.S. EPA 1999; NESCAUM 2001; McIlvaine Company 2002).

\footnotetext{
${ }^{9}$ The first SCR was installed in Japanese plant in 1977 using crude, heavy oil, and liquid natural gas.
} 


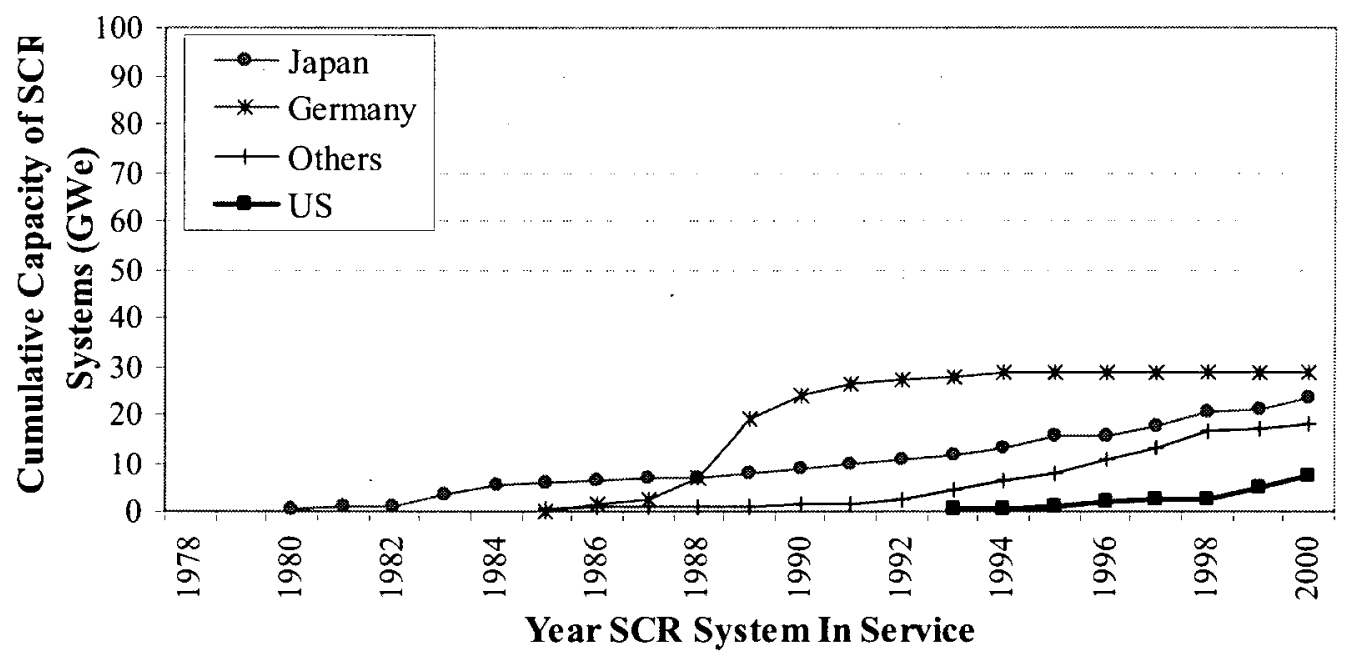

Figure 18. Cumulative installed capacity of SCR systems on coal-fired power plants in different countries. Adapted from (Soud 2001).

The earliest installations of SCR systems on power plants in the United States were at oil and gas-fired plants (principally in California), where problems of operability and high cost are less severe than at coal-burning power plants. As of 1996, the total capacity of SCR systems on noncoal utility systems in the U.S. was approximately $11.5 \mathrm{GW}$ (U.S. EPA 2002). ${ }^{10}$ Data on noncoal systems in other countries are not readily available, but are believed to be small relative to coal-based applications.

\subsection{Experience curves for SCR}

\subsubsection{Early (Pre-Commercial) Experience}

The earliest cost estimates of the SCR system in the United States (Mobley 1978) were based on the extrapolation of Japan experience. Dissimilarities in fuel characteristics (such as sulfur content, and heavy metals) and operating conditions were anticipated but were not directly factored into the cost estimates, which were not based on actual plant designs but instead on standard design practices and trend in utility boiler construction at that time. Later economic studies showing higher capital and O\&M costs incorporated uncertainties for lack of experience in high sulfur content of US coal, and lack of operational experience with the system (Maxwell, Burnett et al. 1980; Maxwell and Humphries 1981; EPRI 1982). Cost estimates declined after German experience and U.S. pilot programs revealed lower capital and operating cost, proven longer catalyst lifetimes, and lower catalyst price. The historical capital cost and total levelized costs trends for SCR systems are shown in Figure 19.

\footnotetext{
${ }^{10}$ In 1997 , retrofit SCR systems were in operation on 14 gas-fired utility boilers ranging in size from 147 to 750 MW in California (total of 5,482 MW) and 7 coal-fired boilers (total of 1,535 MW). SCR is also used to control $\mathrm{NO}_{\mathrm{x}}$ emissions from more than 40 industrial boilers and process heaters and more than 176 gas turbines (approximately 7,784 MW) in the U.S. These include both field-erected and small package boilers (ICAC 1997).
} 
(a).

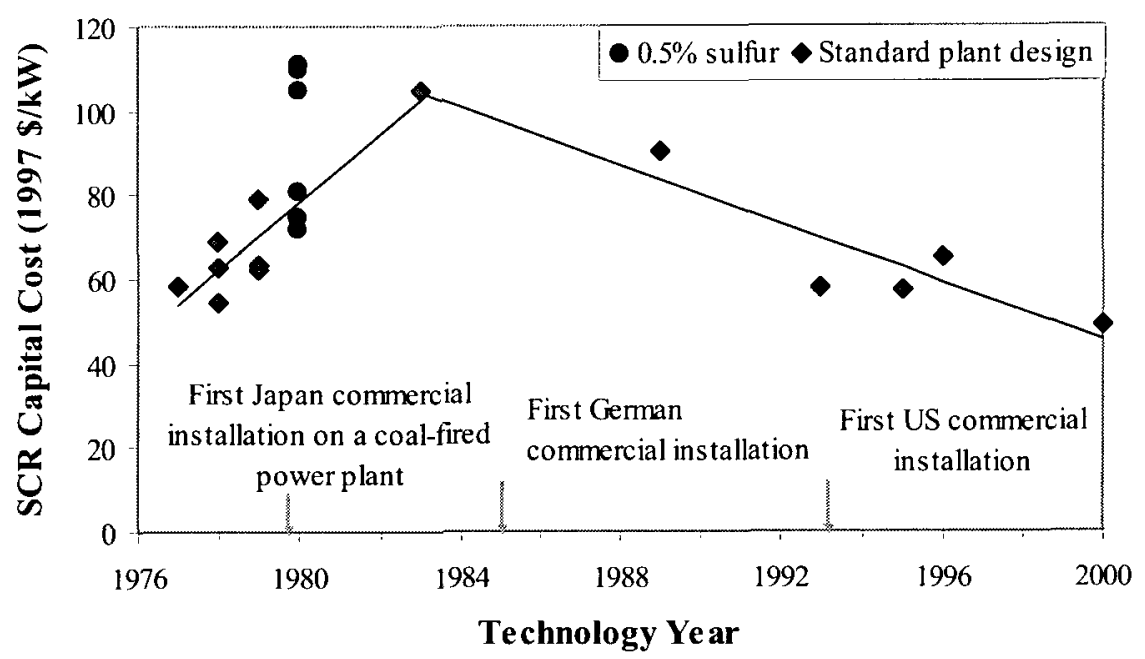

(b).

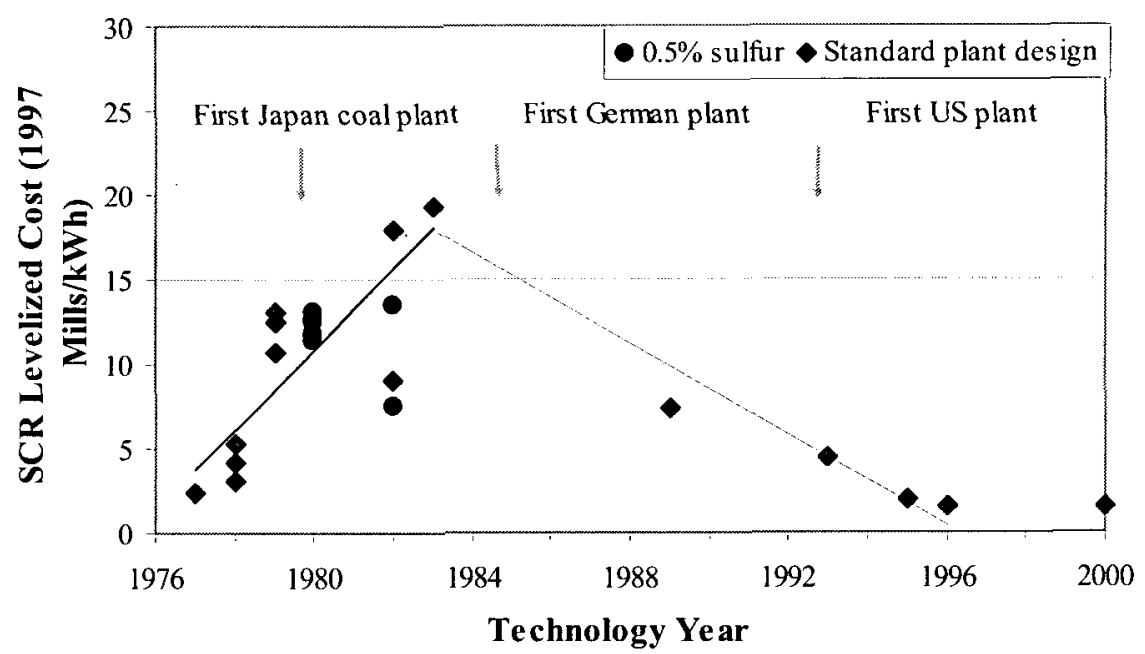

Figure 19. Capital and levelized costs of a SCR system for a standard new coal-fired power plant. Except where specified, a standard plan is of the size of $500 \mathrm{MWe}$, burning medium sulfur coal, $\mathrm{SCR}$ inlet $\mathrm{NO}_{\mathrm{x}}$ concentration $0.6 \mathrm{lb} / \mathrm{MBtu}$, and achieving $80 \% \mathrm{NO}_{\mathrm{x}}$ removal. Levelized cost $=$ capital cost $\times$ fixed charge factor + levelization factor $\times$ O\&M cost.

\subsubsection{Results for Large-Scale Deployment}

Cost trends for SCR system capital cost were developed using the same methodology employed for FGD technology, namely the use of historical cost studies for new installations based on a standardized power plant design and $\mathrm{NO}_{\mathrm{x}}$ removal efficiency. As before, a detailed computer model was used to adjust key design parameters to a consistent basis where necessary, and all results were converted to 1997 dollars using Chemical Engineering construction cost index.

Figure 20 shows the resulting trend for SCR capital costs. Significant cost decreases have occurred as worldwide use of SCR systems has grown. Again, this trend reflects the effects of investments in R\&D as well as learning by doing and other factors. Much of the decrease in capital cost is related to the initial cost of SCR catalyst, as SCR process improvements, coupled with improvements in catalyst manufacturing methods and competition among catalyst 
manufacturers, lowered both the total catalyst requirements and the unit cost of catalyst significantly. During the 1990s, for example, the unit price of SCR catalyst fell by a factor of two, during which time there was no systematic decline in the real prices of the principal metals, mainly vanadium and titanium, used for SCR catalysts (U.S. Geological Survey 2001).

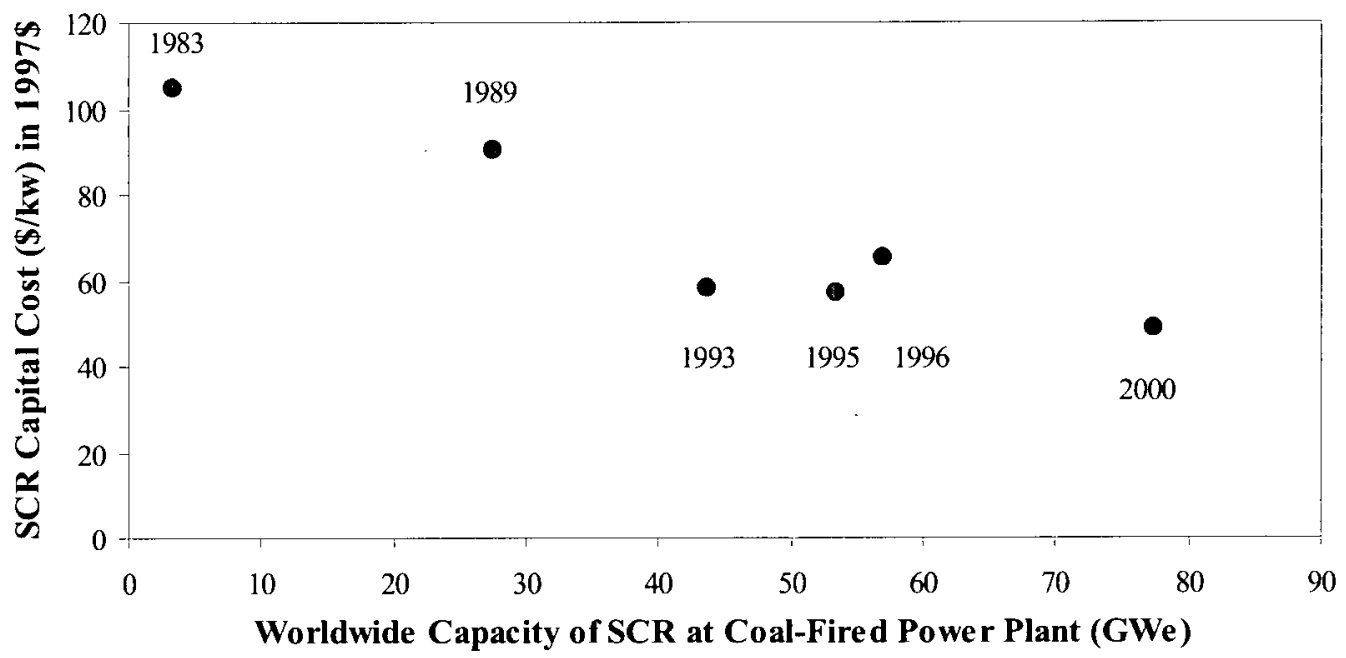

Figure 20. Capital cost of a new SCR system for a standard coal-fired power plant (500 MWe, medium sulfur coal, $0.6 \mathrm{lb} / \mathrm{MBtu}$ inlet $\mathrm{NO}_{\mathrm{x}}, 80 \% \mathrm{NO}_{\mathrm{x}}$ removal) as a function of cumulative worldwide capacity of coal-based SCR installations. Based on data from(Maxwell and Humphries 1985; Robie and Ireland 1991; Rao, McIlvried et al. 1994; Healy, Maxwell et al. 1996; Foerter and Jozewicz 2001).

Another factor contributing to the decline in total capital cost was the lack of early experience with SCR in the United States. Thus, there were great uncertainties in the early 1980s about the applicability and reliability of SCR for power plants burning U.S. coals. A number of technical problems were anticipated because of the much higher sulfur content of U.S. coals relative to those used in Japan and Germany, and such concerns were reflected in more conservative and more costly designs for U.S. plants. Cumulative foreign experience and later applications with U.S. coals subsequently demonstrated that less conservative (and less expensive) designs were indeed viable for U.S. facilities.

The data in Figure 20 provided the basis for an SCR experience curve based on U.S. coal-fired power plants, which is illustrated later in Section V. However, as with the FGD analysis, the relevant measure of cumulative production was taken to be the worldwide capacity of coal-based SCR installations to again reflect the global nature of markets and innovations in these environmental technologies. The potential contribution of SCR experience at oil and gas-fired facilities is not reflected in these estimates, in part because of data limitations, but also because many of the designs and technical problems associated with coal-fired plants (such as high flyash loadings and trace contaminants that can poison SCR catalysts) do not apply in these cases. Nonetheless, to the extent that any spillover effects from these SCR markets have benefited coalfired plants the learning rates derived in this study would decline slightly as the experience base (cumulative capacity) is expanded. 
As with FGD systems, the systematic design studies used to characterize SCR capital costs do not provide a rigorous basis for an experience curve for O\&M costs, since these studies report expected costs rather than actual costs. Nonetheless, they are again instructive as they reflect changes in expectations based on contemporaneous process improvements and operating experience with earlier designs. Figure 21 shows the total expected annual O\&M costs derived from several studies over a 13-year period, adjusted to a common basis. While several factors contribute to O\&M cost, for SCR systems the single dominant factor is the cost of replacement catalyst (Hjalmarsson 1990; ICAC 1997). By the 1990s, the unit price of SCR catalyst had been reduced by half, while at the same time the expected catalyst lifetime (replacement interval) was more than four times longer than estimates of the early 1980s. Further improvements in catalyst formulations have resulted in decreased unwanted side reactions such as $\mathrm{SO}_{2}$ to $\mathrm{SO}_{3}$ conversions, ${ }^{11}$ increased resistance to flue gas poisoning, and increased catalyst activity. Consequently, catalyst volumes needed to achieve a given level of $\mathrm{NO}_{\mathrm{x}}$ reduction have decreased and the operating life of catalysts has increased (Foerter and Jozewicz 2001). The overall result was a sharp drop in expected annualized O\&M costs, as seen in Figure 21. As the basis for an O\&M cost experience curve, however, these data likely overestimate the true learning rate since the earliest estimates of catalyst lifetime and replacement cost were based primarily on manufacturers' guarantees at the time (typically a one-year catalyst life for U.S. coal-fired plants) and very limited operating experience (mainly on Japanese power plants). Later cost projections were revised to reflect new process developments and experience that achieved significantly longer catalyst life. Thus, the O\&M cost reduction of over $80 \%$ seen in Figure 21 represents the change in outlook for SCR costs over the past two decades. While further study is needed to quantify actual learning rates based on long-term experience at coal-fired power plants, the data in Figure 21 can be used to derive a rough estimate, as presented later in Section $\mathrm{V}$.

\footnotetext{
${ }^{11}$ This combined with unreacted $\mathrm{NH}_{3}$ (ammonia slip) and generate ammonium sulfate and bisulfate compounds that causes fouling of downstream equipment, especially air preheater.
} 


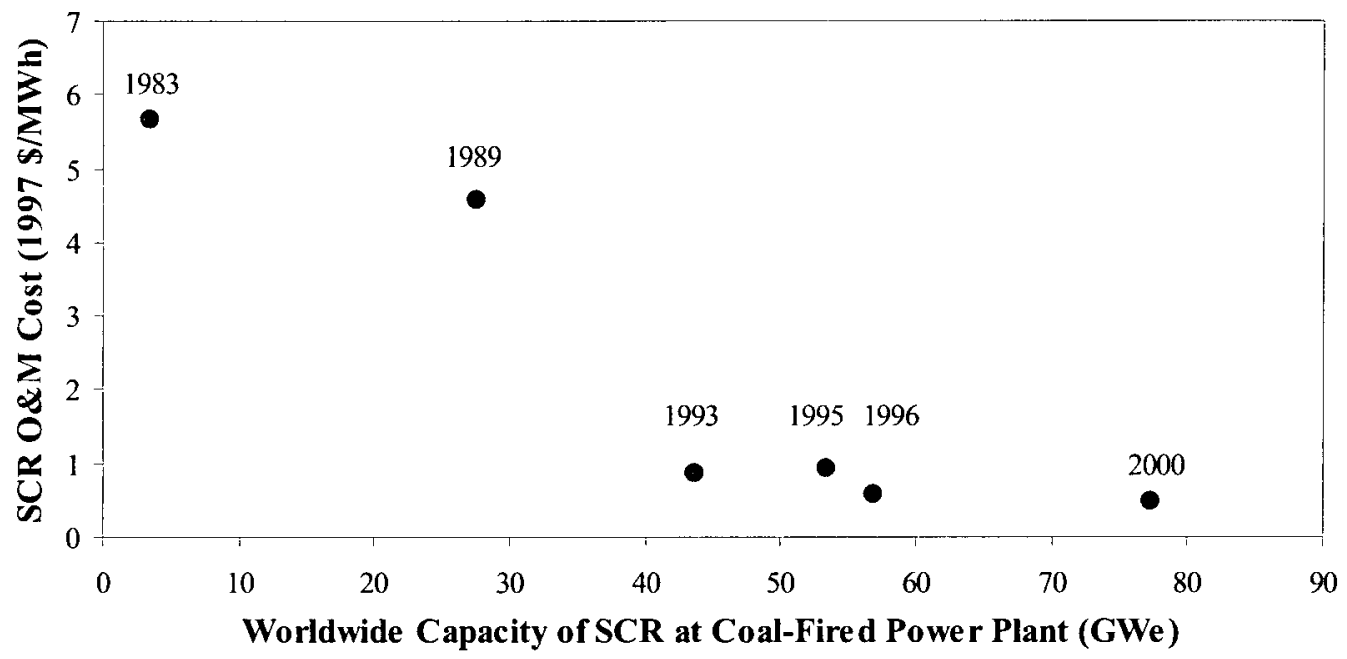

Figure 21. Annualized operating and maintenance (O\&M) cost of a new SCR system for a standard coal-fired power plant $\left(500 \mathrm{MWe}\right.$, medium sulfur coal, $0.6 \mathrm{lb} / \mathrm{MBtu}$ inlet $\mathrm{NO}_{\mathrm{x}}, 80 \% \mathrm{NO}_{\mathrm{x}}$ removal, $65 \%$ capacity factor) as a function of cumulative worldwide capacity of coal-based SCR installations. Based on data from (Maxwell and Humphries 1985; Robie and Ireland 1991; Rao, Mcllvried et al. 1994; Healy, Maxwell et al. 1996; Foerter and Jozewicz 2001). 


\section{Technology Innovation in $\mathrm{CO}_{2}$ Control}

\subsection{Overview}

A potentially attractive strategy for carbon management involves the separation and capture of $\mathrm{CO}_{2}$ from the flue gas stream of electric power plants and other industrial processes. The $\mathrm{CO}_{2}$ would then be stored in geologic formations (e.g., deep saline reservoirs, depleted oil and gas wells, unmineable coal seams) or in other repositories including (potentially) the world's oceans. In contrast to terrestrial-based sequestration, where carbon is absorbed from the atmosphere and stored in soils or newly-grown biomass, this method of carbon management is a technologybased approach similar in principle to other types of environmental control technologies now used at power plants, such as the post-combustion $\mathrm{SO}_{2}$ and $\mathrm{NO}_{\mathrm{x}}$ systems discussed previously.

The basic amine process was first patented by R. R. Bottom in 1930 as absorbents for acidic gas treating (Bottoms 1930). The alkanolamine gas treating basic process flow scheme has remained relatively unchanged over the years (Figure 22). The technology for $\mathrm{CO}_{2}$ separation and capture exists today is the same that used commercially for $\mathrm{CO}_{2}$ removal from natural gas and hydrogen, and to remove $\mathrm{CO}_{2}$ from flue gas and captured for the use of food and chemical production, chemical processing, and enhanced oil recovery (EOR). The storage of $\mathrm{CO}_{2}$ in geological formations also has been demonstrated on a limited scale, predominantly in the oil and gas industries. Indeed, $\mathrm{CO}_{2}$ removal efficiencies of about 90 percent are commonly assumed as a potential carbon management strategy for power plants. However, the cost of $\mathrm{CO}_{2}$ capture and separation is currently prohibitive for large-scale power generation applications (Herzog 1999; Simbeck 2001). But if cheaper methods can be developed to capture and reliably store the $\mathrm{CO}_{2}$ produced by power plants and other industrial sources, the world's resources of fossil fuels could continue to be used while avoiding the potential consequences of global climate change. Such a scenario would represent a paradigm shift in the current thinking about solutions to the global warming problem.

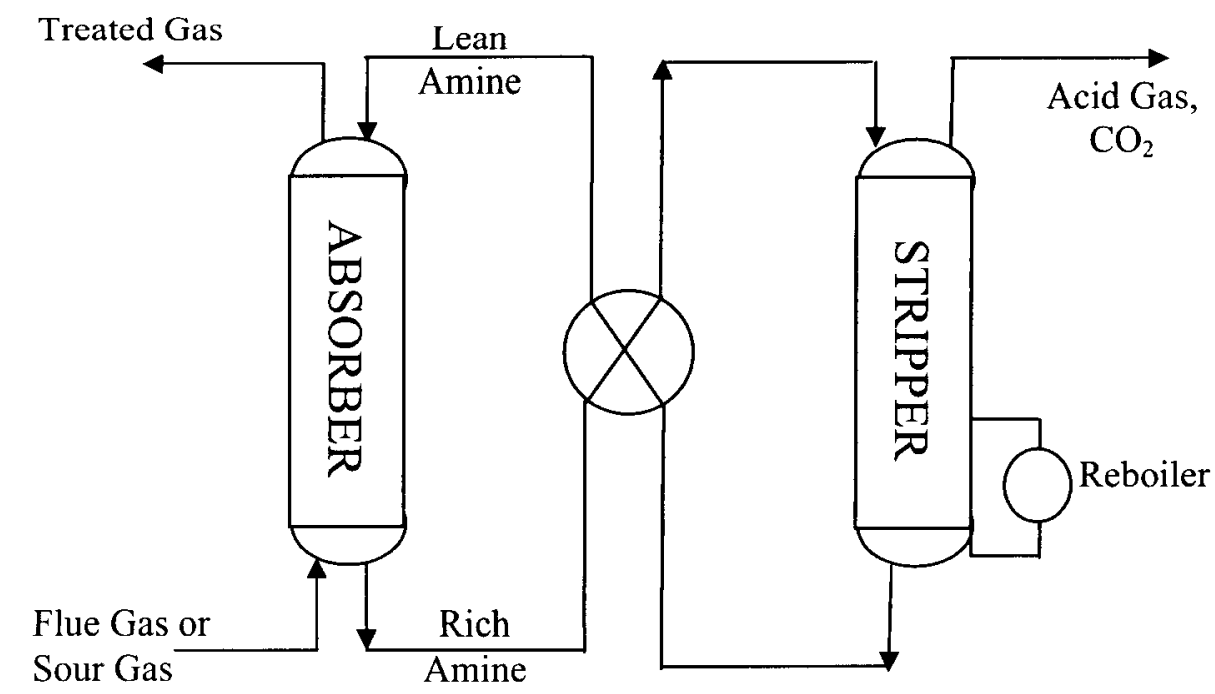

Figure 22. Typical amine gas treating plant process flow diagram 


\section{2 $\mathrm{CO}_{2}$ Regulation in the U.S.}

No regulations currently exist to control $\mathrm{CO}_{2}$ emissions from power plants and other industrial and transportation sources. However, worldwide interest in greenhouse gas control has stimulated government-sponsored R\&D efforts to develop improved technology for $\mathrm{CO}_{2}$ capture and storage (CCS). Private-sector R\&D, such as the $\mathrm{CO}_{2}$ Capture Project (a consortium of seven major oil companies and two European utilities), also is actively pursuing technology innovations in this area, with the goal of commercial demonstrations within the decade.

In contrast to $\mathrm{SO}_{2}$ and $\mathrm{NO}_{\mathrm{x}}$ emissions, $\mathrm{CO}_{2}$ is not formally designated as a "pollutant." And because it is both a valuable industrial commodity, as well as an impurity in oil and gas production, technology for separating and capturing $\mathrm{CO}_{2}$ from industrial gas streams has been developed over many decades, especially in the post-World War II era when oil and gas production soared. During 1970's and 1980's, the price for crude oil soared and there were great interests in the application of EOR to separate $\mathrm{CO}_{2}$ from flue gas and inject into oil well to recover the remaining unrecovered crude oil. When the price of crude oil dropped dramatically in 1986, the EOR market disappeared. It was not until 1990's that the interest in recovering $\mathrm{CO}_{2}$ from flue gases has taken a dramatic turn and being propelled by the need to reduce greenhouse gas emissions. Today, due to serious concerns of potential policy actions to curb $\mathrm{CO}_{2}$ emissions from industrial, electricity and transportation sources at international level, interests in CCS have gone up significantly.

As part of this project, we have begun to track technology innovations in CCS - as measured by patent activity - to provide a baseline indicator analogous to those developed for $\mathrm{SO}_{2}$ and $\mathrm{NO}_{\mathrm{x}}$ control technologies.

\section{3 $\mathrm{CO}_{2}$ Technology Innovation: Evidence from Patents}

As before, efforts were spent to construct two datasets in order to analyze inventive activity in $\mathrm{CO}_{2}$ capture and sequestration technologies. As in the $\mathrm{SO}_{2}$ and $\mathrm{NO}_{\mathrm{x}}$ case, the first step in creating the $\mathrm{CO}_{2}$ datasets was an exploration of a (very) few highly relevant CCS patents. For the "CO 2 -class based dataset," a list of potential class and subclass combinations was developed from these preliminary searches. Then, interviews were conducted with several U.S. patent examiners responsible for the wide-ranging art units that encompassed these classes. Unlike the other two cases, no single patent examiner could be identified by his or her colleagues as having considerable experience with these technologies. In addition, according to the patent examiners that we interviewed, unlike $\mathrm{SO}_{2}$ and $\mathrm{NO}_{\mathrm{x}}$ cases, there was no good classification that is specifically designated for the removal and capture of $\mathrm{CO}_{2}$ technologies.

The resulting class/subclass combinations that emerged from these interviews, displayed in Table 4 , are therefore much more uncertain than the classes identified for $\mathrm{SO}_{2}$ and $\mathrm{NO}_{\mathrm{x}}$ technologies. The $\mathrm{CO}_{2}$ class-based dataset that resulted from these class/subclass combinations encompassed 4,529 patents since 1872 . However, a close examination of the resulting class-based database found that not only does the database contain a small percentage of relevant patents, but it also missed most of highly relevant patents that we identify through keyword search. The result of the class-base database is therefore not presented in here. 
Table 4. U.S. patent classes and subclasses that comprise the $\mathrm{CO}_{2}$ class-based dataset. Source: (U.S. Patent and Trademark Office 2003)

\begin{tabular}{|c|c|}
\hline $\begin{array}{l}\text { USPC Class/ } \\
\text { Subclasses }\end{array}$ & Definition of USPC Class/Subclasses \\
\hline $\begin{array}{l}423 / 220,223- \\
34,437.1\end{array}$ & $\begin{array}{l}\text { Class } 423 \text {, the "chemistry of inorganic compounds," includes these subclasses } \\
\text { representing the ( } 220 \text { ) modification or removal of carbon dioxide by ( } 223-34) \text { : utilizing } \\
\text { inorganic and organic reactants (including amine and ethanolamine); oxidizing or } \\
\text { burning a component; suspending metal oxide or hydroxide in liquid; and utilizing a } \\
\text { solid sorbent, catalyst, or reactant such as an iron oxide or carbonate (and possibly } \\
\text { regenerating said reactant, for which process an ammonium or metal hydroxide solution } \\
\text { may be used). It also includes this subclass ( } 437.1) \text { which involves products or } \\
\text { processes wherein the product is carbon dioxide. }\end{array}$ \\
\hline $\begin{array}{l}95 / 51,139 \\
236\end{array}$ & $\begin{array}{l}\text { Class 95, "gas separation processes," includes these subclasses representing (51) the } \\
\text { selective diffusion of carbon dioxide or carbon monoxide gases through a substantially } \\
\text { solid barrier; (139) solid sorption of carbon dioxide; and (236) liquid contacting process } \\
\text { (e.g., sorption, scrubbing, etc.) in which carbon dioxide is separated. }\end{array}$ \\
\hline $62 / 928$ & $\begin{array}{l}\text { Class } 62 \text {, "refrigeration," includes this subclass for recovery of carbon dioxide from a } \\
\text { gas mixture. }\end{array}$ \\
\hline $166 / 402$ & $\begin{array}{l}\text { Class } 166, \text { "wells," includes this subclass for the process of injecting carbon dioxide or } \\
\text { carbonated gas. }\end{array}$ \\
\hline $405 / 59$ & $\begin{array}{l}\text { Class } 405, \text { "hydraulic and earth engineering," includes this subclass for the supply or } \\
\text { recovery of stored fluid by a separate fluid. }\end{array}$ \\
\hline $588 / 250$ & $\begin{array}{l}\text { Class } 588 \text {, "hazardous or toxic waste destruction or containment," includes this subclass } \\
\text { for geologic marine or extraterrestrial storage and containment. }\end{array}$ \\
\hline
\end{tabular}

An abstract-based patent dataset was then developed in order to more narrowly identify relevant patents. The list of keyword that we used is the combination of $\mathrm{CO}_{2}$ (or carbon dioxide, or CO.sub.2) and seperat $\$$, sequest $\$$, remov\$, captur\$, membrane, absor\$, adsor\$, or reduc\$. The list of keywords is used to search the entire USPTO database, limited to patents granted after January 1, 1976. As mentioned in previous sections, the patents granted prior to 1976 are image files and not searchable by text. The resulting " $\mathrm{CO}_{2}$ abstract-based dataset" totaled 10,428 patents granted from 1976 to September 2003. One additional task is needed to refine this $\mathrm{CO}_{2}$ abstract-based database. These patents have to be coded, and irrelevant patents discarded based on a reading of the full abstract. (Our preliminary screening base on one year, 2003, suggests that the percent of relevance to CCS is about $40 \%$.)

Since unlike $\mathrm{SO}_{2}$ and $\mathrm{NO}_{\mathrm{x}}$, no federal environmental regulations yet exist for $\mathrm{CO}_{2}$ emissions. Thus the development of $\mathrm{CO}_{2}$ separation and capture technology has been driven by commercial needs (although the expectation of future regulations may stimulate increasing activity in the future). Thus, the patenting activity displayed in Figure 23 reflects the inventive activity related to the industrial applications discussed earlier. The patent number on CCS rose from 1976, most likely due to the interests in EOR, and diminished around 1985. The interests in $\mathrm{CO}_{2}$ grew again and sustained in the 1990s. However, this trend of increasing number of patents is insignificant when compared to the baseline growth trend of the overall patents. The decline in the last few

\footnotetext{
${ }^{12} \mathrm{~S}$ denotes right-truncation "wildcards" on the right side of a search term in order to retrieve words that begin with a certain string. For example, sequest\$ would retrieve patents that contain the words sequester, sequestered, sequestering, sequesters, sequestrate, sequestration, etc.
} 
years of the patent data is attributed to the lag time between the times when patents being filed and patents being granted, usually between 6 months to 3 years.

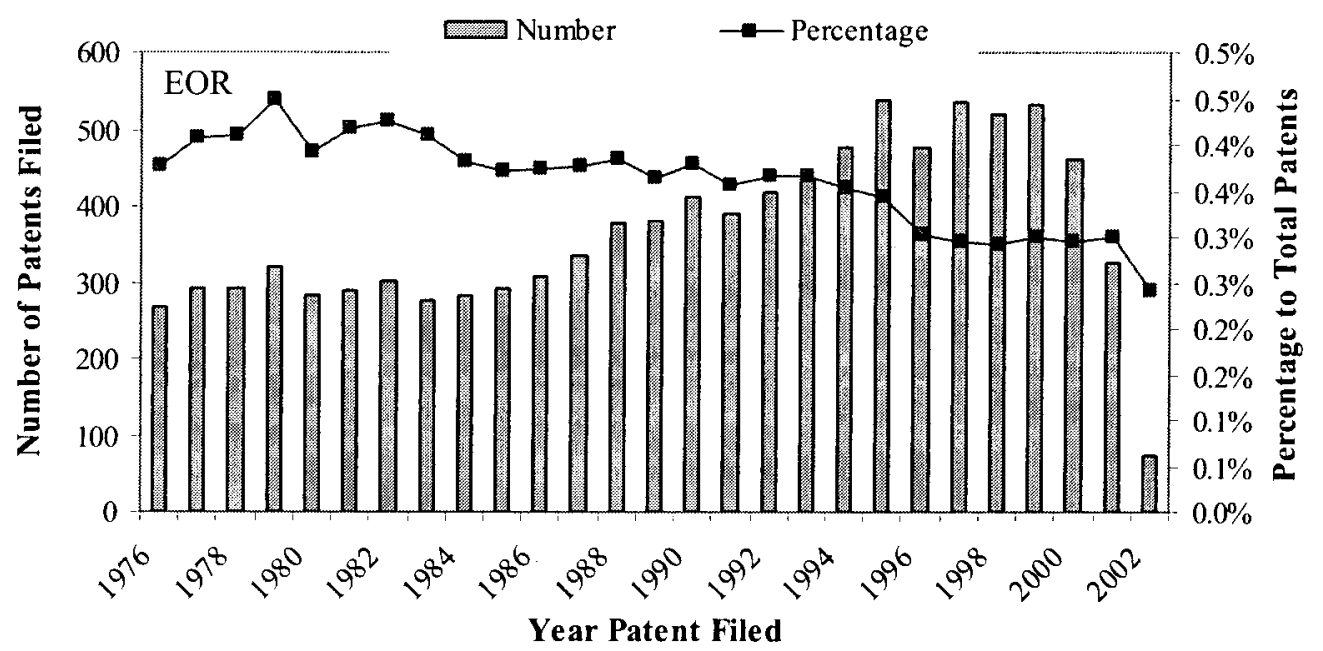

Figure 23. Patent trends for the $\mathrm{CO}_{2}$ abstract-based dataset, and the percentage of CCT patents relative to baseline overall patents.

We also examined the assignee of patents by country of origin, the same methodology we described in the $\mathrm{NO}_{\mathrm{x}}$ technology to develop a patent activity index. Patent activity index is calculated by the ratio of $\mathrm{CO}_{2}$ patents from a country divided by the ratio of overall patent from the same country in the same year. This index helps to detect high patenting activity when a country has unusually high patenting activity in the area of interest in a given year. Figure 24 shows that U.S. and Germany have roughly average patent interests in this area, while Japan has relatively low patent activities throughout the study period. In contrast, Canada and (especially) Great Britain have high CCS patenting activities relative to their overall portfolios. Further study of the patent database is needed to draw any inferences or hypotheses regarding these trends.

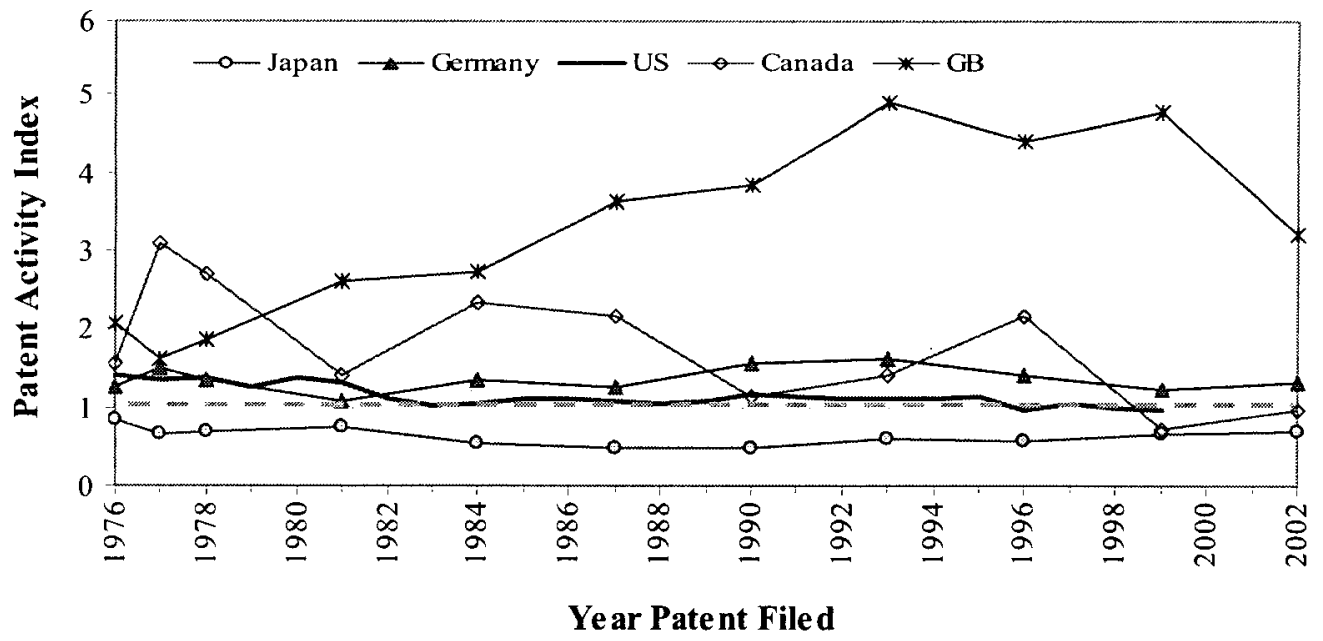

Figure 24. Patent activity index for $\mathrm{CO}_{2}$ capture and storage patents. 
In addition to patent analysis, we also analyzed the number of publications related to carbon capture and storage. We used the same string of keyword shown in the previous section and searched the "web of science" reference database (ISI Web of Science 2003). This web portal contains database in multidisciplinary information from approximately 8,500 research journals in the world. The citation database currently contains references from 1945-2003. We plot the number and the percentage of publications that contains the specified keywords in Figure 25 . The figure shows a significant jump in both the number and the percentage of publications in 1991, a roughly 15-fold increase from the previous year. Also note that no surge of publications between the 1970s and early 1980's observed in this analysis, as we had observed for the patent analysis. A possible explanation is that the interest in CCS in that period was primarily driven by industrial interests, primarily the oil and gas industry, which may patent new technologies or inventions without publication in peer-review journals.

The surge in publications in the early 1990s corresponds to emergence of global warming as a major national and international concern. Also in 1990, the Intergovernmental Panel on Climate Change (IPCC) established in 1988 by the World Meteorological Organization (WMO) and the United Nations Environment Programme (UNEP), published its first Assessment Report (Houghton, Jenkins et al. 1990; IPCC 1990; McG Tegart, Sheldon et al. 1990). Subsequent to that period, international interests in CCS began to grow more rapidly, and the publication counts in Figure 25 reflect that trend.

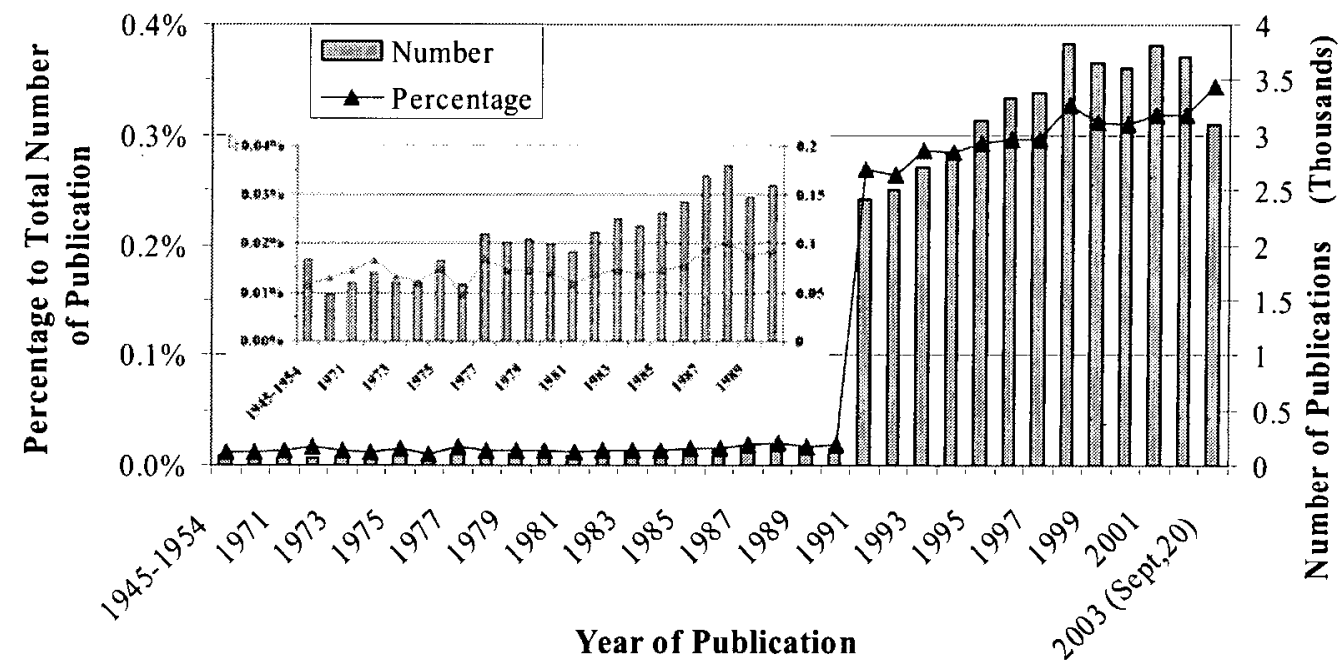

Figure 25. Number and percent of publications on $\mathrm{CO}_{2}$ capture and storage

\subsection{Worldwide Use of MEA Systems}

Alkanolamine absorption/stripping has long been a commercial technology for $\mathrm{CO}_{2}$ removal from natural gas and hydrogen. Members of alkanolamine family were subsequently introduced into gas purification market and still remain the choice of technology for the removal of $\mathrm{H}_{2} \mathrm{~S}$ and $\mathrm{CO}_{2}$ for gas purification (Kohl and Riesenfeld 1960; Kohl and Riesenfeld 1985; Kohl and Nielsen 1997). Natural gas is a mixture of several different gases, the process of gas purification involves the removal of vapor-phase impurities from gas streams. The principle gas phase impurities that must be removed by gas purification processes include hydrogen sulfide, carbon dioxide, water vapor, sulfur dioxide, nitrogen oxides, VOCs and more. Carbon dioxide and 
hydrogen sulfide must be removed from natural gas stream to minimize corrosion as well as freeze-out in pipelines and process equipment. In addition, if the carbon dioxide content of natural gas is large enough, the heating value of the gas is reduced. The carbon dioxide is predominantly extracted by amine scrubbing (Kohl and Riesenfeld 1985; Kohl and Nielsen 1997; EIA 2000). However, rather than capture and sequestration, in common practice at gas fields worldwide the scrubbed $\mathrm{CO}_{2}$ from natural gas is vented to the atmosphere. ${ }^{13}$ Figure 26 shows the US production, consumption and use of ethanolamines for gas purification. For comparison, Figure 27 shows the use of ethanolamines for gas purification and the quantity of natural gas production in the United States from 1930-2000.

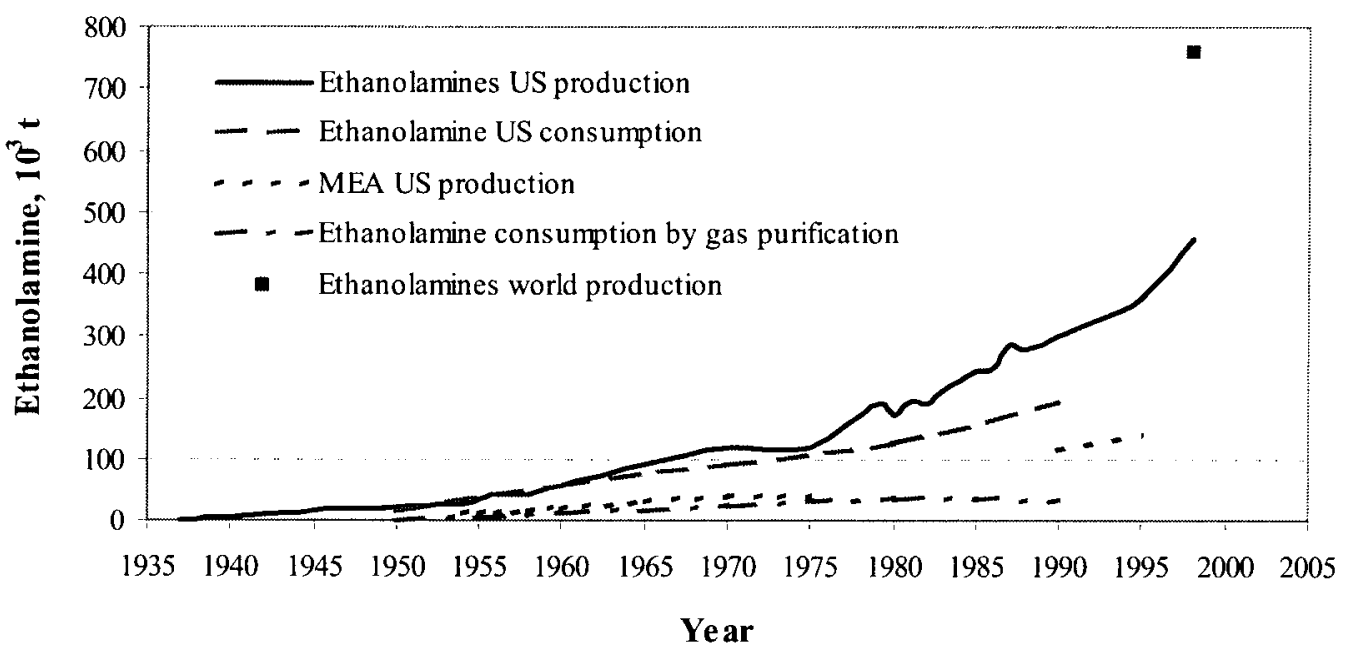

Figure 26. The US production, consumption and use of ethanolamines.

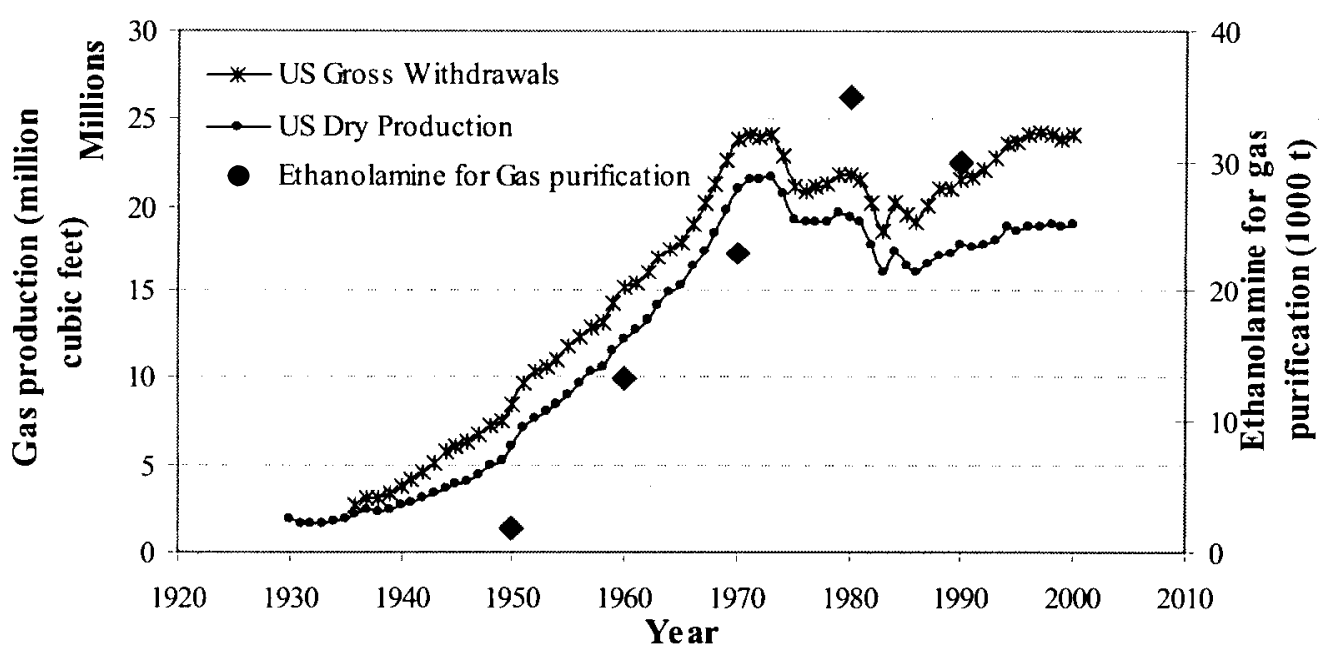

Figure 27. The use of ethanolamines for gas purification and the quantity of natural gas production in the United States, 1930-2000.

\footnotetext{
${ }^{13}$ The only exception is a $\mathrm{CO}_{2}$ sequestration project in the North Sea where, in response to a Norwegian $\mathrm{CO}_{2} \operatorname{tax}$, Statoil adopted an aquifer storage strategy for the Sleipner gas field, starting in 1996 . The $\mathrm{CO}_{2}$ is extracted by using aqueous alkanolamines (MDEA + BEA) as the solvent and produces 1 million tonnes $\mathrm{CO}_{2}$ per year for geological storage.
} 
Dow Chemical and Union Carbide developed MEA (monoethanolamine) processes for recovery of $\mathrm{CO}_{2}$ from flue gases in the 1970's and 1980's primarily for the enhanced oil recovery (EOR) market. Merchant $\mathrm{CO}_{2}$ markets also exist for use in food and chemical industries. When the price of crude oil dropped dramatically in 1986, the EOR market disappeared. Dow Chemical sold its GAS/SPEC FT-1 ${ }^{\mathrm{TM}}$ process to Fluor Daniel, Inc. in 1989. It was not until 1990's that the interest in recovering $\mathrm{CO}_{2}$ from flue gases took a dramatic turn, propelled by interest in options for reducing greenhouse gas emissions. For $\mathrm{CO}_{2}$ capture from flue gas, amine-based systems remain the prominent technology currently available, with three major suppliers of commercial systems (Fluor Daniel, ABB, and Mitsubishi Heavy Industries). To date, however, few commercial applications of $\mathrm{CO}_{2}$ capture and sequestration technologies have involved treatment of flue gases from coal-fired power plants. Further, the scale of most industrial applications is an order of magnitude or two smaller than what would be required for an environmental control system at a modern coal-based power plant (Figure 28).

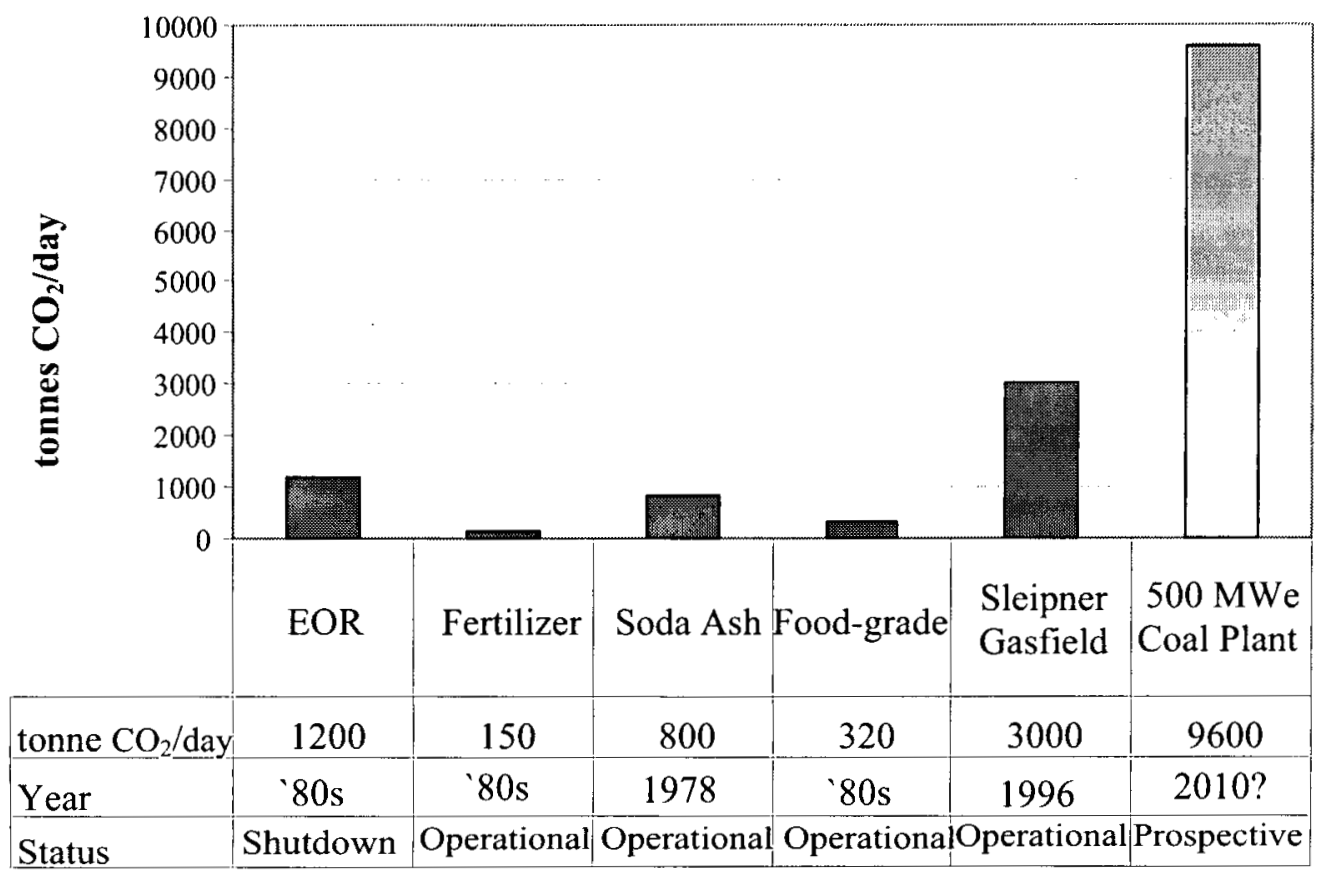

Figure 28. Scale of historical and current flue gas $\mathrm{CO}_{2}$ capture applications using alkanolamine absorption/stripping technology. Source: (Rao 2003)

\subsection{Experience Curve for MEA}

\subsubsection{Early (Pre-Commercial) Experience}

As we discussed in the previous sections, contrary to the historical experiences of FGD and SCR, where the novel technologies were developed (in response to regulatory requirements) specially for the purpose of treating gas pollutants from utility plants, capturing $\mathrm{CO}_{2}$ from flue gas is already practiced for commercial reasons. More than a dozen capture plants exist worldwide, with the $\mathrm{CO}_{2}$ being sold into commercial markets. The earliest studies of the cost of $\mathrm{CO}_{2}$ recovery from the flue gas at coal-fired power plants were prepared for the purpose of enhanced oil recovery (EOR) when the oil prices were at its peak, around 1976-1985 (Pappano, Sears et al. 1976; Anada, King et al. 1982). Since the attention was focused on the production cost per ton of 
$\mathrm{CO}_{2}$, there was no mention in these early studies of the energy penalty incurred at the electric plants. As such the costs per ton of $\mathrm{CO}_{2}$ recovered at coal-fired power plant were underestimated from the view of power production. It was not until $1990 \mathrm{CO}_{2}$ capture for reducing $\mathrm{CO}_{2}$ emissions at electric plant gained serious attention due to concerns for climate change. Systematic evaluations of the overall recovery cost, including the production loss for power plant, were subsequently published (Smelser, Stock et al. 1991; Hendriks 1994; IEA Greenhouse Gas R\&D Programme 1995).

The main challenge regarding $\mathrm{CO}_{2}$ capture technology is to reduce the overall cost by lowering both the energy and the capital cost requirements. Generally, the higher the amine concentration, the less energy input required to regenerate the amine solution, but the more corrosive the solution. The advent of high strength inhibited amine formulations in the post-1980 era has made $\mathrm{CO}_{2}$ recoveries from flue gas more economically viable, though costs still remain high. Low solvent concentrations require large equipment sizes and high regeneration energy requirements. Use of inhibited amines at higher concentrations significantly reduces the energy penalty associated with chemical absorption and stripping. The energy/heat requirement of monoethanolamine (MEA) solvent has fallen from more than $9 \mathrm{MBtu} / \mathrm{ton}$ of $\mathrm{CO}_{2}$ recovered in the 1950s to $4 \mathrm{MBtu} /$ ton or less today (Figure 29). This advancement contributes to major cost reductions for studies evaluated in recent years (Figure 30) (Chapel, Ernst et al. 1999; DeLallo, Buchanan et al. 2000; Simbeck and McDonald 2000; Rao and Rubin 2002). Further technology advancement leading to both capital and O\&M cost reductions are generally anticipated by experts (Rao 2003). Note that unlike the cost trends reported earlier for FGD and SCR systems, no $\mathrm{CO}_{2}$ capture systems for coal-fired plants at the $500 \mathrm{MW}$ scale have actually been built. Thus, all cost estimates shown here have yet to be validated by actual projects.

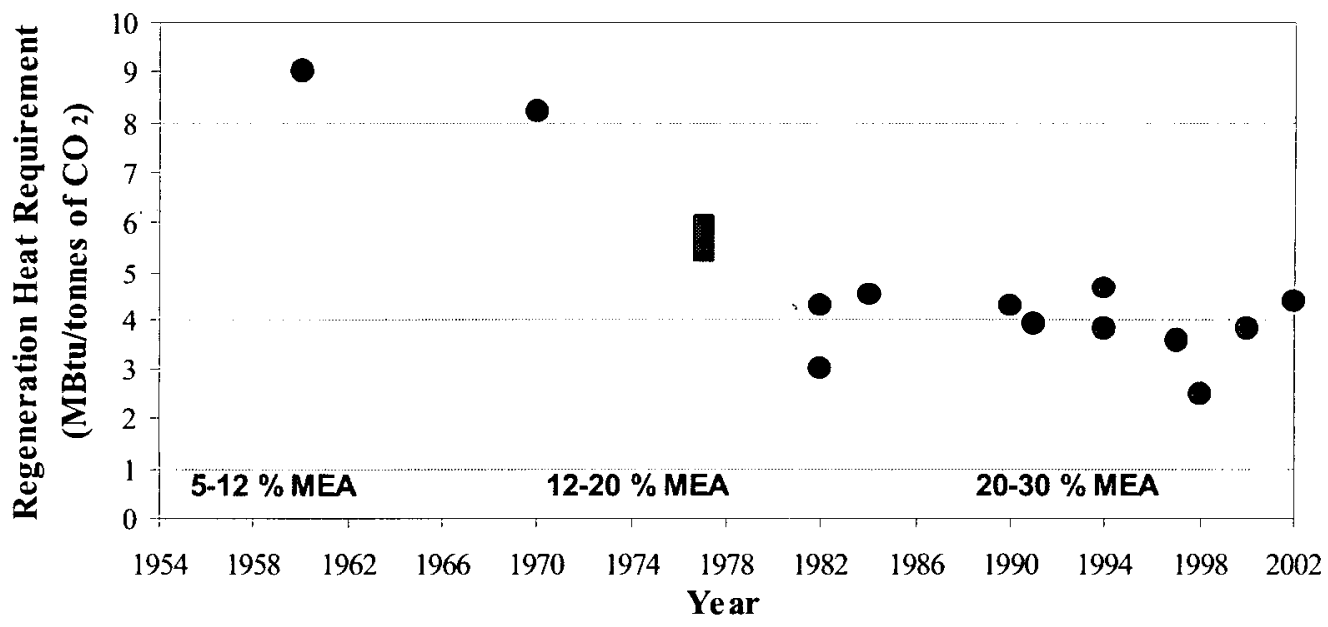

Figure 29. Minimum regeneration heat requirement of MEA solvent for $\mathrm{CO}_{2}$ recovery. 


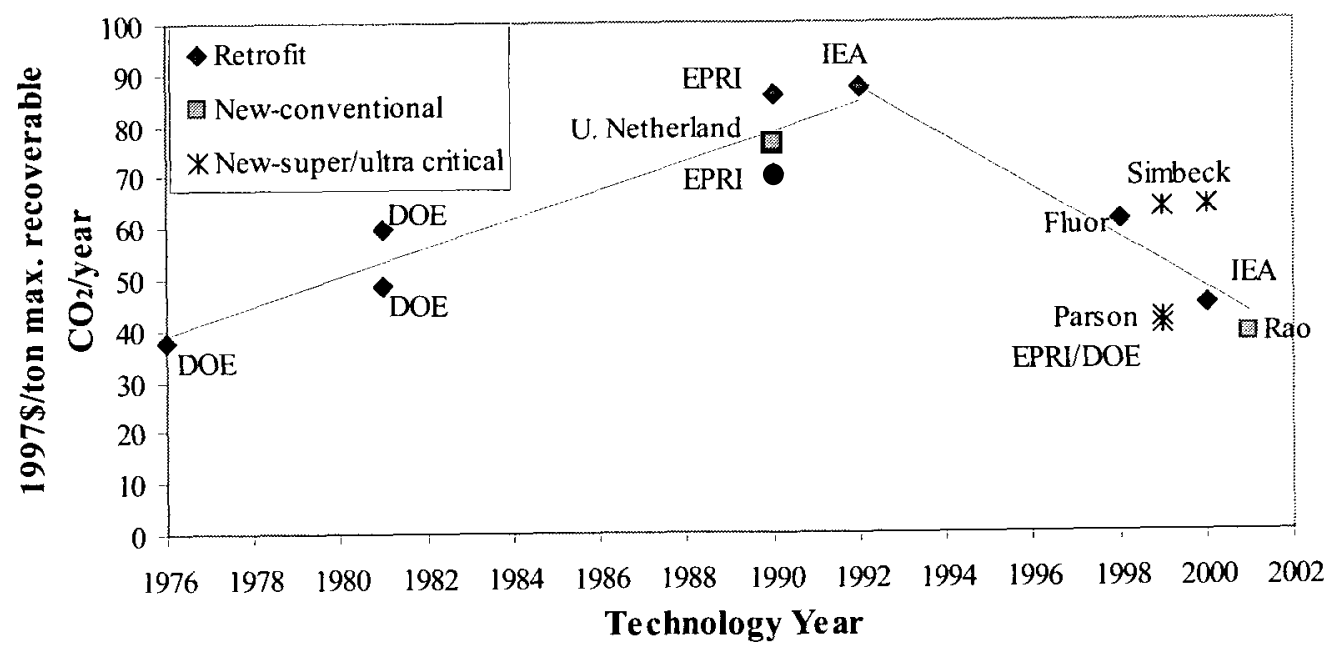

Figure 30. Estimated capital cost of an amine (MEA) carbon capture system at a standard coalfired power plant. Except where specified, a standard plat is of the size of $500 \mathrm{MWe}$ and achieving $\mathrm{CO}_{2}$ capture efficiency $=90 \%$. The capital cost estimates include the cost of compression (to about 2000 psia) and drying captured $\mathrm{CO}_{2}$, but do not include the cost of building new power generation plants to supply the energy required for capture plant operation. 


\section{Summary of Experience Curves for Environmental Technology}

\subsection{FGD and SCR Capital Costs}

Figure 31 compares the capital cost experience curves derived in this study for FGD and SCR systems. The results shown earlier are normalized on the initial data point for each curve, and the log-linear relationship given by Equation (2) is used to represent the experience curve. The resulting learning rates are $11 \%$ and $13 \%$ for the capital cost of FGD and SCR systems, respectively (corresponding to progress ratios of 0.89 and 0.87 , respectively). These values are well within the range of learning rates found in the literature for a wide range of market-based technologies that we will discuss later.

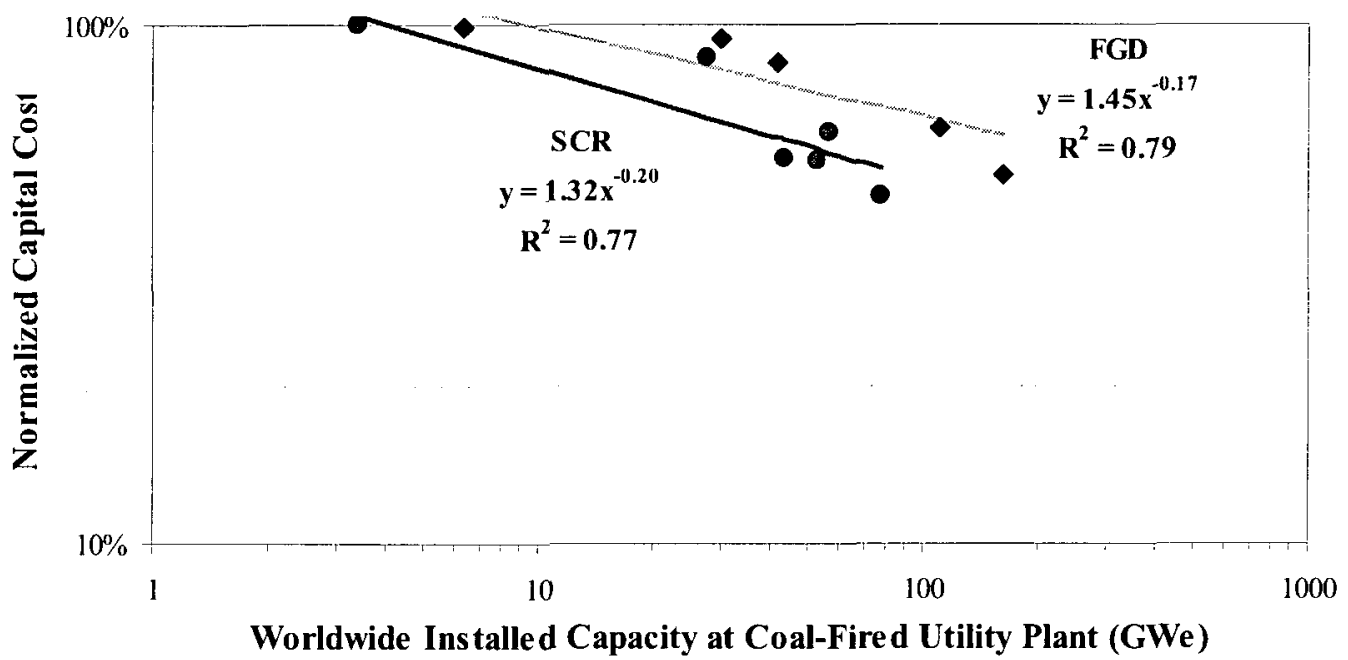

Figure 31. Capital cost experience curves for SCR and FGD systems. Based on Equation (2) using data from Figures 9 and 20. The regression exponents correspond to learning rates of $11 \%$ and $13 \%$ for FGD and SCR systems, respectively.

\subsection{FGD and SCR O\&M Costs}

Operating and maintenance (O\&M) costs for these technologies also have declined significantly as a result of technology innovation and experience, but further study is needed to quantify these learning rates accurately. However, if the expected cost estimates in Figures 10 and 21 are used as surrogates for actual long-term O\&M costs for technologies of different vintage, the implied learning rates (based on Equation 2) would be $22 \%$ for FGD systems and $30 \%$ for SCR systems (Figure 32). These values too are typical of learning rates found in the literature for other technologies, though the value for SCR in particular is at best an upper bound, for reasons discussed earlier. 


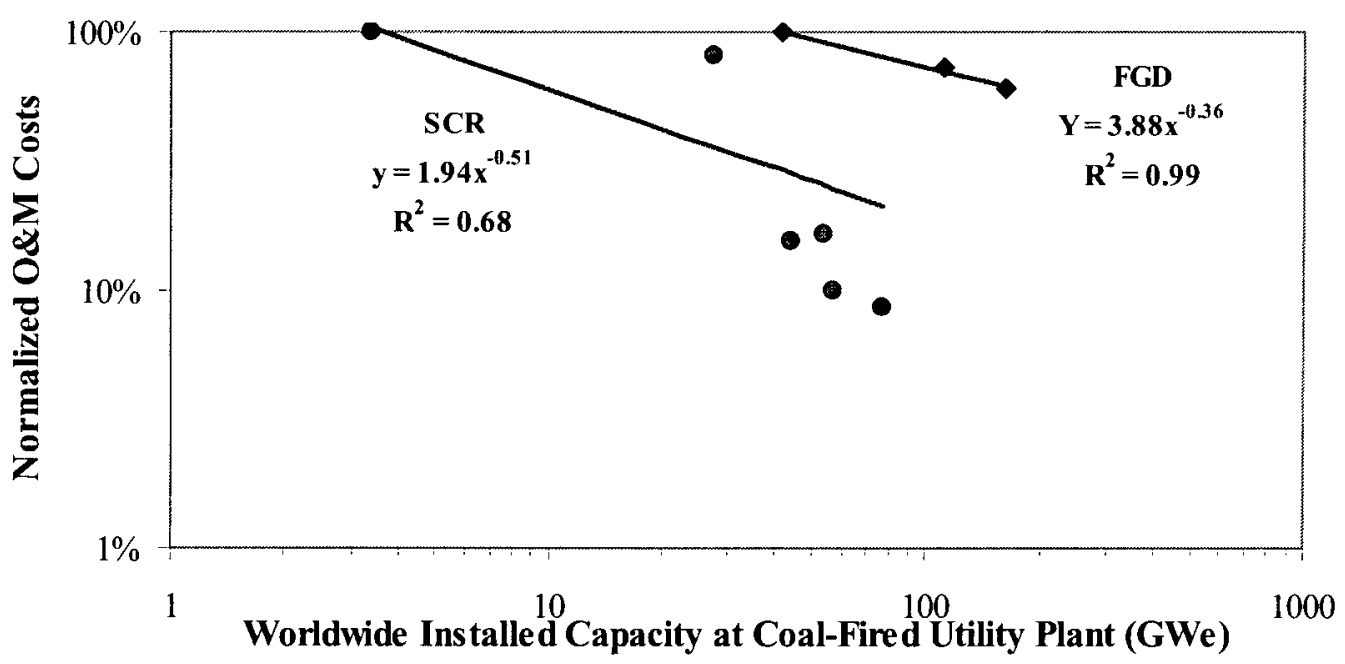

Figure 32. O\&M cost experience curves for SCR and FGD systems. Based on Equation (2) using data from Figures 10 and 21 . The regression exponents correspond to learning rates of $22 \%$ and $30 \%$ for FGD and SCR systems, respectively.

\subsection{Comparisons with Other Energy Technologies}

The concept of a learning curve originally proposed by Wright (1936) for relating the reduction in manufacturing man-hours with cumulative production has been extended to characterize the reductions in capital cost associated with the continued development and deployment of a wide variety of technologies, including energy technologies (Grubler, Nakicenovic et al. 1999). Systematic reviews of this extensive literature can be found elsewhere (Arrow 1962; Rapping 1965; Yelle 1979; Dutton and Thomas 1984), see also further discussion in Section VI. Despite a rich body of historical observations, our knowledge of the underlying mechanisms of the learning process still remains limited. No theory offers a quantitative model to explain the great variations in the observed learning rate. Dutton and Thomas surveyed 100 empirical and theoretical studies of progress functions in industrial engineering, economics, and management, and showed that the values generally fall in the range of $60 \% \sim 94 \%$ (studies showing price increase were not included in the analysis) (Dutton and Thomas 1984). McDonald and Schrattenholzer found a range of learning rates for energy-related technologies varying from $14 \%$ to $34 \%$ and a median value of $16 \%$ (McDonald and Schrattenholzer 2002) (Figure 33). Our observed values for the capital and O\&M costs of FGD and SCR systems is within the range of those reported in McDonald and Schrattenholzer, and those observed for production of electricity from renewable and advanced fossil technologies deployed in the European Union (Figure 34). These rates fall in the range reported for other non-energy technologies (The Boston Consulting Group 1968). 


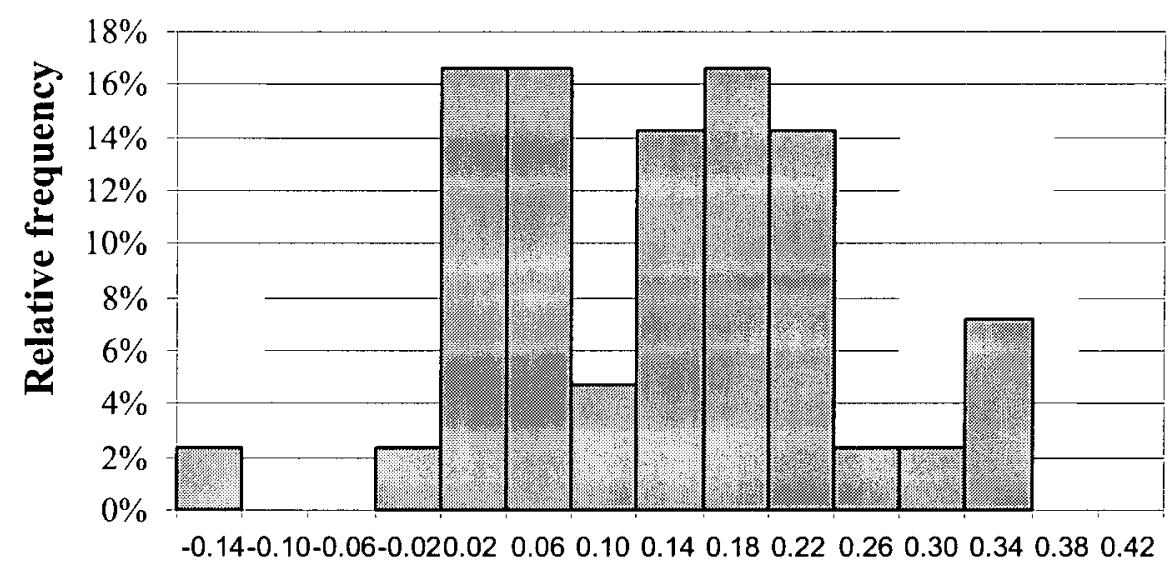

\section{Learning rate}

Figure 33. Distribution of learning rates for 42 energy technologies. Source: (McDonald and Schrattenholzer 2002)

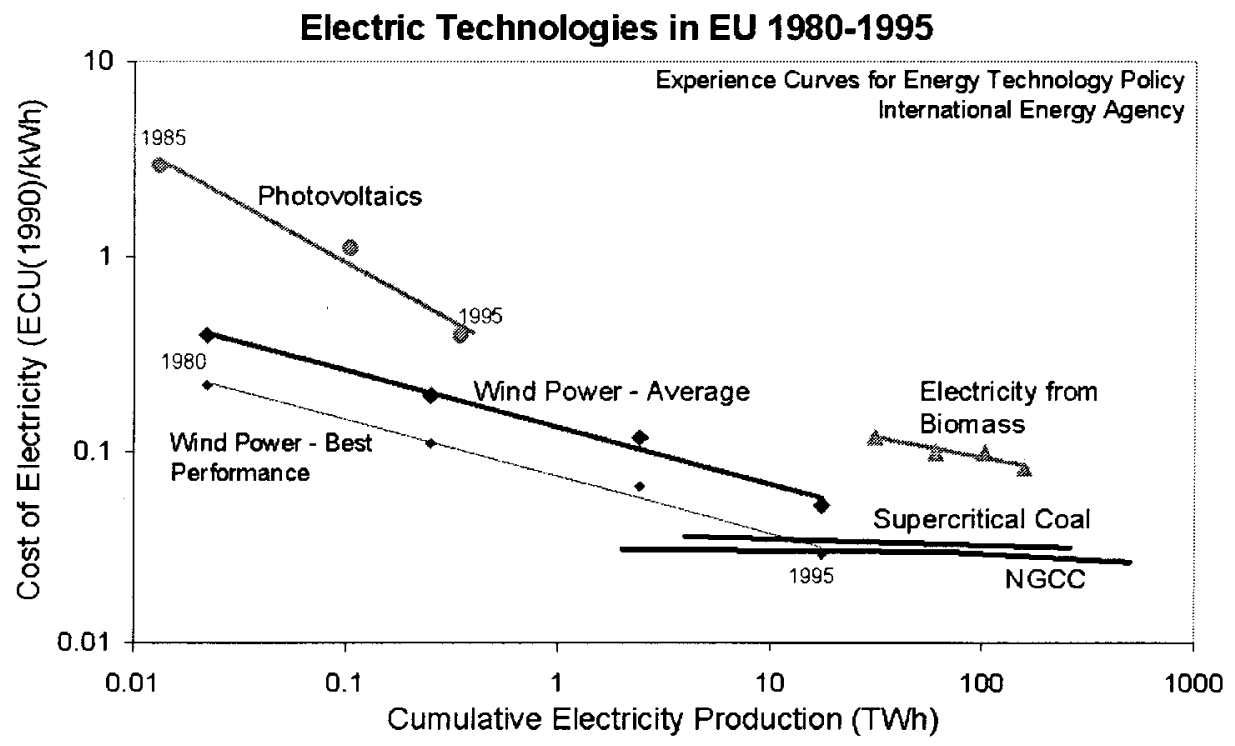

Figure 34. The experience effect for production of electricity from renewable and advanced fossil technologies deployed in the European Union in the period 1980-1995. Source: (Wene 2000).

\subsection{Implications for Modeling and Policy Analysis}

The data presented in this research offer compelling evidence that the real cost of environmental control technologies employed at coal-fired power plants declined significantly once they were widely deployed in response to environmental policies that either required their use or made them economically attractive relative to other environmental control options. These findings are consistent with a large body of literature showing similar trends for a wide variety of marketbased products and technologies. 
A major implication of these findings is that environmental policy analysis that ignores technological change is likely to overestimate the true cost of future compliance with new environmental control requirements that are met using technologies that already exist commercially, but are not widely deployed or fully developed. In such cases, we believe the quantitative results presented here can serve as a guideline for how such costs might decline with increasing adoption under a sufficiently stringent policy regime.

One case in point is the potential for $\mathrm{CO}_{2}$ capture and sequestration technology to control greenhouse gas emissions (one of the leading options now being examined in climate policy studies). There are substantial technical similarities between current commercial technologies for $\mathrm{CO}_{2}$ capture (such as chemical and physical absorption systems applicable to power plant gas streams) and the FGD and SCR gas treatment systems used for $\mathrm{SO}_{2}$ capture and $\mathrm{NO}_{\mathrm{x}}$ reduction. Thus, the experience curves derived in this research provide reasonable estimates for the rate of cost decline that might be expected if $\mathrm{CO}_{2}$ capture systems were to be deployed at coal-based power plants as part of a future strategy to reduce greenhouse gas emissions. In this regard, preliminary results from an integrated assessment modeling study (Riahi, Rubin et al. 2002a) indicate that the cost of achieving a climate stabilization target is significantly lower when the learning rates derived in the present study are applied to $\mathrm{CO}_{2}$ capture and storage systems for fossil fuel power plants. Section VI of this report elaborates on these results.

Several methodological issues remain to be further explored in the context of modeling studies with relatively long time horizons, such as the 50- to 100-year time frames commonly used for climate change policy analysis. In particular, it is unlikely that the learning rates observed during the initial development and deployment of a new environmental technology (like $\mathrm{CO}_{2}$ capture) can be sustained as the technology matures. Indeed, Klepper and Graddy found that a broad spectrum of technologies typically exhibit a declining rate of price reductions over long time periods. Rather, there were "leveling offs" in the rate of learning, typically after 30-40 years (Klepper and Graddy 1990). At some point, other technologies that accomplish the same goal in this case, a given reduction of power plant $\mathrm{SO}_{2}$ and $\mathrm{NO}_{\mathrm{x}}$ emissions - may replace the environmental technologies currently in use, and market cost reductions may resume. Pending the accumulation of longer-term data, parametric studies employing either a bounding assumption (such as no further cost decreases beyond a certain point) or more gradual rates of decline, such as those suggested by the data in Klepper and Grady (1990), may be more appropriate for policy analyses extending over many decades. Such issues will be explored further in the next section.

Another subject for future research is the relationship between cost trends and performance trends for environmental technologies. As noted earlier, for example, the $\mathrm{SO}_{2}$ capture efficiency of FGD systems has continued to improve markedly over the past few decades (Figure 35). As a result, new plants frequently face more stringent control requirements commensurate with this improved technological capability. The overall cost trends associated with changing levels of regulatory stringency and environmental technology performance are beyond the scope of this report, but are of significant interest and relevance to future environmental policy analysis. 


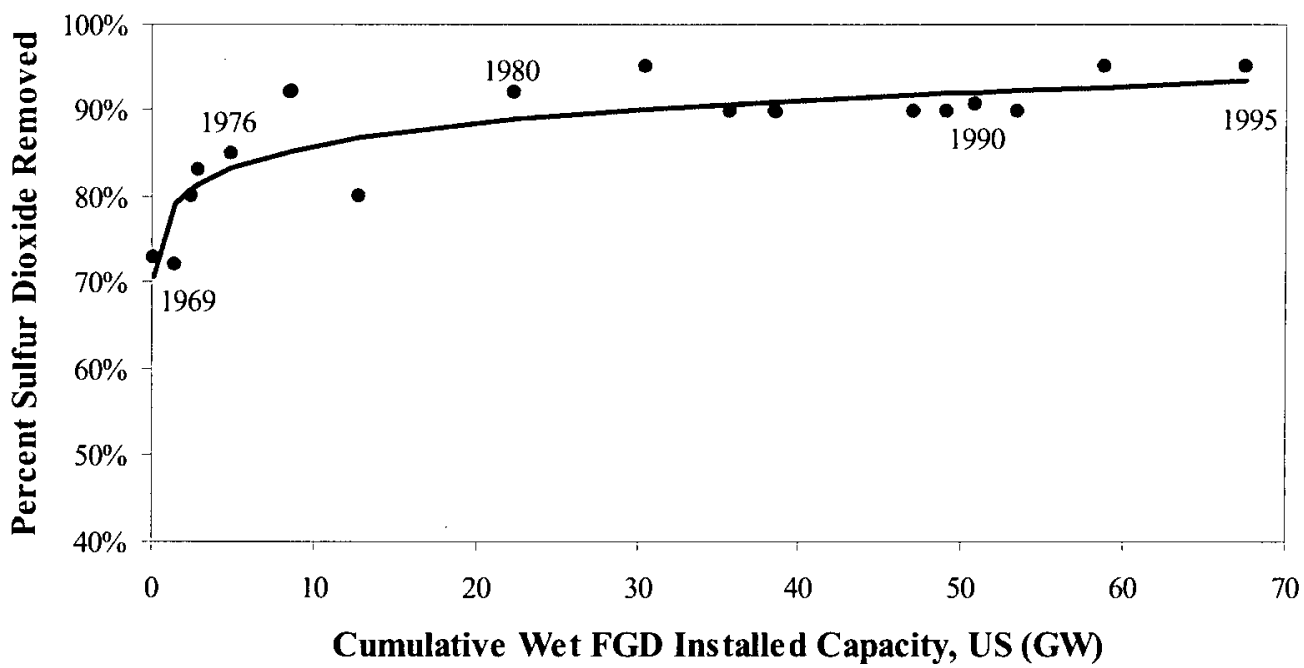

Figure 35. Improvements in $\mathrm{SO}_{2}$ removal efficiency of commercial lime and limestone FGD systems as a function of cumulative installed wet FGD capacity in the US. Source: (U.S. DOE 2000) 


\section{Application of Experience Curves to Integrated Assessment Models}

\subsection{Introduction}

In 1936 the aeronautical engineer Thomas P. Wright published a landmark article in the Journal of the Aeronautical Sciences, entitled "Facts Affecting the Cost of Airplanes," in which he observed that the average direct man-hours required to manufacture a given model of Boeing aircraft dropped systematically with each unit produced (Wright 1936). Wright captured this phenomenon with the following equation, which generates what he termed a "progress curve" (Equation 2). Specifically, Wright demonstrated that man-hour inputs dropped by 20 percent for every doubling of cumulative output - an 80 percent "progress ratio," where the exponent $b$ equaled 0.32 .

Wright's work remained relative obscure until a group of economists at the recently founded RAND Corporation, a "think tank" created by the U.S. Air Force in 1946, revisited Wright's work when large bodies of data on the production of ships and aircraft during World War II became available. The RAND economists became vitally interested in what they would eventually call "learning by doing" because the U.S. faced grave threats to its national security as the Cold War emerged pitting the Soviet Union against the U.S. and "the West." RAND's charge from the Air Force was to develop a complete "science of warfare" in which all aspects of war making, including the production of war material, could be optimized mathematically. Although several well-known economists at RAND worked on the phenomenon of learning using World War II data, Kenneth Arrow's work probably had the greatest impact, at least on the economics profession, owing to the publication of his 1962 Review of Economic Studies article, "The Economic Implications of Learning by Doing."

Since the subsequent work by the Boston Consulting Group's 1968 examination of the relationship between average unit price and the industry cumulative volume for 24 selected products (The Boston Consulting Group 1968), it has became a standard practice to use the loglinear form of the experience curve (Equation 2) for applied model prediction and business strategic planning (Dutton and Thomas 1984). Today, this phenomenon has been observed in

\footnotetext{
${ }^{14}$ Volume 29,1962 , pp. 155-173. In addition to Wright's work, the RAND group also relied on F. Montgomery, "Increased Productivity in the Production of Liberty Vessels," Monthly Labor Review 57 (1943): 861-864 and A.D. Searle, "Productivity Changes in Selected Wartime Shipbuilding Programs," Monthly Labor Review 61 (1945): 1132-1147. RAND's work on learning included: Armen A. Alchian, "Reliability of Progress Curves in Airframe Production," RM-260-1, October 7, 1949 (revised February 3, 1950), RAND Corporation. Alchian delivered a related paper at the American Economic Association in New York, December 27-39, 1949, entitled "An Airframe Production Function," P-108, October 10. 1949, RAND Corporation. This paper was abstracted in Econometrica in June 1950. RM-260-1 was initially classified because it was based on classified data but published later as Armen A. Alchian, "Reliability of Progress Curves in Airframe Production," Econometrica 31 (1963): 679-93; Harold Asher, "Cost-Quality Relationships in the Airframe Industry," R-291, 1956, RAND Corporation (also issued as Ph.D. diss., Ohio State University, 1956); Werner Z. Hirsch, "Manufacturing Progress Functions," Review of Economics and Statistics 34 (1952): 143-155. Prior to Asher and Hirsch, Kenneth Arrow and Selma Schweitzer Arrow carried out analyses of progress curves using World War II aircraft production data. See their two RAND reports, "Methodological Problems in Airframe Cost-Performance Studies," RM-456, September 20, 1950, RAND Corporation" and (with H. Bradley) "Cost-Quality Relations in Bomber Airframes," RM-536, February 6, 1951, RAND Corporation.
} 
empirical studies of a wide range of technologies in many different sectors (Joskow and Rozanski 1979; Yelle 1979; Dutton and Thomas 1984; Dutton, Thomas et al. 1984; Argote and Epple 1990; McDonald and Schrattenholzer 2001; Rubin, Taylor et al. 2003).

Technical change in the energy sector is central for addressing long-term environmental issues, including climate change (Mattsson and Wene 1997; Azar and Dowlatabadi 1999; Grubb, Kohler et al. 2002). Assumptions concerning technological development are among the most critical for the energy sector and often prove to have huge impacts on long-term energy policy analyses. In conventional energy system models, the usual method involves explicitly specifying a timetable for future rate of improvement in efficiency and investment cost reductions (exogenous technological change) (Goldstein 1991; Manne and Richels 1992; Prinn, Jacoby et al. 1999). The drawback of this method is the assumption that learning is autonomous and free, and does not depend upon other policy or economic variables. Thus investments in emerging technologies are postponed until the costs become sufficiently low. This model behavior is unreasonable, since early investments are necessary to realize the cost reductions (Grubler and Messner 1998; Azar and Dowlatabadi 1999; Grubb, Kohler et al. 2002). The literature on technical change has shown that learning curves or experience curves are not autonomous nor free but can be explained by discrete phenomena, like investment in research and development (Watanabe, Nagamatsu et al. 2003), capital deepening (Cohen 1995; Thompson and Strohm 1996; Sinclair, Klepper et al. 2000), and economy-of-scale effect. More recently, Rubin et al. show that the "learning process" for environmental control technologies is driven mainly by sufficiently stringent government regulations (Rubin, Yeh et al. 2003).

Due to the computational complexity of large-scale integrated assessment models, and the nonlinear, nonconvex nature of the experience curve (Equation 2), it was not until recently that endogenous learning has been incorporated into economic models of environmental policy (Mattsson and Wene 1997; Messner 1997; Dowlatabadi 1998; Grubler, Nakicenovic et al. 1999; Weyant and Olavson 1999; Riahi, Rubin et al. 2002a) . In general, the incorporation of induced technological change (endogenous experience curve) in both "top-down" and "bottom-up" types of energy-environmental-economic models provides a valuable tool to examine wider range of policy options, such as R\&D investment strategies and the appropriate degree, timing, and distribution of the emissions mitigation effort (Mattsson and Wene 1997; Azar and Dowlatabadi 1999; Grubb, Kohler et al. 2002; Loschel 2002; Riahi, Rubin et al. 2002a). Detail reviews of induced technology change in energy and environmental modeling can be found elsewhere (Azar and Dowlatabadi 1999; Grubb, Kohler et al. 2002).

\subsection{Case studies using the IIASA Model}

A key objective of the $\mathrm{SO}_{2}$ and $\mathrm{NO}_{\mathrm{x}}$ case studies was to quantify the rates of technology innovation in $\mathrm{CO}_{2}$ capture and storage technologies (CCT), in response to government actions, and to incorporate those results into a large-scale modeling framework for integrated assessments of climate change policy options. A collaboration with IIASA has achieved such objectives and goals. The IIASA group has been in the forefront of energy modelers who have tried to build technological learning-by-doing phenomena into their energy systems engineering models (see, e.g., (Messner 1995; Riahi, Roehrl et al. 2001)). The collaborative effort focused on the following two policy scenarios: 
Policy Case I. Incorporate a learning curve for carbon capture and sequestration technologies (CCT) as an endogenous process to analyze the potential of CCT in a set of long-term energy-economic-environmental scenarios. That optimizes the global energy system so as to stabilize atmosphere $\mathrm{CO}_{2}$ concentrations by 2100 .

Policy Case II. Illustrate the impacts of a technology policy that requires over time an increasing fraction of fossil-fired power generation to incorporate carbon capture and sequestration technologies. The technological changes for CCT and global energy systems are both represented as an endogenous process.

\subsection{Case I Policy Scenario}

\subsubsection{Case I Scenario Description}

The work done by IIASA to incorporate endogenous learning curves for CCT is described in detail in Appendix B (Riahi, Rubin et al. 2002b). The learning curve that was developed in the $\mathrm{SO}_{2}$ case study was incorporated into the energy modeling framework MESSAGE-MACRO. The A2 and B2 scenarios developed by IIASA for the IPCC Special Report on Emission Scenarios (SRES 2000) reflect different assumptions about economic development, demographic changes, and energy demands over the next 100 years. In the baseline case, with no climate policy, global $\mathrm{CO}_{2}$ emissions from industrial activity (mainly fossil fuel combustion) in the A2 scenario increase from their current annual level of $7 \mathrm{GtC}$ to $28 \mathrm{GtC}$ in 2100 . The A2 scenario is characterized as fossil intensive, with slow technological progress, limited environmental concerns and low global average per capita income. In contrast, the B2 baseline scenario exhibits more slowly increasing global GHG emissions, with $\mathrm{CO}_{2}$ emissions rising to only $14 \mathrm{GtC}$ by 2100. The various assumptions for the $\mathrm{A} 2$ and $\mathrm{B} 2$ scenarios are summarized in the Table 5 of Appendix B.

\subsubsection{Results and Effects of Environmental Technology Learning}

In order to study the potential for CCT technologies, a policy scenario is imposed to stabilize atmospheric $\mathrm{CO}_{2}$ concentrations at 550 parts per million by volume (ppmv) by the end of the $21^{\text {st }}$ century. The IIASA model again assumes an idealized world with "perfect foresight," and chooses the energy technology deployment path that minimizes overall (global) costs over the 100 -year time period. In order to quantify the effects of endogenous learning for CCTs, two stabilization scenarios for each baseline were developed - one assuming constant costs for CCTs (A2-550s, B2-550s), and one including learning for CCTs (A2-550t, B2-550t). The unit carbon reduction cost as a function of cumulative installed CCT capacity in the scenarios is illustrated in Figure 36. 


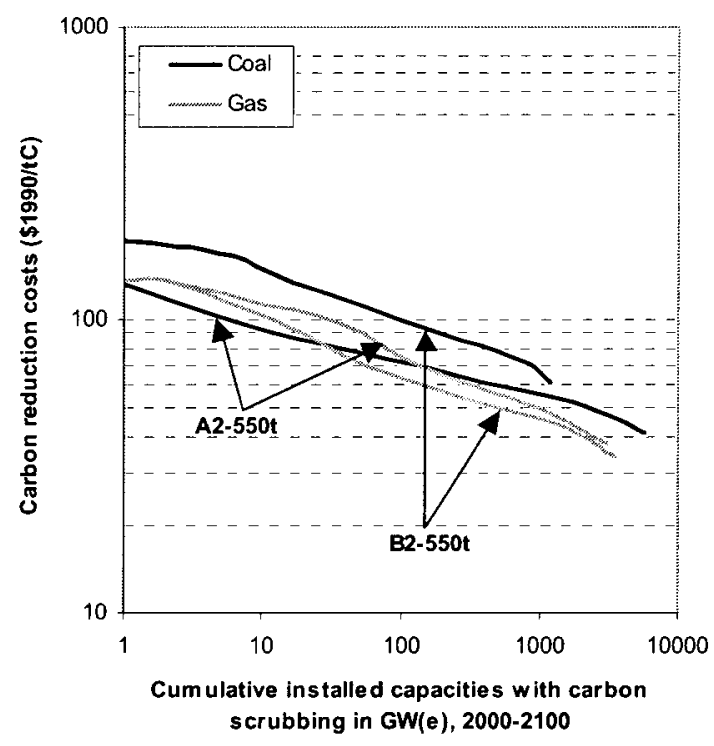

Figure 36. Technological learning of carbon capture technologies in the A2-550t and B2-550t scenarios, illustrated as decreasing specific carbon reduction costs over accumulated experience (cumulative installed power generation capacities).

The market penetration of CCT technologies (added on natural gas and coal technologies) into the electricity generation market depicts a typical S-shaped pattern: low at the beginning when CCTs are expensive and limited in their application, followed by accelerating growth when subsequent improvements and cost reductions lead to a wider applications, then slowing down as the market is saturated (Figure 52 in Appendix B). The amounts of CCT scrubbers predicted by model depend strongly on several factors, which include the socio-economic and technological assumptions in the baseline scenarios, and the assumptions of learning for CCT. As illustrated in Figure 37, cumulative carbon sequestration is higher in the case of the A2 scenarios compared to B2 scenarios, because the A2 baseline depicts a future of heavy reliance on fossil fuel such as coal technologies. The relatively fast and more complete market diffusion of CCTs in the case of learning also results in considerably higher cumulative carbon sequestration when compared to the scenarios with static CCT costs. 


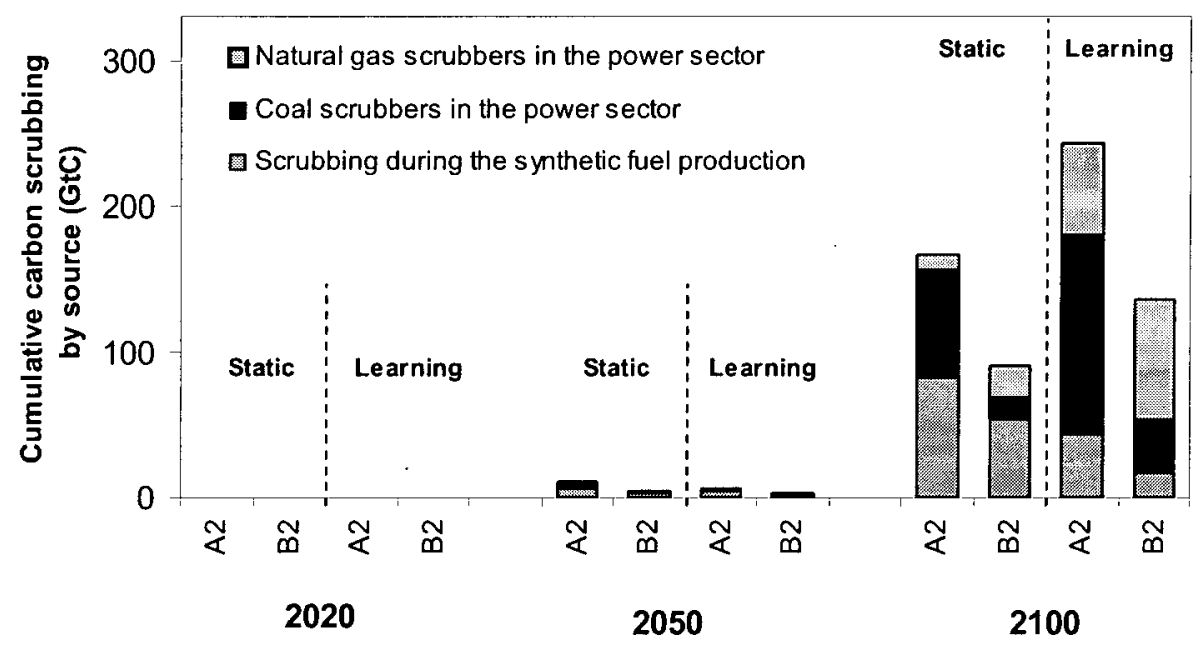

Figure 37. Cumulative carbon capture and sequestration by source for Policy Case I. Learning for CCT leads to comparatively high deployment of carbon capture technologies, in particular, in the electricity sector.

In summary, this study finds that:

- The contribution of CCTs (carbon capture technologies) to the emissions reduction is considerably higher under learning assumptions;

- The introduction of exogenous cost improvement for CCT leads to S-shaped diffusion curves for market penetration;

- The diffusion cycle (from initial introduction to saturation) of CCTs is about five decades, which is very similar to the life cycles of other technologies observed in the past;

- Large-scale investment into CCT and the accumulation of experience lead to rapid cost decrease of carbon capture and sequestration;

- Due to the increasing cost-effectiveness of CCTs in the case of learning, the effective carbon tax is lower in stabilization scenarios with dynamic CCT costs, compared to those based on static costs.

\subsection{Case II Policy Scenario}

\subsubsection{Case II Scenario Description}

As an alternative to the stabilization scenarios of Case I, a second policy scenario analyzed the impacts of a technology policy that requires over time an increasing fraction of fossil-fueled power generation to incorporate carbon capture technologies, with different implementation schedules for developed and developing countries. The assumption of technological learning applies both to fossil power plants and carbon capture technologies. The results of the study are summarized in a journal publication (Riahi, Rubin et al. 2002a) and in the detailed final report attached in Appendix C.

The $\mathrm{CO}_{2}$ reduction scenarios (called A2-CCT) are based on the baseline A2 scenario developed at IIASA for SRES (2000), as described in the previous section. The A2-CCT scenarios reflect a technology-forcing policy in which an increasing fraction of the total fossil-fired installed 
capacity is required to use $\mathrm{CO}_{2}$ capture and storage technologies (CCTs). The technology policy is represented by logistic penetration curves for industrialized and developing countries, enabling a smooth transition from unabated power generation to a regime where carbon dioxide is captured in all fossil-fueled power plants in the long run (Figure 38).

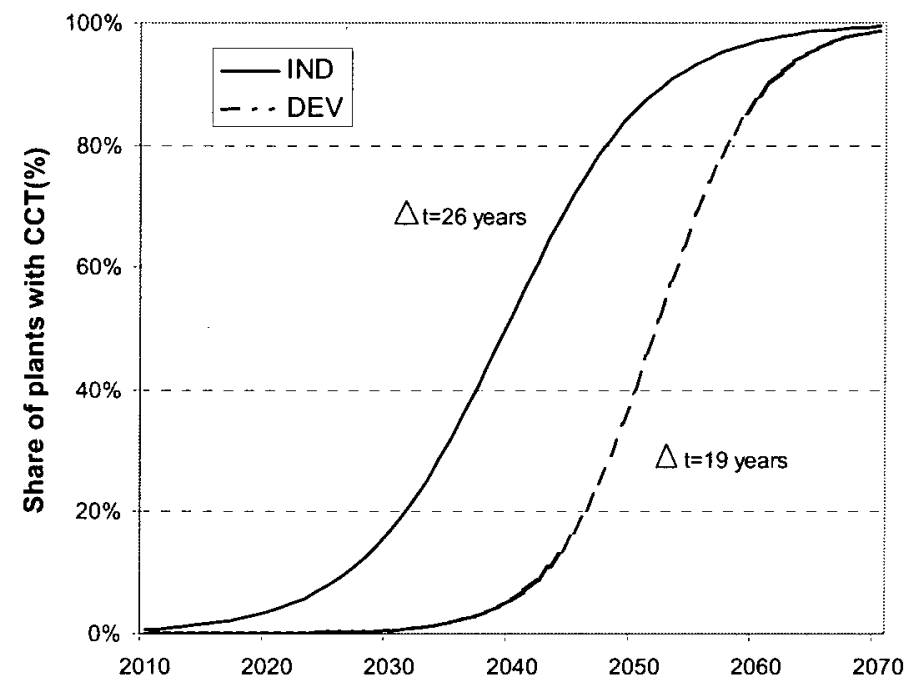

Figure 38. Logistic penetration curves assumed for the penetration of fossil-fired power plants with carbon capture technologies in the A2-CCT scenario for the industrialized (IND) and developing regions (DEV). $\Delta \mathrm{t}$ is the time in years that takes the innovation process to go from $10 \%$ to $90 \%$ of its duration.

Five scenarios were developed with respect to the assumptions for technological learning of fossil power plants and CCT:

- A2 (no learning) - baseline with no learning

- A2 (PPL learning) - baseline with learning for power plants

- A2-CCT (no learning) - policy case with no learning

- A2-CCT (CCT learning) - policy case with learning for carbon capture technologies

- A2-CCT (PPL \& CCT learning) - policy case with learning for power plants \& carbon capture technologies

Endogenous technological learning is applied to seven fossil electricity generation technologies (that include subcritical/supercritical coal, NGCC, conventional gas, IGCC, and high temperature fuel cell coal/gas), and to three carbon capture technology clusters (that include CCT_coal, CCT_gas, and CCT_IGFC). The learning rate for each technology varies according to model assumptions (see Tables 12 and 15 of Appendix C).

\subsubsection{Results and Effects of Environmental Technology Learning}

Figure 39 presents the total emissions from the electricity generation system in industrialized and developing regions for the A2 baseline case without learning and the A2-CCT case with learning for power plants as well as capture technologies. The figure shows the influence of the CCT policy in significantly reducing $\mathrm{CO}_{2}$ emissions in the industrialized countries (after year 2000) and developing countries after 2040. 


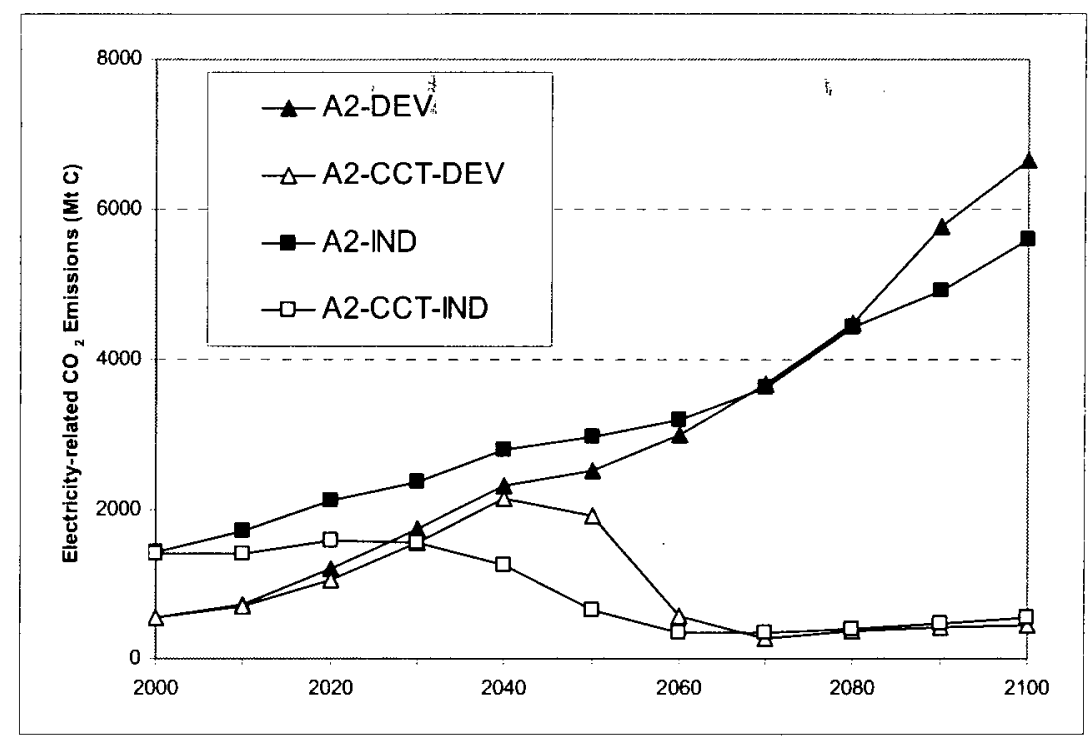

Figure 39. Electricity-related carbon dioxide emissions in industrialized (IND) and developing (DEV) regions in the A2 (no learning) and A2-CCT (PPL \& CCT Learning) scenarios.

Imposition of the CCT policy results in higher cost for electricity production (Figure 40). The electricity shadow prices also are higher. More importantly, technological learning reduces the shadow prices of electricity in both cases with and without CCT policy, with the largest reduction in the A2-CCT scenario that assumes learning both for PPL\& CCT.

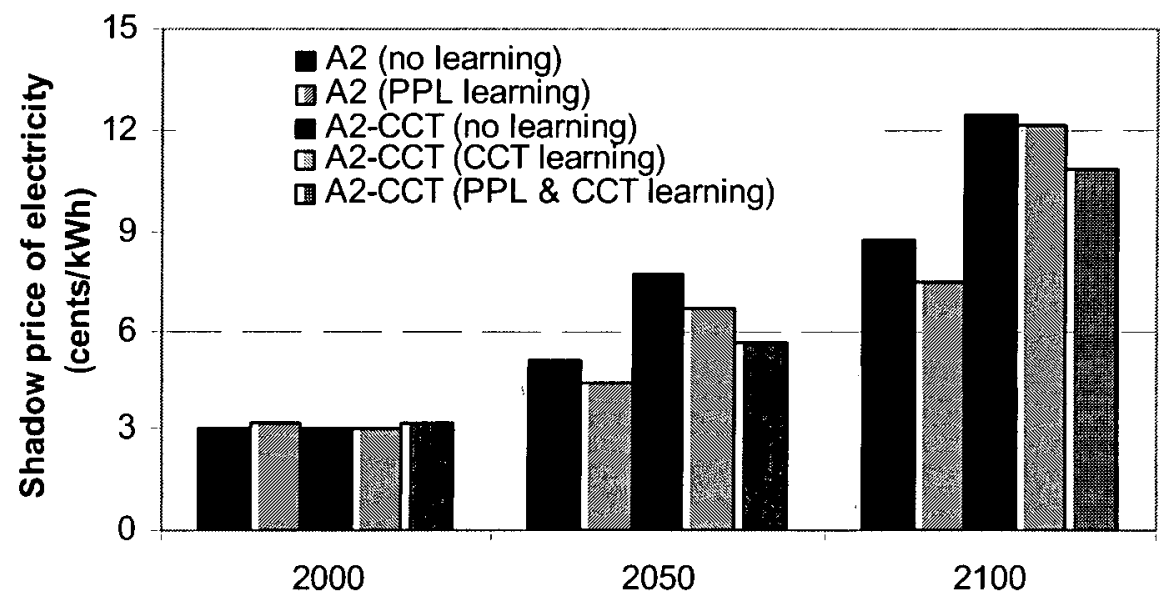

Figure 40. Shadow prices of electricity.

The cumulative storage requirements in scenarios A2-CCT (no learning) and A2-CCT (PPL \& CCT learning) showed that the amount of carbon dioxide captured by each technology differ between the learning and no learning cases. Figure 41 shows that the cumulative storage is considerably higher in the case of learning (due to cost improvement through learning) and the majority of $\mathrm{CO}_{2}$ is captured by CCT_IGFC. 


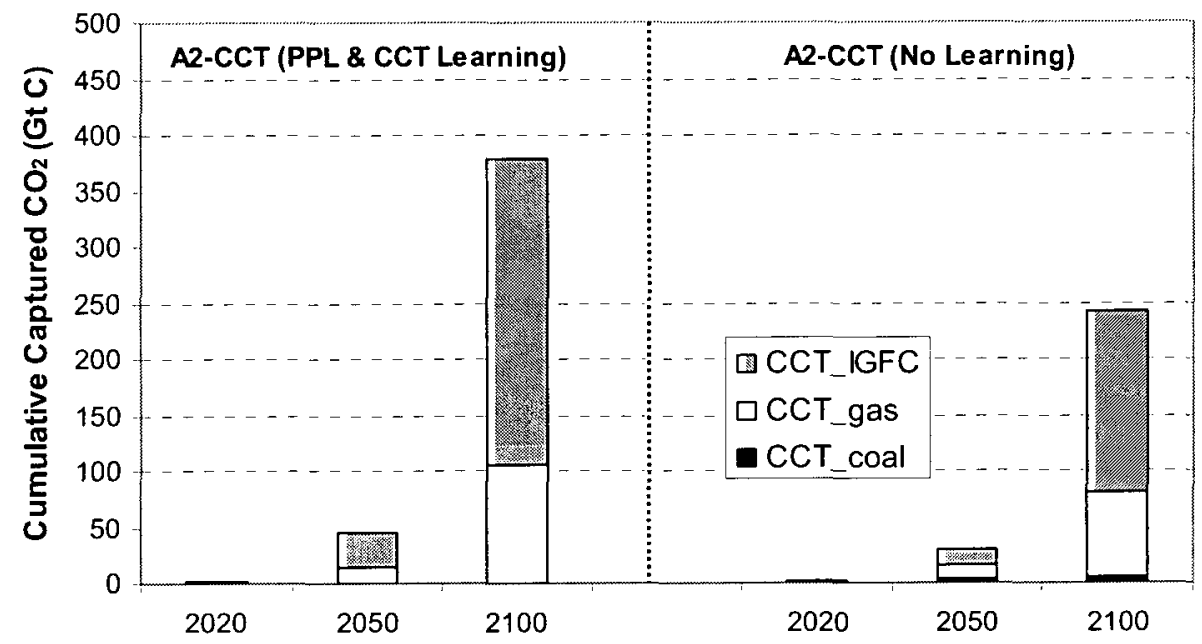

Figure 41. Cumulative amounts of captured $\mathrm{CO}_{2}$ in the A2-CCT scenario (PPL \& CCT learning case on the left side and no learning case on the right side). The contributions of the three CCT clusters are distinguished.

The net emission reduction in the A2-CCT scenarios compare to A2 baseline scenario is shown in Figure 42. The graph shows that the largest influence in the emission reduction is the capture and sequestration of $\mathrm{CO}_{2}$ from fossil-fired power plants, with 8.6 gigatons of carbon in year 2100 in the case of full learning (PPL \& CCT). However, this emission reduction is reinforced/compensated by structural change to other renewable-based electricity generation owing to the policy making fossil-fired power plants more expensive. As a result, additional decarbonization takes place and, since the cost of fossil electricity generation is higher for CCT without learning, there is a bigger impact in the CCT scenario without learning.
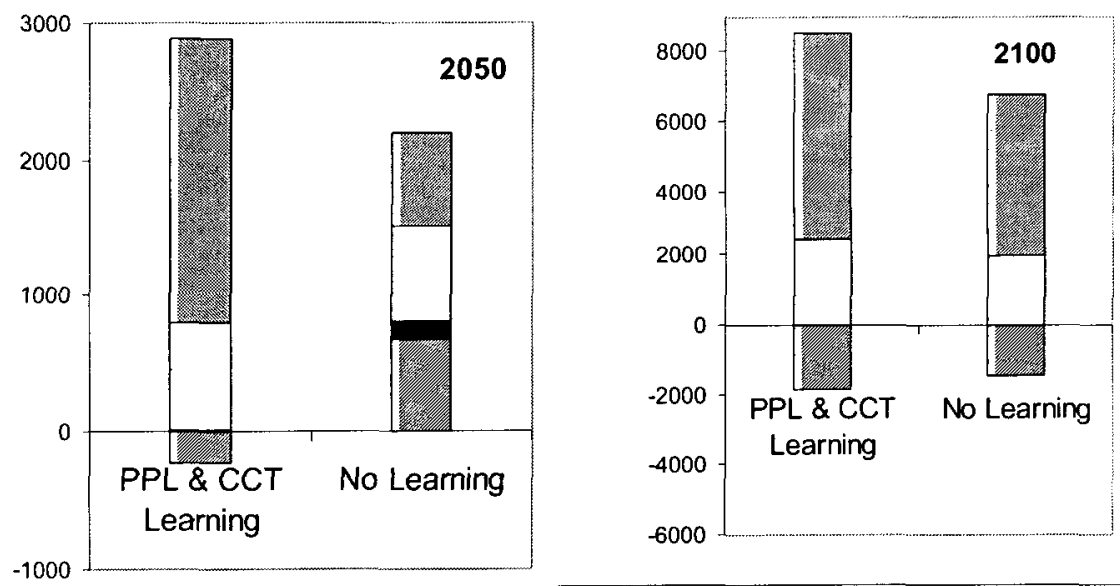

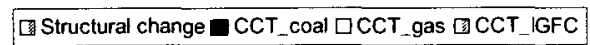

Figure 42. Contribution of carbon capture and sequestration and structural changes in the energy system to the net $\mathrm{CO}_{2}$ emissions reduction in the A2-CCT (no learning, and PPL \& CCT learning) scenarios relative to the $\mathrm{A} 2$ scenario without learning.

In summary, the Case II policy scenarios find that: 
- The inclusion of learning leads to significant changes in the fossil-fuel share of the power generation mix and fosters the penetration of advanced and more efficient power generation technologies. The introduction of learning for reference plants leads to the comparatively early investments in advanced fossil power generation technologies, especially IGCC.

- With the imposition of the CCT policy on the global electricity system, technologies are chosen based on the most cost-effective methods of electricity generation and carbon capture. In particular, integrated gasification combined cycle (IGCC) plants appear as the most attractive option in the long run, followed by gasification with high temperature fuel cells and natural gas combined cycle plants.

- The effect of technology learning results in lower shadow prices of electricity in the long run compared to the base case scenario (A2). The imposition of CCT policy results in higher costs for electricity production. However, the effect is highest in the case where no learning is assumed and lowest in the A2-CCT scenario that assumes learning for the base power plants as well as capture technologies.

- The effect of technology learning (PPL \& CCT) is most substantial as the CCT policy becomes more stringent and the amount of captured and sequestered carbon dioxide increases along the time horizon. 


\section{Directions for Future Study}

The work presented in this report has, for the first time, introduced endogenous technological change in the modeling of carbon capture and sequestration technologies as an option to address global climate change. The results showed that considering the effects of technological learning can make a significant difference in the outcome of alternative policy scenarios to abate global $\mathrm{CO}_{2}$ emissions. In this section of the report we outline several directions for future research that can build on the advances made in this study.

\subsection{Uncertainties in Experience Curves}

Our limited understanding of the technology innovation process, such as the one described in Equation 2, creates many uncertainties in applying learning curves. Many theories have been proposed to explain the reduction in unit cost as cumulative output increases, and they generally fall into the following three categories: (1) changes in production, such as process innovations, familiarity in the use of tooling, managerial perfection, and economies of scale; (2) changes in the product itself, such as product innovations, product redesign, and product standardization; and (3) changes in input prices. Experience curves typically aggregate all of these factors. However, most of these explanations are qualitatively descriptive and provide little evidence of the direct relationships and are therefore impossible to quantify (and thus predict their contributions to the effect of learning).

In addition, there are other uncertainties concerning the use of learning curves for the purpose of forecasting and predicting future trends. For example: What is the "correct" progress ratio for a new technology? What is the right functional form of the experience curve for the selected technology? Does the learning rate of the technology experience curve remain constant throughout the entire modeling period, or does the effect of "learning-by-doing" change over long periods of time? While we don't have answers for all these questions, it is important to recognize these sources of uncertainties, understand their limitations, and their influence on results of integrated assessment (IA) modeling.

\subsubsection{Studies of Concave Learning Curve}

Today, the linear form of the experience curve on a log-log scale (Equation 2) remains the most popular, if not the only, equation used to represent learning. Historically, there were many attempts to revise the log-linear curve. Other functional forms were proposed, especially in the early days before the log-linear shape of the experience curve became considered as "standard." Most arguments focus on the deviations from the linearity at the beginning and the tail of the curve.

G.W. Carr. argued that the cumulative average curve of airplane production was best represented by an S-type curve (Carr 1946). This concavity early in the series was theorized from that fact that the crews were hired one at a time and hence worked at different points on their individual progress curves (assume to be the same rate) at the same point in time. The steeper segment of the S-curve is, according to Carr, dependent on the extent of tooling and the breakdown of the airplane into accessible production subassemblies. The flat tail of the S-curve occurs when manhour cost slowly approaches an "optimum". 
This concavity early in the series was also recognized independently by the Boeing Airplane Company and by the Stanford Research Institute (SRI 1949b; SRI 1949a; Boeing (n.d.)). The Stanford Research Institute (1949b; SRI 1949a) made several studies of learning curves and observed that the curve tends to follow a concave shape in the early part of the program and added an additional term called the " $B$ " factor to the conventional formula. The parameter $B$ represents the equivalent units of experience available at the start of a manufacturing program. The studies claimed that the revised formula $Y=a(x+B)^{b}$ described the empirical production data more adequately than the existing log-linear function. Hoffmann attempted to evaluate the superiority of the "Stanford" curve using the same data used by SRI, and concluded that there was little basis for choice between the restricted form of the curve and the original form despite the fact that in several cases the inclusion of parameter $B$ did result in smaller sums of squared deviations (Hoffmann 1950).

Asher used an illustrative example of a linear direct-labor progress curve with two model changes requiring no cost premium and showed that the unit cost curve of each new series would be concave (Asher 1956). His work indicated that for certain values of cumulative output, both the labor and the total-production cost curves became convex. For a given linear model, if the technology was modified after several installations, a concave curve would result. Ignoring the effect of learning experience from related technology, and fitting a log-log linear learning curve to the data, he obtained a smaller learning rate and therefore underestimated the learning potential in the future.

\subsubsection{Studies of Level-off in Learning}

In contrast to the efforts in introducing concavity at the beginning of the learning curve, many challenge the log-linearity hypothesis in the latter part of the progress curve. Guibert viewed the progress curve as having a horizontal asymptote that is approached after a large number of aircraft construction units have been produced (Guibert 1945). A study by the Boeing Airplane Company summarized the cost reduction on the L-15 airplane and concluded that the slope of the unit curve becomes flat ("level-off") with sufficiently large cumulative output. They believed this was probably due to limitations imposed by a given set of tooling, and that the level-off point seemed to occur sooner for steeper learning slope than for a flat slope, and sooner on small aircraft than on large aircraft (Boeing (n.d.)).

Asher analyzed data for nine fighter aircraft models and found that the learning curve began to level off at about unit 125, and that extrapolations made between units 100 and 1000 would result in an estimating error of about 25\% (Asher 1956). Conway and Schultz studied the existence of learning in four firms among the products for which the man-hour data were those of complex as well as simple design, and included cumulative production quantities from fifty to two hundred million units (Conway and Schultz 1959). This extensive survey also found leveling off or a change in the curve slope observed where large cumulative production quantities were reached. 
Klepper and Graddy assembled data on the number of firms, output, and price for 46 new products from their initial commercial stage through 1972 (Klepper and Graddy 1990). ${ }^{15}$ They developed the quantitative and qualitative regularities characterizing the evolution of new industries and found that all products appear to follow a similar pattern in terms of changes over time in the number of firms, output, and price, though with considerable variations. During both the growth (stage 1) and shakeout (stage 2) stages, the number of firms and total output grow ${ }^{16}$ while price falls. Once the number of firms stabilized, the percentage fall in price and the percentage rise in output level off remained constant over time (stage 3, typically after $30-40$ years).

\subsection{Factors That Contribute To Uncertainties}

In this section, we suggest factors and circumstances which could explain or could potentially contribute to uncertainties in the experience curve where wide ranges of learning rates were observed, resulting in diverse shapes of the learning curve.

\subsubsection{Technology Uncertainties}

Many technological studies of experience curves for conventional and renewable energy systems (Joskow and Rozanski 1979; Ostwald and Reisdoft 1979; Neij 1997; Grubler, Nakicenovic et al. 1999; Neij 1999; McDonald and Schrattenholzer 2001; Ibenholt 2002) measure technology progress by fitting the log-linear experience curve (Equation 2) to calculate a progress ratio. Occasionally, the raw data show nonlinearities, but most often these are ignored, and only the value of the linear progress ratio (the value of $2^{-b}$ in Equation 2) is reported. In all these studies, however, cumulative installed capacities were used as the independent variable, and only the technology progresses beyond $\mathrm{R} \& \mathrm{D}$ and after the commercialization stage are reported. However in many cases, early cost estimates based on laboratory projects or pilot plants are usually lower than the costs subsequently realized when the commercialization phase begins. Therefore, the cost of technology sometimes increases, rather than decreases, in the early phase of commercial production.

Our examination of past experience for environmental control technologies in controlling emissions from coal-fired electric plants - flue gas desulfurization (FGD) systems for sulfur dioxide $\left(\mathrm{SO}_{2}\right)$ control, selective catalytic reduction ( $\left.\mathrm{SCR}\right)$ systems for nitrogen oxides $\left(\mathrm{NO}_{\mathrm{x}}\right)$ control, and chemical absorption with monoethanolamine (MEA) for capturing carbon dioxide $\left(\mathrm{CO}_{2}\right)$ - shows such trend (Figures 8, 19, and 30 for FGD, SCR, and MEA systems, respectively). The sources of the studies include economic reports that evaluate the feasibility of the technology, R\&D reports, conference proceedings, and consultant contracts with government agencies. Historical series of new design and economic premises for future evaluations reflects the prevailing technology utilized, the design practices, and economic conditions at that time. The results suggest that, in the cases we reviewed, including FGD, SCR and MEA technologies, early cost estimates based on laboratory projects or pilot plants were usually lower than the costs (both capital cost and annual revenue requirement) that were subsequently realized when the commercialization phase began. Reasons include insufficient information for detailed

\footnotetext{
${ }^{15}$ Some products were introduced in the nineteenth century, while others were introduced as late as the post -World War II period. They include consumer (e.g., shampoo, computers) and producer goods (e.g., nylon) as well as goods developed primarily for the military (e.g., rocket engines).

${ }^{16}$ Percentage changes are computed as the first differences in logarithms.
} 
engineering design, additional problems identified in the actual operation. Thus higher costs were incurred to achieve desired performance \& reliability. Uncertainty in the cost estimates also occurred when scale-up factors for the size of the technology were based on prior insufficient installation experience.

Many other studies also found cost increase for increased production or installation of energy systems, especially in the early stage of the application. Colpier et al. found PR $>100$ percent from the period of 1981-1991 for the experience curve of the combined cycle gas turbine (CCGT) (Colpier and Cornland 2002). The authors label the periods of the price increase to be development stage and price-umbrella stage, according to the definition by the Boston Consulting Group (more detail description in the next section), given that not many plants were installed and competition on the CCGT market was weak during that period. In addition, prices also rose as a result of increasing complexity, the use of new advanced materials and thermal efficiency improvements made during this period. Studies of renewable energy technologies such as British and Germany wind power (Ibenholt 2002), and photovoltaic technologies (Schaeffer 2003) also found $P R \geq 100$ at the initial stage of deployment. Though no explanations were provided in the original studies, it is likely due to the general observation that the total cost of new technology cannot be reduced as fast as costs are added through design changes and product performance improvements (Neij 1997).

\subsubsection{Market Structural Change, Forgetting and Other Social Factors}

Regular non-linearity in experience curves was observed by the Boston Consulting Group (BCG) when plotting the progress of cost improvement for a certain product or technology life cycle (The Boston Consulting Group 1968). It was hypothesized that at development stages, prices are set below cost to establish an initial market. As volume and experience reduce cost, the prices are maintained, graduating converting the negative margin to positive one. If prices do not decline as fast as costs, then competitors are attracted to enter. At some point prices do start to decline faster than costs and a reverse bend in the price curve is reached when markets became mature. In addition, policy measures such as investment subsidies, production subsidies, tax credits and buy-back rates are usually adopted to provide incentives and stimulate demand for high-cost, sustainable environmental technologies. These policy measures create price umbrella and thus prices decline slower than actual cost improvement. After the technologies gain a foot-hold, shakeout begins following the emergence of the dominant design, product innovation slows down and process innovation kick off. The steep slope in the shakeout stage is likely achieved through acceleration in the trend of capital-labor ratio, labor productivity, and vertical integration (Klepper and Simons 2003).

The analysis by Colpier et al. of the specific investment price for larger CCGT power plants shows a progress ratio $>100$ percent from the period of 1981-1991 and a PR of around $70 \%$ during the 1990s (Figure 43) (Colpier and Cornland 2002). However, the authors caution that this decrease mainly reflects market developments/strategies and not actual cost reductions due to gained experience. It is the authors' view that the market experienced shakeout stage at the time of the study due to several manufactures competing to gain market share. Nevertheless, the decline of the curve does reflect the cost reduction due to improved performance of the CCGT and the shift towards making more standardized and modularized machines. Patente et al. also characterize a similar structural change in the experience curve of photovoltaic modules with a 
slower progress ratio of $80 \%$ from the period of $1981-1990$ compared to $77 \%$ from $1991-2000$ (Parente, Goldemberg et al. 2002). The bend of the curve is highly significant and likely due to market competition and increasing economies of scale for growing production and use of PV technology.

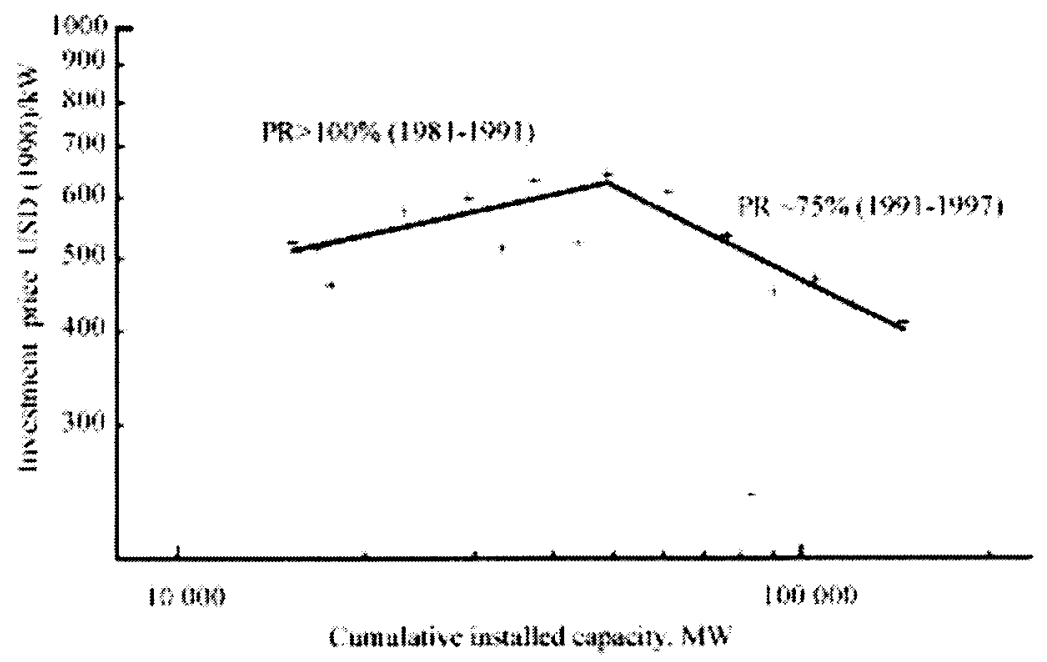

Figure 43. The experience curve for the specific investment price of CCGT technology (19811997). Source: (Colpier and Cornland 2002) Figure 3.

Argote and her colleagues are among the pioneers who empirically showed the existence of organizational "forgetting," in which the knowledge acquired through learning by doing may decay or depreciate in time (Argote and Epple 1990; Argote 1996; Argote 1999). Her research found the production of Lockheed L-1011 TriStar aircraft had a positive progress ratio from product increases in 1972-1975, but a negative progress ratio after the product cut occurred in late 1975, after which costs rose to exceed price and appeared to remain above price for the rest of the product program. This "forgetting-by-not-doing" is attributed to the loss of knowledge associated with laying off many experienced workers, shortage of personnel and parts, and lack of experienced workers when production resumes.

Sturm analyzed the operating experience of nuclear power plants from 1981 to 1991 in Eastern and Western Europe, the former Soviet Union, and the United States. He suggested that while all Western countries reduced their unplanned outages, the former Soviet Union and all countries in Eastern Europe experienced increasing unplanned outages and decreasing plant availability as plants aged (Sturm 1993). It was suggested that the forgetting phenomenon could be due to political and economic reorganization that caused labour turnover, difficulties in obtaining spare parts and maintaining plants, and lack of incentives to provide good training programs.

\subsection{The Implications for IA Modeling}

The factors discussed in the previous sections can have significant implications for applications of experience curves in integrated models. The direction and extent of changes in technology costs and/or performance can have significant impacts in determining the technological response to policy and the economic implications of these changes. 


\subsubsection{The Importance of Uncertainties}

In general, models that endogenously incorporate induced technological change in energyeconomic models tend to find reduced costs of environmental policy and accelerated abatement of emissions (Messner 1997; Grubler and Messner 1998; Loschel 2002; Zwaan, Gerlagh et al. 2002). Consequently, the sensitivity of policy-related variables to variability in learning rate can be highly non-linear (McDonald and Schrattenholzer 2002). Small changes in technology progress ratio can change learning investments considerably and thus the conditions for longterm competitiveness of new technology (Dowlatabadi 1998; Barreto and Klaassen 2003).

Incorporating progress ratios into energy and economic models usually requires picking a number, and assume learning rates ex ante (Messner 1997; Riahi, Rubin et al. 2002a). Although evidence indicates that progress rate have great variation and uncertainties as discussed in previous sections, it has not yet been reduced to a stable, explainable, and predictable function (Dutton and Thomas 1984). On top of that, when learning rates are selected ex ante, optimization (perfect foresight) models tend to identify the most promising technologies and invest in them heavily and early (Barreto and Klaassen 2003). The cost reduction potential of a promising technology depends, among other things, on the learning rate assigned to the experience curve, and the maximum potential capacity of the different technologies represented in the model. In the real world, however, learning rates (and mechanisms that contribute to learning) are not known perfectly. Therefore it is suggested that the use of input distributions of learning rates better represents our limited understanding of the processes underlining technology progress functions. Grubler and Gritsevskii used a simple optimization model with endogenous technological change with uncertainty in learning rates, represented by a lognormal distribution function around the mean value (Grubler and Gritsevskii 1997). They showed that when the rate of learning is certain (i.e. known with perfect foresight), the optimal solution is to invest heavily and early in new technology because the resulting cost declines through learning and causes the technology to quickly become competitive. However, when learning rates are uncertain, the optimal solution is less certain and companies invest in portfolios. Thus when the learning is uncertain, which is the case in the real world, diffusion is predicted to be more gradual, and market entry is delayed. Messner et al. also incorporated uncertainties concerning future technology performance and found that the model tends to spread risk over more technologies to cope with the uncertainties concerning development paths (Messner, Golodnikov et al. 1996).

The "shape" of the technology experience curve also could have important impacts on modeling technological change in climate models. The initial shape of the curve (e.g., concave instead of convex) affects the relative attractiveness and optimum growth rates of new technology, and thus influences the policy choices. For example, slow reductions of cost in the initial stage may discourage investments that are needed for long-term productivity growth and technological innovation, thus causing the technology to be "locked-out" in the model. On the other hand, technologies with an "optimistic" experience curve (e.g. the prevailing log-linear versus an $S$ shape) are more likely to be chosen to enter the market earlier and diffuse more rapidly in the model. Such issues have not been examined in the past due to the computational difficulties cited earlier. Nor have modelers incorporated cost increases that may occur with initial deployment. However, now that there have been overcome to an increasing extent, further computer experiments are warranted, jointly with the modeling of learning rate uncertainties. 
The assumption of technological learning, by definition, drives down technology costs, and models based on cost minimization take up new technologies once their costs have fallen. The path of technology adoption is sensitive to perturbations and thus major innovations may set up long sequences of path-dependent activities. In other cases, path discontinuities may arise from gradual, continuous technological change (Klepper and Simons 2003). The use of experience curve suggests that existing technologies following a series of gradual improvements that may amount to significant change over the long term and may direct the focus of R\&D on incremental improvements in that technology (Weyant and Olavson 1999). However, current learning models usually do not incorporate the possibility of technological displacement or technologies of different generations, which may have significant improvements in technology performance and efficiencies (e.g., an improved CCT technology that capture $99 \% \mathrm{CO}_{2}$ instead of $90 \%$ ). Combining reduction in cost and improvements in performance is thus another area for future research.

\subsubsection{The Risk of Forgetting}

Experience curve of technology change assumes continuous incremental technological changes. However, if a discontinuity occurs in the experience curve, it can cause the improvements in costs and/or performance to slow down or to reverse direction. For example, if the use of a technology falls below a certain threshold, learning could discontinue and be replaced by forgetting due to loss of experienced experts, discontinuation of replacement parts and supports, and loss of knowledge and know-how inside organizations. This cost of forgetting should not be neglected if the technology later regains popularity in the future. This too is another area for further research.

\subsubsection{Other Factors Affecting IA Modeling}

This paper does not address other factors that potentially contribute to induced technological change, such as investments in R\&D and spillovers from R\&D. Developing and incorporating more detailed models of the learning process will improve the ability of IA models to better represent the policy-related outcome of technology innovations. Early work by others has began to explore the effects of R\&D investment and spillovers (Watanabe, Wakabayashi et al. 2000; Grubb, Hope et al. 2002). In general, such models found that the incorporation of these two factors, along with learning-by-doing, tends to reduce the costs of environmental policy, accelerate abatement, and often lead to positive spillover and negative leakage (Dowlatabadi 1998; Grubb, Hope et al. 2002; Grubb, Kohler et al. 2002; Loschel 2002). Future improvement in the modeling of induced technological change should seek to fully endogenize the complete models, and thus improve current modeling capability based on experience curve. 


\section{Conclusions}

This study has shown the importance of incorporating environmental technology innovation into large-scale integrated assessment models used for climate change policy analysis. We also have shown that sustained inventive activity in environmental technologies, as indicated by U.S. patent data, is strongly linked to government actions that establish a market for environmental control technologies via the regulatory regimes that are imposed. Our analysis of cost and performance trends for two major environmental technologies used at coal-fired power plants (FGD systems for $\mathrm{SO}_{2}$ control, and $\mathrm{SCR}$ systems for $\mathrm{NO}_{\mathrm{x}}$ control) has yielded a set of "experience curves" that represent technological learning as a function of the cumulative installed capacity of these technologies. These experience curves can be used in integrated assessment models to more effectively represent endogenous technical change for similar environmental technologies, in particular, $\mathrm{CO}_{2}$ capture and sequestration technologies.

For $\mathrm{SO}_{2}$ control technologies, we found that the implementation of stringent government regulations produced substantial and measurable innovative activity in control technology development over the past three decades. The stringency of such regulations (both threatened and real) provided much greater explanatory power for the appearance and diffusion of technology innovations than did federally funded research and development programs alone. We can measure the rates of progress or learning from its two principal components: (1) new and improved generations of the technology, and (2) learning how to operate existing equipment more efficiently. These two components contribute to what is often referred to as "experience curves" that represent the change in technology cost as a function of its cumulative installed capacity.

Experience curves for SCR systems were developed using the same methodology employed for FGD technology, namely the use of historical cost studies for new installations based on a standardized power plant design and $\mathrm{NO}_{\mathrm{x}}$ removal efficiency of eighty percent. The resulting trends for capital cost and O\&M cost show significant cost decreases as the worldwide use of SCR systems has grown. Catalyst price and catalyst lifetime are the two dominate factors responsible for the drastic cost reduction of new SCR. SCR process improvements have substantially lengthened the average catalyst lifetime while improvements in catalyst manufacturing methods, as well as competition among catalyst manufacturers, have simultaneously lowered catalyst installation prices by 50 percent over a recent ten-year period.

The learning rates derived in this study for the capital costs of FGD and SCR systems are 11\% and $13 \%$, respectively. These values are well within the range of learning rates found in other studies for a wide range of market-based technologies. We believe the quantitative results presented here can serve as a guideline for how $\mathrm{CO}_{2}$ capture costs might decline in the future under a sufficiently stringent policy regime. The empirical data also show that widespread deployment of high-efficiency (but costly) environmental technologies like FGD and SCR systems require the adoption of sufficiently stringent government regulations, policies, and other actions to create and sustain a market for these technologies. Given such policies, failure to account for the effects of technology innovation can lead to erroneous estimates of future compliance costs for new environmental initiatives. 
These experience curves have been incorporated into the large-scale integrated assessment model, MESSAGE-MACRO, developed by the International Institute for Applied Systems Analysis (IIASA), as a surrogate for the expected rates of cost reduction for $\mathrm{CO}_{2}$ capture technologies (CCTs). Results indicated that the cost of achieving a climate stabilization target was significantly lowered when learning rates based on the present study were applied to $\mathrm{CO}_{2}$ capture and storage systems for fossil fuel power plants. Compared to scenarios based on static cost assumptions for CCT, the contribution of carbon sequestration is about 50 percent higher in the case with learning. The results illustrate that assumptions about environmental technology change are a critical determinant of future characteristics of the energy systems. While the technology for $\mathrm{CO}_{2}$ capture and sequestration remains to be demonstrated for large-scale power plant applications, it is nonetheless one of the leading options being examined in current policy studies. Policy scenarios that assume specific penetration rates of CCT technologies to electric systems were run to examine the impacts of a climate policy that requires over time an increasing fraction of fossil-fueled power generation to incorporate carbon capture technologies. The results again showed that the inclusion of learning leads to significant changes in the fossil-fueled share of the generation mix, and fosters the penetration of advanced and more efficient power generation technologies. The incorporation of technology learning in the IIASA model also leads to lower electricity shadow prices, more $\mathrm{CO}_{2}$ capture and sequestration, and slightly lower $\mathrm{CO}_{2}$ emissions at the end of the century. A broad portfolio of technologies, ranging from energy efficiency improvement to structural changes in both the energy supply and demand side, are needed in the long-term to stabilize the atmospheric concentration of $\mathrm{CO}_{2}$.

To improve the representation of induced technical change in long-term energy and environmental modeling, issues of uncertainties of the experience curve are of great importance. We explore such issues as the shape of the experience curves, the "plateauing" phenomenon, the rate of technological change, and technology uncertainties. The uncertainties of the experience curve and the assumptions about learning characteristics will change the results of integrated assessment models. Further research should focus on the issues of the uncertainties of the experience curves, future improvement in the modeling of induced technological change, and improved mechanistic modeling the process of technological innovation. 


\section{References}

(1973). Final Report: Sulfur Oxide Control Technology Assessment Panel (SOCTAP) on Projected Utilization of Stack Gas Cleaning Systems by Steam-Electric Plants, Submitted to the Federal Interagency Committee Evaluation of State Air Implementation Plans by Sulfur Oxide Control Technology Assessment Panel.

Anada, H. R., M. F. King, et al. (1982). Feasibility and Economics of By-Product CO2 Supply for Enhanced Oil Recovery. Final Report, DOE/MC/08333-3, Vol. 1: Technical Report. Springfield, Virginia, U.S. DOE.

Anon (1972). " $\mathrm{SO}_{2}$ removal technology enters growth phase." Environmental Science \& Technology 6(8): 688-691.

Argote, L. (1996). "Organizational Learning Curves: Persistence, Transfer and Turnover." International Journal of Technology Management. Special Publication on Learning and Unlearning 11(7/8): 759-69.

Argote, L. (1999). Organizational Learning: Creating, Retaining and Transferring Knowledge. Norwell, Massachusetts, Kluwer Academic Publishers.

Argote, L. and D. Epple (1990). "Learning curves in manufacturing." Science 247( 4945): 920924.

Arrow, K. (1962). "The Economic Implications of Learning by Doing." Review of Economic Studies 29: 155-173.

Asher, H. (1956). Cost-Quantity Relationships in the Airframe Industry. Santa Monica, CA, The RAND Corporation.

Ashford, N. A., C. Ayers, et al. (1985). "Using regulations to change the market for innovation." Harvard Environmental Law Review 9: 419-66.

Azar, C. and H. Dowlatabadi (1999). "A review of technical change in assessment of climate policy." Annual Review of Energy and the Environment 24: 513-544.

Barbour, W. (1996). Gas absorbers. OAQPS control cost manual (EPA 453/B-96-001). W. M. Vatavuk. Research Triangle Park, NC, U.S. Environmental Protection Agency, Office of Air Quality Planning \& Standards.

Barreto, L. and G. Klaassen (2003). "Emissions trading and the role of learning-by-doing spillovers in the "bottom-up" energy-systems ERIS model." International Journal of Energy Technology and Policy: submitted.

Battelle Columbus Laboratory (1973). Stack Gas Treatment.

Boeing ((n.d.)). The Experience Curve and Improvement Curve Study. Wichita, Kansas, Boeing Airplane Company.

Boston Consulting Group (1968). Perspectives on Experience, Boston Consulting Group Inc.

Bottoms, R. R. (1930). Process for Separating Acidic Gases.

Carr, G. W. (1946). "Peacetime cost estimating requires new learning curves." Aviation 45: 7677.

Chapel, D., J. Ernst, et al. (1999). Recovery of $\mathrm{CO}_{2}$ from Flue Gases: Commercial Trends. Canadian Society of Chemical Engineers Annual Meeting, Saskatoon, Saskatchewan, Canada.

Cohen, W. (1995). Empirical Studies of Innovative Activity. Handbook of Economics of Innovation and Technological Change. P. Stoneman. Cambridge, Mass, Blackwell: 182264. 
Cohen, W. and R. Levin (1989). Empirical studies of innovation and market structure. Handbook of Individual Organization. R. Schmalensee and R. D. Willig. Amsterdam, Elsevier. 2: 1059-1107.

Colpier, U. C. and D. Cornland (2002). "The Economics of the Combined Cycle Gas Turbine an Experience Curve Analysis." Energy Policy 30(4): 309-316.

Conway, R. W. and A. Schultz, Jr. (1959). "The manufacturing progress function." The Journal of Industrial Engineering(1): 39-54.

Damon, J. E., P. A. Ireland, et al. (1987). Updated technical and economic review of selective catalytic NOx reduction systems. 1987 Symposium on Stationary Combustion Nitrogen Oxide Control, New Orleans, Louisiana, Electric Power Research Inc. CS-5361s.

DeLallo, M. R., T. L. Buchanan, et al. (2000). Evaluation of innovative fossil cycles incorporating $\mathrm{CO}_{2}$ removal. 2000 Gasification Technologies Conference, San Francisco, California.

Dowlatabadi, H. (1998). "Sensitivity of climate change mitigation estimates to assumptions about technical change." Energy Economics 20(5-6): 473-93.

Dutton, J. M. and A. Thomas (1984). "Treating Progress Functions as a Managerial Opportunity." Academy of Management Review 9(2): 235-247.

Dutton, J. M., A. Thomas, et al. (1984). "The History of Progress Functions as a Managerial Technology." Business History Review 58(2): 204-233.

EIA (2000). Emissions of Greenhouse Gases in the United States. Washington, DC, Energy Information Administration.

EPRI (1982). Technical and Economic Feasibility of Ammonia-Based Post Combustion NOx Control. Palo, CA, Electric Power Research Institute.

Foerter, D. and W. Jozewicz (2001). Cost of Selective Catalytic Reduction (SCR) Applications for $\mathrm{NO}_{\mathrm{x}}$ Control on Coal-Fired Boilers, US EPA Office of Research and Development.

Goldstein, G. (1991). PC-MARKAL and the MARKAL User's Support System (MUSS): User's Guide. Tech. Rep. BNL 46319. Upton, NY, Brookhaven Natl. Lab.

Griliches, Z. (1990). "Patent Statistics as Economic Indicators: A Survey." Journal of Economic Literature 28: 1661-1707.

Grubb, M. J., C. Hope, et al. (2002). "Climatic implications of the Kyoto Protocol: The contribution of international spillover." Climatic Change 54(1-2): 11-28.

Grubb, M. J., J. Kohler, et al. (2002). "Induced technical change in energy and environmental modeling: Analytic approaches and policy implications." Annual Review of Energy and the Environment 27(271-308).

Grubler, A. and A. Gritsevskii (1997). A model of endogenous technological change through uncertain returns on learning (R\&D and investments). Conf. Induc. Technol. Change Environ., Laxenburg, Austria, International Institute of Applied System Analysis.

Grubler, A. and S. Messner (1998). "Technological change and the timing of mitigation measures." Energy Economics 20(5-6): 495-512.

Grubler, A., N. Nakicenovic, et al. (1999). "Dynamics of Energy Technologies and Global Change." Energy Policy 27(5): 247-280.

Guibert, P. (1945). Mathematical Studies of Aircraft Construction. Dayton, Ohio, Central Air Documents Office, Wright-Patterson Air Force Base.

Healy, E. C., J. D. Maxwell, et al. (1996). Demonstration of Selective Catalytic Reduction (SCR) Technology for the Control of Nitrogen Oxide $\left(\mathrm{NO}_{\mathrm{x}}\right)$ Emissions from High-Sulfur CoalFired Boilers: Final Report. Birmingham, AL, Southern Company Services, Inc. 
Hendriks, C. F. (1994). Carbon Dioxide Removal from Coal-fired Power Plants. Norwell, MA, Kluwer Academic Publishers.

Herzog, H. (1999). The Economics of $\mathrm{CO}_{2}$ Capture. Greenhouse Gas Control Technologies. P. Reimer, B. Eliasson and A. Wokaum. Oxford, Elsevier Science Ltd.: 101-106.

Hjalmarsson, A.-K. (1990). $\mathrm{NO}_{\mathrm{x}}$ control technologies for coal combustion. London, UK, IEA Coal Research.

Hoffmann, F. S. (1950). Comments on the Modified Form of the Aircraft Progress Functions. Santa Monica, California, The RAND corporation.

Houghton, J. T., G. Jenkins, et al., Eds. (1990). Scientific Assessment of Climate change Report of Working Group I. Cambridge, UK, Cambridge University Press.

Ibenholt, K. (2002). "Explaining Learning Curves for Wind Power." Energy Policy 30: 11811189.

ICAC (1997). Selective Catalytic Reduction (SCR) control of $\mathrm{NO}_{\mathrm{x}}$ emissions. Washington, DC, SCR committee of Institute of Clean Air Companies, Inc: 33.

IEA Greenhouse Gas R\&D Programme (1995). Global Warming Damage and the Benefits of Mitigation, IEA Greenhouse Gas R\&D Programs.

IPCC, Ed. (1990). The IPCC Response Strategies - Report of Working Group III. Covelo CA, USA, Island Press.

ISI Web of Science (2003). 2003.

Joskow, P. L. and G. A. Rozanski (1979). "The effects of learning by doing on nuclear plant operating reliability." Review of Economics and Statistics 61(2): 161-18.

Keeth, R. J., P. A. Ireland, et al. (1986). Economic evaluation of twenty-four FGD systems. $\mathrm{SO}_{2}$ Control Symposium, Atlanta, GA, Environmental Protection Agency, Washington D.C.

Keeth, R. J., P. A. Ireland, et al. (1991). Economic evaluation of twenty-eight FGD processes. $\mathrm{SO}_{2}$ Control Symposium, Washington, D.C, EPRI, Palo Alto, CA.

Keeth, R. J., P. A. Ireland, et al. (1990). 1990 update of FGD economic evaluations. $\mathrm{SO}_{2}$ Control Symposium, New Orleans, LA, EPRI, Palo Alto, CA.

Keeth, R. J., P. A. Ireland, et al. (1995). Utility response to phase I and phase II acid rain legislation and economic analysis. EPRI/DOE/EPA $1995 \mathrm{SO}_{2}$ Control Symposium, Miami, Florida, EPRI, Palo Alto, California.

Kemp, R. (1997). Environmental Policy and Technical Change: A Comparison of the Technological Impact of Policy Instruments. Cheltenham, UK, Edward Elgar.

Klepper, S. and E. Graddy (1990). "The Evolution of New Industries and the Determinants of Market Structure." RAND Journal of Economics 21(1): 27-44.

Klepper, S. and K. Simons (2003). "Technological change and industry shakeouts." Draft.

Kohl, A. L. and R. B. Nielsen (1997). Gas Purification. Houston, Texas, Gulf Publishing Company.

Kohl, A. L. and F. C. Riesenfeld (1960). Gas Purification. Houston, Texas, Gulf Publishing Company.

Kohl, A. L. and F. C. Riesenfeld (1985). Gas Purification. Houston, Texas, Gulf Publishing Company.

Krolewski, M. J. and A. S. Mingst (2000). Recent $\mathrm{NO}_{\mathrm{x}}$ reduction efforts: an overview. Washington, DC, Clean Air Markets Division, Office of Atmospheric Programs, U.S. EPA.

Laitos, J. G. and J. P. Tomain (1992). Energy Law in a Nutshell. St. Paul, MN, West Publishing. 
Loschel, A. (2002). "Technological change in economic models of environmental policy: a survey." Ecological Economics 43(2-3): 105-126.

Manne, A. and R. Richels (1992). Buying Greenhouse Insurance: The Economic Costs of CO2 Emission Limits. Cambridge, MA, MIT.

Mattsson, N. and C. O. Wene (1997). "Assessing new energy technologies using an energy system model with endogenized experience curves." International Journal of Energy Research 21(4): 385-393.

Maxwell, J. D., T. A. Burnett, et al. (1980). Preliminary Economic Analysis of NOx Flue Gas Treatment Processes.

Maxwell, J. D. and L. R. Humphries (1981). Evaluation of the Advanced Low-NOx Burner, Exxon, and Hitachi Zosen DeNOx Processes.

Maxwell, J. D. and L. R. Humphries (1985). Economics of Nitrogen Oxides, Sulfur Oxides, and As Control Systems for Coal-Fired Utility Power Plants. Washington, D.C., U.S. Environmental Protection Agency: 277.

McDonald, A. and L. Schrattenholzer (2001). "Learning rates for energy technologies." Energy Policy 29: 255-261.

McDonald, A. and L. Schrattenholzer (2002). "Learning curves and technology assessment." International Journal of Technology Management 23(7/8): 718-745.

McG Tegart, W. J., G. W. Sheldon, et al., Eds. (1990). Impacts Assessment of Climate Change Report of Working Group II. Canberra, Australia, Australian Government Publishing Service.

McGlamery, G. G., W. E. O'Brien, et al. (1980). FGD economics in $1980 . \mathrm{SO}_{2}$ Control Symposium, Houston, TX, Environmental Protection Agency, Washington D.C.

McIlvaine Company (2002). Utility Data Tracking Service, SCR Projects: Bid and Award Tracking. 2002.

Messner, S. (1995). Endogenized Technological Learning in an Energy System Model, WP-95114. Laxenburg, Austria, International Institute for Applied Systems Analysis.

Messner, S. (1997). "Endogenized technological learning in an energy system model." Journal of Evolutionary Economics 7: 291-313.

Messner, S., A. Golodnikov, et al. (1996). "A stochastic version of the dynamic linear programming model MESSAGE III." Energy 21(9): 775-784.

Mobley, J. D. (1978). Status of EPA's NOx flue gas treatment program. Proceedings: Second NOx Control Technology Symposium, Denver, Colorado, EPRI.

Mowery, D. C. and N. Rosenberg (1982). The Influence of Market Demand upon Innovation: A Critical Review of some Recent Empirical Studies. Inside the Black Box: Technology and Economics. N. Rosenberg. New York, Cambridge University Press: 193-241.

Neij, L. (1997). "Use of Experience Curves to Analyze the Prospects for Diffusion and Adoption of Renewable Energy Technology." Energy Policy 23(13): 1099-1107.

Neij, L. (1999). "Cost dynamics of wind power." Energy 24: 375-389.

NESCAUM (2001). Power Companies' Efforts to Comply with the $\mathrm{NO}_{\mathrm{x}}$ SIP Call and Section 126. Boston, MA, Northeast States for Coordinated Air Use Management: 13.

Ostwald, P. and J. Reisdoft (1979). "Measurement of technology progress and capital-cost for nuclear, coal-fired, and gas-fired power-plants using the learning curve." Engineering and Process Economics 4(4): 435-453. 
Pappano, A. W., J. T. Sears, et al. (1976). Availability and Economics of $\mathrm{CO}_{2}$ for Enhanced Oil Recovery in Appalachia. Morgantown, West Virginia, Department of Chemical Engineering, West Virginia University.

Parente, V., J. Goldemberg, et al. (2002). "Comments on experience curves for PV modules." Progress in Photovoltaics 10(8): 571-574.

Prinn, R., H. Jacoby, et al. (1999). "Integrated global system model for climate policy assessment: Feedbacks and sensitivity studies." Climatic Change 41(3-4): 469-546.

Rao, A. B. (2003). A Technical, Environmental, and Economic Assessment of Amine-Based Carbon Capture Technologies for Greenhouse Gas Control. Department of Engineering and Public Policy. Pittsburgh, PA, Carnegie Mellon University.

Rao, A. B. and E. S. Rubin (2002). "A technical, economic, and environmental assessment of amine-based $\mathrm{CO}_{2}$ capture technology for power plant greenhouse gas control." Environmental Science \& Technology 36(20): 4467-4475.

Rao, S. N., H. G. McIlvried, et al. (1994). Evaluation of $\mathrm{NO}_{\mathrm{x}}$ removal technologies. Volume 1. Selective catalytic reduction. Revision 1., Burns \& Roe Services Corporation. Prepared for the U.S.DOE Pittsburgh Energy Technology Center.

Rapping, L. (1965). "Learning and world war II production functions." Review of Economics and Statistics 47: 81-86.

Riahi, K., R. A. Roehrl, et al. (2001). Technology Clusters in Sustainable Development Scenarios. Progress Reports of Environmental Issue Groups. International Forum of the COllaboration Projects, Tokyo, JP.

Riahi, K., E. S. Rubin, et al. (2002a). "Technological Learning for Carbon Capture and Sequestration Technologies." Energy Economics: accepted.

Riahi, K., E. S. Rubin, et al. (2002b). Technological Learning for Carbon Capture and Sequestration Technologies (Interim Report). Laxenburg, Austria, International Institute for Analysis Systems Analysis.

Robie, C. P. and P. A. Ireland (1991). Technical Feasibility and Cost of Selective Catalytic Reduction (SCR) $\mathrm{NO}_{\mathrm{x}}$ Control. Palo Alto, CA, Prepared by United Engineers and Constructors, Inc. for the Electric Power Research Institute.

Rogers, E. M. (1995). DIffusion of Innovations. New York, Free Press.

Rosenberg, N. (1994). Exploring the Black Box: Technology, Economics, and History. Cambridge, UK, Cambridge University Press.

Rubin, E. S., J. R. Kalagnanam, et al. (1995). New models for FGD performance, cost and hazardous air pollutant removal. $\mathrm{SO}_{2}$ Control Symposium, Miami, FL.

Rubin, E. S., J. R. Kalagnanam, et al. (1997). "Integrated environmental control modeling of coal-fired power systems." Journal of the Air \& Waste Management Association 47: 1180-88.

Rubin, E. S., M. R. Taylor, et al. (2003). "Learning curves for environmental technology and their importance for climate policy analysis." Energy: In Press.

Rubin, E. S., S. Yeh, et al. (2003). "Experience curves for power plant emission control technologies." International Journal of Energy Technology and Policy: Accepted.

Schaeffer, G. J. (2003). Experience curves as policy tool - the case of PV. EXCETP-EXTOOL workshop, Paris.

Schumpeter, J. A. (1942). Capitalism, Socialism and Democracy. New York, Harper Brothers. 
Simbeck, D. R. (2001). $\underline{\mathrm{CO}}_{2}$ Mitigation Economics for Existing Coal-Fired Power Plants. U.S. Dept. of Energy National Energy Technology Laboratory (NETL) First National Conference on Carbon Sequestration, Washington, DC.

Simbeck, D. R. and M. McDonald (2000). Existing Coal Power Plant Retrofit CO2 Control Options Analysis. Fifth Conference on Greenhouse Gas Control Technologies (GHGT5), Cairns, Australia.

Sinclair, G., S. Klepper, et al. (2000). "What's Experience Got to Do with it? Sources of Cost Reduction in a Large Specialty Chemical Producer." Management Science 46(1): 28-45.

Skopp, A. (1969). Fluid Bed Studies of the Limestone Based Flue Gas Desulfurization Process, Esso Research and Engineering Company prepared under contract No. PH 86-67-130 for National Air Pollution Control Administration.

Smelser, S. C., R. M. Stock, et al. (1991). Engineering and Economic Evaluation of $\mathrm{CO}_{2}$ Removal from Fossil-Fuel-Fired Power Plants. EPRI IE-7365, Vol. 1: Pulverized-CoalFired Power Plants. Palo Alto, CA, Project 2999-10. Prepared by Fluor Daniel Inc., for EPRI and IEA; EPRI.

Soud, H. (2001). Personal communication. London, IEA Coal Research.

Soud, H. N. (1994). FGD Installations on Coal-Fired Plants. London, IEA Coal Research.

Spaite, P. W. (1972). "SO 2 control: status, cost and outlook." Power Engineering October: 34 37.

SRES (2000). A Special Report on Emissions Scenarios for Working Group III of the Intergovernmental Panel on Climate Change (IPCC). Cambridge, UK, Cambridge University Press.

SRI (1949a). An Improved Rational and Mathematical Explanation of the Progress Curve in Airframe Production. Stanford, California, Stanford Research Institute.

SRI (1949b). Relationships for Determining the Optimum Expansibility of the Elements of a Peacetime Aircraft Procurement Program. Stanford, California, Stanford Research Institute, Prepared for Air Materiel Command, USAF.

STAPPA\&ALAPCO (1994). Controlling Nitrogen Oxides under the Clean Air Act: A Menu of Options, State and Territorial Air Pollution Program Administrators and the Association of Local Air Pollution Control Officials.

Straub, G. P. (1999). Personal interview. Washington, D.C, U.S. Patent and Trademark Office.

Sturm, R. (1993). "Nuclear-power in eastern Europe - learning or forgetting curves." Energy Economics 15(3): 183-189.

Taylor, M. (2001). The Influence of Government Actions on Innovative Activities in the Development of Environmental Technologies to Control Sulfur Dioxide Emissions from Stationary Sources. Department of Engineering and Public Policy. Pittsburgh, PA, Carnegie Mellon University.

Taylor, M., E. S. Rubin, et al. (2003). "The effect of government actions on technological innovation for $\mathrm{SO}_{2}$ control." Environmental Science \& Technology 37(20): 4527 - 4534.

Taylor, M. R., E. S. Rubin, et al. (2001). The effect of government actions on technological innovation for $\mathrm{SO}_{2}$ control. EPRI-DOE-EPA Combined Utility Air Pollutant Control Symposium: The Mega Symposium, Chicago, IL, EPRI.

The Boston Consulting Group (1968). Perspectives on Experience, The Boston Consulting Group, Inc. 
The M. W. Kellogg Company (1971). Evaluation of $\mathrm{SO}_{2}$ - Control Processes. Task \#5 Final Report. Submitted to Environmental Protection Agency, Office of Air Programs. Contract No. CPA 70-68. Piscataway, NJ, The M. W. Kellogg Company.

Thompson, P. and L. A. Strohm (1996). "Trade and environmental quality: a review of the evidence." Journal of Environment \& Development 5(4): 363-388.

Torstrick, R. L., L. J. Henson, et al. (1978). Economic evaluation techniques, results, and computer modeling for flue gas desulfurization. Symposium on Flue Gas Desulfurization, Hollywood, Florida, EPA-600/7-78-058B, Environmental Protection Agency, Washington, D.C., 1978.

U.S. DOE (1997). Control of Nitrogen Oxide Emissions: Selective Catalytic Reduction (SCR), National Energy Technology Laboratory, U.S. Department of Energy: 28.

U.S. DOE (1999). Demonstration of Selective Catalytic Reduction Technology to Control Nitrogen Oxide Emissions From High-Sulfur, Coal-Fired Boilers: A DOE Assessment. Morgantown, PA, U.S. Department of Energy, Office of Fossil Energy, Federal Energy Technology Center.

U.S. DOE (2000). Steam-Electric Plant Operation and Design Report, 2000. Schedule VII: Flue Gas Desulfurization (FGD) Unit Information, Department of Energy Form EIA-767.

U.S. EPA (1999). Regulatory Impact Analysis for the NOx SIP Call, FIP, and Section 126 Petitions. Washington DC, Environmental Protection Agency, Office of Air and Radiation.

U.S. EPA (2002). EPA Clean Air Market Program: Emissions Data \& Compliance Reports.

U.S. Geological Survey (2001). Minerals Information: commodity statistics and information. 2001.

U.S. Patent and Trademark Office (2003). Patents Bibliographic Database. 2003.

Watanabe, C., A. Nagamatsu, et al. (2003). "Behavior of technology in reducing prices of innovative goods - an analysis of the governing factors of variance of PV module prices." Technovation 23(5): 423-436.

Watanabe, C., K. Wakabayashi, et al. (2000). "Industrial dynamism and the creation of a "virtuous cycle" between R\&D, market growth and price reduction - The case of photovoltaic power generation (PV) development in Japan." Technovation 20(6): 299312.

Wene, C.-O. (2000). Experience Curves for Energy Technology Policy. Paris, France, International Energy Agency.

Weyant, J. P. and T. Olavson (1999). "Issues in modeling induced technological change in energy, environmental, and climate policy." Environmental Modeling and Assessment 4: 67-85.

Wright, T. P. (1936). "Factors affecting the cost of airplanes." Journal of Aeronautical Sciences 3(2): 122-128.

Yelle, L. E. (1979). "The learning curve: historical review and comprehensive survey." Decision Sciences 10: 302-328.

Zipper, C. E. and L. Gilroy (1998). "Sulfur dioxide emissions and market effects under the Clean Air Act Acid Rain Program." J. Air Waste Manage. Assoc. 48: 829-37.

Zwaan, B. C. C. v. d., R. Gerlagh, et al. (2002). "Endogenous technological change in climate change modeling." Energy Economics 24(1-19). 


\section{Appendix A. List of Publications and Activities Sponsored by the Grant}

\section{JOURNAL PAPERS}

Taylor, M.R., E.S.Rubin and D.A.Hounshell, "The Effect of Government Actions on Technological Innovation for SO2 Control," Environmental Science and Technology, 37(20): 4527 - 4534.

Rubin, E.S., Yeh, S., Taylor, M.R., and Hounshell, D.A., "Experience curves for power plant emission control technologies", International Journal of Energy Technology and Policy (2003), accepted.

Rubin, E.S., Taylor, M.R., Yeh, S., and Hounshell, D.A., "Learning curves for environmental technology and their importance for climate policy analysis", Energy (2003), accepted.

Riahi, K, Rubin, E S and Schrattenholzer, L., "Technological Learning for Carbon Capture and Sequestration Technologies", Energy Economics (2003), accepted.

\section{REPORTS AND WORKING PAPERS}

Taylor, M.R., E.S. Rubin, and D.A. Hounshell, "The Effect of Government Actions on Technological Innovation for $\mathrm{SO}_{2}$ Control," Proceedings of The EPA/DOE/EPRI Mega Symposium, Chicago IL, August 20-23, 2001 .

Taylor, M.R., E.S. Rubin, D.A. Hounshell, and S. Yeh, "The Effect of Government Actions on Environmental Technology Innovation," Proceedings of the International Energy Workshop, International Institute for Applied Systems Analysis, June 2002.

Riahi, K., E.S. Rubin,. L. Schrattenholzer, "Prospects for Carbon Capture and Sequestration Technologies Assuming Technological Learning," Proc. $6^{\text {th }}$ Conf. On Greenhouse Gas Control Technologies (GHGT6), Kyoto, Japan, International Energy Agency, Cheltenham, UK, October 2002.

Rubin, E.S., M.R. Taylor, S. Yeh, D.A. Hounshell, "Experience Curves for Environmental Technology and Their Relationship to Government Actions," Proc. $6^{\text {th }}$ Conf. On Greenhouse Gas Control Technologies (GHGT-6), Kyoto, Japan, International Energy Agency, Cheltenham, UK, October 2002.

Riahi, K., E. S. Rubin, et al. (2002). Technological Learning for Carbon Capture and Sequestration Technologies (Interim Report). Laxenburg, Austria, International Institute for Analysis Systems Analysis.

Alic, J.A., D.C. Mowery and E.S. Rubin, U.S. Technology and Innovation Policies: Lessons for Climate Change, Pew Center on Global Climate Change, Arlington, VA, November 2003.

Yeh, S, Rubin, E S, Hounshell, D A and Taylor, M R (2003) "On the use of technology experience curves in integrated assessment models". Working paper.

Riahi, K., L. Barreto, et al. (2003). Long-term Perspectives for Carbon Capture in Power Plants: Scenarios for the 21st Century (Final Report): 00-133 ECS. Laxenburg, Austria, Environmentally Compatible Energy Strategies (ECS) Project, International Institute for Applied Systems Analysis (IIASA). Submitted to Carnegie Mellon University (CMU) Pittsburgh, PA USA. Sponsored by the US Department of Energy Award number DE-FG02-00ER63037. 


\section{CONFERENCES AND WORKSHOPS}

Rubin, E.S., "Environmental Technology Innovation and Its Implications for Carbon Management", EXCETP5 Workshop, International Energy Agency, Washington, DC, March 11, 2002.

Rubin, E.S., "Learning Our Way to Zero Emissions Technologies", International Energy Agency, Task Force on Zero Emissions Technology, Washington, DC, March 19, 2002.

Rubin, E.S., "Reducing the Costs of $\mathrm{CO}_{2}$ Capture", IEA $\mathrm{CO}_{2}$ Capture Network, Kyoto, Japan, October 5 , 2002.

Rubin, E.S., "Understanding Uncertainties in $\mathrm{CO}_{2}$ Capture and Sequestration Costs", Massachusetts Institute of Technology, Cambridge, MA, November 13, 2002.

Rubin, E.S., "Carbon Sequestration and the Hydrogen Economy", National Coal Council Washington, D.C., November 21, 2002.

Rubin, E.S., S. Yeh, M.R. Taylor and D.A. Hounshell, "Experience Curves for Environmental Technology: Implications for $\mathrm{CO}_{2}$ Capture and Storage Systems," International Energy Agency, Paris, France, January 23, 2003.

Rubin, E.S. "Estimating learning rates for CO2 capture technology," CO2 Experience Curve Workshop, IEA, Paris, France (January 24, 2003)

Yeh, S., "Experience curves for environmental technology and their relationship to government actions." 6 th Annual Electric Utilities Environmental Conference on Air Quality \& Global Change, Tucson, Arizona (January 28, 2003)

Rubin, E.S., "The Government Role in Environmental Technology Innovation," Clean Coal Technology Roadmap Workshop, Calgary, Alberta, Canada, March 20, 2003.

Rubin, E.S., K. Riahi, S. Yeh, D. Hounshell, L. Schrattenholzer, "The Importance of Technological Innovation in Policy Assessments of Carbon Capture and Storage," U.S. Department of Energy Second Annual Conference on Carbon Sequestration, Alexandria, VA, May 6, 2003.

Yeh, S. "On the use of technology experience curves in integrated assessment models," Annual Meeting of the International Energy Workshop, Laxenburg, Austria (24-26 June 2003)

Rubin, E.S., "Technology Innovation for $\mathrm{CO}_{2}$ Mitigation: The Government Role and Implications for Climate policy, MIT Carbon Sequestration Forum IV, Cambridge, MA, November 6, 2003. 
Appendix B. IIASA Interim Report

(June 2002) 


\title{
Technological Learning for Carbon Capture and Sequestration Technologies
}

\author{
-DRAFT-
}

Keywan Riahi, Ed Rubin, Leo Schrattenholzer

June, 2002

This article results from our participation in Energy Modeling Forum Study 19. The authors are indebted to Bing Zhu and Takeyoshi Kato for valuable comments and research assistance. Funding was provided by the Department of Energy under Award Number DE-FG0200ER63037. Any opinions, findings, conclusions or recommendation expressed herein are those of the authors and do not reflect the views of DOE, IIASA, or the Carnegie Mellon University. 


\begin{abstract}
This paper analyzes potentials of carbon capture and sequestration technologies (CCT) in a set of long-term energy-economic-environmental scenarios based on alternative assumptions for technological progress of CCT. In order to get a reasonable guide to future technological progress in managing $\mathrm{CO}_{2}$ emissions, we review past experience in controlling sulfur dioxide emissions $\left(\mathrm{SO}_{2}\right)$ from power plants. By doing so, we quantify a "learning curve" for CCT, which describes the relationship between the improvement of costs due to accumulation of experience in CCT construction. We incorporate the learning curve into the energy modeling framework MESSAGE-MACRO and develop greenhouse gas emissions scenarios of economic, demographic, and energy demand development, where alternative policy cases lead to the stabilization of atmospheric $\mathrm{CO}_{2}$ concentrations at 550 parts per million by volume (ppmv) by the end of the $21^{\text {st }}$ century. We quantify three types of contributors to the carbon emissions mitigation: (1) demand reductions due to the increased price of energy, (2) fuel switching, primarily away from coal, and (3) carbon capture and sequestration from fossil fuels. Due to the assumed technological learning, costs of the emissions reduction for CCT drop rapidly and in parallel with the massive introduction of CCT on the global scale. Compared to scenarios based on static cost assumptions for CCT, the contribution of carbon sequestration is about 50 percent higher in the case of learning resulting in cumulative sequestration of $\mathrm{CO}_{2}$ ranging from 150 to 250 billion $\left(10^{9}\right)$ tons carbon during the $21^{\text {st }}$ century. Also, carbon values across scenarios (to meet the 550 ppmv carbon concentration constraint) are between 2 and 10 percent lower in the case of learning for CCT by 2100 . The results illustrate that assumptions on technological change are a critical determinant of future characteristics of the energy system, hence indicating the importance of long-term technology policies in mitigation of adverse environmental impacts due to climate change.
\end{abstract}




\section{Introduction}

The mitigation of adverse environmental impacts due to climate change requires the reduction of carbon dioxide emissions from the energy sector, the dominant source of global greenhouse-gas emissions. There is a variety of possibilities to reduce carbon emissions, ranging from the enhancement of energy efficiency to the replacement of fossil-based energy production by zerocarbon technologies. Most of the currently viable mitigation technologies, however, are more costly and inferior in some ways compared to the older and more "mature" fossil alternatives. Thus, there is an increasing interest among experts and policy makers in "add-on" environmental strategies to combine state-of-the-art fossil technologies with advanced technologies that capture carbon for subsequent sequestration. Such strategies, if successfully implemented, could enable the continuous use of fossil energy carries at low (or almost zero) emissions.

Carbon capture and sequestration is not a completely new technology. E.g., the United States alone are sequestering about 8.5 million tons of carbon for enhanced oil recovery each year. Nevertheless, present costs for carbon capture technologies (CCT) to reduce emissions are between 35 and $264 \$ / \mathrm{tC}$ (DOE, 1999), corresponding to a prohibitive cost increase for electricity of at least $25 \mathrm{mills} / \mathrm{kWh}$. Given the current costs, it is unlikely that CCT successfully enter the energy market, even if international agreements and efficient institutions for $\mathrm{CO}_{2}$ abatement would exist. Their pervasive diffusion will require substantial efforts to induce "technological learning", which could accomplish considerable cost reductions in the long run.

With this perspective, this paper examines future market perspectives of carbon capture and sequestration by analyzing the dynamics, pace, and future potential for technological learning of CCT. Generally, costs - and other indicators of technology performance - improve as experience is gained by producers (learning-by-doing) and consumers (learning-by-using). In order to get a reasonable guide to future technological progress of carbon capture technologies, we review past experience in controlling sulfur dioxide emissions $\left(\mathrm{SO}_{2}\right)$ from power plants. By doing so, we quantify a "learning curve" for CCT, which describes the relationship between the improvement of costs due to accumulation of experience in CCT construction.

The long-term nature of climate change and its inherent uncertainties call for robust strategies taking into account a number of possible alternative futures. Hence, we incorporate the learning curve into the energy modeling framework MESSAGE-MACRO and develop a set of global greenhouse gas emissions scenarios of economic, demographic, and energy demand development, where alternative policy cases lead to the stabilization of atmospheric $\mathrm{CO}_{2}$ concentrations at 550 parts per million by volume (ppmv). Our analysis shows that, given CCT technologies learn at a similar pace as $\mathrm{SO}_{2}$ abatement technologies in the past, the long-term reduction potential for CCT is vast. This is particularly due to large-scale investments into CCT, and the accumulation of experience, which leads to rapid cost decrease of carbon capture and sequestration. Even though that their widespread deployment requires decades to come, at the end of the $21^{\text {st }}$ century almost all fossil power plants in the scenarios are equipped with CCT. Thus, we conclude that carbon capture and sequestration is one of the obvious priority candidates for long-term technology policies and enhanced R\&D efforts to hedge against the risk associated with high environmental impacts of climate change. 
Although the capturing of carbon from fossil-fueled power plants might lead to considerable reductions of anthropogenic carbon emissions in the long run, our scenario analysis showed also that these reductions might still not be sufficient to meet a $550 \mathrm{ppmv}$ stabilization constraint in the year 2100. CCT is rather one mitigation option in a diversified portfolio of abatement measures. Other main types of emissions mitigation, which considerably contributed to the scenarios emissions reductions, are enhanced energy conservation and in particular fuel switching, primarily away from carbon-intensive coal to low or zero-carbon fuels.

The sequel of this paper is structured as follows: Section 2 describes how the learning curve for carbon capture and sequestration technologies was developed. A brief introduction into how technological learning is implemented into the MESSAGE-MACRO is given in Section 3. Section 4 presents our scenario analysis including the estimates of future potentials of carbon capture technologies. Section 4.1 summarizes the main characteristics of the baseline and mitigation scenarios. The main mitigation measures to decarbonize the future energy system are analyzed in Section 4.2 , with Section 4.3 focusing mainly on the role of carbon scrubbing and sequestration. Finally, Section 5 concludes.

\section{Estimation of Learning Curves for Carbon Capture and Sequestration Technologies}

In 1936, a seminal paper by Wright (1936) introduced a quantitative model of "learning by doing" to describe the time savings (and associated cost reductions) achieved in manufacturing aircrafts. Wright found that the time required to assemble an aircraft decreased with increasing production levels. The relationship was well-predicted by an equation of the form:

$$
y=a x^{-b}
$$

where,

$a$ equals the costs (hours) to manufacture the first unit,

$x \quad$ depicts the cumulative number of units produced,

$y \quad$ is the costs (hours) required to produce unit number $x$,

$-b \quad$ gives the slope for the improvement in costs (hours) in producing the units

On a log-log scale this equation plots as a straight line with slope $-b$. Wright coined the term "progress ratio" to describe the ratio of current cost to initial cost after a doubling of production. Thus, a progress ratio of 0.80 meant that costs decreased by 20 percent for each doubling. Some authors therefore prefer the term "learning rate" for the latter quantity.

Wright's "learning curve" equation was subsequently found to describe the decline in production costs for a wide range of manufacturing activities remarkably well (e.g., Dutton and Thomas, 1984). The concept of learning-by-doing was further extended to model the anticipated capital cost reductions in new generations of a technology, including a variety of advanced energy technologies (Nakićenović et al., 1998; McDonald and Schrattenholzer, 2001). In this paper, we measure the overall rate of progress or learning from its two principal components: new and improved generations of the technology, and learning how to operate existing equipment more efficiently. These two components contribute to what is often referred to as "experience curves" 
that represent the change in technology cost as a function of its cumulative installed capacity (IEA, 2000).

We have estimated learning rates of capital and operating cost reduction for the most common flue gas desulfurization (FGD) technology used at coal-fired power plants for $\mathrm{SO}_{2}$ capture. This FGD system employs a slurry of lime or limestone as the chemical reagent to absorb $\mathrm{SO}_{2}$ from flue gases. Figure $\mathbf{4 4}$ shows the historical growth in installed capacity of these systems since they were first introduced in Japan in the late 1960s. The largest market has been the United States, which adopted stringent standards for $\mathrm{SO}_{2}$ control under the Clean Air Act Amendments of 1970 and 1977. A decade later Germany adopted FGD systems as part of its acid rain control strategy. Subsequently the technology was deployed more widely in Europe and elsewhere.

Both the capital and operating costs of FGD systems depend on a large number of plant-specific design and operating factors such as plant size, plant utilization, coal properties, emission reduction requirements and other parameters (Rubin et al., 1997). To obtain a systematic measure of FGD cost reductions attributable to technology innovation (without the confounding effects of other plant variables), we used a set of engineering-economic analyses of new FGD systems applied to a fixed U.S. plant design. These studies were performed primarily by two major utility-industry organizations (the Tennessee Valley Authority, TVA, and the Electric Power Research Institute, EPRI) at different points in time, using consistent methodologies and assumptions (McGlamery, et. al., 1980; Laseke, et. al., 1983; Keeth, et. al. 1986, 1990, 1991; and Soud, 1994). Thus, differences in FGD cost over time (adjusted for inflation) reflected real improvements in the cost of FGD technology for the standard plant application (i.e., $90 \% \mathrm{SO}_{2}$ removal at a new $500 \mathrm{MW}$ plant burning a bituminous coal with $3.5 \%$ sulfur, and a plant capacity factor of $65 \%$ ). In a few cases, a power plant cost model was used to adjust reported cost figures to a consistent design basis where power plant design premises differed slightly from earlier studies.

Figure 44 shows the resulting decline in FGD capital cost as a function of total cumulative capacity installed in the U.S., Germany and Japan over the past several decades. This measure of cumulative capacity was used as the basis for the estimation of an experience curve because other research showed that these three countries dominated (and shared) inventive activities and innovations in this technology (Taylor, 2001). 


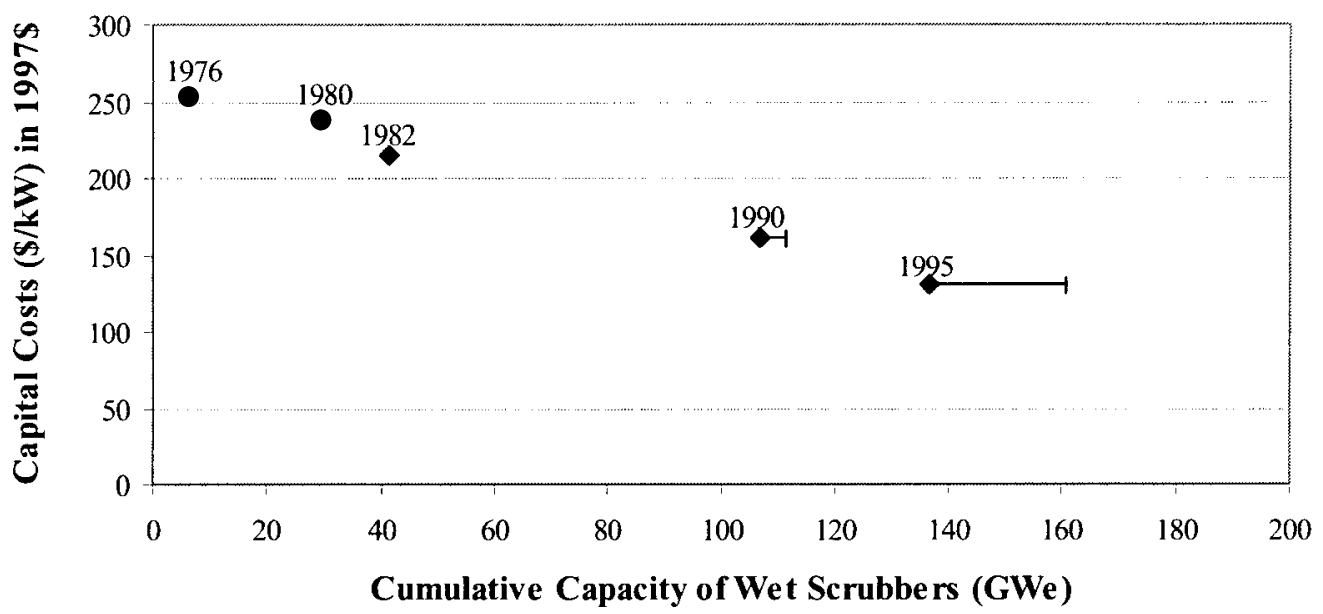

Figure 44: Reductions in capital cost of a new wet limestone FGD system for a standardized coal-fired power plant (500 MWe, $3.5 \%$ sulfur coal, $90 \% \mathrm{SO}_{2}$ removal). Cumulative GWe capacity based on wet lime/limestone scrubbers in the U.S., Germany, and Japan, with the error bars including the rest of the world.

For the purposes of this study, the data in Figure 44 was normalized and fitted with an equation of the form of Equation (1) to obtain an experience curve showing the rate of cost decline with increasing capacity. This function shows that as cumulative worldwide scrubbed capacity doubled, capital cost declined to about $87 \%$ of its original value. This relationship (Figure 45) is used in the MESSAGE-MACRO model to represent the expected cost decrease for $\mathrm{CO}_{2}$ capture systems in coal- and natural-gas-based power plants.

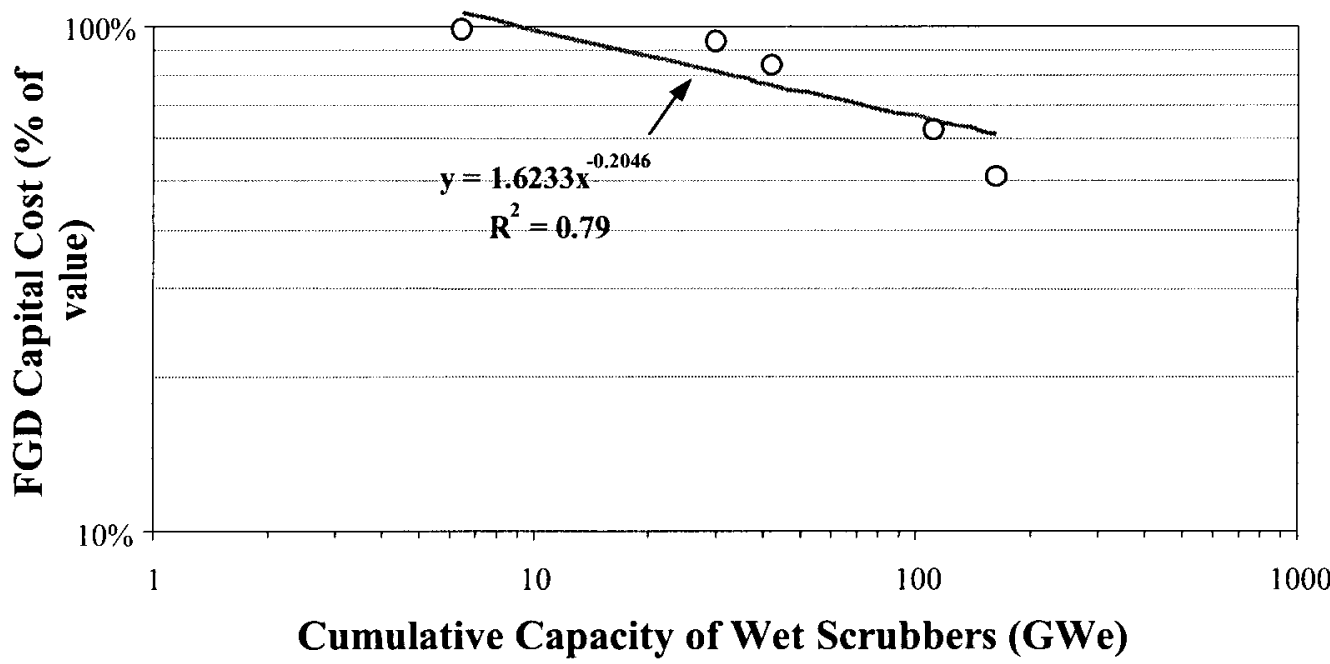

Figure 45: Normalized experience curve for FGD capital cost.

\section{Representation of Technological Change in MESSAGE-MACRO}

This section briefly summarizes the main features of the modeling framework MESSAGEMACRO (Messner and Schrattenholzer, 2000), which was used for the development of the scenarios analyzed in this paper. In particular, we describe how the concept of technological 
learning is introduced into the models, and give a brief description of the reference energy system with focus on the representation of carbon capture technologies.

The Systems Engineering Model MESSAGE (version IV) is a linear programming (LP) systems engineering optimization model, used for medium- to long-term energy system planning and policy analysis. The model minimizes total discounted energy system costs, and provides information on the utilization of domestic resources, energy imports and exports and traderelated monetary flows, investment requirements, the types of production or conversion technologies selected (technology substitution), pollutant emissions, and interfuel substitution processes, as well as temporal trajectories for primary, secondary, final, and useful energy.

$M A C R O$ is a top-down macroeconomic model. In the form it is as it is used here, it has its roots in a long series of models by Manne and others. The latest model in this series is MERGE 4.5 (Manne and Richels, http://www.stanford.edu/group/MERGE/). Its objective function is the total discounted utility of a single representative producer-consumer. The maximization of this utility function determines a sequence of optimal savings, investment, and consumption decisions. In turn, savings and investment determine the capital stock. The capital stock, available labor, and energy inputs determine the total output of an economy according to a nested constant elasticity of substitution (CES) production function. Energy demand in two categories (electricity and non-electric energy) is determined within the model, consistent with the development of energy prices and the energy intensity of GDP. When MACRO is linked to MESSAGE, internally consistent projections of realized GDP and energy demand are calculated in an iterative fashion that takes price-induced changes of demand and GDP into account.

A typical model application is constructed by specifying performance characteristics of a set of technologies and defining a Reference Energy System (RES) that includes all the possible energy chains that MESSAGE can make use of. In the course of a model run MESSAGE will then determine how much of the available technologies and resources are actually used to satisfy a particular end-use demand, subject to various constraints, while minimizing total discounted energy system costs. A simplified illustration of the MESSAGE Reference Energy System is shown in Figure 46. The gray box (Figure 46) shows where the carbon capture technologies (CCT) are linked into the Reference Energy System. In sum, MESSAGE distinguishes between three types of CCTs:

(1) carbon capture from conventional coal and natural gas-based power plants (flue-gasdecarbonization)

(2) carbon capture from coal-based integrated-gasification-combined-cycles (IGCC)

(3) carbon capture during the production of synthetic gaseous and liquid fuels (predominantly hydrogen and methanol) 


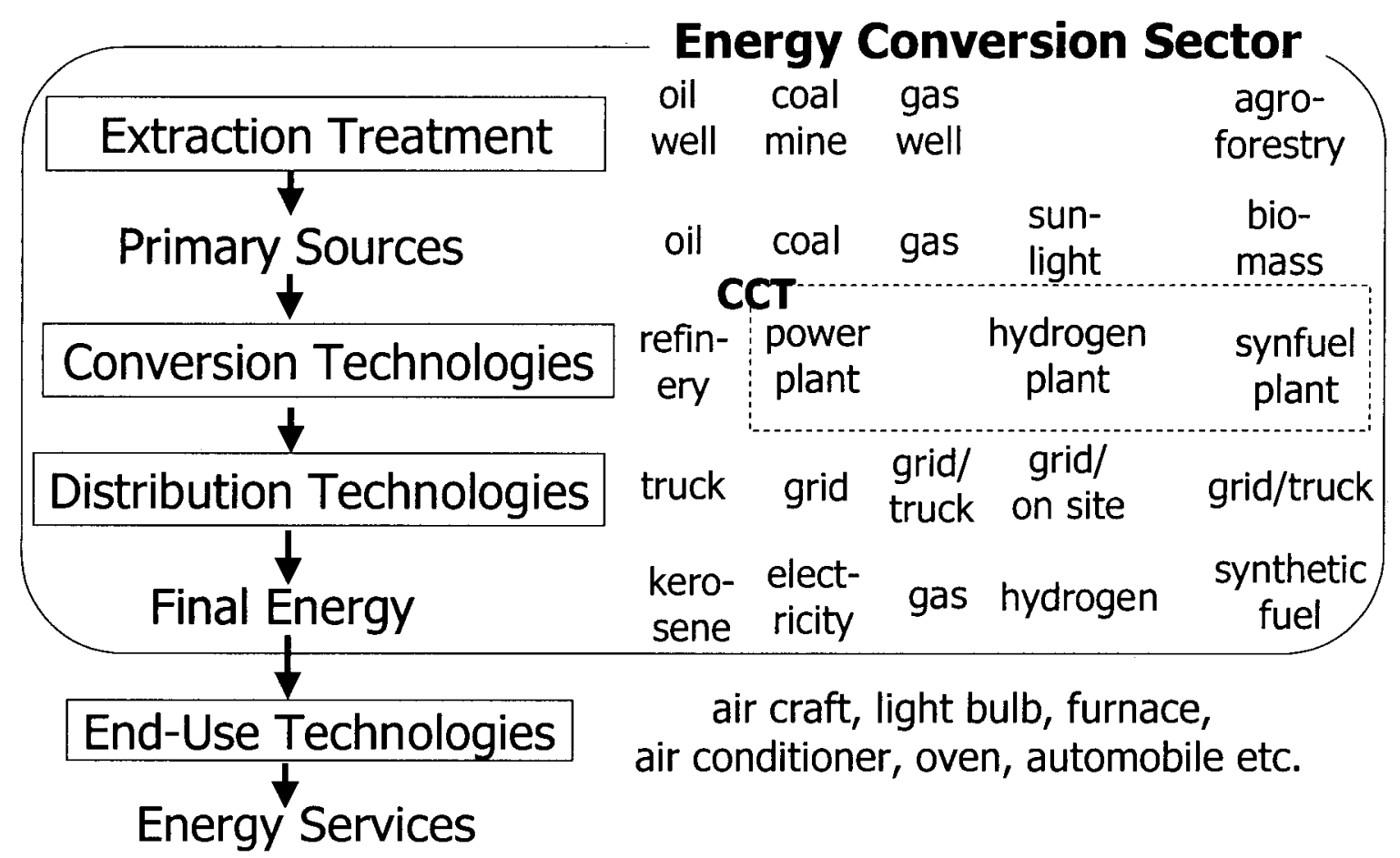

Figure 46: Schematic illustration of the Reference Energy System (RES) in MESSAGE.

Important inputs for MESSAGE are technology costs and other technology parameters, which are taken from the energy technology database $C O 2 D B^{17}(\mathrm{xx}, \mathrm{REF})$. For the scenarios included in this paper, technical, economic and environmental parameters for over 400 energy technologies are specified explicitly in the model. Costs of technologies are assumed to decrease over time as experience (measured as a function of cumulative output) is gained. As described earlier (Section 0 ), the relationship between costs and cumulative deployment of individual technologies is described by learning curves, characterized by a single learning rate and initial unit cost. However, assuming fixed learning rates ex ante is not possible within an LP formulation, because of the non-linearity of the relationship and the resulting non-convexity of the optimization problem, which would have to be tackled for example with Mixed Integer Programming (MIP). Illustrative MIP versions of MESSAGE to endogenize technological change through uncertain returns from learning have been developed (Messner 1997), but are computationally infeasible for the detailed scenarios described in this study (which include over 400 energy technologies and operate on 11 world regions).

Thus, an iterative, "ex post" approach was used to obtain scenario results with the full-scale MESSAGE model, where technological improvements follow patterns consistent with those of learning curves. For this purpose, we assume that specific costs of technologies decrease at predefined rates over time. Such a time profile of costs will at first not necessarily mimic the behavior as postulated by learning curves. Hence, we increase the consistency of MESSAGE results with the learning-curve concept by iteratively adjusting technology costs and cumulative installed capacities. This approach is made possible with additional dynamic market penetration

\footnotetext{
${ }^{17}$ CO2DB currently includes more than 1600 technologies and associated information on their recent, current, and projected costs, efficiencies, and environmental characteristics.
} 
constraints in order to avoid "flip-flop" behavior for the most important technologies, and to emulate the initial slow growth in niche markets of newly introduced technologies due to upfront investments. Figure 47 shows examples of resulting cost decrease curves versus cumulative installed capacities in a typical baseline scenario. Since investment costs are a power function of cumulative installed capacities, they appear as straight lines when plotted with doublelogarithmic axis. All in all, the results in Figure 47 show that the unit costs for the main technologies follow roughly a dynamics consistent with learning curves.

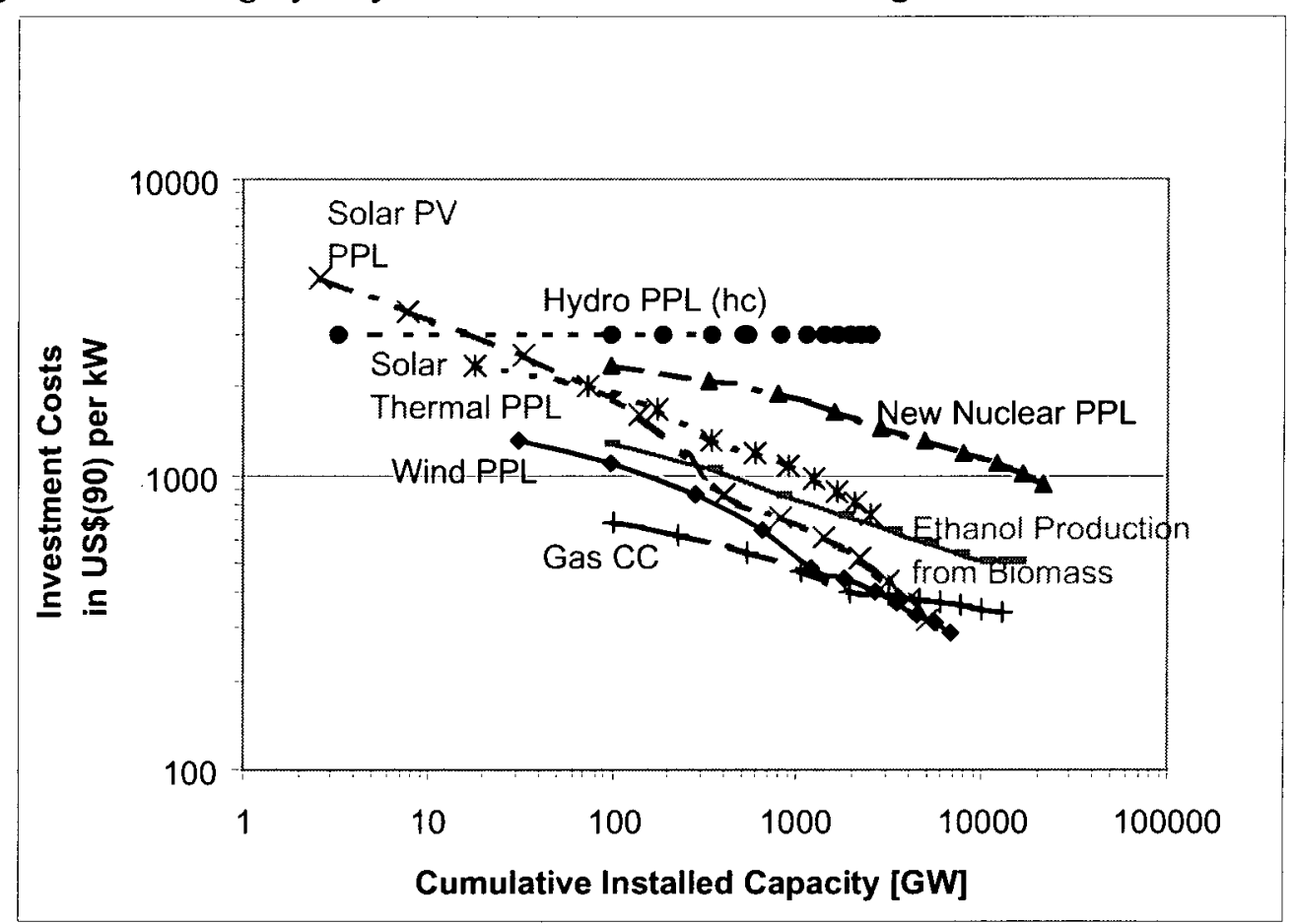

Figure 47: Examples of investment cost (1990-2100) as implemented in MESSAGE. Literal learning curve would appear as straight lines on this double-log scale. Abbreviations: PV: Photovoltaic, PPL: Power plant, Gas CC: Gas combined cycle power plant, New Nuclear PPL: Future design of a new nuclear reactor.

\section{Long-term Perspectives for Carbon Capture and Sequestration Technologies}

In order to estimate future potentials of CCT technologies, a set of global greenhouse gas emissions scenarios of economic, demographic, and energy demand development are analyzed. Frequently, scenario analyses are based on a static view of CCT technologies, where technology costs and performance are assumed to stay constant over time. Hence, important feedbacks on technology characteristics of e.g., gaining experience in CCT construction and accumulated knowledge due to targeted R\&D efforts, are often not taken into account. We will analyze the future prospects of CCT technologies using a more dynamic representation of technology, where costs improve as a function of cumulative experience (i.e., CCT deployment). Our assumptions on the learning potential for CCT are guided by the past experience of sulfur abatement technologies (see Section 0). In particular, we compare scenario results including learning for CCT technologies with scenarios based on static cost assumptions, and study the market potentials, costs and impacts of CCT as a long-term carbon abatement technology. 
For this purpose we selected two baseline scenarios of the IPCC Special Report of Emissions Scenarios (SRES, 2000) as our reference scenarios. For each we develop two carbon mitigation scenarios (one with and one without CCT learning) aiming at the stabilization of atmospheric carbon concentrations at about $550 \mathrm{ppmv}$. The sequel of this section first presents the main characteristics of the respective baseline and carbon mitigation scenarios, proceeding later to the implications for CCT.

\subsection{Baseline reference scenarios}

Baseline assumptions of technological and socio-economical development are paramount drivers of future GHG emissions, strongly influencing the choice of emissions mitigation strategies. As shown by the recent set of IPCC baseline scenarios (SRES, 2000), the uncertainty associated with the drivers as well as the future GHG emissions is vast. In order to obtain a plausible range of estimates for the deployment of CCT, we analyze two alternative baseline scenarios, depicting future worlds of increasing carbon emissions with presumably high impacts due to climate change.

Both baseline scenarios are selected from the set of 40 IPCC-SRES reference scenarios. The B2MESSAGE scenario was selected because it is a kind of "middle of the road" (dynamics-asusual) scenario. In addition, we selected the A2-MESSAGE scenario, since A2 portrays a fossilintensive future characterized by heavy reliance on coal-based energy production. A2 and B2 are based on different assumptions of socioeconomic development, technological progress, and political change. They result in widely differing world energy systems, which are cost-optimal strategies under the given assumptions, and lead to a wide range of emissions levels (Figure 48 ). Assumptions for the main scenario drivers and results are presented in Table 5.

Table 5: Overview of scenario drivers and results. Compare with 1990 values for population (5.3 billion), GDP (20.9 trillion (1990)US\$), primary energy (352 EJ), total $\mathrm{CO}_{2}$ emissions (6.2 GtC), $\mathrm{CO}_{2}$ concentration (354 ppmv).

\begin{tabular}{|c|c|c|c|c|c|c|c|}
\hline \multirow[b]{3}{*}{ Scenario } & \multirow{3}{*}{ Year } & \multirow{2}{*}{\multicolumn{2}{|c|}{ Baseline scenarios }} & \multicolumn{4}{|c|}{ Stabilization scenarios } \\
\hline & & & & \multicolumn{2}{|c|}{ Static CCTs } & \multicolumn{2}{|c|}{ Learning CCTs } \\
\hline & & $\mathrm{A} 2$ & $\mathrm{~B} 2$ & A2-550s & B2-550s & $A 2-550 t$ & B2-550t \\
\hline \multirow{2}{*}{ Population (billion) } & 2050 & 11.3 & 9.4 & 11.3 & 9.4 & 11.3 & 9.4 \\
\hline & 2100 & 15.1 & 10.4 & 15.1 & 10.4 & 15.1 & 10.4 \\
\hline \multirow{2}{*}{$\begin{array}{l}\text { Global gross domestic product } \\
\text { (trillion 1990US\$) }\end{array}$} & 2050 & 82 & 110 & 81 & 109 & 81 & 109 \\
\hline & 2100 & 243 & 235 & 236 & 231 & 237 & 231 \\
\hline \multirow{2}{*}{ Primary energy (EJ) } & 2050 & 1014 & 869 & 959 & 881 & 960 & 883 \\
\hline & 2100 & 1921 & 1357 & 1571 & 1227 & 1636 & 1257 \\
\hline $\begin{array}{l}\text { Cumulative carbon emissions } \\
\text { (GtC) }\end{array}$ & $\begin{array}{l}1990- \\
2100\end{array}$ & 1527 & 1212 & 992 & 948 & 990 & 950 \\
\hline $\begin{array}{l}\text { Cumulative carbon sequestration } \\
(\mathrm{GtC})\end{array}$ & $\begin{array}{l}1990- \\
2100\end{array}$ & - & - & 167 & 90 & 243 & 137 \\
\hline Carbon concentrations (ppmv) & 2100 & 783 & 603 & 550 & 550 & 550 & 550 \\
\hline
\end{tabular}




\section{The A2 baseline scenario (narrative)}

The A2 world represents a differentiated world, which "consolidates" into a series of economic regions. Economic growth is uneven across regions and the income gap between poor and rich regions does not narrow as much as in the other SRES scenarios. Global average per capita income in A2 is low relative to B2, and global gross domestic product (GDP) reaches about US $\$ 243$ trillion. International disparities in productivity, and hence income per capita, are largely maintained or increased in absolute terms. ${ }^{18}$ Fertility rates decline relatively slowly, which leads to a steadily increasing world population reaching 15 billion by 2100 .

A combination of slow technological progress, more limited environmental concerns, and low land availability because of high population growth means that the energy needs of the A2 world are satisfied primarily by fossil (mostly coal) and nuclear energy. However, in some cases regional energy shortages force investments into renewable alternatives, such as solar and biomass. Regions with abundant energy and mineral resources evolve to more resource-intensive economies, while those poor in resources place a very high priority on minimizing import dependence through technological innovation to improve resource efficiency and make use of substitute inputs. The fuel mix in different regions is determined primarily by the resource availability (limited to conventional reserves and resources). High-income but resource-poor regions shift toward advanced post-fossil technologies, while low-income resource-rich regions generally rely on traditional fossil technologies. The A2 world is characterized by relatively slow end-use and supply-side energy efficiency improvements and slow convergence between regions. All this leads to steadily increasing levels of GHG emissions (Figure 48), with $\mathrm{CO}_{2}$ emissions approaching $28 \mathrm{GtC}$ in 2100 .

\section{The B2 baseline scenario (narrative) ${ }^{19}$}

In the B2 world, GDP grows from US\$20 trillion in 1990 to US\$235 trillion in 2100 (Table 5). This corresponds to a long-term average growth rate of $2.2 \%$ from 1990 to 2100 . Most of this growth takes place in today's developing countries, but over the long term, economic growth rates in these regions also decline as labor productivity levels approach those of the leading countries. The B2 scenario uses the UN median 1998 population projection (UN, 1998), which describes a continuation of historical trends, including recent faster-than-expected fertility declines, toward a completion of the demographic transition within the next century. Global population increases to 10.4 billion by 2100 . Global primary-energy needs increase by almost a factor of four (in comparison to 1990) to $1360 \mathrm{EJ}$ in 2100 . Most of this increase takes place in today's developing regions. The aggregate global rate at which final-energy intensity declines is about one percent per year through 2100. Cost improvement rates for most technologies are moderate, however, they are largest for non-sulfur-emitting technologies due to local and regional pollution control. These include in particular wind and solar photovoltaics, but also gas combined-cycle, integrated gasification combined-cycle (IGCC), solar thermal power plants, and advanced nuclear power plants . Coal costs increase in regions with large shares of deep mined coal and high population densities, although coal costs are assumed to remain relatively low in regions with abundant surface coal reserves such as North America and Australia. Altogether,

\footnotetext{
${ }^{18}$ When not mentioned explicitly otherwise, gross world product (GWP), gross domestic product (GDP), and related parameters are reported at market exchange rates, in 1990 US\$.

${ }^{19}$ See Riahi and Roehrl (2000b) for more details.
} 
the B2 scenario exhibits linearly increasing global GHG emissions (Figure 48), with CO2 emissions reaching $14 \mathrm{GtC}$ by 2100 .

\subsection{Carbon mitigation scenarios}

In order to study future potentials for CCT technologies, we developed carbon mitigation scenarios aiming at the stabilization of atmospheric $\mathrm{CO}_{2}$ concentrations at about $550 \mathrm{ppmv}$. In sum, two stabilization scenarios for each baseline were developed - one assuming constant costs for CCTs (A2-550s, B2-550s), and one including learning for CCTs (A2-550t, B2-550t).

All four stabilization scenarios are based on iterated runs of MESSAGE and MACRO. The macroeconomic model MACRO is important in this connection because the carbon constraint increases energy prices, which reduces energy demand and increases the demand for the other production factors (capital and labor), other things being equal. MACRO calculates this macroeconomic effect. Because both MESSAGE and MACRO are global optimization models, the model results are cost-optimal actions to meet the given carbon constraint. The results assume full spatial and temporal flexibility, including the free movement of investments. However, cost-optimal $\mathrm{CO}_{2}$ emissions reduction possibilities do not necessarily occur in regions that give high priority to such reductions and that have the money to pay for them. Indeed, currently the cheapest $\mathrm{CO}_{2}$ reduction opportunities appear to be in developing countries, while it is the industrialized countries that currently appear most willing to pay for them. The stabilization scenarios can thus be seen as possible answers to the question, "Which are the best strategies to achieve stabilization if the world generally consistent with the (respective) baseline was able to successfully coordinate and cooperate on efforts to limit potential global warming?"

The resulting $\mathrm{CO}_{2}$ emissions trajectories of the mitigation scenarios are shown in Figure 48. They are characterized by a peak of about 9 to $12 \mathrm{GtC}$ around the middle of the $21^{\text {st }}$ century. Subsequently, emissions decline to slightly less than the 1990 emissions level (6 GtC) by 2100 . These emissions profiles are similar to other emissions trajectories for 550 ppmv stabilization cases found in the literature (Wigley et al., 1996; Roehrl and Riahi, 2000). The similarity of the emissions pathways indicates limited flexibility of the timing and pace of emissions trajectories, to achieve $\mathrm{CO}_{2}$ concentration stabilization at $550 \mathrm{ppmv}$ with the least effort. Furthermore, the development of emissions is quite similar through 2020 in the stabilization runs and their baseline counterparts. Only after 2020 do emissions reductions become more pronounced. This is partly because power plants have lifetimes on the order of 30-40 years, which makes for slow turnover in the energy capital stock, and partly because of the temporal flexibility built into the concentration constraint. MESSAGE is free to choose when and where to reduce carbon emissions, and later reductions coinciding with turnover in capital plant are usually cheaper, because of both technological progress and discounting ${ }^{20}$.

\footnotetext{
${ }^{20}$ For the scenarios presented in this paper, a discount rate of $5 \%$ was applied.
} 


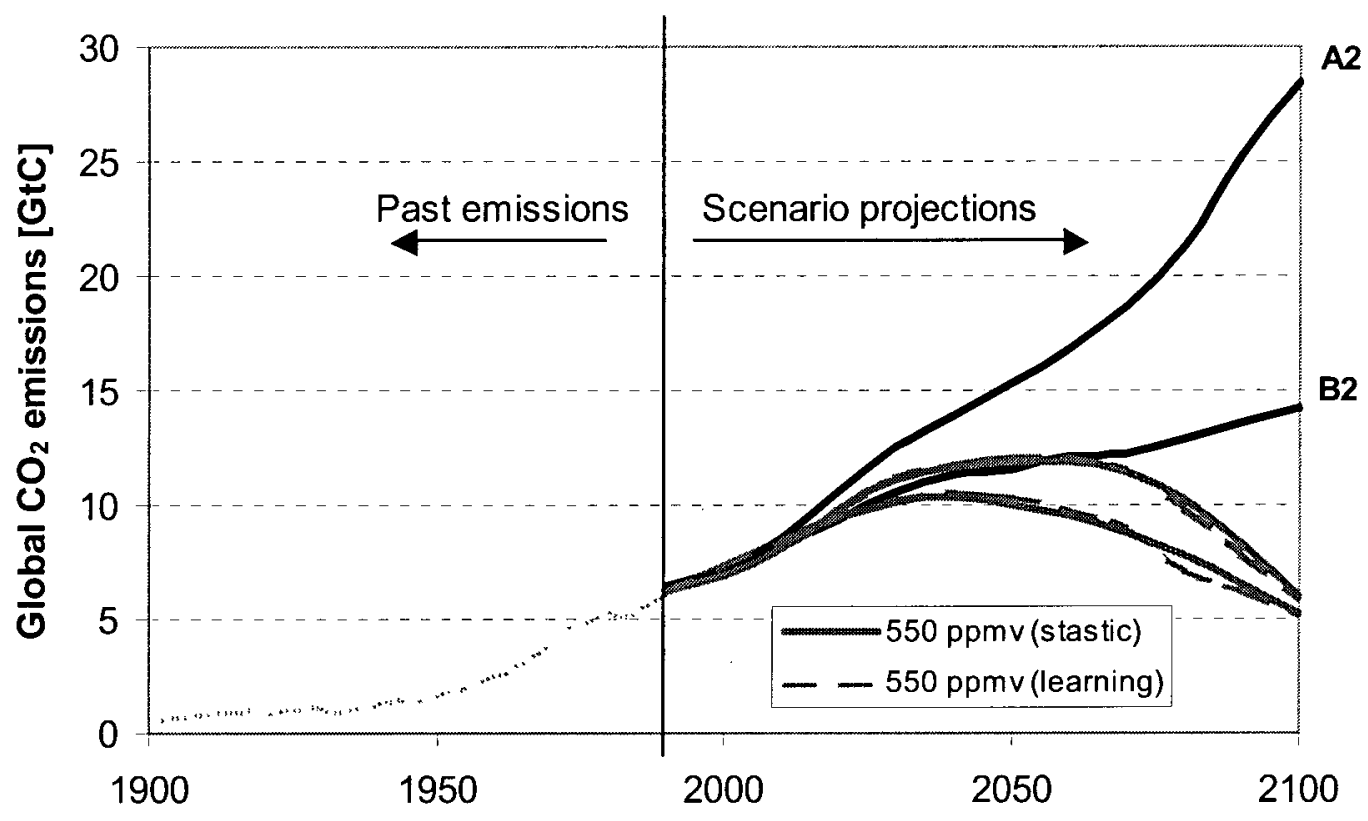

Figure 48: Global carbon dioxide emissions in the $\mathrm{A} 2$ and $\mathrm{B} 2$ baseline scenarios, and in the respective stabilization scenarios with and without learning for CCT.

Although the resulting emissions trajectories of the four stabilization scenarios are similar, the contributions of individual mitigation measures to bring down emissions differ significantly. In particular, the choice of the mitigation strategy, and the widespread deployment of specific mitigation options depend strongly on two factors:

(1) the socio-economic and technological assumptions in the baseline scenarios; and

(2) the assumptions with respect to technological learning for CCT technologies

We shall now discuss specific contributions of main mitigation options.

\subsection{Three kinds of mitigation measures}

In general, strategies to mitigate $\mathrm{CO}_{2}$ emissions may be based on technological change, economic incentives, and institutional frameworks. They range from using the carbon sequestering potential of afforestation to demand-side or supply-side-oriented measures in the energy sector, and even so-called geo- and cosmo-engineering schemes (Nakićenović et al., 1993). Here we confine our discussion to $\mathrm{CO}_{2}$ abatement measures in the energy sector.

Applying the carbon concentration constraint to the baseline scenarios results in significant changes of energy demand and technology mix. Compared to the respective baseline scenarios, three principal contributors were identified by MESSAGE and MACRO as the most costeffective route to meet the required stabilization target:

- Fuel switching away from carbon-intensive fuels such as coal. 
- Scrubbing and removing $\mathrm{CO}_{2}$ in power plants and during the production of synthetic fuels, mainly methanol and hydrogen.

- Lower energy demand (enhanced energy conservation) of the stabilization case compared to the baseline counterpart, due to higher energy costs in the stabilization cases compared to their baseline scenario counterparts.

The carbon reductions of specific mitigation measures in the stabilization scenarios are summarized in Table 6. In all stabilization scenarios the comparatively largest contribution comes from structural changes in the energy system. Principally, this is a shift away from coal, which has the highest $\mathrm{CO}_{2}$ emissions per unit of energy. To satisfy the carbon constraint, all mitigation scenarios make pronounced shifts to less carbon-intensive primary-energy resources, and coal's share of primary energy decreases considerably.

The second most important contribution is due to carbon capture and sequestration, where the emissions reductions are particularly high in the case of learning CCT technologies. Cost improvements in the case of technological learning for CCT result in additional markets for carbon capture and enable comparatively higher shares of fossil energy production, compared to the cases with static CCT costs. The contribution of main carbon capture technologies relative to other mitigation measures is shown in Figure 49 for the A2-550t, and in Figure 50 for B2-550t, respectively.

As regards the timing of the mitigation measures, the first half of the century is dominated by structural shifts in the energy system, which is mainly due to the widespread diffusion of gascombined-cycle power plants (GCC) at the expense of coal technologies. GCC's comparatively low carbon intensity and electricity generation costs makes GCC to a "transitional" technology, accomplishing a smooth and cost-effective transition to more pronounced changes in the energy structure in the latter half of the century. Generally, the pressure on the energy system to reduce emissions increases with time, since the reduction requirements in absolute quantities increases (Table 6). Eventually, this leads to the large-scale introduction of more costly abatement options, such as renewable energy and carbon capture from fossil fuels (Figure 49, Figure 50).

As illustrated by the results, each of the three main mitigation measures is important, and none of the suggested mitigation options alone is sufficient to meet a 550 ppmv stabilization target. Hence, we conclude that effective mitigation strategies have to take into account the whole portfolio of technological possibilities, which includes also carbon capture with subsequent sequestration.

Table 6: Emissions reductions (in GtC) of the main mitigation measures in the stabilization scenarios for the years 2050 and 2100.

\begin{tabular}{lcccccccc} 
& \multicolumn{2}{c}{ Demand reduction } & \multicolumn{2}{c}{ Fuel switching } & $\mathrm{CO}_{2}$ capture and sequestration & \multicolumn{2}{c}{ Total } \\
\cline { 2 - 10 } & 2050 & 2100 & 2050 & 2100 & 2050 & 2100 & 2050 & 2100 \\
\hline Static CCTs & & & & & & & & \\
A2-550s & 0.3 & 3.6 & 2.2 & 12.5 & 0.5 & 5.8 & 3.0 & 21.9 \\
B2-550s & 0.3 & 1.3 & 1.4 & 3.9 & 0.3 & 3.0 & 2.0 & 8.2 \\
\hline Learning CCTs & & & & & & & & \\
A2-550t & 0.3 & 3.7 & 2.1 & 9.5 & 0.4 & 8.9 & 2.9 & 22.0 \\
B2-550t & 0.3 & 1.5 & 1.1 & 4.0 & 0.3 & 4.0 & 1.7 & 9.5 \\
\hline
\end{tabular}




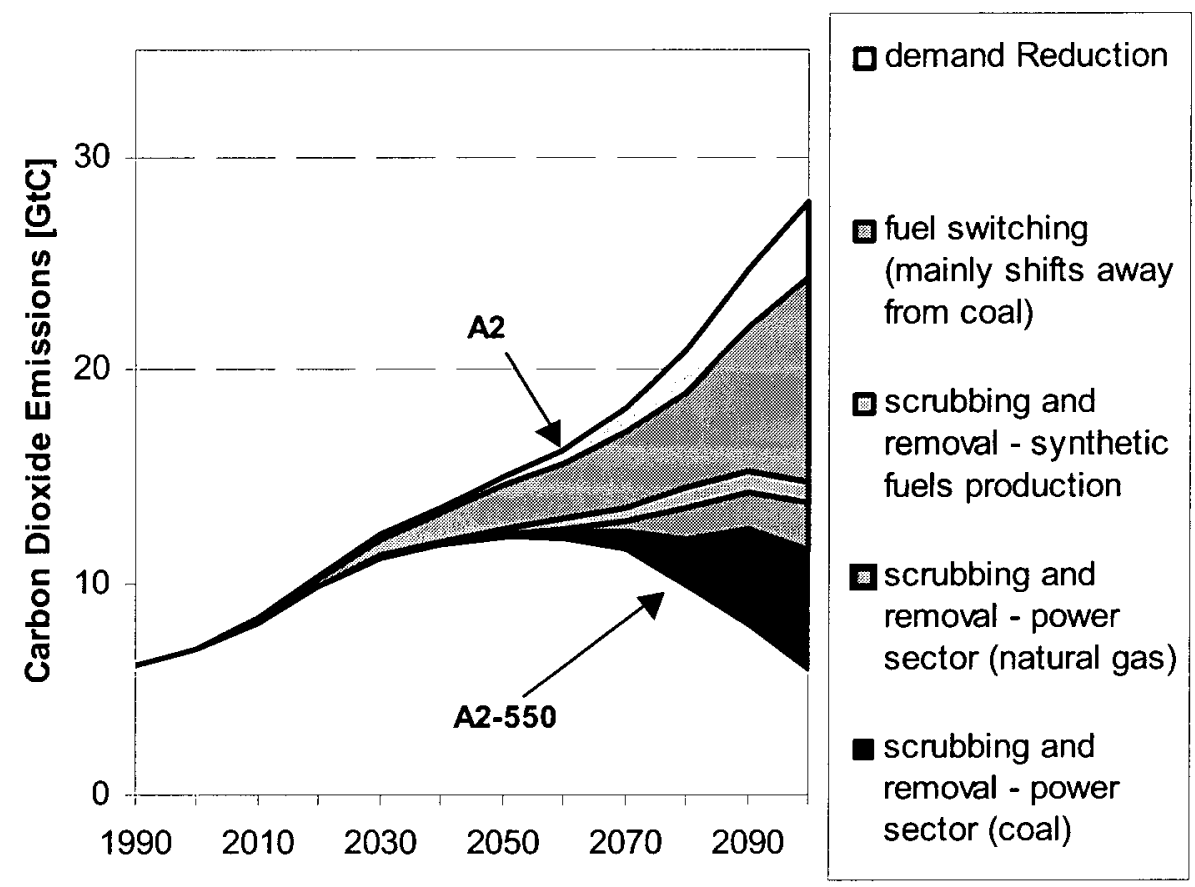

Figure 49: $\mathrm{CO}_{2}$ emissions in the $\mathrm{A2}$ baseline scenario and in the $\mathrm{CO}_{2}$ mitigation scenario in the case of learning CCTs (A2-550t). The shaded areas depict sources of $\mathrm{CO}_{2}$ reductions in the global energy system of the mitigation scenario, compared to the baseline scenario.

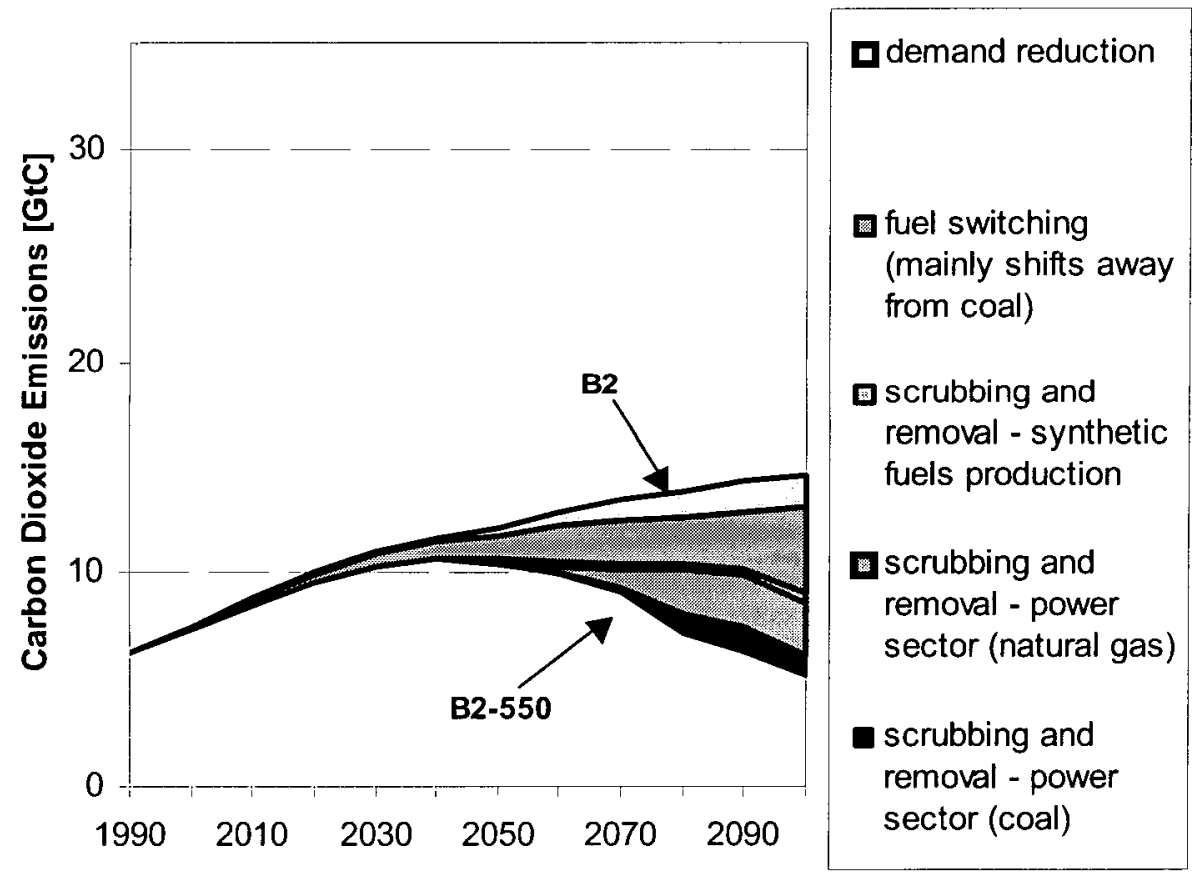

Figure 50: $\mathrm{CO}_{2}$ emissions in the $\mathrm{B} 2$ baseline scenario and in the $\mathrm{CO}_{2}$ mitigation scenario in the case of learning CCTs (B2-550t). The shaded areas depict sources of $\mathrm{CO}_{2}$ reductions in the global energy system of the mitigation scenario, compared to the baseline scenario. 


\subsection{Potentials for carbon scrubbing and removal}

The previous section analyzed the important role of carbon capture technologies as compared to other principal mitigation measures. In this section we will focus on CCTs only. In particular, we will review estimates of global storage possibilities for the disposal of $\mathrm{CO}_{2}$ and compare them with the carbon sequestration figures in the scenarios. In addition, we present the underlying assumptions for costs and performance of CCTs in the scenarios; and analyze their dynamics of market penetration. Finally, we conclude on potentials and macroeconomic costs of carbon capture assuming technological learning for CCT versus no learning (static costs).

\section{Global carbon storage capacities}

Generally, $\mathrm{CO}_{2}$ removal by scrubbing and $\mathrm{CO}_{2}$ recovery from flue gases is referred to as "addon " environmental strategies. After its recovery from the energy system, $\mathrm{CO}_{2}$ has to be disposed of, stored or otherwise used. One example of putting it to productive use is enhanced oil recovery, where $\mathrm{CO}_{2}$ is injected in oil fields (originally to improve the oil recovery rate). $\mathrm{CO}_{2}$ may also be stored in depleted natural gas and other underground reservoirs, eventually also in the deep ocean (Marchetti, 1989).

Original natural-gas production sites alone correspond to a potential storage capacity of about $150 \mathrm{GtC}$. After the extraction of higher-cost gas categories, this storage capacity may be larger than at least $250 \mathrm{GtC}$. The Second Assessment Report of the IPCC estimated the potential storage capacity of depleted oil and gas fields alone to be as high as $500 \mathrm{GtC}$ (IPCC, 1996). If structural traps are needed for secure storage, deep subterranean sandstone aquifers have a longterm $\mathrm{CO}_{2}$ storage capacity of at least $60 \mathrm{GtC}$ (Hendricks, 1994). Without structural traps, the estimated worldwide sequestering capacity of aquifers is about $15,000 \mathrm{GtC} . \mathrm{CO}_{2}$ is also stored in chemical feedstocks and basic materials, e.g., $\mathrm{CO}_{2}$ is used in the synthesis of urea $(>10 \mathrm{MtC}$ p.a.). A promising method of storing carbon is part of the hydrocarb process (Yamada et al., 1992), originally developed by M. Steinberg to produce methanol and carbon from biomass and fossil fuels with subsequent storage of (very large volumes of) carbon in elemental form. A recent method developed by Steinberg is the Carnol system, which consists of methanol production by $\mathrm{CO}_{2}$ recovered from coal-fired power plants and natural gas and the use of methanol as an alternative automotive fuel (Steinberg, 1996) ${ }^{21}$. By far the largest reservoir for carbon disposal in form of solid $\mathrm{CO}_{2}$ ice is the deep ocean, which currently stores about 36,000 $\mathrm{GtC}$. Orders of magnitude estimates for the various global sequestration options are presented in Table 7.

\footnotetext{
${ }^{21}$ Carnol System CO2 Reduction: When methanol is used in automotive internal combustion engines, a $\mathrm{CO} 2$ reduction by $56 \%$ compared to conventional system of coal plants and gasoline engines is achieved, and a $\mathrm{CO} 2$ reduction by as much as $77 \%$ when methanol is used in fuel cells in automotive engines (M. Steinberg, 1996).
} 
Table 7: Global carbon sequestration capacitiès (GtC)

\begin{tabular}{ll}
\hline Storage option & Capacity $(\mathrm{GtC})$ \\
\hline Depleted oil and gas reservoirs & $100 \mathrm{~s}$ \\
Deep saline quifiers & $100 \mathrm{~s}-1000 \mathrm{~s}$ \\
Coal seams & $10 \mathrm{~s}-100 \mathrm{~s}$ \\
Ocean & $1000 \mathrm{~s}$ \\
\hline
\end{tabular}

Data source: Herzog, 2001

In none of the stabilization scenarios, the cumulative carbon sequestration from 1990 to 2100 exceeds $300 \mathrm{GtC}$ (see Table 7). This means that the amount of carbon emissions that has been captured in the scenarios is well below the maximum potential of storage capacity of depleted oil and gas fields alone. Even though it seems that global storage possibilities are abundant compared to the sequestration requirements of the scenarios, it still has to be proved, whether all reservoirs proposed for carbon sequestration are effective, safe and environmentally sound. Given the widespread deployment of CCT technologies in the scenarios, a better scientific understanding of the long-term fate of $\mathrm{CO}_{2}$ in storage reservoirs appears to be called for.

\section{Costs of carbon capture and sequestration}

There are many viable and promising methods for $\mathrm{CO}_{2}$ seperation and capture from power plants. The most likely options currently identified are (DOE, 1999):

- Chemical and physical absorption

- Chemical and physical adsorption

- Low temperature destillation

- Gas seperation membranes

- Minearalization and biomineralization

The capturing of $\mathrm{CO}_{2}$ accounts for about three-fourths of the total cost of a carbon capture, storage, transport, and sequestration system. The cost assumptions in the sceanrios are based upon estimates from, assuming that $\mathrm{CO}_{2}$ is captured from flue gases by chemical absorption. For transportation and disposal we assumed that captured $\mathrm{CO}_{2}$ is transported in liquid state, through $250 \mathrm{~km}$ of pipeline and disposed of in geological formations. The cost for $\mathrm{CO}_{2}$ transportation is based on estimates from the IEA (1999), assuming originally a distance of $500 \mathrm{~km}$ at $45 \$ / \mathrm{tC}$. Here, half the distance and an economy of scale factor of $2 / 3$, which results in $28 \$ / \mathrm{tC}$ of transport plus disposal cost is assumed. Technology costs and performance assumptions for coaland natural-gas-based reference plants and the respective carbon capture plants are summarized in Table 8. Generally, the capturing of $\mathrm{CO}_{2}$ is associated with efficiency losses of the power generation process, and additional costs for the carbon capture facilities. As shown in Table 8, the carbon abatement costs for coal technologies resulting from our assumptions are $196 \mathrm{US} \$ / \mathrm{tC}$, compared to $137 \mathrm{US} \$ / \mathrm{tC}$ for natural-gas (both figures including transportation and disposal). ${ }^{22}$

\footnotetext{
${ }^{22}$ Costs of carbon removal in synthetic fuels production (and from IGCC) were assumed to be $46 \mathrm{US} \$ / \mathrm{tC}$ (inclusive transportation and disposal).
} 
Table 8: Total carbon reduction costs, illustrated on the basis of two reference plants: (1) standard coal power plant, (2) natural gas combined cycle power plant.

\begin{tabular}{|c|c|c|c|c|c|}
\hline & \multirow[b]{2}{*}{ Unit } & \multicolumn{2}{|l|}{ Coal } & \multicolumn{2}{|l|}{ Natural gas } \\
\hline & & $\begin{array}{l}\text { Reference technology: } \\
\text { standard coal power plant }\end{array}$ & ind. CCT & $\begin{array}{c}\text { Reference technology: } \\
\text { NGCC }\end{array}$ & incl. CCT \\
\hline Investment costs & $\$ / \mathrm{kW}$ & 1000 & 1749 & 730 & 1089 \\
\hline Fixed O\&M costs & $\$ / \mathrm{kW}$ & 27 & 20.7 & 52 & 78.1 \\
\hline Variable O\&M costs & $\$ / k W y r$ & n.a. & 188.7 & n.a. & n.a. \\
\hline Efficiency & $\%$ & 40 & 30.4 & 50 & 42.5 \\
\hline Plant life & years & 30 & 30 & 30 & 30 \\
\hline Plant factor & $\%$ & 65 & 65 & 65 & 65 \\
\hline Fuel cost & $\$ / G J$ & 1.75 & 1.75 & 3.53 & 3.53 \\
\hline levelized investment costs & $\mathrm{mills} / \mathrm{kWh}$ & 11.8 & 20.6 & 8.6 & 12.9 \\
\hline levelized O\&M costs & $\mathrm{mills} / \mathrm{kWh}$ & 4.8 & 30.4 & 9.2 & 13.8 \\
\hline levelized fuel costs & mills/kWh & 15.7 & 20.7 & 25.4 & 29.9 \\
\hline Electricity generation costs & mills/kWh & 32.3 & 71.8 & 43.2 & 56.5 \\
\hline Carbon emissions & $\mathrm{gC} / \mathrm{kWh}$ & 232 & 30 & 110 & 13 \\
\hline Total carbon reduction costs & $\$ / t C$ & - & 196 & - & 137 \\
\hline
\end{tabular}

In the stabilization scenarios with static costs (A2-550s, B2-550s), we assumed that the capital costs for CCTs remain constant over time, at the values shown in Table 8 . In contrast, in the case of learning CCTs (A2-550t, B2-550t), we assumed that their costs decrease with accumulated experience in CCT construction. As described in Section 0, the investment cost declines by $13 \%$ for each doubling of CCT capacity. The development of carbon reduction costs as a function of cumulative installed CCT capacities in the scenarios is illustrated in Figure $\mathbf{5 1 .}$

Due to technological learning, CCT costs drop rapidly in the stabilization scenarios, leading to cost reductions by a factor of four until the end of the century. In line with the development of costs, CCT technologies diffuse pervasively into the energy markets, accomplishing the continuous use of fossil fuels at relatively modest costs and low carbon emissions. Total reduction costs for natural gas technologies drop to 34-38 US\$/tC, and those of coal technologies to 41-61 US\$/tC (Figure 51).

The development of the carbon reduction costs for CCTs depend also on the regional resource availability and the development of fuel costs. In addition, assumptions on technological change for the power plants themselves influence the carbon reduction costs of CCTs. A sensitivity analysis using different initial costs for CCTs suggests that the learning rate might be the most decisive factor, not only for the costs, but also for the successful diffusion and dissemination of CCTs (given a specific carbon constraint). 


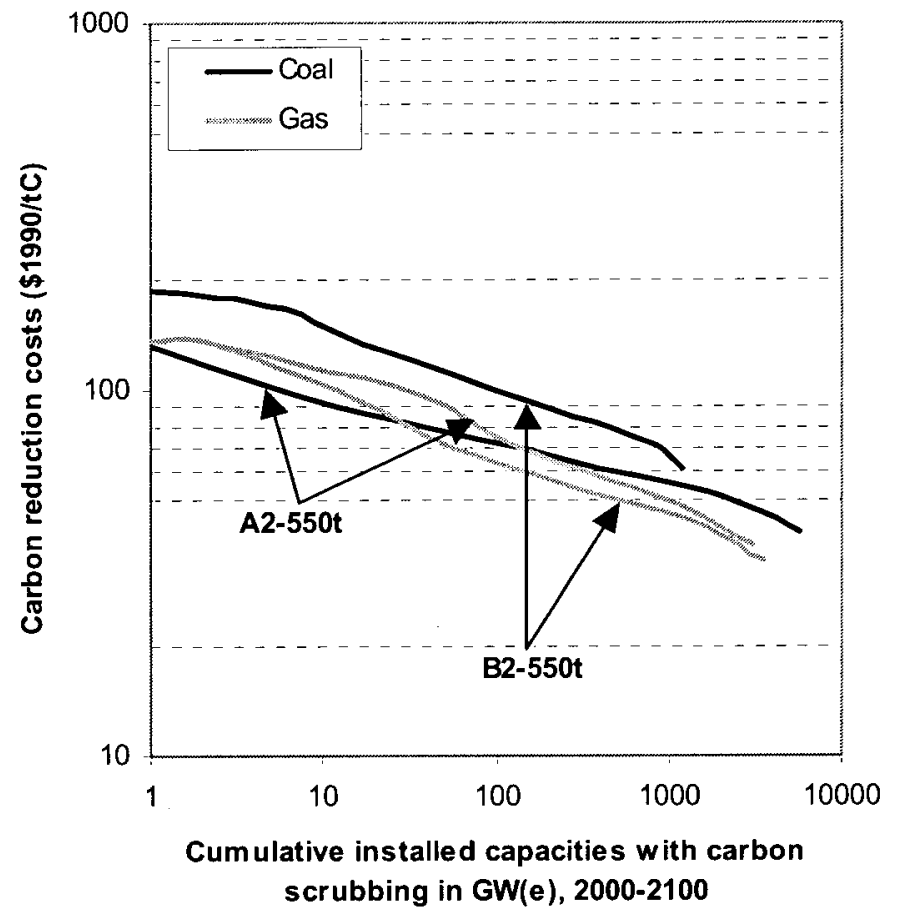

Figure 51: Technological learning of carbon capture technologies in the A2-550t and B2-550t scenarios, illustrated as decreasing specific carbon reduction costs over accumulated experience (cumulative installed power generation capacities).

\section{CCT market shares in the electricity sector}

The scenario's market shares of CCT technologies are the result of complex interactions between demand-pull to supply-push activities. On the demand side, the carbon concentration limit enforces the introduction of new and advanced technologies with low carbon intensities. On the supply side, increasing returns from induced technological learning of CCTs, pushes their market penetration from the supply side. Together, this results in very successful penetration of CCT technologies in the scenarios with technological learning, compared to scenarios with static cost assumptions.

Figure 52 depicts the diffusion of carbon capture technologies (added on natural gas and coal technologies) into the electricity generation market in the case of technological learning for CCTs. The graph shows the increasing shares of $\mathrm{CO}_{2}$ capture plants, depicting examples of very successful market introduction. Initially, CCTs are expensive and limited in their application. They have to first prove themselves during the demonstration phase where performance rather than costs is the overriding criterion. Then subsequent improvements and cost reductions lead to a wider application. Finally, growth rates slow down as markets become saturated. The diffusion of CCTs proceeds along a typical S-shaped pattern: slow at the beginning, followed by accelerating growth that ultimately slows down as markets become saturated. The literature on Sshaped diffusion is large, and there have been many studies, which have applied these curves to the spread of e.g., transportation infrastructures and other types of technologies (Marchetti 1983; Haegerstrand 1967; Fisher and Pry 1997; Nakićenović 1986; Gruebler 1998). 
Comparing the diffusion of CCTs in scenarios with learning (A2-550t, B2-550t) with those assuming constant costs of these technologies (A2-550s, B2-550s) shows that the market penetration of CCTs is accelerated due to technological learning. Particularly, the carbon capture from coal technologies benefits considerably from the learning effect, leading to global market shares of more than 90 percent in 2100 (compared to 60-70 percent in the case of static costs). At the end of the century, almost all fossil power plants are equipped with carbon capture technologies in the case of learning (Figure 52).

The resulting $\mathrm{CO}_{2}$ emissions from coal and natural gas-based power generation are also shown in Figure 52. The $\mathrm{CO}_{2}$ emissions path in the scenarios follows an inverse $\mathrm{U}$-shaped pattern similar to environmental Kuznets curves, observed for other pollutant emissions in the past, such as sulfur (Gruebler, 1999, xx check!). After initial growth, $\mathrm{CO}_{2}$ emissions peak around the middle of the century and decline later, when the carbon capture and sequestration technologies gain considerable market shares. Most notably, until the end of the century, global $\mathrm{CO}_{2}$ emissions from coal and gas power generation decreases by more than a factor of three, while power generation from these technologies grow three to five times their present production.

Another characteristic of the scenarios is the comparatively late diffusion of CCTs. It requires decades for them to diffuse widely. In all four stabilization scenarios, first large-scale applications emerge as late as in the 2030s. However, once introduced, they are continuously gaining market shares. The entire diffusion of CCTs, from the initial introduction to the saturation, spans, in all scenarios, about 50 years, which is similar to diffusion speeds of other types of technologies found in the literature (see e.g., Gruebler and Nakićenović, 1991). Most importantly, our results should not be interpreted as a pretext to wait decades and then start the installation of CCTs. In fact, to make the technology diffusion (as shown by the stabilization scenarios) operational requires early action, including the creation of niche markets, the development of small-scale demonstration plants, and targeted R\&D. 


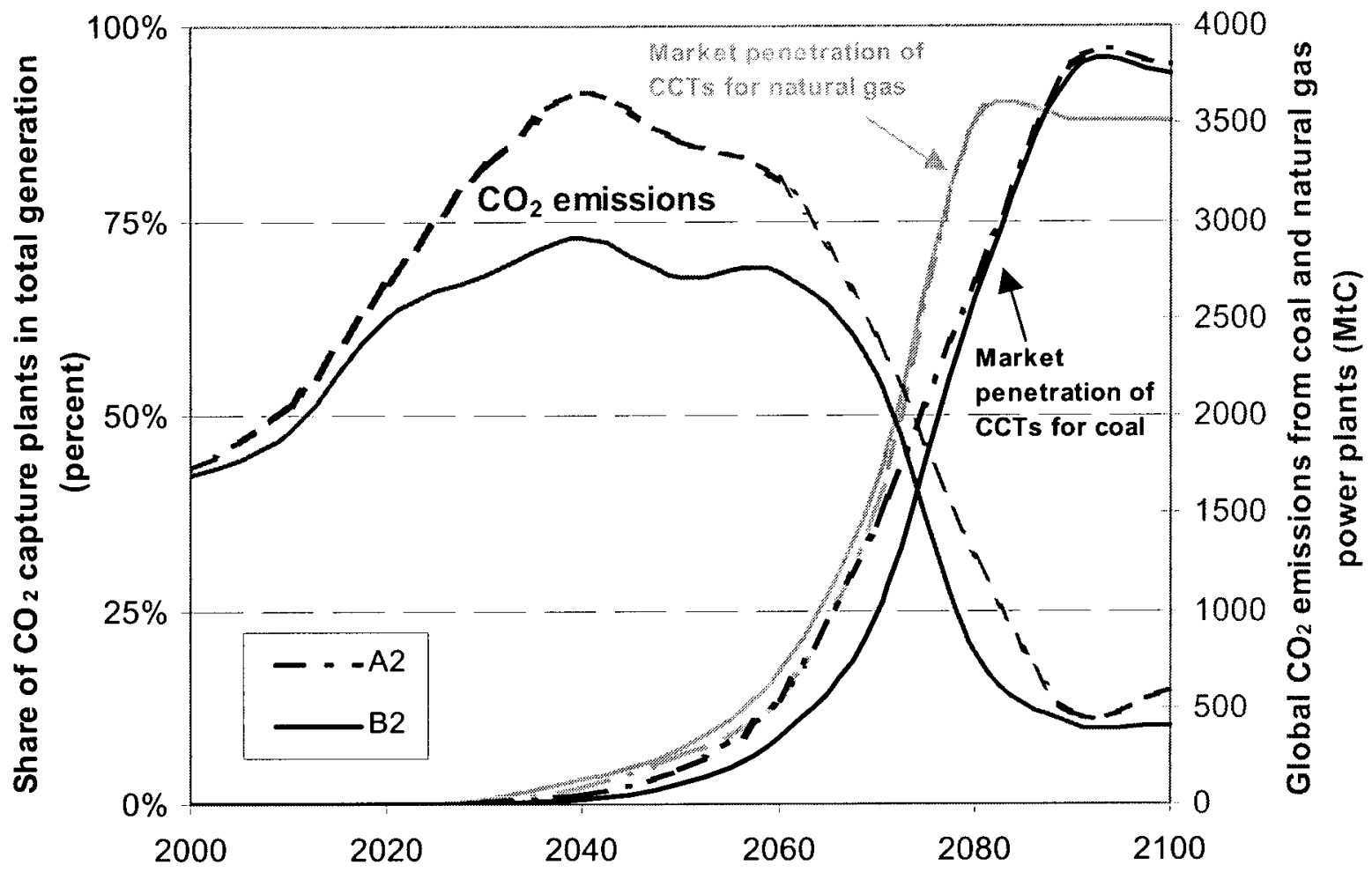

Figure 52: Market penetration of "learning" CCT technologies for natural-gas and coal power plants in the A2-550t and B2-550t scenarios (left-hand axis). Dashed lines depict the development in the A2-550t scenario, and uninterrupted lines in B2-550t. Also shown are the aggregated $\mathrm{CO}_{2}$ emissions from coal and natural-gas power generation in the respective scenarios (right-hand axis).

\section{Cumulative carbon sequestration}

The cumulative carbon sequestration in the scenarios - from 1990 to the years 2020,2050 and 2100 respectively - are shown in Figure 53. Generally, the amounts scrubbed depend strongly on (1) the socio-economic and technological assumptions in the baseline scenarios; and (2) the assumptions with respect to technological learning for CCT technologies. As illustrated in Figure 53, cumulative carbon sequestration is higher in the case of the A2 scenarios compared to $\mathrm{B} 2$, and higher in scenarios with learning CCTs than in those with static cost assumptions.

Since the A2 baseline depicts a future of heavy reliance on coal technologies, cumulative carbon sequestration is particularly high in A2, calling for environmentally compatible solutions that permit the continuous use of coal at low carbon emissions. In contrast, fossil-based power generation plays a less prominent role in the B2 baseline scenario, and is mainly dominated by advanced natural gas technologies, in particular gas-combined-cycle. Hence, in A2 coal scrubbers dominate, while in B2 natural-gas scrubbers account for the bulk of the reductions (Figure 53).

The relatively fast and more complete market diffusion of CCTs in the case of learning results also in considerably higher cumulative carbon sequestration (when compared to the scenarios with static CCT costs). In the case of learning CCT's cumulative carbon emissions from 1990 to 
2100 range between 137 and $243 \mathrm{GtC}$. This corresponds to a 50 percent increase of sequestration due to learning effect for CCTs, compared to the scenarios with static costs (90 to $167 \mathrm{GtC}$ ).

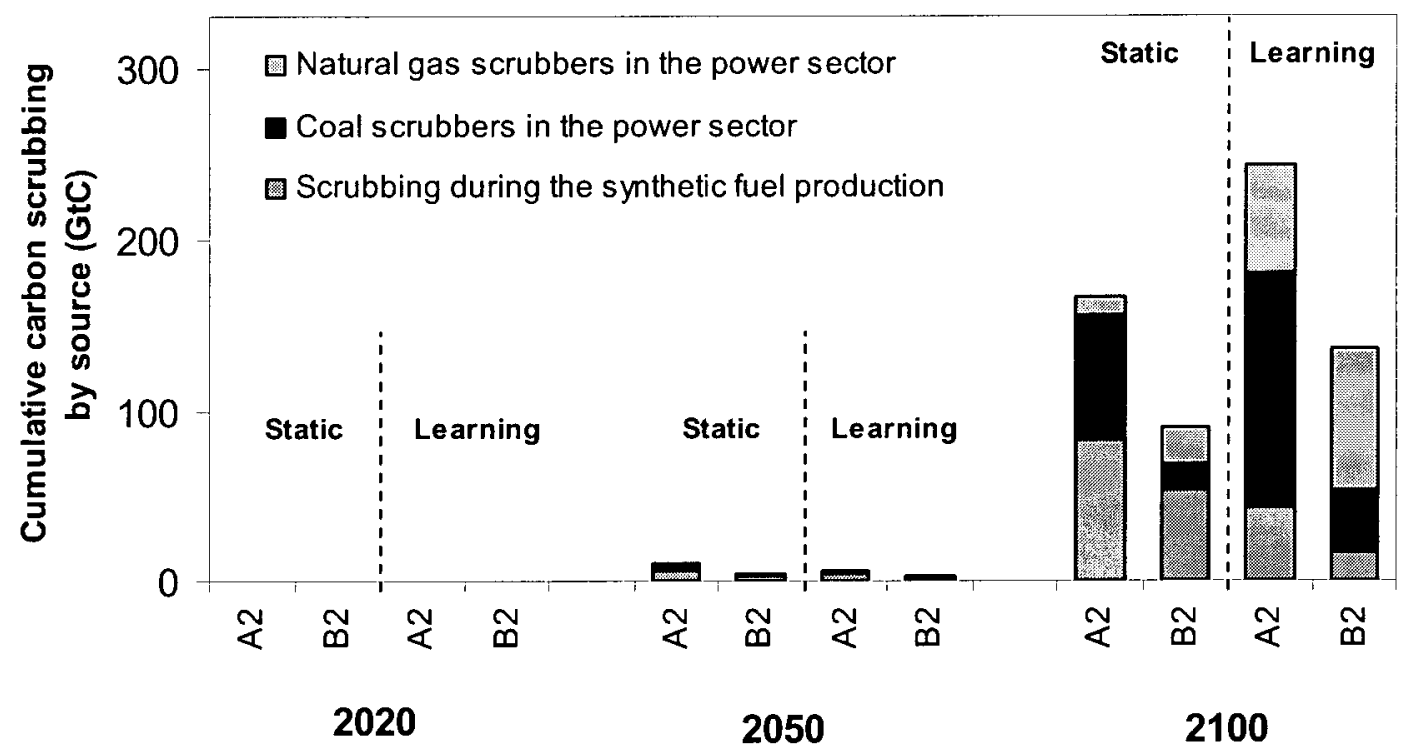

Figure 53: Cumulative carbon capture and sequestration by source. Learning for CCT leads to comparatively high deployment of carbon capture technologies, in particular, in the electricity sector.

\section{Impact on the electricity price}

The development of the electricity prices in the baseline and the stabilization scenarios is shown in Figure 54. As for total energy demand (see Section 0), electricity consumption is reduced in the stabilization cases compared to their respective baselines. This is due to the assumed price elasticity of electricity demand, which leads to demand reductions in response to higher prices in all mitigation cases, compared to the baseline scenarios. Due to the lower costs for CCT, the price increase is less pronounced in stabilization scenarios with learning CCTs than in the cases with static CCT costs. 


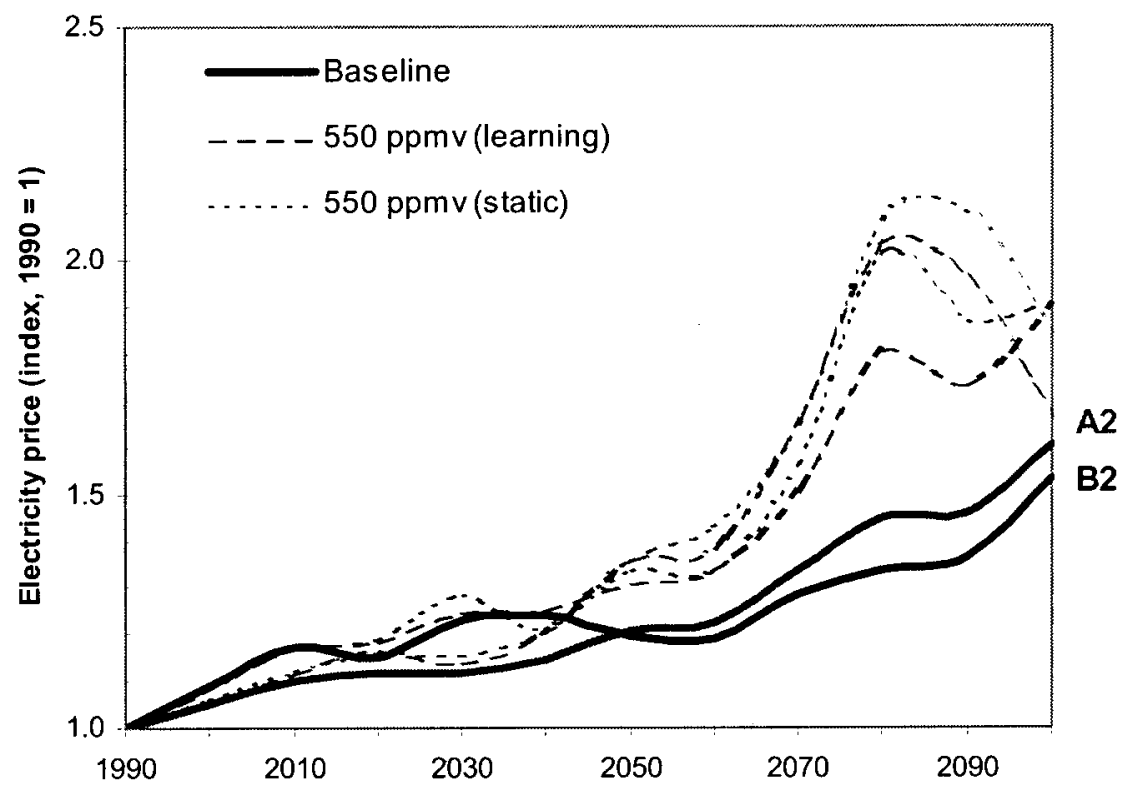

Figure 54: Development of electricity price in the scenarios.

\section{Carbon values and macroeconomic costs of the emissions reduction}

Table 9 shows the resulting carbon values in the mitigation scenarios. The carbon value is an endogenous output calculated by the MESSAGE model. It can be interpreted as the average carbon tax that has to be introduced in a carbon-constrained world, in order to meet the stabilization target. Due to the steadily increasing emissions in the baselines, the pressure on the global energy system to reduce emissions increases over time, particularly in the latter half of the century. In the stabilization scenarios, carbon values grow steadily from about $20 \mathrm{US} \$ / \mathrm{tC}$ in 2020 to about 400-500 US\$/tC in 2100. Due to the increasing cost-effectiveness of CCTs in the case of learning, the required carbon value (tax) is lower in stabilization scenarios with dynamic CCT costs, compared to those based on static costs. This result suggests that assumptions on technological change might be the overriding criterion for the cost-effectiveness of long-term carbon abatement policies in general. (see also Roehrl and Riahi, 2000).

Table 9: Carbon values in four stabilization scenarios. The carbon values are an endogenous result of the model calculations and can be interpreted as the carbon tax that is required to meet the $550 \mathrm{ppmv}$ stabilization target.

\begin{tabular}{cccc}
\hline & \multicolumn{3}{c}{ Carbon tax (1990US\$/tC) } \\
\cline { 2 - 4 } & $\mathbf{2 0 2 0}$ & $\mathbf{2 0 5 0}$ & $\mathbf{2 1 0 0}$ \\
\hline Static CCT costs & & & \\
A2-550s & 25 & 82 & 496 \\
B2-550s & 23 & 59 & 447 \\
\hline Learning CCTs & & & \\
A2-550t & 19 & 27 & 490 \\
B2-550t & 18 & 64 & 406 \\
\hline
\end{tabular}

Table 10 summarizes the macroeconomic costs of the emissions reductions, measured as the loss of global gross domestic product (GDP) in the stabilization scenarios, compared to the respective 
baselines. GDP losses are generally higher in the A2 stabilization scenarios $(2.6 \%$ in 2100$)$ than in B2 (1.7\% in 2100), once more illustrating the importance of the socio-economic and technological assumptions in the baseline scenarios in determining the choice and costs of mitigation strategies.

One striking result of our analysis is that the GDP losses do not differ significantly in the case of learning CCTs, compared to scenarios with static CCT costs. There seems to be no direct relationship between total amounts of cumulative carbon sequestration and GDP losses, indicating that the macroeconomic stabilization cost is the result of a more complex price building system, in which CCTs are just one influencing factor among many. CCT costs contribute to the price building, but do not solely determine them.

Table 10: Global gross domestic product (GDP), and GDP losses from the reference case to the stabilization scenarios for the year 2100 .

\begin{tabular}{lcc}
\hline & GDP (trillion 1990US\$) & $\begin{array}{c}\text { GDP losses (percent } \\
\text { of baseline) }\end{array}$ \\
\hline Baseline scenarios & 242.8 & - \\
A2 & 234.9 & - \\
B2 & & \\
Static CCT costs & 236.4 & $2.65 \%$ \\
A2-550s & 230.8 & $1.74 \%$ \\
B2-550s & & \\
Learning CCts & 236.6 & $2.55 \%$ \\
A2-550t & 230.9 & $1.72 \%$ \\
B2-550t & & \\
\hline
\end{tabular}

The range of GDP losses given in Table 10 are comparable to results from similar studies. For example, Edmonds and Richels (1995) report losses of 0.5 to $1 \%$ for a 500 -ppmv stabilization constraint. Results for a 550-ppmv stabilization case from the 14th Energy Modeling Forum for four different models (CSERGE, CETA, PEF, and CONN) suggest losses between 0.4 and 3.4\% of GDP (EMF14, 1994). Most notably, however, the GDP losses in all of our stabilization scenarios are rather small, compared to the scenario's increase of total GDP by a factor of 11 (from 1990 to 2100), which illustrates that atmospheric carbon concentration stabilization at 550 ppmv is possible at moderate costs.

\subsection{Summary and Conclusions}

In order to estimate future potentials of carbon capture and sequestration technologies (CCT), we developed a set of global greenhouse gas emissions scenarios of economic, demographic, and energy demand development, where alternative policy cases lead to the stabilization of atmospheric $\mathrm{CO}_{2}$ concentrations at 550 parts per million volume (ppmv). Frequently, scenario analyses are based on a static view of CCT technologies, where technology costs and performance are assumed to stay constant over time. Hence, important feedbacks on technology characteristics of e.g., gaining experience in CCT construction and accumulated knowledge due to targeted R\&D efforts, are often not taken into account. 
In this paper we analyzed the future prospects of CCT technologies using a more dynamic representation of technology. In particular, we quantified a "learning curve" for CCT, which describes the relationship between the improvement of costs due to accumulation of experience in CCT deployment. To do this, we examined past experience with managing other major power plant emissions that serve as a reasonable guide to technological progress in managing $\mathrm{CO}_{2}$ emissions. In particular, we focused on U.S. and other experience in reducing emissions of sulfur dioxide $\left(\mathrm{SO}_{2}\right)$ over the past 30 years using flue gas desulfurization (FGD) systems. This technology (commonly known as $\mathrm{SO}_{2}$ "scrubbers") employs similar principles of operation as currently commercial $\mathrm{CO}_{2}$ capture systems that use chemical sorbents to remove $\mathrm{CO}_{2}$ from gas mixtures such as combustion products. Thus, we used past experience with FGD systems worldwide to quantify a learning curve for CCTs, where investment costs declines by $13 \%$ for each doubling of CCT capacity.

Part of the integrated assessment was to analyze the potential of CCTs in the context of other possible carbon mitigation technologies and measures. We did this by including (learning) CCTs into the energy supply optimization model MESSAGE-MACRO, in which carbon capture and sequestration have to compete with other mitigation measures such as fuel switching and priceinduced conservation. Our analysis shows that the timing, costs, and contribution of carbon mitigation measures strongly depend on (1) the socio-economic and technological assumptions in the baseline scenario, and (2) the assumed learning potential of carbon capture and sequestration technologies. Given CCT technologies learn at a similar pace as $\mathrm{SO}_{2}$ abatement technologies in the past, the long-term reduction potential for CCT is vast; in our scenarios ranging between 140 and $250 \mathrm{GtC}$ of cumulative $\mathrm{CO}_{2}$ sequestration (from 1990 to 2100 , assuming a stabilization target of $550 \mathrm{ppmv}$ ). This is particularly due to large-scale investments into CCT, and the accumulation of experience, which leads to rapid cost decrease of carbon capture and sequestration. Even though that their widespread deployment requires decades to come, CCTs gain much higher market shares in the case of learning, compared to scenario results with static CCT cost assumptions. Consequently, at the end of the $21^{\text {st }}$ century almost all fossil power plants are equipped with CCT in the case of learning.

Our scenario analysis showed also that the capturing of carbon with subsequent sequestration might not be sufficient to meet a 550 ppmv stabilization constraint (in the year 2100), even in the case of a very successful market penetration for CCTs. Carbon sequestration is not an alternative to better energy efficiency or increased use of low-carbon emitting energy sources. They are, however, in a least cost mitigation strategy, an important complement in a diversified portfolio of abatement measures. Other main types of emissions mitigation, which considerably contributed to the scenarios emissions reductions, are enhanced energy conservation and in particular fuel switching, primarily away from carbon-intensive coal to low or zero-carbon fuels.

Acknowledging the major differences between scenarios with learning CCTs and those with static cost assumptions leads us to two methodological and policy conclusions. First, improved future models should be capable of characterizing future changes in cost and performance resulting from technology innovation (learning). Second, climate policies need to be extended to include technology policies, in order to make the diffusion of environmentally sound technologies operational in the long run (as shown by our stabilization scenarios). This calls particularly for early action to accomplish the required cost and performance improvements in 
the long term, including the creation of niche markets, the development of small-scale demonstration plants, and targeted R\&D.

\section{Acknowledgements:}

Bing, Take

DOE, CMU, EMF 19

\section{References:}

Dutton, J.M., and Thomas, A. 1984. Treating progress ratios as a marginal opportunity. Academy of Management Review, 9(2):235-247

IEA (International Energy Agency). 2000.Experience Curves for Energy Technology Policy, IEA Publications, France, Paris, ISBN 92-64-17650-0.

Keeth, R.J., Ireland, P.A., \& Moser, R.E.,1986. Economic evaluation of twenty-four FGD systems. Paper presented at the $\mathrm{SO}_{2}$ Control Symposium, Atlanta, GA.

Keeth, R.J., Ireland, P.A., \& Radcliffe, P.T., 1990. 1990 update of FGD economic evaluations. Paper presented at the $\mathrm{SO}_{2}$ Control Symposium, New Orleans, LA.

Keeth, R.J., Ireland, P.A., \& Radcliffe, P.T., 1991. Economic evaluation of twentyeight FGD processes. Paper presented at the $\mathrm{SO}_{2}$ Control Symposium, Washington, D.C.

Laseke, Jr., B.A., Melia, M.T., \& Bruck, N.G. 1982. Trends in commercial application of FGD technology. Paper presented at the $\mathrm{SO}_{2}$ Control Symposium, Hollywood, FL.

McDonald, A. and Schrattenholzer, L., 2001. Learning curves and technology assessment, Special Issue of the International Journal of Technology Management, Vol. 8, No. 23.

McGlamery, G.G., O'Brien, W.E., Stephenson, C.D., \& Veitch, J.D. 1980. FGD economics in 1980. Paper presented at the $\mathrm{SO}_{2}$ Control Symposium, Houston, TX.

Nakicenovic N, Gruebler A, and McDonald A (eds.). 1998. Global Energy Perspectives. Cambridge University Press, Cambridge, UK, ISBN 0521642000.

Rubin, E.S., Kalagnanam, J.R., Frey, H.C. \& Berkenpas, M.B. 1997. Integrated Environmental control modeling of coal-fired power systems. Journal of the Air \& Waste Management Association, 47, 1180-88.

Soud, H.N. 1994. FGD installations on coal-fired plants. London: IEA Coal Research.

Taylor, M., 2001. The Influence of Government Actions on Innovative Activities in the Development of Environmental Technologies to Control Sulfur Dioxide Emissions from Stationary Sources. Ph.D. Thesis, Carnegie Mellon University, Pittsburgh, PA, Jan 2001.

Wright, T.P., 1936. Factors affecting the costs of airplanes. Journal of the Aeronautical Sciences, 3(February): 122-128 


$$
54
$$

\section{Appendix C. IIASA Final Report}

(September 2003) 


\title{
Long-term Perspectives for Carbon Capture in Power Plants: Scenarios for the 21st Century
}

\author{
Final Report
}

Submitted to Carnegie Mellon University (CMU)

Pittsburgh, PA USA

Sponsored by the US Department of Energy

Award number DE-FG02-00ER63037

IIASA Reference: 00-133 ECS

Keywan Riahi, Leonardo Barreto, Shilpa Rao

Environmentally Compatible Energy Strategies (ECS) Project

International Institute for Applied Systems Analysis (IIASA)

September 2003 


\section{Acknowledgements}

This work has been conducted as a sub-contract with Carnegie Mellon University (Professor Edward Rubin) for the Office of Biological and Environmental Research (Dr. John Houghton) of the U.S Department of Energy (DOE). We would like to thank Leo Schrattenholzer, leader of the Environmentally Compatible Energy Strategies (ECS) project at IIASA, and Professor Edward S. Rubin, from the Center for Energy and Environmental Studies of Carnegie Mellon University, for their support and very useful comments. We would also like to extend our appreciation to Pat Wagner from IIASA for her editorial assistance.

This paper reports on work of the International Institute for Applied Systems Analysis and has received only limited review. Views or opinions expressed in this report do not necessarily represent those of the Institute, its Nations Member Organizations, or other organizations sponsoring the work. 


\section{Introduction}

Already since the early 1970s a number of stringent environmental policies on fossil-fired power plants became effective in the mitigation of various pollutant emissions, such as $\mathrm{SO}_{2}$ or nitrogen oxides. One important not-yet-addressed aspect concerns, however, the carbon emissions from fossil power generation, particularly relevant in relation to possible adverse impacts of climate change (IPCC, 2001).

Hedging against the risks of climate change would require significant and long-term structural changes of the global electricity generation, transmission and distribution systems, as well as the institutions and markets associated with them (Riahi and Roehrl, 2000). An obstacle for achieving this goal in the short term is the large inertia of the energy system, due to the long lifetimes of its infrastructure. Hence, fossil power plants are bound to continue playing a significant role in meeting the increasing global electricity demand well into the future. Even under moderate assumptions for the growth of energy demand this would lead to a very significant increase of global carbon emissions (Nakicenovic and Riahi, 2001). Technologies are required, which are capable of "bridging" the long-term transformation of today's energy system into a less carbon intensive one, while minimizing the environmental impacts during the transition period. Carbon removal and storage technologies appear to have a promising potential, since these technologies can be added to existing fossil infrastructure permitting a relatively rapid introduction compared to other clean and advanced alternatives (e.g., renewables), which if introduced at the same pace as carbon capture, would require fundamental structural changes and the premature replacement of fossil power generation.

The assessment of the potential role of technologies requires an adequate representation of the main mechanisms of technological change, which is one of the principal driving forces in shaping the evolution of energy systems. Its dynamics, pace, and direction, however, is subject to large uncertainties, calling for scenario analysis with integrated assessment models evaluating the possible contribution of specific energy technologies under alternative policy configurations. The competitiveness of technologies in different scenarios depends, among other things, on assumptions regarding their cost evolution, i.e., on their patterns of technological learning, and on how such patterns are represented (endogenous or exogenously). The cost assumptions and their methodological treatment in models are important for all technologies but they can be particularly' significant for currently expensive and promising emerging technologies, such as carbon capture and sequestration systems.

Previous work (Rubin et al., 2001, Riahi et al., 2002) has illustrated the effects of changes in the cost assumptions for carbon capture technologies in the outcome of integrated assessment models. In particular, it has been shown that introducing cost trends for these technologies in a consistent way with the technological learning concept and under the assumption that they are able to follow the kind of learning patterns that "add-on" scrubbing technologies for other pollutants have shown in the past, their contribution to a carbon mitigation strategy could increase significantly.

In this report we analyze the role of fossil-fired power plants equipped with carbon capture systems in long-term scenarios of the global energy system representing technological change as an endogenous process. Within this framework the impacts of a technology policy is illustrated that requires over time an increasing fraction of fossil-fired power generation to incorporate carbon capture technologies. In particular, we examine the potential costs and the contribution 
that such a policy could offer in reducing energy-related carbon dioxide emissions and highlight some of the technologies that may play a role in doing so. The analysis is carried out with the energy-systems optimization MESSAGE model (Messner and Strubegger 1995) considering endogenous technology learning for fossil power plants and the corresponding carbon capture technologies, such that they experience cost reductions as a function of accumulated capacity installations. The report presents five alternative scenarios: two baseline scenarios, which differ with respect to the learning in fossil power plants - one including learning and the other with no learning. In addition, three policy cases are presented, distinguishing between future worlds assuming (1) no learning for fossil systems, (2) learning just for the carbon capture component, and (3) full learning for the reference plants as well as for the carbon capture systems.

The utilization of carbon capture and sequestration technologies is associated with additional costs and efficiency losses for energy conversion processes (compared to unabated energy production). Clearly, the large-scale deployment of these technologies will just occur if international climate policies are in place, which would give carbon an economic value, and hence, create an incentive for investments into emissions mitigation technologies. In our scenario analysis, we assume ex-ante that these policies are in place leading to the introduction of a technology policy for carbon capture systems in the electricity sector. We do not assume any additional carbon mitigation measures in the other sectors or a carbon tax, since we want to primarily analyze the implications of the technology policy as a tool to foster the innovation and learning process for carbon capture systems. ${ }^{23}$

We acknowledge that large-scale carbon capture and sequestration systems still face a number of scientific, technical, and economic problems that have to be addressed before they become a viable option in a global greenhouse gases mitigation strategy. In this sense, our scenarios should be regarded solely as an attempt to address the questions: (1) "what-if" carbon capture and storage technologies would be able to overcome those barriers and be deployed successfully and (2) what could be their potential contribution to achieve a clean, low-carbon global power generation sector?

The scenarios are based upon the A2 scenario developed at IIASA for SRES (2000), which portrays a world with relatively moderate economic growth, where electricity needs increase substantially and fossil-based technologies play a major role. With these characteristics, it provides a good context for the examination of the role of carbon capture technologies in the power generation sector. Our policy scenarios are labeled A2-CCT, where the acronym CCT stands for Carbon Capture Technologies. In the A2-CCT scenarios, following a departure in technology and environmental policies from the original A2 world, the fossil-based power systems face pressure to evolve into cleaner configurations with low release of carbon to the atmosphere in the long term.

The remainder of this paper is organized as follows. Section 2 briefly describes carbon capture technologies in the power sector. It also introduces a storyline that illustrates the main scenario characteristics and describes how a world consistent with fossil power plants incorporating carbon capture might unfold in the future. Section 3 presents the main model and scenario assumptions, with particular emphasis on the technical and economic characteristics for carbon capture technologies. Section 4 describes the methodology, which was applied for the

\footnotetext{
${ }^{23}$ For multi-sectoral mitigation analysis focusing on carbon capture in the context of specific climate targets (e.g., stabilization of atmospheric carbon concentrations at 550 ppmv) see e.g., Riahi et al. 2002.
} 
endogenization of learning curves for carbon capture technologies. Main scenario results for the power sector, $\mathrm{CO}_{2}$ emissions, and implications for carbon capture technologies are presented in Section 5. Finally, Section 6 presents the conclusions and policy implications from our analysis.

\section{Towards clean fossil power plants \\ 2.1 Carbon capture technologies in power plants}

The increasing evidence of anthropogenic interference with the earth's climate system and mounting concerns about possible serious adverse impacts of future global climate change (IPCC, 2001), call for the investigation of alternatives for energy production, conversion and final use with a low release of greenhouse gases to the atmosphere.

Carbon capture and sequestration technologies could permit the use of carbon-rich primary energy sources while reducing their net emissions to the atmosphere. There are two basic possibilities for carbon sequestration. The first is preventing that carbon produced by human activities reaches the atmosphere. The second is removing carbon from the atmosphere (Socolow, 1997, DOE, 1999a). We are concerned here only with the first alternative. In such context, carbon removal and sequestration requires the capture, transport and long-term storage of the $\mathrm{CO}_{2}$ resulting from production of fossil-based or biomass-based energy carriers.

The electricity sector is one of the main sources of carbon emissions, responsible for more than 35 percent of total $\mathrm{CO}_{2}$ emissions worldwide. In comparison to other sectors such as transportation, electricity generation appears attractive for carbon mitigation because of the more reduced number of actors, large facilities and a relatively wide range of technological options. Thus, this sector is likely to become a prime target in any greenhouse gases mitigation strategy. Besides other options such as renewable sources, nuclear power, efficiency improvements and fuel switching, emissions to the atmosphere can be reduced through carbon capture in fossil-fired power plants and subsequent long time storage.

The capture of the $\mathrm{CO}_{2}$ in fossil-fired power plants can be made either before or after the combustion process. ${ }^{24}$ Post-combustion capture refers to the separation of $\mathrm{CO}_{2}$ from the stream of flue gases resulting from fossil fuel combustion. In the conventional approach, combustion occurs in the presence of air and the resulting concentration of $\mathrm{CO}_{2}$ in the flue gas stream is very low, making the process of separation very laborious. As an alternative, oxygen-based combustion has been proposed, which leads to a more concentrated stream of $\mathrm{CO}_{2}$, thus facilitating the capture process. In the latter, however, combustion temperatures may become very high. In order to mitigate this problem, $\mathrm{O}_{2} / \mathrm{CO}_{2}$ cycles can be used, where $\mathrm{CO}_{2}$ is recycled and used as a working fluid (IEA/CERT, 2002).

The separation and capture of $\mathrm{CO}_{2}$ from the mix of combustion by-products is typically made using chemical or physical solvents. Although commercially available, solvents still have to be improved. Current work is concentrated in the development of solvents with higher $\mathrm{CO}_{2}$ adsorption capacities and rates and which could reduce the significant energy requirements of the capture process (IEA/CERT, 2002). Efforts are also being devoted to the development of alternative technologies, such as membranes for flue gas separation or adsorption.

\footnotetext{
${ }^{24}$ While we do refer here to the combustion process, a more general, and probably more correct, designation should be the electricity production process, since technologies like fuel cells do not rely on combustion but on electrochemical conversion for electricity generation.
} 
In pre-combustion capture, the fossil fuel is decarbonized, i.e. its carbon content is removed, before it is used for electricity generation. This is typically achieved by a gas shifting process from which a synthesis gas (syngas), consisting mainly of hydrogen and carbon monoxide, is obtained. A highly concentrated stream of $\mathrm{CO}_{2}$ can be separated using chemical or physical adsorption, membranes or pressure swing adsorption. The remaining hydrogen-rich syngas is then used as input to the combustion process (IEA/CERT, 2002).

Since the same process is used for hydrogen production from fossil fuels, the application of precombustion carbon capture approaches in power plants could make attractive the co-production of hydrogen and electricity in so-called poly-generation schemes. This could pave the way for the introduction of hydrogen as an energy carrier in the long run, as a suitable complement to electricity, and for the development and deployment of integrated multi-product energy technologies (DOE, 1999b, Williams et al., 2000).

Post-combustion capture can be applied to conventional existing fossil-fired power plants. Precombustion capture, however, requires technologies able to work with a hydrogen-rich gas efficiently and cleanly. Thus, the latter needs an adaptation and re-design of current technologies, such as combined-cycle turbines (Audus and Jackson, 2000), or the introduction of advanced technologies, such as integrated gasification combined-cycle (IGCC), high temperature fuel cells $^{25}$ or a combination of both.

Very likely, carbon capture technologies would be initially introduced as an "add-on" technology for conventional fossil power technologies, thus favoring the conventional post-combustion approach. Later on, as both the power generation and carbon capture technologies evolve, advanced power plants might have carbon capture as a "built-in" feature. This would contribute to optimize the process from the conception and design stages of the power plant and would open the way for advanced $\mathrm{O}_{2} / \mathrm{CO}_{2}$ cycles and pre-combustion capture approaches.

\subsection{The storyline of a clean fossil-power world}

This subsection presents the storyline based on which we have adopted a set of assumptions to quantify the policy scenarios presented in Section 5. The storyline is an account of how a future consistent with carbon capture and sequestration technologies might unfold, and gives a brief characterization of its main driving forces. First, we present a qualitative description of the economic, technical, environmental and social developments in the scenario. Finally, we will focus on the role of clean fossil power technologies with carbon capture and sequestration.

The scenarios developed here build upon the IIASA-SRES-A2 scenario (SRES, 2000) with an updated set of technology characteristics for fossil power plants and carbon capture and sequestration technologies. To distinguish the policy scenarios from the original A2, we have labeled them the A2-CCT scenarios, with the acronym CCT referring to carbon capture technologies. In its context, we explore the contribution of fossil power plants that incorporate carbon capture to the global energy system in the long run.

The A2-CCT scenarios are characterized by relatively slow economic growth and nonconverging worlds, where regional welfare disparities are very slowly reduced along the $21^{\text {st }}$

\footnotetext{
${ }^{25}$ For instance, solid oxide fuel cells (SOFC) or molten carbonate fuel cells (MCFC). For a description of these technologies see e.g. Srinivasan et al. (1999).
} 
century. Economic growth follows an uneven increase across world regions, as differences in productivity, social structures and technological change rates remain significant. As for demographic trends, following a slow decrease in fertility rates, the global population increases along a high-growth path reaching about 15 billion people at the end of the $21^{\text {st }}$ century.

As a consequence of the consolidation of distinct regional economic blocks, the globalization process slows down, and international flows of knowledge, people and technology are reduced. Different regions, thus, evolve along dissimilar technological paths and technology transfer between industrialized and developing countries is less significant.

Still, within the different regional systems, business and governments promote the management of natural capital and markets evolve gradually as to value ecosystem services, following mainly regional environmental concerns. With a drive to increase the productivity of regionallyavailable natural resources and minimize waste, technologies and production schemes are deployed that, while being cost-effective, allow recycling and/or separating materials and substances that could produce undesired environmental effects (Lovins et al., 1999), which on their turn could potentially dislocate economic activities, leading to comparative disadvantages.

Technological change in the energy system is relatively slow and highly dependent on regional resource availability. International trade of energy commodities is not very significant since, due to geopolitical reasons, regions seek to reduce their dependence on others. Thus, while some regions evolve towards high efficiency post-fossil energy systems, others rely on more resourceintensive fossil-based technologies. Rates of change across different fossil technology clusters are similar, but the cluster of coal-based technologies experiences somewhat faster improvements, being coal an indigenous resource abundant enough to fuel economic activity, particularly in developing regions. This is a fossil-intensive world, but one that faces pressure to evolve towards a cleaner form. Therefore, clean fossil technologies, environmentally superior to those of today, emerge in the long term.

Business-government partnerships in energy-related research, development, demonstration and deployment activities (summarized as RD3, following PCAST, 1999) help in sharing the costs and overcoming the risks of developing and introducing new energy technologies appropriate to regional needs and resources. However, given the short-term-profit orientation of industrial partners, government intervention is still necessary in filling gaps in long-term energy RD3 needs.

Without the possibility of significant technology spillovers between regions, the developing world is forced to devote more resources to local science and technology capacity building, recognized as a strategic factor for survival in this divided world. Also, as economies grow, and with the need to carefully manage the regionally available resources, environmental issues gradually become a more relevant topic in their development agenda.

In the A2-CCT scenarios, electricity needs increase substantially. Such growth provides opportunities for technological learning in electricity-related technologies. It also triggers responses as to minimize environmental impacts from the electricity system. As part of the response to those needs, carbon capture technologies are developed and incorporated into power plants, initially as "add-on" devices and later on as a "built-in" feature. With intensified R\&D efforts, effective demonstration projects and sound deployment strategies, substantial but achievable performance improvements and cost reductions occur in power plants with carbon 
capture and they diffuse widely. Large, centralized power plants are favored since they facilitate the capture of carbon and benefit from corresponding economies of scale.

Simultaneously, scientific advances in the understanding of carbon sequestration processes allow a better assessment of the sequestration potential of different reservoirs, their leakage characteristics and associated risks and costs. Together with the development of measurement, monitoring and verification (MMV) technologies, this allows resolving concerns regarding the physical integrity of the carbon storage reservoirs, the environmental impacts of sequestration and the overall effectiveness of the storage schemes. These actions, combined with adequate communication and information-sharing strategies and the imposition of a regulatory and legal regime suitable for the long-term storage case (Reiner and Herzog, 2002), increase the public acceptability of this option. Eventually, a network of pipelines and maritime fleets for the transportation of $\mathrm{CO}_{2}$ from carbon sources to storage reservoirs is deployed.

Accompanying changes in the electricity generation technologies a number of technologies emerge to enable the transformation of the electrical grid itself into a more flexible, reliable and stable system for transmitting and delivering power and communication signals. An "intelligent" grid with entirely new capabilities materializes, where multiple generation sources and storage systems interact and around which new business models and services are created, as the advantages of new technologies are recognized and valued in the marketplace. Among others, flexible AC transmission systems (FACTS), advanced (e.g. superconducting) cables, new "backup" concepts, electricity and hydrogen storage systems and advanced control and communication devices are introduced.

\section{Main scenario assumptions}

As mentioned above, the analysis presented here has been carried out with MESSAGE, an energy systems-engineering optimization model with a detailed representation of energy resources and energy extraction, conversion, transportation and end-use technologies. But, although optimization plays an important technical role in our analysis, we emphasize more the "scenario aspect" of our model runs. This is to say that, with a time horizon of 100 years where huge uncertainties exist, a much more decisive role is played by input assumptions. These assumptions, for example, specify the underlying population and economic trends, the amount of primary energy resources available, the cost reductions and/or performance improvements of different technologies, etc. They are chosen in a consistent way with the underlying scenario storyline. Here we describe those deemed relevant for this exercise. 26

In the version of the MESSAGE model used for this analysis, the global energy system is disaggregated into four world macro-regions, as follows:

- The OECD90 region groups the countries belonging to the OECD in 1990.

- The REF region brings together the economies-in-transition in the Former Soviet Union and Eastern Europe.

- The ASIA region represents the developing countries in the Asian continent.

\footnotetext{
${ }^{26}$ Note that a discount rate of $5 \%$ has been applied in all our calculations.
} 
- The ALM region covers the rest of the world, grouping countries in sub-Saharan Africa, Latin America and the Middle East.

The first two regions (OECD90 and REF) grouped together will be referred to as industrialized regions (labeled as IND). The ASIA and ALM regions together conform the developing regions (labeled as DEV) group.

Five scenarios were developed for the purpose of this study. The scenarios share the same socioeconomic and demographic assumptions, but differ with respect to the assumptions for technological learning of fossil power plants and carbon capture technologies. The scenario set comprises two baseline scenarios and three scenarios including the CCT technology policy. In the sequel of the report the following labels for the individual scenarios are used:

- A2 (no learning) - baseline including no learning

- $A 2$ (PPL learning) - baseline including learning for power plants

- A2-CCT (no learning) - policy case including no learning

- A2-CCT (CCT learning) - policy case including learning for carbon capture technologies

- $A 2-C C T$ (PPL \& CCT learning) - policy case including learning for power plants \& carbon capture technologies

\subsection{Economic and demographic trends}

All scenarios presented in this report share the same economic and demographic assumptions. Economic growth follows dissimilar paths in different world regions. Gross World Product (GWP) grows at an average rate of approximately $2.3 \%$ per year, reaching approximately 243 trillion US dollars (in 1990 values at market exchange rates) by the end of the $21^{\text {st }}$ century, representing a 12-fold increase respect to that of the year 1990. Income per capita rises in both industrialized and developing countries but at a different pace and a slow reduction in income inequities across world regions takes place (SRES, 2000). This is a non-converging world. Essentially, the relative isolation between blocks of regions limits the potential of developing regions to "catch up" with the industrialized regions. By the end of the century, the average income per capita in the developing world reaches US\$10,957 or only $24 \%$ percent of that of the industrialized one (US\$46,235).

The population trajectory underlying the scenarios corresponds to a high population projection reported by Lutz (1996). Due to the lack of educational measures, slow improvement of social conditions and difficulties in changing the traditional role of women in many societies, less open to the outside world, the population in the developing regions grows at a rapid pace. As a consequence, global population follows a high-growth path during the $21^{\text {st }}$ century reaching about 15 billion people in 2100 (12.8 billion in developing countries and 2.2 billion in industrialized ones).

\subsection{Assumptions on resources}

Assumptions on the fossil-fuel resource availability are based on the estimates reported by Rogner (1997). The categorization distinguishes between conventional and unconventional 
reserves and resources and reflects increasing degrees of geological uncertainty and decreasing degrees of economic attractiveness. A relatively large availability of oil and gas is assumed. The oil and natural gas resource base comprises both conventional resources and potential for their enhanced recovery plus unconventional recoverable resources. Following Rogner (1997) notation, categories I-VI have been considered for gas and categories I-V for oil. Categories I-III represent conventional reserves and resources. Category IV represents the potential for enhanced recovery of the conventional resources. Category $\mathrm{V}$ corresponds to the identified reserves of unconventional recoverable oil and gas. Category VI corresponds to the unconventional gas resource estimates.

Coal resources are also based on Rogner (1997) and are considered globally abundant, although they can be limited in some regions. Following Rogner (1997), categories A to E for both hard coal and brown coal have been considered. Category A represents proved recoverable reserves. Category B represents additional recoverable resources. Category $\mathrm{C}$ represents additional identified reserves while Categories $\mathrm{D}$ and $\mathrm{E}$ group together additional resources.

Equally important as the assumptions on the ultimate resource base is the actual resource use in the scenarios. Table 11 summarizes the global hydrocarbon resource availability and the cumulative fossil fuel use of the baseline and policy scenarios. The cumulative resource consumption results from the interplay between the different driving forces involved in the scenario and represents a more appropriate indicator than the exogenously specified resource base.

Table 11: Categories of conventional and unconventional oil, gas and coal reserves, resources and additional occurrences in Zetajoules, $\mathrm{ZJ}\left(10^{21} \mathrm{~J}\right)$. The table shows which of the categories are considered in the A2 and A2-CCT scenarios (shaded cells) and presents resulting cumulative extraction of oil, gas and coal in the A2 and A2-CCT scenarios between the years 2000 and 2100.

\begin{tabular}{|c|c|c|c|c|c|c|c|c|}
\hline \multirow[b]{2}{*}{ Category } & \multirow{2}{*}{$\begin{array}{c}\begin{array}{c}\text { Conventional } \\
\text { Reserves and } \\
\text { Resources }\end{array} \\
\text { I, II, III }\end{array}$} & \multicolumn{3}{|c|}{ Unconventional Reserves and Resources } & \multirow{2}{*}{$\begin{array}{c}\begin{array}{c}\text { Unconventional } \\
\text { and Additional } \\
\text { Occurrences }\end{array} \\
\text { VII-VIII }\end{array}$} & \multirow[b]{2}{*}{ Total } & \multicolumn{2}{|c|}{$\begin{array}{c}\text { Scenario Result } \\
\text { Cum. Extraction 2000-2100 }\end{array}$} \\
\hline & & IV & $\mathrm{V}$ & VI & & & $\begin{array}{c}\text { A2 } \\
\text { no learning } \\
\text { (learning) }\end{array}$ & $\begin{array}{c}\text { A2-CCT } \\
\text { no learning } \\
\text { (PPL \& CCT } \\
\text { learning) } \\
\end{array}$ \\
\hline Oil & 12.4 & 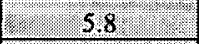 & 19 & 14.1 & 59.8 & 94 & $18.9(18.9)$ & $19.0(18.9)$ \\
\hline Gas & 165 & 1. 2.3 ? & I. $5.8=17$ & 10.8 & 801.6 & 837.1 & $24.2(24.1)$ & $25.5(25.0)$ \\
\hline & $\begin{array}{c}\text { Proved } \\
\text { Recoverable } \\
\text { Reserves } \\
\end{array}$ & $\begin{array}{c}\text { Additional } \\
\text { Recoverable } \\
\text { Resources } \\
\end{array}$ & $\begin{array}{l}\text { Additional } \\
\text { Identified } \\
\text { Reserves } \\
\end{array}$ & \multicolumn{2}{|c|}{ Additional Resources } & & & \\
\hline Category & $\mathrm{A}$ & $\mathrm{B}$ & $\mathrm{C}$ & $\mathrm{D}$ & E & Total & & \\
\hline Coal & 18.7 & 12,4 & $.233 \cdot \square$ & 6411.4 & 165.7 & 261.5 & $42.1(45.0)$ & $41.4(43.1)$ \\
\hline
\end{tabular}

For non-fossil resources, like uranium and renewable energy, future resource potentials are primarily a function of the assumed rates of technological change, energy prices, and other factors such as safety and risk considerations for nuclear power generation. 


\subsection{Investment costs for electricity generation technologies}

The MESSAGE model provides a detailed technology characterization in the electricity sector. Table 12 presents the scenario's investment costs of fossil power generation technologies for the years 2000 and 2100 . In the scenarios that consider endogenous learning, the costs of fossil power plants decrease in line with the deployment of the respective technology and the increase in cumulative installed capacity. ${ }^{27}$ The learning rates of the fossil reference power plants are based on estimates from IEA, 2000; Nakićenović et al., 1998; and Rabitsch, 2001. ${ }^{28}$ As shown by Table 12 the potential for learning is higher for today's advanced and comparatively expensive technologies, such as IGCC and high-temperature fuel cells. In the case of learning the contribution of these technologies increases significantly leading to considerable changes of the future electricity mix (as compared to the cases without learning). The corresponding "buydown" of costs is shown in Table 12 (for more details on how technological learning is introduced into the model and on the resulting deployment of the electricity generation technologies in the scenarios see Section 4 and Section 5.2).

All five scenarios presented in this report share the same assumptions for the costs of zerocarbon power generation technologies (nuclear \& renewables). The cost improvements of these technologies are given exogenously, since due to computational limitations, just a limited number of technologies can be endogenized in the full-scale MESSAGE model. As shown in Table 12, these technologies are assumed to experience noticeable cost reductions, making them increasingly competitive in the long run. The scenario's cost assumptions for categories of zerocarbon technologies are given in Table 13. Each category may contain one or several types of plants. A more detailed description of the technologies can be found in Appendix C1.

Table12: Investment costs in $\$ / \mathrm{kW}$ for the year 2000 and 2100 and the assumed learning rate for fossil electricity generation technologies.

\begin{tabular}{|c|c|c|c|c|c|c|c|}
\hline & \multirow{2}{*}{$\begin{array}{l}\text { Learning } \\
\text { rate }\end{array}$} & \multirow{2}{*}{$\begin{array}{l}\text { Initial investment } \\
\text { costs (base } \\
\text { year) } \$ / \mathrm{kW}\end{array}$} & \multicolumn{5}{|c|}{ Investment costs in $2100, \$ / \mathrm{kW}$} \\
\hline & & & $\underset{\text { (no learning) }}{\mathrm{A} 2}$ & $\begin{array}{c}\mathrm{A} 2 \\
\text { (PPL learning) }\end{array}$ & $\begin{array}{c}\text { A2-CCT } \\
\text { (no learning) }\end{array}$ & $\begin{array}{c}\text { A2-CCT } \\
\text { (CCT learning) }\end{array}$ & $\begin{array}{c}\text { A2-CCT } \\
\text { (PPL \& CCT learning) }\end{array}$ \\
\hline \multicolumn{8}{|l|}{ Reference power plants: } \\
\hline Subcritical coal (coal conv.) & $0 \%$ & $1000-1300$ & $1000-1300$ & $1000-1300$ & $1000-1300$ & $1000-1300$ & $1000-1300$ \\
\hline Supercritical coal (coal adv.) & $3 \%$ & 1165 & 1165 & 1165 & 1165 & 1165 & 1165 \\
\hline NGCC & $7 \%$ & 542 & 542 & 420 & 542 & 542 & 360 \\
\hline Single steam cycle gas PPL (gas conv.) & $0 \%$ & 710 & 710 & 710 & 710 & 710 & 710 \\
\hline IGCC & $10 \%$ & 1400 & 1400 & 630 & 1400 & 1400 & 630 \\
\hline High temperature fuel cell (coal) & $10 \%$ & 2000 & 2000 & 890 & 2000 & 2000 & 1100 \\
\hline High temperature fuel cell (gas) & $10 \%$ & 1150 & 1150 & 1150 & 1150 & 1150 & 1150 \\
\hline
\end{tabular}

\footnotetext{
${ }^{27}$ In scenarios with no learning for reference power plants their costs are assumed to stay constant over time.

${ }^{28}$ Due to the limited experience with high temperature fuel cell systems, there is presently no information on their learning rate available. In addition, uncertainty for the learning rate of the single fuel cell component is vast, ranging between 13 to 30\% (Schaeffer, 1998; Whitacker, 1998; Kordesch and Simader, 1996). Since the high temperature fuel cell systems include a number of components with considerably lower learning potential (than the single fuel cell component), we assume for the scenarios a somewhat lower aggregate learning rate of $10 \%$, i.e., the same rate as for IGCC.
} 
Table 13: Range of investment costs in $\$ / \mathrm{kW}$ for the main categories of zero-carbon electricity generation technologies for the year 2000 and 2100 .

\begin{tabular}{|c|c|c|c|}
\hline \multirow{2}{*}{ Abbreviation } & \multirow{2}{*}{ Technology description } & \multicolumn{2}{|c|}{ Investment costs for selected years $(\$ / \mathrm{kW})$} \\
\hline & & 2000 & 2100 \\
\hline Biomass & various types of biomass power plants & $1567-1756$ & $1300-1400$ \\
\hline Nuclear & various types of nuclear power plants & $1900-2567$ & $1900-2300$ \\
\hline Hydro & small to large scale hydro power plants & $1000-3000$ & $1000-3000$ \\
\hline Solar & $\begin{array}{l}\text { solar thermal power plants, solar PV power plants, and } \\
\text { decentralized PV power generation }\end{array}$ & $2756-4756$ & $1600-2000$ \\
\hline Wind & wind power plant & 1344 & 800 \\
\hline
\end{tabular}

\subsection{Assumptions on capture, transport and storage of $\mathrm{CO} 2$}

This section presents the assumptions on costs and performance of the carbon capture technologies included in our analysis together with costs of $\mathrm{CO}_{2}$ transport and long-term storage. For this analysis, the investment costs of these carbon capture technologies are assumed to follow learning curves. The description of the approach for endogenizing the learning curves and the assumptions on the corresponding learning parameters are presented in Section 4 below.

The carbon capture technologies are represented as separate technologies in our model. That is, they are not embedded in the power generation technologies. The latter would have been a more straightforward procedure and is also the way most of the sources available in the literature report analysis on the economics of carbon capture (see e.g. David and Herzog, 2000; Simbeck, 2001; among others). Using a separate technology for carbon capture permits to distinguish between the learning of the different components (i.e., the reference plants and the capture technologies), and helps to examine the implications of learning for capture technologies in a more detailed way.

In addition, this study uses the concept of "carbon capture clusters". The idea of technology clusters has been applied in several modeling approaches (Seebregts et al., 2000, Gritsevskyi and Nakićenović, 2000). Technology clusters are shaped when related technologies interact and cross-enhance each other, contributing to their mutual development (Nakićenović, 1997). As part of the clustering process, spillovers of learning between technologies can occur.

We follow the so-called key technology approach (Seebregts et al., 2000), and consider a carbon capture technology that is shared by different power plants. The power plants are associated to each capture technology on the basis of the similarities of their carbon capture approach. Hence, the "carbon capture clusters" learn with the cumulative capacity added across a group of power plants that share similar characteristics concerning the capture process. In addition, also each individual power plant does learn independently, based on its own cumulative capacity installations.

Table 14 presents the CCT clusters considered in the MESSAGE model for this analysis together with the power plants associated with them. The first two are post-combustion systems, one encompassing conventional steam-cycle coal power plants (labeled as CCT_coal) and a second capture technology for conventional gas and natural gas combined-cycle plants (CCT_gas). The third one is a pre-combustion system, which is assumed to be common to IGCC power plants and, as a simplification, to high-temperature fuel cells (CCT_IGFC). 
Table 14: Carbon capture technologies considered in this analysis and power plants associated to them. For a brief description of the electricity generation technologies considered in the model and the corresponding abbreviations see Appendix C1.

\begin{tabular}{ll}
\hline $\begin{array}{l}\text { Carbon capture } \\
\text { technology }\end{array}$ & Power generation technologies associated \\
\hline CCT_coal & $\begin{array}{l}\text { Conventional coal (coal_stdu, coal_stda), advanced coal (coal_adv) } \\
\text { Conventional gas power plants and gas combined-cycle turbines (gas_ppl, } \\
\text { CCT_gas }\end{array}$ \\
$\begin{array}{l}\text { gas_cc) } \\
\text { Coal-based IGCC (coal_igcc), coal (coal_htfc) and gas-fired (gas_htfc) high } \\
\text { temperature fuel cells }\end{array}$ \\
\hline
\end{tabular}

Our assumptions for these carbon capture technologies are based on David and Herzog (2000). They conducted a comparative cost analysis of carbon capture for conventional (subcritical) and advanced (supercritical) coal power plants, IGCC and gas combined-cycle turbines assuming commercially available capture technologies. That is, flue gas capture using a Monoethanolamine (MEA) solvent is considered for pulverized coal power plants and natural gas combined-cycle turbines and the shift gas process combined with a physical absorption process (e.g. Selexol) for the IGCC plants. Under this assumption, they estimated costs and efficiencies for a reference plant with no capture and the same plant with carbon capture both for today's conditions and a possible development in 2010 . The figures used here correspond to their today's estimation and are summarized in Table 15 below.

Table 15: Main economic and technical characteristics of carbon capture technologies in this analysis.

\begin{tabular}{lcccc}
\hline & $\begin{array}{c}\text { Investment Costs } \\
(\text { US\$/kW) }\end{array}$ & $\begin{array}{c}\text { O\&M Costs } \\
(\mathrm{US} \$ / \mathrm{kWh})\end{array}$ & $\begin{array}{c}\text { Energy Penalty } \\
(\%)\end{array}$ & $\begin{array}{c}\text { Efficiency of } \\
\text { Carbon Capture } \\
(\%)\end{array}$ \\
\hline CCT_coal & 940 & 0.85 & 25 & 90 \\
CCT_gas & 578 & 0.26 & 13 & 90 \\
CCT_IGFC & 509 & 0.37 & 15 & 90 \\
\hline
\end{tabular}

The main economic and technical characteristics of the carbon capture clusters used in this analysis are presented in Table 15 . Investment costs for the carbon capture technologies have been considered here as the difference in investment costs between plants with and without $\mathrm{CO}_{2}$ capture. The same applies for operation and maintenance (O\&M) costs. In addition, following David and Herzog (2000), the efficiency of the capture process is assumed to be $90 \%$. As a simplification, both the capture efficiency and the "energy penalty" are considered constant along the time horizon. It must be noticed, however, that, as both fossil electricity generation and carbon capture technologies develop and new approaches for carbon capture are conceived and used, significant "energy penalty" reductions could be expected and the capture efficiency could improve. For this exercise, however, we remain on the conservative side regarding potential improvements of the process. Notice also that we do not consider here novel technologies such as membrane systems (see e.g. IEA/CERT, 2002). 
When applying the concept of "CCT clusters" some simplifications are required. That is, since we are associating different power plants with a common capture technology average values for the energy penalty and carbon-capture efficiency have to be used. This is an approximate representation but one that helps in having a better representation of the learning process of the carbon-capture technologies.

It should be noticed here that the choice of the clusters of learning technologies might have an influence on the results, i.e. with a different clustering the shares of the learning technologies in the model outcome could be different. In addition, in considering clusters where the cumulative capacities of the member technologies are added up to compute the cumulative capacity of the key technology and, therefore, the corresponding cost reduction, we are relying on the assumption that spillovers of learning are full across technologies. That is, we assume that a given technology fully profits from the experience accumulated in other technologies within the same cluster.

The incorporation of carbon capture technologies in the power plants affects their technical and economic characteristics. Table 16 presents the main characteristics of the fossil-fired technologies for which carbon capture is considered in this analysis.

Table 16: Characteristics of power plants with carbon capture. Levelized costs figures exclude fuel costs (for the base year 2000)

\begin{tabular}{|c|c|c|c|c|c|c|c|}
\hline & & $\begin{array}{l}\text { Coal } \\
\text { Conv. }\end{array}$ & $\begin{array}{l}\text { Coal } \\
\text { Adv. }\end{array}$ & $\begin{array}{c}\text { Coal Fuel } \\
\text { Cell }\end{array}$ & Gas CC & $\begin{array}{c}\text { Gas Fuel } \\
\text { Cell }\end{array}$ & IGCC \\
\hline \multicolumn{8}{|l|}{ Reference Plant } \\
\hline Investment & $\$ / \mathrm{kW}$ & 1150 & 1165 & 2000 & 542 & 1150 & 1400 \\
\hline O\&M & $\notin / \mathrm{kWh}$ & 0.74 & 0.8 & 1.65 & 0.25 & 0.91 & 0.79 \\
\hline Efficiency & $\%$ & 41 & 43 & 55 & 55 & 60 & 42 \\
\hline Load factor & $\%$ & 75 & 75 & 65 & 75 & 65 & 75 \\
\hline Plant life & Years & 30 & 30 & 25 & 30 & 25 & 30 \\
\hline Levelized investment costs & $\notin / \mathrm{kWh}$ & 1.1 & 1.2 & 2.5 & 0.5 & 1.4 & 1.4 \\
\hline Total levelized costs & $\ell / \mathrm{kWh}$ & 1.9 & 2.0 & 4.1 & 0.8 & 2.3 & 2.2 \\
\hline Carbon Emissions & $\mathrm{tC} / \mathrm{kWyr}$ & 1.98 & 1.89 & 1.48 & 0.88 & 0.80 & 1.93 \\
\hline \multicolumn{8}{|l|}{ Plant with carbon capture } \\
\hline Investment & $\$ / \mathrm{kW}$ & 2090 & 2105 & 2509 & 1120 & 1659 & 1909 \\
\hline O\&M & $\phi / \mathrm{kWh}$ & 1.59 & 1.65 & 2.02 & 0.51 & 1.28 & 1.16 \\
\hline Efficiency & $\%$ & 31 & 32 & 47 & 48 & 51 & 36 \\
\hline Load factor & $\%$ & 75 & 75 & 65 & 75 & 65 & 75 \\
\hline Plant life & Years & 30 & 30 & 25 & 30 & 25 & 30 \\
\hline Levelized investment costs & $\not / \mathrm{kWh}$ & 2.1 & 2.1 & 3.1 & 1.1 & 2.1 & 1.9 \\
\hline Carbon emissions & $\mathrm{tC} / \mathrm{kWyr}$ & 0.23 & 0.22 & 0.17 & 0.11 & 0.10 & 0.23 \\
\hline Total Levelized Cost & $\notin / \mathrm{kWh}$ & 3.7 & 3.7 & 5.1 & 1.6 & 3.4 & 3.1 \\
\hline Carbon Reduction Costs & $\$ / t C$ & 89.4 & 93.3 & 67.3 & 94.2 & 124 & 45 \\
\hline
\end{tabular}

Reference plants and plants with carbon capture are shown and levelized costs of electricity production (excluding fuel costs) and carbon mitigation costs are included. Carbon mitigation costs are computed with reference to the same plant without carbon capture. 
The costs of $\mathrm{CO}_{2}$ transportation and storage are based on estimates from Freund et al. (2002). They report that a plausible range for costs of storage of $\mathrm{CO}_{2}$ in deep saline aquifers or depleted oil/gas fields is 1-3 USS/ton $\mathrm{CO}_{2}$ (3.7-11 US\$/ton C). Here we have adopted the mean value of this range, which corresponds to $7.3 \mathrm{US} \$ /$ ton $\mathrm{C}$, for our calculations. It must be recognized, however, that many uncertainties surround these figures. Storage costs will depend on many factors, among others on the geological characteristics of specific reservoirs and the rates of injection.

As for transportation of captured $\mathrm{CO}_{2}$ from the sources to the reservoirs, again Freund et al. (2002) mention a likely range of $1-3$ US\$/ton $\mathrm{CO}_{2} / 100 \mathrm{~km}(3.7-11 \mathrm{US} \$ /$ ton $\mathrm{C} / 100 \mathrm{~km})$. Using the mean value and a pipeline length of $250 \mathrm{~km}$, we arrive at $5 \mathrm{US} \$ /$ ton $\mathrm{CO}_{2} / 250 \mathrm{~km}$ (or 18.3 US\$/ton $\mathrm{C} / 250 \mathrm{~km}$ ), the figure used here. It must be noticed that in pipeline transportation significant economies-of-scale can be achieved.

As for $\mathrm{CO}_{2}$ storage capacities, given the huge uncertainties that exist in the figures, we have not imposed an upper bound for storage capacity in the model. Nonetheless, in order to provide some perspective on the orders of magnitude of sequestered amounts, in section 5.4 below we compare the cumulative figures resulting in our A2-CCT scenarios with some estimates available in the literature (IEA, 2001). A more precise assessment of the storage potential of natural reservoirs is required, taking into account their physical characteristics, the technical feasibility of the storage process and the associated environmental impacts.

In addition, it must be noticed that leakage of carbon storage reservoirs is not considered here. We acknowledge, however, that this issue is important and should be addressed in future scenario exercises. Due to the possibility of leakage, sequestering carbon is not fully equivalent to avoiding carbon emissions and, thus, it may not have the same value. Although this point is beginning to receive attention in the literature (see e.g. Keller et al., 2002, Herzog et al., 2003), in particular regarding the comparison of the value of carbon capture and sequestration and that of other mitigation options, efforts are still necessary in several fronts to gain a better understanding of this issue and its implications. On the one hand, it is very important to understand the leakage characteristics of different potential reservoirs and the environmental consequences of leakage in order to assess the overall effectiveness of the storage process. On the other hand, the present economic value of future leaky sequestration should be estimated (Keller et al., 2002).

\subsection{An illustrative policy for the penetration of carbon capture technologies}

We turn now to the description of the illustrative technology policy that has been imposed on the global fossil-fired electricity systems in the A2-CCT scenarios. Following a rise in global environmental concerns, a technology policy is introduced that enforces an increasing use of fossil-fired power plants with carbon capture. For doing so, it is assumed that these technologies must achieve a minimum pre-specified share of the total fossil-fired installed capacity. This share increases in time up to the point where all fossil-based power plants are equipped with carbon capture. The technology policy is simulated in the MESSAGE model by logistic penetration 
curves $^{29}$, enabling a smooth transition from unabated power generation to a regime where carbon dioxide is captured in all fossil-fired power plants in the long term.

We specify two different logistic penetration curves, one for the industrialized regions (labeled as IND) and a second curve for the developing regions (labeled as DEV). We assume that the technology policy will be introduced first in the industrialized regions (i.e. OECD90 and REF). In these regions, the share of carbon capture technologies in total installed capacity of fossil power plants is forced to increase gradually from less that $1 \%$ percent in 2010 up to practically 100 percent by 2070 . As for the developing regions (ASIA and ALM), we assume that they will follow with a delay of about two decades. That is, they start adopting carbon capture technologies in fossil-fired power plants in 2030. However, we assume that the diffusion takes a shorter time there and they achieve approximately $100 \%$ of adoption also in 2070 . This appears consistent with historical patterns of technology diffusion discussed in the literature (e.g. Grübler, 1996), where the adoption of a technological innovation experiences a time delay between regions belonging to the core and regions in the periphery of its spatial diffusion domain. Here, we assume that the industrialized world operates as the core of the diffusion process of carbon capture technologies.

The curves are presented in Figure 55. The time in years that takes the diffusion process to go from $10 \%$ to $90 \%$ of its duration $(\Delta t)$ is presented. With our assumptions, $\Delta t$ of 26 years and 19 years result for the diffusion of carbon capture technologies in, respectively, industrialized and developing regions. Since carbon capture technologies are still in their infancy, we cannot provide an empirical justification for the parameters of the logistic curves used here, but our assumptions lie within the ranges reported in the literature for other technology diffusion processes. $^{30}$

\footnotetext{
${ }^{29}$ This does not mean that in the model the constraint that represents the CCT policy is formulated as a logistic (i.e. non-linear) expression. The constraint in the model is linear, specifying the fraction of the total installed capacity of fossil power plants that must incorporate carbon capture in each time period, but the values assigned to such fraction in each time period follow the logistic curve described.

${ }^{30}$ Grübler (1996) constructed a histogram for $\Delta t$ for a number of different diffusion processes using two samples. For the first sample ( 117 cases collected at IIASA), a mean value of 57.5 years (std. deviation 52.5) was found. For the second ( 265 cases, including the previous sample and cases from other sources), a mean value of 41 years (std. dev. 42) was estimated. The highest frequency was found in the range 15-30 years.
} 


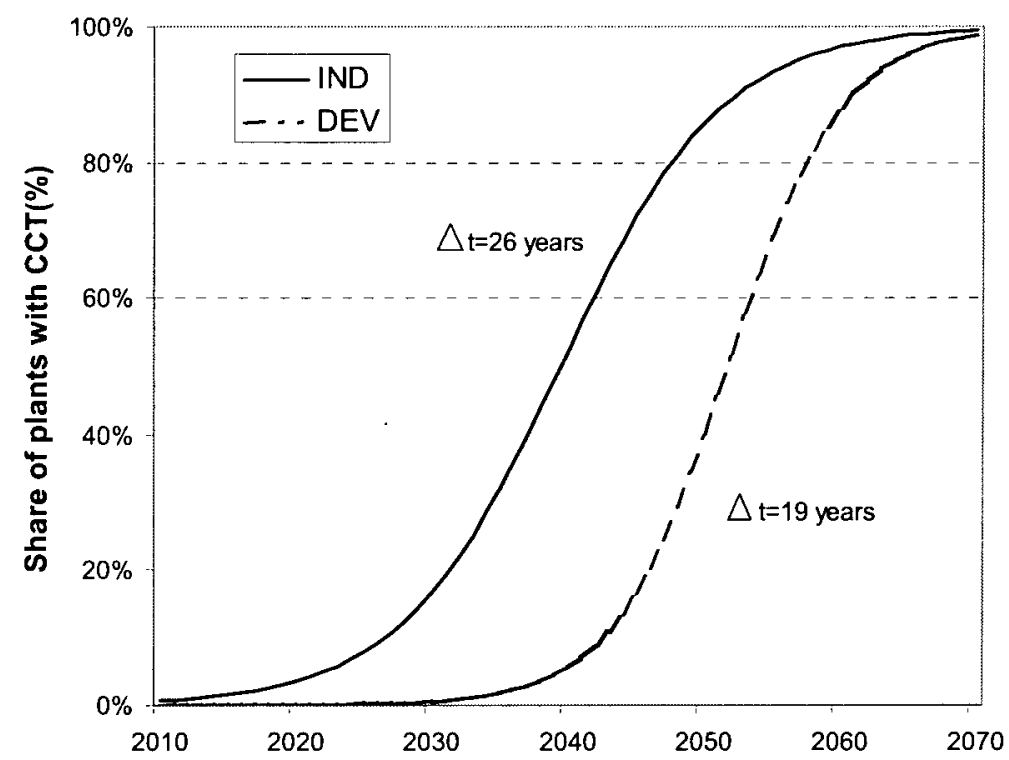

Figure 55: Logistic penetration curves assumed for the penetration of fossil-fired power plants with carbon capture technologies in the A2-CCT scenario for the industrialized (IND) and developing regions (DEV). $\Delta t$ is the time in years that takes the innovation process to go from $10 \%$ to $90 \%$ of its duration.

We recognize that this is an arbitrary assumption, which imposes a somewhat fast penetration of the carbon-capture technologies, and model results are sensitive to it. However, we only intend to examine the effects of an illustrative technology policy here, without making any claim about its likelihood. In our study, we assume the introduction of a phased-in mandatory scrubbing policy on a fraction of the installed fossil fuel fired capacity. The basis for this assumption is the general nature of existing global policies for environmental control. For instance, in the U.S. Acid Rain Program, the first Phase of the Clean Air Act is limited to 263 of the most polluting units, while the second Phase encompasses more than 2000 existing and new units across the U.S. The formulation of such a policy ensures that all major sources of pollution gradually fall under the umbrella of regulation. Limiting the policy to only new sources, leads to an imbalance in both spatial and temporal reduction profiles, as many of the existing electricity plants have lives of 30 years or more.

Notice that this technology policy is imposed on the whole set of fossil-fired technologies and not on individual technologies. That is, fossil-fired technologies with $\mathrm{CO}_{2}$ capture will compete against each other to fulfill the constraint. Thus, the resulting fossil-fired mix and the corresponding amounts of carbon sequestered by individual carbon capture technologies will depend, among other factors, on the combined effects of the costs of the different power plants and their efficiencies and the learning curve characteristics, capture efficiencies and energy penalties of the associated carbon capture technologies. 


\section{Endogenizing technological learning for carbon capture technologies}

This section presents a brief description of the methodology used to endogenize technological learning for fossil power plants and carbon-capture technologies in the MESSAGE model. MESSAGE is an energy systems-engineering optimization model that disaggregates the world in a number of regions, providing a detailed technology representation of the energy systems in each of them (Messner and Strubbeger, 1995, Messner and Schrattenholzer, 2000).

We consider here the typical formulation of learning, or experience curves, describing the specific investment cost of a given technology as a function of the cumulative capacity, a proxy for the accumulated experience (Argote and Epple, 1990). The curve reflects the fact that some technologies experience declining costs as a result of their increasing adoption due to, among others, learning-by-doing (manufacturing) and learning-by-using (use) effects. The specific investment cost (SC) is formulated as:

$$
S C(C C)=a^{*} C C^{-b}
$$

Where:

CC: Cumulative capacity

b: $\quad$ Learning index

a: $\quad$ Specific cost at unit cumulative capacity

Usually, instead of the learning index $b$ the learning rate (LR), i.e. the rate at which the cost declines each time the cumulative production doubles, is specified as:

$$
L R=1-2^{-b}
$$

For instance, a LR of $10 \%$ means that the costs are reduced in $10 \%$ for each cumulative capacity doubling. Cumulative capacity refers here to the cumulative installed MWs of power plants with carbon capture systems. Notice that this is but one possibility to approximate the experience accumulated with carbon capture and sequestration systems. Other studies (Keller et al., 2002) have used the cumulative amount of $\mathrm{CO}_{2}$ sequestered instead.

As mentioned above, in a previous exercise a comparison of the role of carbon capture technologies when static costs are assumed and when costs trends are consistent with the learning curve concept was performed for different scenarios (Rubin et al., 2001, Riahi et al., 2002). For doing so, an iterative "ex-post" approach was applied that allowed an adequate emulation of learning curves. However, the costs trends still remained exogenously given.

In order to address such shortcoming in this analysis we resort to the endogenization of learning curves in the MESSAGE model. This allows the model considering the "up-front" investments that are necessary for a technology to make progress along its learning curve. Typically, when learning curves are endogenized in optimization models with perfect foresight, such as MESSAGE, it results cost-effective for the model to make higher early investments in initially expensive technologies if they exhibit sufficient cost reduction potential along the time 
horizon. ${ }^{31}$ This highlights the fact that, from a long-term perspective, it could be sensible to invest today on the "buy-down" process of promising technologies that could become competitive in the long run.

When the original formulation of the learning curves is included in standard linear programming models, the result is a non-linear and non-convex optimization problem. Such kind of problems possesses several local optima, and a global optimal solution cannot be guaranteed with standard non-linear optimization solvers. Thus, here, following the work of Messner (1997) and Mattsson (1997), we resort to a linearization of the problem applying Mixed Integer Programming (MIP) techniques. The MIP approach provides such linearization by a piece-wise interpolation of the cost curve. Binary variables are used to control the sequence of cost segments along the curve. Although more computational intensive, an optimal solution can be identified for this linear approximation. For a more detailed description of this approach see Messner (1997), Mattsson (1997) or Barreto (2001).

In our exercise endogenized learning curves are considered only for the carbon capture technologies. Given the fact that these technologies are still in an early stage of development, it is very difficult to assess their learning characteristics. As an approximation, the learning characteristics of scrubbing technologies for other pollutants are used.

Our assumptions rely on the work of Rubin et al. (2001). They conducted an estimation of historical learning rates for capital and operating cost in flue gas desulfurization (FGD) technologies used in coal-fired power plants for $\mathrm{SO}_{2}$ capture. Such estimation was made on the basis of cumulative capacity installed in the U.S., Germany and Japan over the past three decades. These three countries dominated (and shared) inventive activities and innovations in this technology (Taylor, 2001) and, therefore, represent an adequate sample to examine the cost reductions that could be attributed to technology innovation. Among other factors, the imposition of stringent regulations regarding $\mathrm{SO}_{2}$ control in power plants, in particular in the U.S., played a major role in pushing the development and adoption of these technologies. That is, innovation in, and diffusion of, these technologies was linked to government actions that imposed regulatory regimes creating markets for environmental control technologies. As a result of this study, a learning rate of approximately $13 \%$ was obtained and it is applied here for all learning carbon capture technologies considered in this analysis.

In order to reduce the computational burden, we just consider learning curves just for the fossil power generation technologies and the associated carbon capture systems. Cost improvements for other zero-carbon technologies are exogenously given as described above in section 3.3.

The learning process is assumed to take place at the global scale. Although we recognize that global learning may not be consistent with a world where separate economic blocks emerge, we have chosen it here mainly for methodological reasons, since it simplifies the computational task. Under the global learning assumption, the deployment of a learning technology in a given region affects its investment costs in all of them and, as a consequence, may render it more attractive also in other regions.

Figure 56 gives an illustration of the learning curves of the carbon capture technologies considered in this analysis. Both the original nonlinear curves and the step-wise approximation

\footnotetext{
${ }^{31}$ The cost reduction potential depends, among others, on the parameters assigned to the learning curve, the maximum growth rates allowed, the maximum potential for capacity of activity of the different technologies, etc.
} 
used by the MIP approach are presented. For the stepwise approximation, five segments have been applied. Similarly, the same step-wise approximation was performed for the learning curves of the reference power plants.

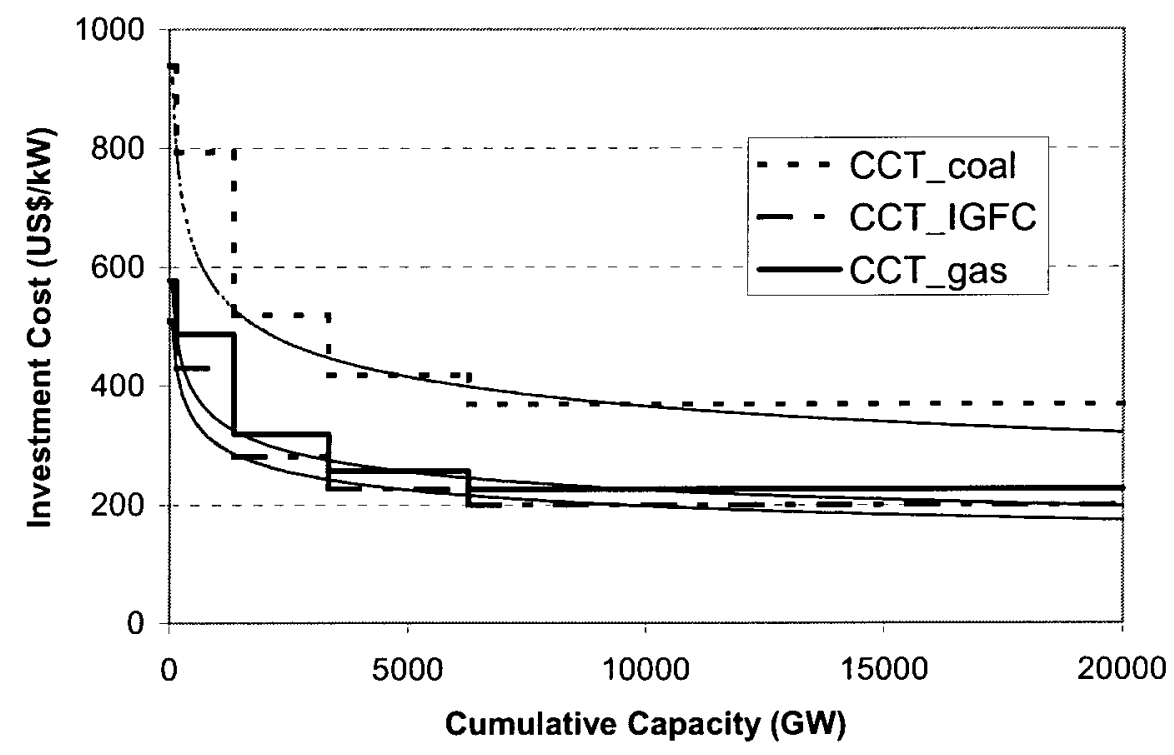

Figure 56: Learning curves assumed in this exercise for the carbon-capture clusters considered in the power sector. The step-wise approximation and the original non-linear curve are presented.

\section{A2-CCT: Scenarios with clean fossil power}

In this section we will discuss selected results from our analysis. We will describe mainly the A2-CCT scenarios, where the policy is applied, and analyze its effects in the global energy system and associated carbon emissions. For the sake of comprehensiveness we consider three different A2-CCT cases. In the first case, labeled "No Learning", the costs for the capture technologies remain constant along the time horizon. In the second case, labeled "CCT Learning", the costs for the carbon-capture technologies follow the learning curves described above, and in the third case, labeled "PPL \& CCT Learning", also the costs of the fossil power plants follow learning curves. For reference purposes, a comparison with the cases without policy, the A2 scenarios (with and without learning for fossil power plants), are also presented. It must be noticed that, since the characteristics of some technologies have been updated, the A2 figures presented here can be different from those reported in Riahi and Roehrl (2000) and SRES (2000). For simplicity, the discussion here is carried out mainly at the global level. Where necessary, specific results for industrialized (IND) and developing (DEV) countries are also shown. Table 17 summarizes the scenario's main global indicators. 
Table 17: Basic global indicators of the A2 and A2-CCT scenarios for 2100. Historical values for the year 1990 are presented for comparison.

\begin{tabular}{|c|c|c|c|c|c|c|}
\hline & & $\mathbf{A 2}$ & & A2CCT & & \\
\hline & & No learning & $\begin{array}{c}\text { PPL } \\
\text { Learning }\end{array}$ & No Learning & $\begin{array}{l}\text { CCT } \\
\text { Learning }\end{array}$ & $\begin{array}{c}\text { PPL \& CCT } \\
\text { learning }\end{array}$ \\
\hline & 1990 & & & 2100 & & \\
\hline Population (billion) & 5.3 & 15 & 15 & 15 & 15 & 15 \\
\hline $\begin{array}{l}\text { GWP (trillion 1990US\$, market } \\
\text { exchange rates) }\end{array}$ & 20.9 & 242.8 & 242.8 & 242.8 & 242.8 & 242.8 \\
\hline $\begin{array}{l}\text { Equity ratio of income } \\
\left(\mathrm{DEV} / \mathrm{IND}^{32}\right)\end{array}$ & 0.062 & 0.24 & 0.24 & 0.24 & 0.24 & 0.24 \\
\hline Primary energy (EJ) & 352 & 1983 & 1924 & 2061 & 2061 & 2057 \\
\hline Final energy $(\mathrm{EJ})$ & 275 & 1342 & 1337 & 1342 & 1350 & 1342 \\
\hline Electricity generation (EJ) & 42 & 539 & 553 & 521 & 535 & 568 \\
\hline Annual $\mathrm{CO}_{2}$ emissions ( $\mathrm{Gt} \mathrm{C}$ ) & 6.0 & 27.9 & 29.1 & 22.5 & 21.5 & 21.1 \\
\hline $\begin{array}{l}\text { Cumulative } \mathrm{CO}_{2} \text { emissions from } \\
2000(\mathrm{Gt} \mathrm{C})\end{array}$ & -- & 1837 & 1908 & 1598 & 1460 & 1497 \\
\hline $\begin{array}{l}\text { Cumulative sequestered } \mathrm{CO}_{2} \\
\text { emissions from } 2000(\mathrm{Gt} \mathrm{C})\end{array}$ & -- & -- & -- & 242 & 284 & 379 \\
\hline
\end{tabular}

\subsection{Primary energy supply}

Figure 57 presents a comparison of the structural changes of the world primary energy mix for the A2 and A2-CCT scenarios. The historical changes, shown as a reference, reflect major technology shifts, from traditional use of renewable energy to the coal age of the 19th century to the dominance of oil along the 20th century and the later emergence of natural gas.

Already in the A2 scenarios, world primary energy consumption experiences a substantial increase, reaching approximately $2000 \mathrm{EJ}$ by the end of the 21 st century. The global energy system weans away from current dependence on conventional oil resources, although they still remain important in the medium term. The introduction of learning for fossil power plants in the A2 baseline leads to comparatively early upfront investments into advanced coal-fired power systems, and hence the contribution of coal is higher, particularly in the medium term (around 2050) as compared to the A2 case without learning. In the long run, coal becomes the dominant primary energy source in both baseline scenarios, accounting for about half of the primaryenergy mix in the year 2100 . Other primary resources that gain importance are natural gas, biomass and nuclear energy.

With the imposition of the CCT policy in the A2-CCT scenarios, a reduction in the share of fossil resources in the global primary-energy mix occurs in the medium term. This is mainly a result of fossil-based power plants becoming comparatively more expensive than other options for electricity generation. In the second half of the $21^{\text {st }}$ century, however, a recarbonization of the primary energy supply of the A2-CCT scenario takes place, as other sectors switch to more carbon-intensive fossil fuels. As a result, the primary-energy path in the long term does not differ

\footnotetext{
${ }^{32}$ DEV stands for developing regions and IND for industrialized regions.
} 
substantially from that of the A2 scenario. A more detailed discussion of these interactions is presented in section 5.2 below.

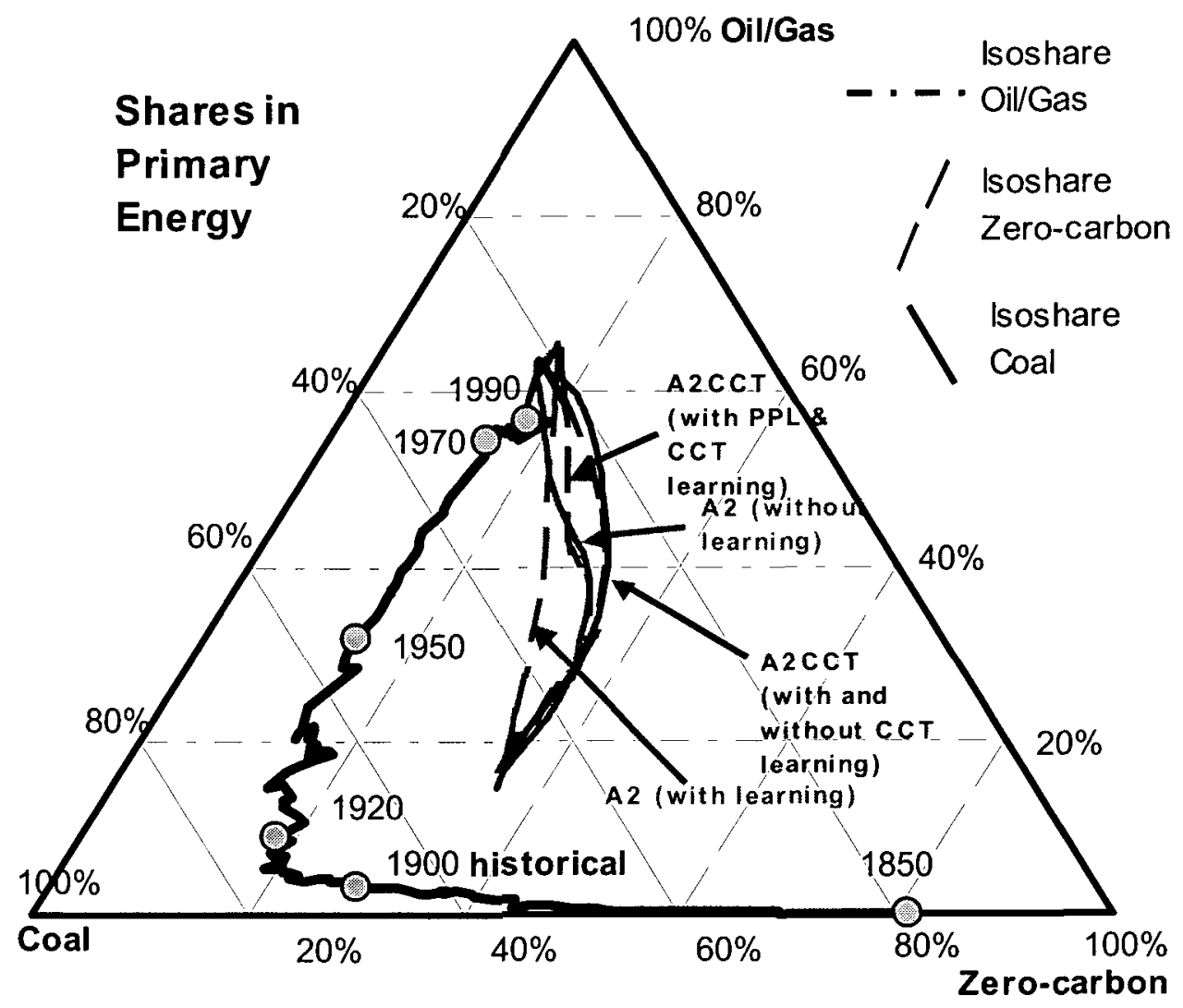

Figure 57: Global shares in primary energy use, coal, oil/gas, and non-fossil energy, illustrated with an "energy triangle" (in percent). Constant market shares of coal, oil/gas, and non-fossil (0carbon) primary sources are denoted by their respective isoshare lines. Historical data from 1850 to 1990 (black) are based on Nakićenović et al. (1998). The development of the primary energy structure for the A2 and A2-CCT scenarios is shown for the years 1990 to 2100 (ten year time steps).

\subsection{Global electricity generation}

Figure 58 presents a comparison of the global electricity generation in the A2 and A2-CCT scenarios for the years 2020,2050 and $2100 .^{33}$ For fossil-fired power plants, the electricity losses due to the incorporation of carbon-capture technologies are included. In the A2 scenarios, global electricity generation increases significantly, reaching a level of around 540 to $550 \mathrm{EJ}$ in the year 2100 , which is about 10 times that of the year 2000 (IEA, 2002b). This growth creates a challenge for the power sector in meeting those enormous needs in an effective, clean and reliable way. But, at the same time, it provides opportunities for technological learning, driving to significant improvements of advanced electric power generation technologies.

\footnotetext{
${ }^{33}$ Details of the evolution of the electricity generation mix in the industrialized and developing regions are shown in Appendix 2.
} 

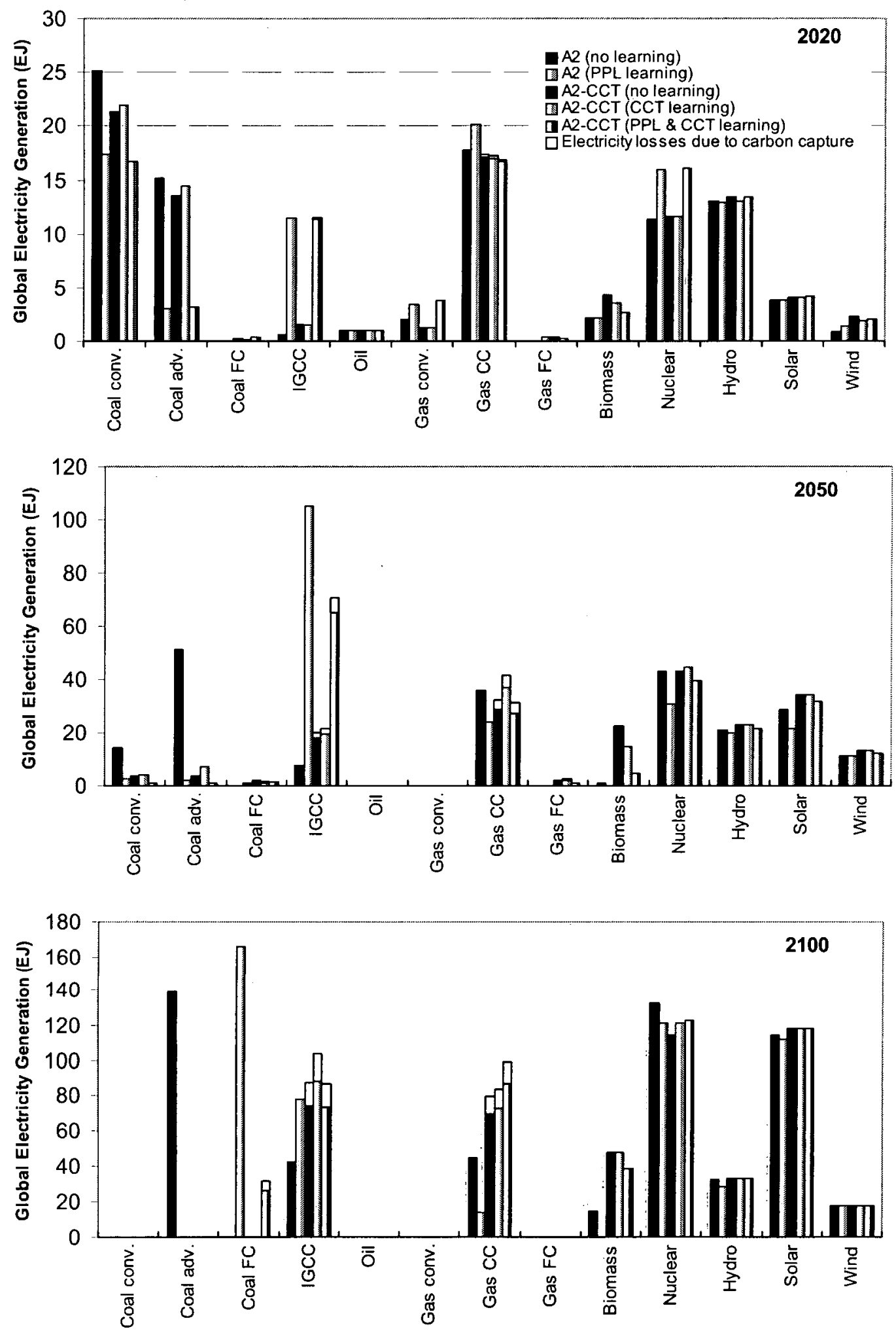

Figure 58: Global electricity generation for the A2 and A2-CCT scenarios in the years 2020, 2050 and 2100 . For the A2-CCT cases, electricity losses due to the carbon capture process are shown as white bars. 
In both baseline scenarios the global electricity generation portfolio remains diversified. A number of primary sources and technologies are required to meet the fast-pace consumption growth. In the case of no learning for fossil-fired technologies, they account for $50 \%$ of the generation mix in 2050 and for $42 \%$ at the end of the $21^{\text {st }}$ century. The introduction of learning makes advanced fossil power generation technologies more competitive in the long run, leading to an increase of the contribution of these technologies. When learning is considered in the baseline, fossil power accounts for $60 \%$ of the total generation mix in 2050 and for $48 \%$ in 2100 respectively.

The major difference between the two baseline scenarios is, however, the evolution of the portfolio of fossil technologies. The introduction of learning for reference plants leads to the comparatively early upfront investments into advanced fossil power generation technologies. As a result, IGCC is dominating the power sector in the medium term (2050), subsequently substituted by the next generation of coal gasification plants (high temperature fuel cells) in the very long term (Figure 58). In contrast, in the baseline without learning, single steam cycle coal technologies (supercritical) play the dominant role, and to some extent also natural gas combined-cycle power plants together with IGCC gain importance. ${ }^{34}$ Both baseline scenarios, depict a world where existing conventional coal systems are phased out along the time horizon, and where highly efficient and clean coal technologies develop and diffuse, allowing coal to maintain its position as a major fuel option well into the future.

Although fossil-fired technologies, mainly based on coal, constitute a significant share of the global electricity production mix in the baselines, other technologies also achieve a significant penetration. Particularly nuclear power plants play an important role in both baseline scenarios, reaching about $25 \%$ share of the generation mix in the year 2100 . Note, however, that adding learning for reference power plants had an impact on the diffusion for nuclear technologies in the medium term. In the new scenarios there is more nuclear power in the first decades and less around the middle of the century. The increase of nuclear in the short term (2020) is due to the rapid substitution of mature fossil power plants by IGCC at initially high costs, giving nuclear a short-term competitive edge. The situation changes in the medium term (2050), when IGCC become available at relatively low costs, leading to the substitution of nuclear.

Also renewable sources increase noticeably their contribution to the global generation mix in both scenarios, reaching about $30 \%$ in the year 2100 . With the exception of solar photovoltaic plants, the individual market shares of renewable technologies remain relatively small, but together they conform a zero-emissions generation cluster that makes sizeable inroads. With exception of biomass technologies, the contribution of individual renewable technologies does not differ significantly across the two baseline scenarios. Adding learning to the fossil power plants, leads in our baseline scenario to the "lock-out" of biomass-fired power generation (compared to contributions of about $15 \mathrm{EJ}$ in 2100 in the case of no learning).

Already in the A2 scenarios, due to the cost reductions assumed for renewable and nuclear power plants, they capture a substantial share of the global electricity production. ${ }^{35}$ As will be seen

\footnotetext{
${ }^{34}$ There is also a significant difference between the deployment of NGCC in the baseline scenarios. Due to its limited potential for learning (as compared to other more advanced fossil power systems - see Table) NGCC loses considerable market shares in the baseline with learning.

${ }^{35}$ Note that the scenarios assume significant exogenous cost reductions for the majority of renewable electricity generation technologies. Endogenizing technological learning for these technologies, would most likely lead to some more diversified results. However, due to computational limitations - just a limited number of technologies can be
} 
below, the penetration of these zero-carbon technologies, among other factors, contributes in keeping the amounts of carbon dioxide captured in the fossil power sector in the A2-CCT scenario well within the ranges of geological storage potentials.

Once the CCT policy is introduced, séveral changes can be observed (see Figure 58). In the first place, since fossil-fired electricity generation becomes more expensive because of the necessary introduction of carbon capture technologies, fossil-based systems decrease their contribution to the global generation mix from $42-48 \%$ to $30-36 \%$ in the year 2100 (depending on the assumptions for learning for fossil power plants and associated capture technologies). Other nonfossil technologies, particularly biomass-based gasification plants and to some extent hydro and solar power plants, increase their electricity output instead.

As mentioned above, the CCT policy is imposed on the whole set of fossil-fired power plants and, therefore, they compete against each other to fulfill it in the least-cost way. As a result, in the remaining fossil-fired share the participation of the individual technologies is modified. A comparison of the three A2-CCT scenarios shows that under the CCT policy coal-based IGCC and natural gas combined-cycle are the most robust options, significantly contributing to the power mix under all three alternative learning cases. An important finding illustrated by the A2CCT (PPL \& CCT learning) scenario is also, that considering learning for power plants leads to additional inroads for the next generation coal gasification plants with high temperature fuel cells in the very long term (2100).

Thus, with the CCT policy in place, the dominant role in the fossil-fired share of global electricity production is played by IGCC plants, which enable a more efficient and less expensive pre-combustion capture of $\mathrm{CO}_{2}$. A complementary role is played by natural gas combined-cycle plants and coal-fired high temperature fuel cells (in the case of learning for power plants), which also allow a competitive combination of electricity production and carbon capture. Advanced supercritical coal-fired plants still play a role in the medium term, bridging the transition between today's coal-based systems and the IGCC-dominated regime, but they are phased out in the long run.

Summarizing, the changes within the fossil-fired set of technologies due to the introduction of the CCT policy in the system consist of two things: A shift towards more efficient coal-fired technologies for which the combined costs of electricity generation and carbon capture is lower (i.e. IGCC, and high temperature fuel cells) and fuel switching towards less carbon-intensive fossil fuels (i.e. natural gas combined-cycle plants), which also allow a competitive combination of electricity production and carbon capture.

Coal gasification technologies and the gas combined-cycle can be seen as key complementary elements of a strategy for achieving a global fossil-fired electricity generation system with low emissions of carbon to the atmosphere. Both technologies can produce electricity with high conversion efficiencies and low levels of pollutants. In addition, the technologies share a number of commonalities and could profit from progress in each other (e.g. through learning spillovers). Moreover, being attractive options for electricity generation and facilitating the carbon capture process in case it becomes necessary, they represent flexible and robust choices.

endogenized in the full-scale MESSAGE model - endogenous technological learning was not introduced for these technologies. 
Gas combined-cycle turbines are, already today, one of the most competitive electricity generation technologies and they are expected to experience additional improvements and to conquer more markets in the future. IGCC systems, however, are at much earlier stage in their life cycle. Nonetheless, IGCC systems have a promising potential for electricity generation because they offer high fuel flexibility, significant efficiency gains and potential synergies with other processes. Being based on a gasification process that produces a hydrogen-rich synthesis gas out of coal, biomass or other fuels, they have the possibility to produce hydrogen or other fuels or chemicals together with electricity in so-called poly-generation schemes (see e.g. NETL, 2001, Williams et al., 2000). In the long term, IGCC systems or their successor technologies could become a key building block of an energy system where carbon-free hydrogen and electricity are the main energy carriers.

From today's perspective, however, ensuring that IGCC becomes competitive in the marketplace will require a number of actions. IGCC is currently in the demonstration phase and a number of technical and economic issues remain to be solved. The technology is still regarded by many power producers as too expensive and too risky an investment in comparison to conventional pulverized coal plants. Thus, significant cost reductions are required, particularly in the gasification process. In addition, efficiencies have to be increased, better gas cleaning and conditioning processes have to be introduced, gas separation technologies must be developed and the utilization of process and waste streams must be optimized (Stiegel, 1998). Demonstration programs, some of them already underway, will help in gaining experience with these plants and improving their performance, thus building confidence on potential adopters of this technology.

Moreover, as shown by the scenarios hybrid systems combining IGCC plants and high temperature fuel cells (HTFC) could be developed and deployed. The potential for those systems has also been highlighted in the literature (e.g. NETL, 2000, Rao et al., 2002). Fuel cells could, for instance, replace combustors in IGCC plants while the gas turbine system could provide the balance of plant for the fuel cell. High temperature fuel cell systems could achieve very high conversion efficiencies and very low pollutant emissions. In addition, they could facilitate the carbon capture process and contribute in substantially reducing the corresponding "energy penalty". High temperature fuel cells, however, must become less expensive and a number of technical problems still have to be surmounted (Srinivasan et al., 1999).

In order to adequately understand the results, it is important to examine the relative prices of the resources, since they play a role in defining the technologies that are chosen by the model. Particularly important for this exercise are those of natural gas and coal, the main primary fossil resources in the electricity sector. Figure 59 presents the evolution of the shadow prices of coal and gas averaged across regions in the A2 and A2-CCT scenarios.

Already in the A2 scenarios, the shadow prices of both resources increase substantially along the time horizon reaching, at the end of $21^{\text {st }}$ century, approximately five times the values in the year 2000. However, coal remains clearly less expensive than natural gas. With the imposition of the CCT policy, the shadow prices of natural gas increase, as compared to the A2 baseline, while those of coal remain approximately the same. The CCT policy drives to a substantially higher installation of gas-fired combined-cycle turbines and, therefore, to a higher consumption of natural gas, thus explaining the increase in its shadow prices. The behavior of the shadow prices is in line with the resulting shares of coal and gas-fired power plants in the electricity sector in the $\mathrm{A} 2$ and $\mathrm{A} 2-\mathrm{CCT}$ scenarios described above. 
The imposition of the CCT policy results in higher costs for electricity production. Figure 60 presents the evolution of the global average of electricity shadow prices for the years 2000, 2050 and 2100 . As shown, in the long-term, electricity shadow prices are relatively higher in the case that the CCT policy on fossil-fired generation technologies is imposed. Clearly, this effect is highest in the case where no learning is assumed and lowest in the A2-CCT scenario that assumes learning for the power plants as well as capture technologies.

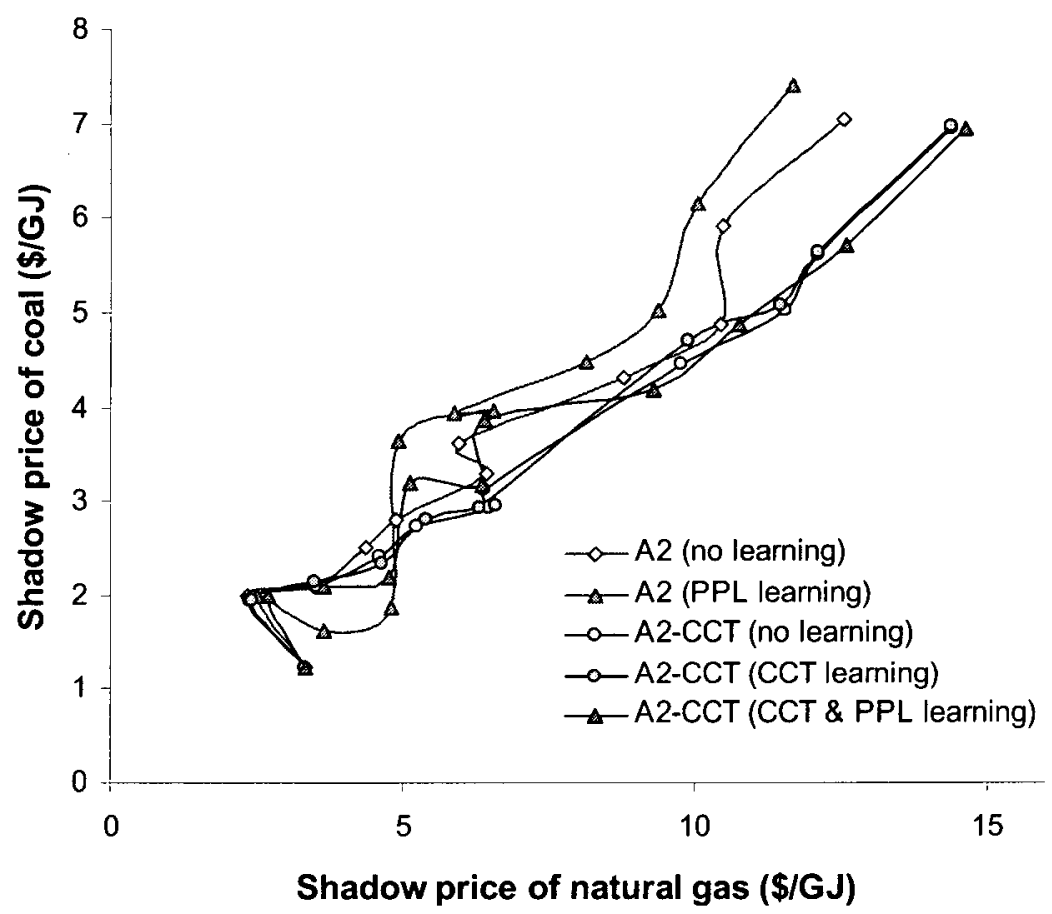

Figure 59: Comparison of the evolution of the shadow prices for natural gas and coal for the period 2000-2100 in the A2 and A2-CCT scenarios.

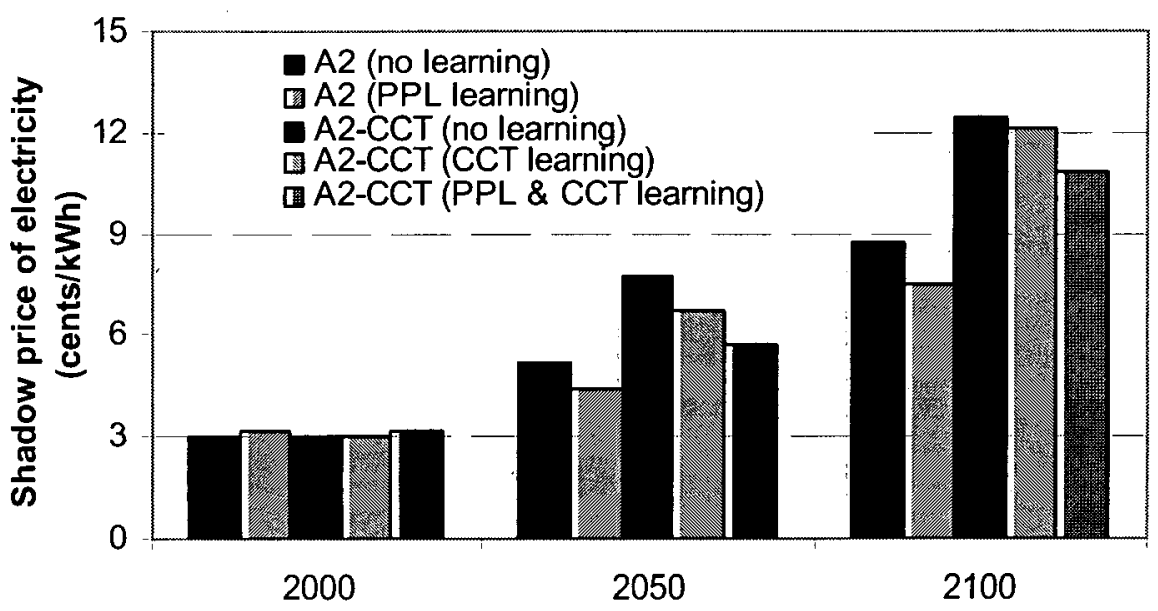

Figure 60: Shadow prices of electricity. 
We turn now to discuss the $\mathrm{CO}_{2}$ emissions associated with the global fossil electricity system. Figure 61 presents the carbon emissions of the global electricity generation system, distinguishing the emissions from individual fossil-fired technologies for the years 2020, 2050 and 2100. Both released and captured emissions are presented.

For all cases, with and without CCT policy, in the short term (up to 2020), today's conventional coal technologies still dominate the fossil generation mix and continue to be mainly responsible for carbon dioxide emissions within the power sector. Scenarios that assume learning for reference power plants are characterized by relatively early penetration of IGCC, substituting advanced coal (supercritical) technologies (which play a prominent role in the short term of scenarios without learning).

Clearly, in the medium and long term, the contribution of different power plants to the global emissions differs substantially in the A2-CCT scenarios compared to the A2 scenario. In the A2 scenario without learning (for power plants), supercritical coal-fired plants dominate fossil-fired electricity production and, thus, evolve to become the main emitters in the long term, reaching $8.4 \mathrm{Gt}$ of carbon by the end of the $21^{\text {st }}$ century. In the case with learning the power sector is dominated by coal-fired high temperature fuel cells responsible for emissions of about $7.8 \mathrm{GtC}$ in 2100. Other technologies such as IGCC and NGCC also contribute noticeable amounts of carbon emissions in the baseline scenarios. By the end of the $21^{\text {st }}$ century, $\mathrm{CO}_{2}$ emissions from advanced supercritical coal plants, IGCC, gas combined-cycle turbines, and coal-fired high temperature account on aggregate for $13 \mathrm{GtC}$ in the case with learning for power plants, and $12.2 \mathrm{GtC}$ in the case of no learning. This corresponds to $45 \%$ of the scenario's total emissions in the case of learning and to $40 \%$ in the case of no learning respectively. In the A2-CCT scenarios all fossil power plants are equipped with carbon capture technologies, and hence the resulting emissions from the power sector corresponds just to 3 to $4 \%$ of the total emissions (depending on the scenarios assumptions concerning learning).

Finally, Figure 62 presents the total emissions from the electricity generation system in industrialized (IND) and developing (DEV) regions for two selected scenarios: the A2 baseline without learning and the A2-CCT case with learning for power plants as well as capture technologies. In the A2 scenario, emissions from the electricity sector in both groups of regions grow substantially along the time horizon, reaching $5.6 \mathrm{Gt}$ carbon and $6.6 \mathrm{Gt}$ carbon by the end of the $21^{\text {st }}$ century in industrialized and developing regions respectively. After the year 2080 emissions in developing regions become larger than those in industrialized regions. With the imposition of the CCT policy, emissions in both groups of regions peak and decline in the long term. Clearly, the time when emissions peak is related to our assumptions concerning the penetration of the carbon-capture technologies described above in section 3.5, under which an early and relatively swift implementation of the CCT policy takes place. Since it is assumed that industrialized regions introduce the policy first, emissions in this group of regions peak already in 2020 at $1.6 \mathrm{Gt}$ carbon as the CCT policy begins to have an effect on the system. As for the developing regions, their electricity-related emissions peak around 2040 at about $2 \mathrm{Gt}$ carbon and decline afterwards. 

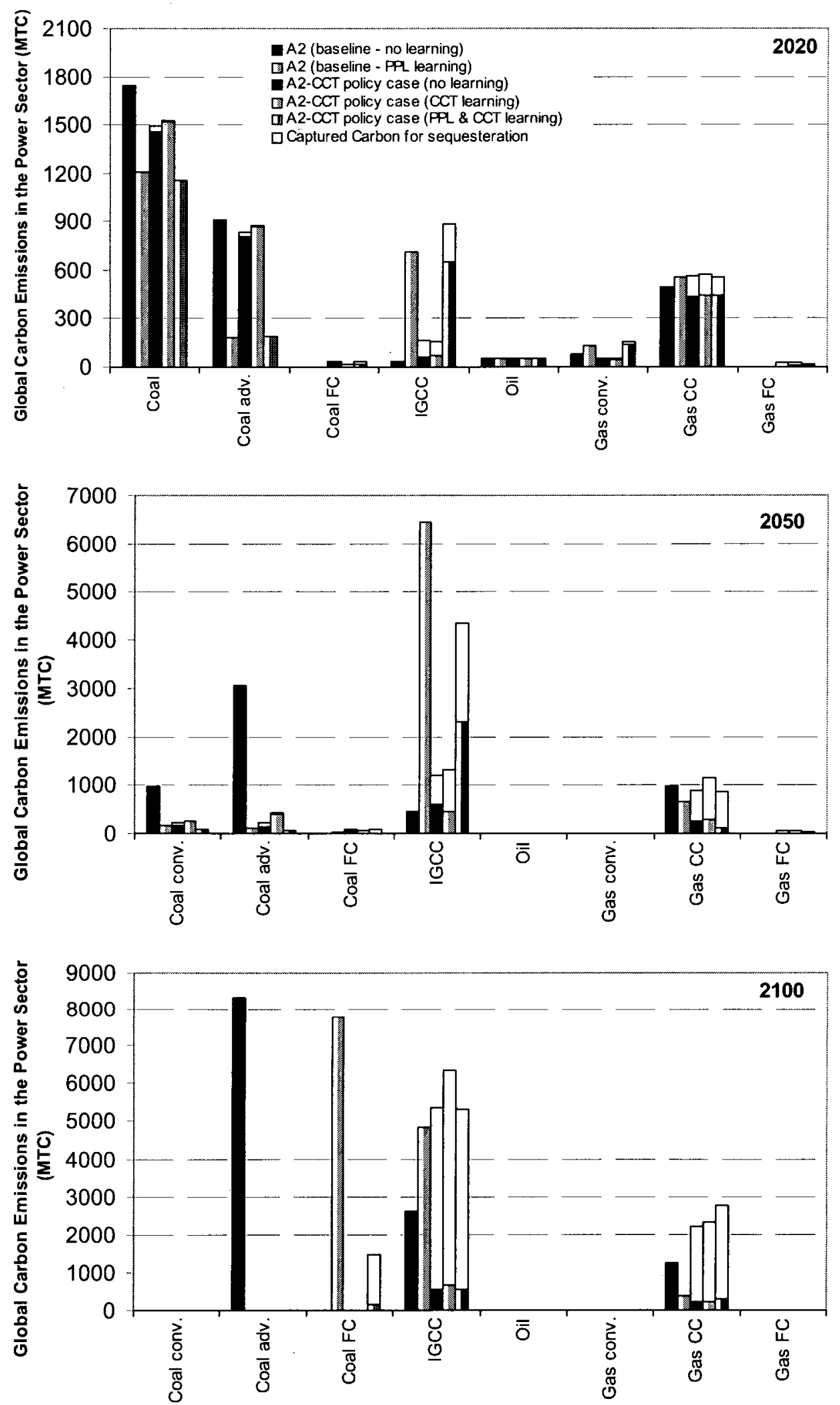

Figure 61: Global carbon emissions in the electricity generation sector by technology. The amounts of carbon captured and released are distinguished. 


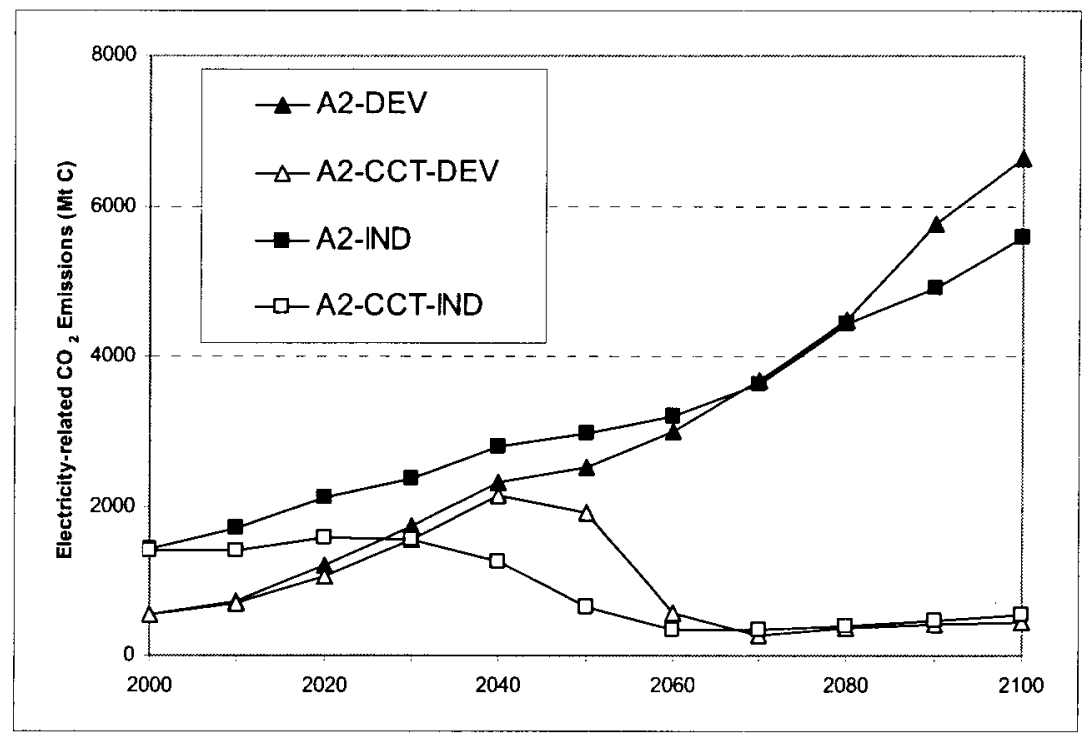

Figure 62: Electricity-related carbon dioxide emissions in industrialized (IND) and developing (DEV) regions in the A2 (no learning) and A2-CCT (PPL \& CCT Learning) scenarios.

\subsection{Final energy mix}

In order to understand better the effects of the CCT policy on the global energy system, it is important to examine the changes in the final-energy mix. As a reference, Figure 63presents the evolution of the market shares of the different energy carriers in the global final-energy mix in the A2 scenario (without CCT policy). ${ }^{36}$

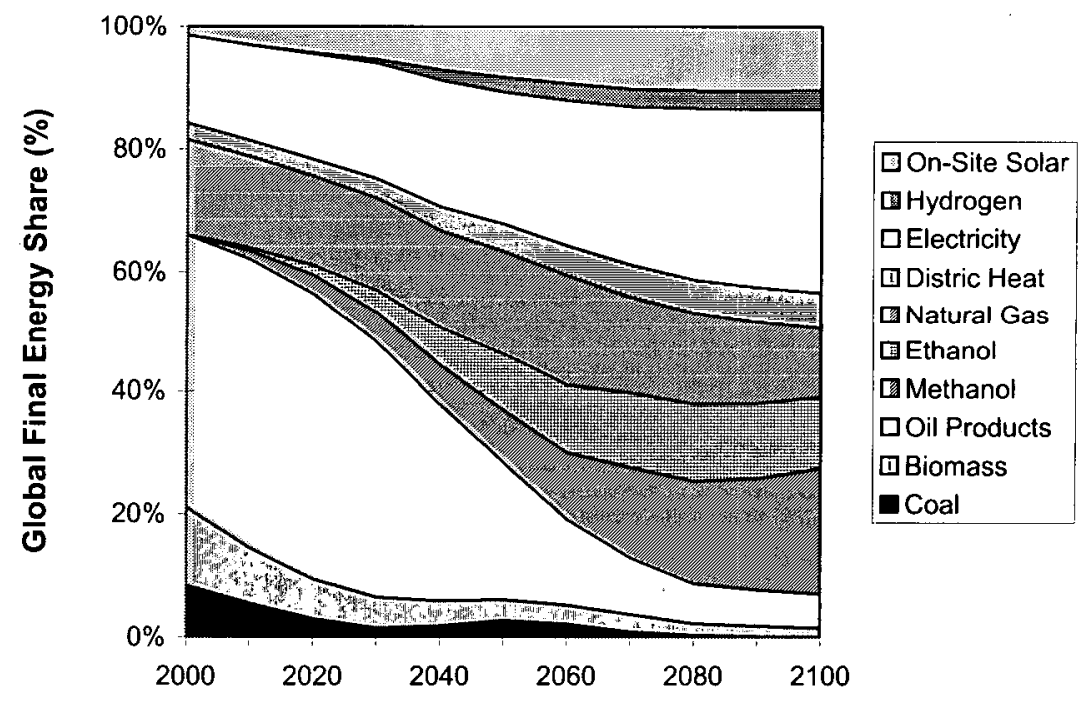

Figure 63: Evolution of global market shares of different final-energy carriers for the period 2000-2100 in the A2 scenario.

\footnotetext{
${ }^{36}$ Note that there is no significant difference between the evolution of the final energy mix in the A2 and the A2 (PPL learning) scenarios.
} 
Although, as mentioned further above, coal is the dominant energy carrier in the primary energy mix, this is not the case at the final energy level. The scenario portrays a consistent trend towards cleaner and more convenient and flexible final energy carriers, which continues well into the future. Therefore, direct uses of coal, together with those of biomass, disappear in the long run. Instead, coal is converted into higher quality final-energy carriers, such as electricity and liquid fuels, mainly methanol. Biomass, on its turn, is converted into ethanol and electricity as well. In the long term, electricity and alcohols, together with natural gas, dominate the final-energy mix. Oil products, today's prevailing fuels, reduce their share drastically. Other energy carriers such as solar energy (on-site facilities), district heat and hydrogen play a more reduced role.

With the introduction of the CCT policy, several changes are observed. Figure 64 presents a comparison of the final-energy mix in the year 2100 for the A2 scenario without learning and two selected A2-CCT cases. Due to the introduction of the CCT policy, electricity becomes relatively more expensive, leading to price-induced changes of electricity demand, and hence, relatively lower electricity consumption in the A2-CCT cases. Also the increased use of biomass for power generation in the CCT scenarios lead to a relative price increase of this energy carrier, which reduces the demand for biomass-based liquid fuels (ethanol). In addition, the contribution of natural gas in the final-energy mix is somewhat reduced. As mentioned before, natural gas combined-cycle plants increase their production in the A2-CCT cases. Finally, since coal is being used less intensively in the power sector in the A2-CCT cases, it becomes available for other purposes. As a result, more carbon-intensive energy carriers such as oil products and coalbased methanol increase their share of the global final-energy mix.

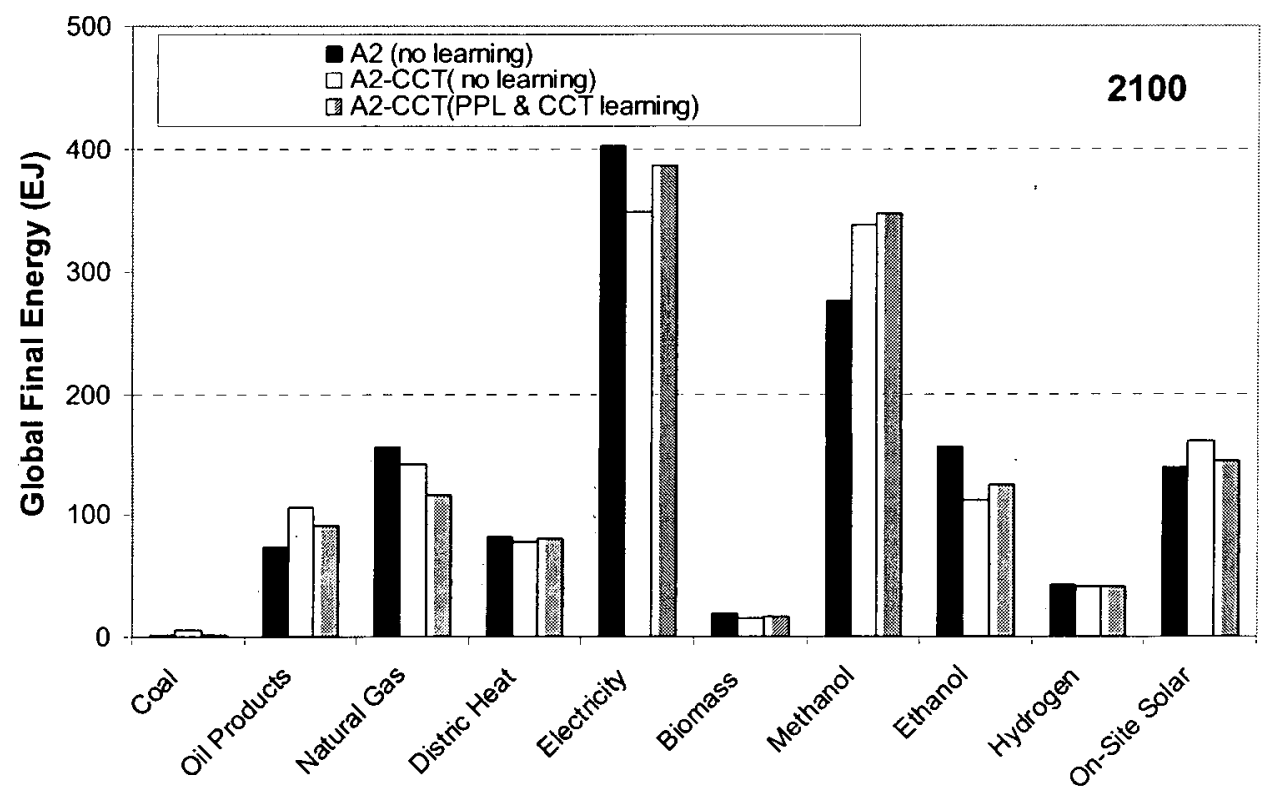

Figure 64: Comparison of the global final-energy mix in the year 2100 for the $\mathrm{A} 2$ (no learning), the A2-CCT (no learning), and the A2-CCT (PPL \& CCT learning) scenario.

\subsection{Carbon capture and storage}

In this section, the contribution of the individual carbon capture technologies in the CCT policy scenarios are analyzed. In addition, we estimate the cumulative amounts of stored carbon in the 
A2-CCT scenarios and compare them with some estimates of storage potential in natural reservoirs available in the literature.

Figure 65 depicts the amounts of captured $\mathrm{CO}_{2}$ along the time horizon in the A2-CCT (PPL \& CCT Learning) case. Following the asssumed implementation of the CCT policy, the amounts of captured carbon increase gradually along the $21^{\text {st }}$ century.

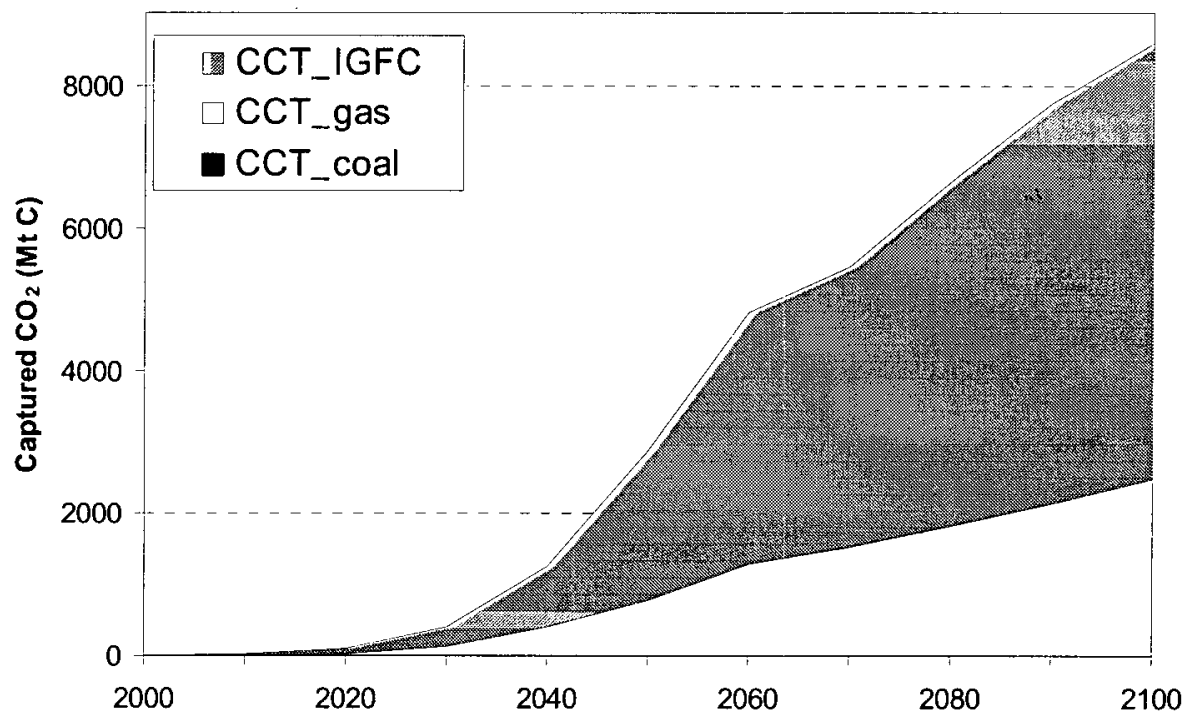

Figure 65: Captured CO2 along the time horizon in the A2-CCT (PPL \& CCT Learning) scenario. The contributions of the three CCT clusters are distinguished.

The largest amounts of carbon are captured by the CCT_IGFC technology (mainly from IGCC power plants). Smaller but still significant amounts are captured by the CCT gas technology (from gas-fired combined-cycle turbines). As conventional coal-fired power plants are displaced from the global generation mix, the capture technology associated to them (CCT_coal) plays no role in the A2-CCT scenario with full learning. Note that this technology cluster plays also just a marginal (transitional) role in the other CCT scenarios (see for a comparison Figure 61). In the long term, pre-combustion systems in IGCC and coal-fired high temperature fuel cells, offering lower additional costs and energy penalties and a more convenient $\mathrm{CO}_{2}$ separation approach, dominate the carbon capture mix.

In our perfect foresight cost-minimization framework, the model endogenizly chooses those pairs of power plants and carbon capture technologies that provide an optimal combination between costs and efficiencies of electricity generation and carbon capture process. Also in the real world, there is a strong complementarity between carbon capture technologies and fossil-based electricity generation plants. Since the technology choice for fossil power generation becomes critical for achieving carbon dioxide separation in an efficient and cost-effective manner, and since the imposition of carbon-capture requirements may lead to significant changes in the characteristics of power-plant designs, their evolution is likely to be intertwined.

The cumulative storage requirements in two selected A2-CCT scenario (no learning case, and the PPL \& CCT learning case) from the year 2000 to 2020,2050 and 2100 respectively are shown in 
Figure 66. Notice that although the amounts of carbon dioxide captured by each technology differ between the learning and no learning cases they both provide the same ranking of carbon capture technologies in our particular exercise. As also shown in Figure 66 the cumulative storage is considerably higher in the case of learning.

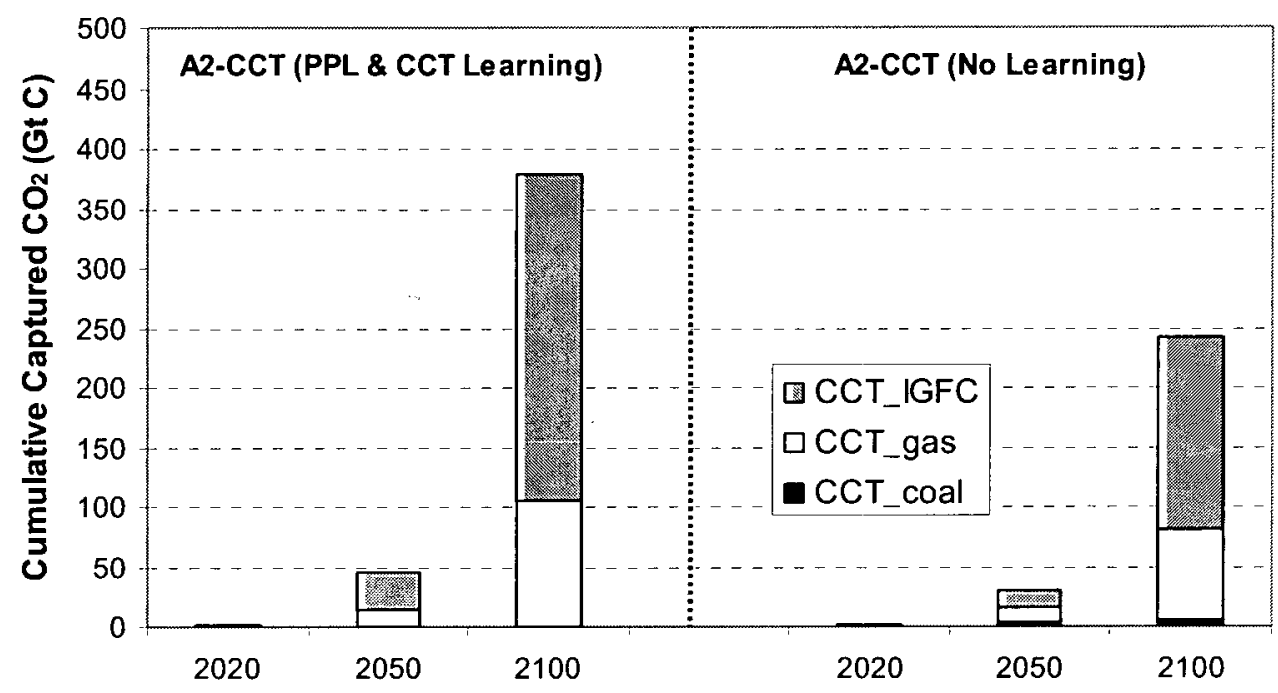

Figure 66: Cumulative amounts of captured $\mathrm{CO} 2$ in the A2-CCT scenario (PPL \& CCT learning case on the left side and no learning case on the right side). The contributions of the three CCT clusters are distinguished.

As mentioned above, in our modeling exercise we did not impose bounds on the amount of carbon that could be sequestered. It seems then instructive to compare the cumulative carbon sequestration figures in the A2-CCT scenario with some available estimates of global $\mathrm{CO}_{2}$ storage potentials. Only preliminary estimates of these potentials have been made (see e.g. Herzog, 2001, IEA, 2001, 2002a) and there are still huge uncertainties about the plausible ranges.

Although alternatives for indirect sequestration of carbon exist, we deal here only with the options for direct sequestration, namely geological reservoirs and ocean storage (NCCTI, 2002, IEA, 2001, 2002a). Geological storage options fall into two main categories: Near-term opportunities in depleted oil and gas fields and unminable coal seams and long-term opportunities in deep saline aquifers. The latter appear to offer a potentially much larger storage capacity than the former. As for the ocean, already the primary natural sink for atmospheric $\mathrm{CO}_{2}$, it appears to have the largest additional storage capacity of all options. However, the ocean storage process seems to be much more complex. Also, its potential environmental impacts could be huge and are not yet well understood (IEA, 2002a). Thus, it is still a controversial alternative. Table 18 presents the preliminary ranges proposed by IEA (2001). Four categories are presented. The first three of them correspond to geological storage options and the last to ocean storage.

When the cumulative amounts of stored carbon obtained in the A2-CCT scenarios are compared to the potentials in Table 18, it can be seen that they lie somewhat above the estimate for storage potential in depleted oil and gas fields but well below the upper estimate for deep saline reservoirs. 
Table 18: Global carbon storage capacity of natural reservoirs (Gt carbon) following estimates of IEA (2001) and cumulative stored carbon in the A2-CCT scenarios (PPL \& CCT learning, CCT leaning, and no learning cases).

\begin{tabular}{lccc}
\hline Storage Option & Global Capacity (Gt C) \\
\hline Depleted oil and gas fields & & 250 \\
Deep saline reservoirs & & $110-2700$ & \\
Unminable coal mines & & $>4$ & \\
Ocean & & $>1400$ & \\
\hline Cumulative stored carbon & PPL \& CCT & CCT learning & no learning \\
in the A2-CCT scenarios & learning & & \\
(2000-2100), GtC & 379 & 284 & 242 \\
\hline
\end{tabular}

\subsection{Global carbon emissions}

The global energy-related $\mathrm{CO}_{2}$ emissions resulting in the A2-CCT cases are compared to those of the A2 scenarios in Figure 67. Without the introduction of the CCT policy, energy-related carbon emissions follow a fast growth path reaching globally around $28 \mathrm{Gt}$ of carbon at the end of the $21^{\text {st }}$ century. This represents about a five-fold increase as compared to the emissions of the year 1990. Note that the introduction of learning in the baseline scenario leads to higher deployment of fossil fuels in the electricity sector (as compared to the baseline without learning). This in turn, leads to an increase of fossil fuel prices, pushing the demand for non-electric renewable energy in other sectors. Hence, some of the emissions increase in the power sector is compensated by additional decarbonization taking place in the non-electric sectors. On aggregate, this effects that the baseline emissions in the case with and without learning do not differ significantly in the long run.

With the CCT policy in place, carbon emissions reach levels between 23.2 and $24.5 \mathrm{GtC}$ in the year 2100 (depending on the assumptions for learning in the power plants and the carbon capture technologies). That is, the imposition of the policy leads to a net emissions reduction of about 6 $\mathrm{GtC}$ in the year 2100 , corresponding to about $20 \%$ of the total baseline emissions. 


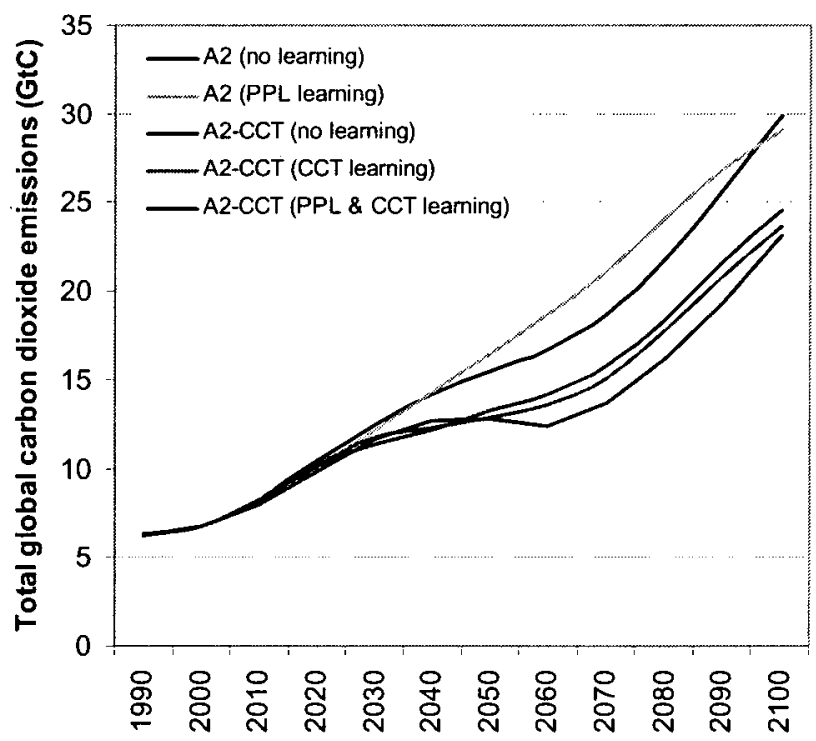

Figure 67: Evolution of the global energy-related carbon dioxide emissions in the A2 and A2CCT scenarios for the period 1990-2100.

This net emissions reduction in the A2-CCT scenarios results from the interaction of two factors, namely the capture and sequestration of $\mathrm{CO}_{2}$ in the fossil-fired power sector and the decarbonization/recarbonization effects that the policy triggers in the electricity sector and other energy sectors. Figure 68 shows a decomposition of the factors that influence the difference in emissions between the A2 and A2-CCT scenarios for the years 2050 and 2100. In order to keep the analysis simple and transparent, we have selected the A2 (no learning) scenario as the baseline and compare sources for emissions reductions (structural change \& carbon capture) for two selected A2-CCT scenarios (no learning case, and the PPL \& CCT learning case). ${ }^{37}$

\footnotetext{
${ }^{37}$ The same conclusions would apply (although exact numbers would differ) if we used the A2 (PPL learning) scenario instead of the A2 (no learning), or the A2-CCT (CCT learning) instead of A2-CCT (PPL \& CCT learning).
} 

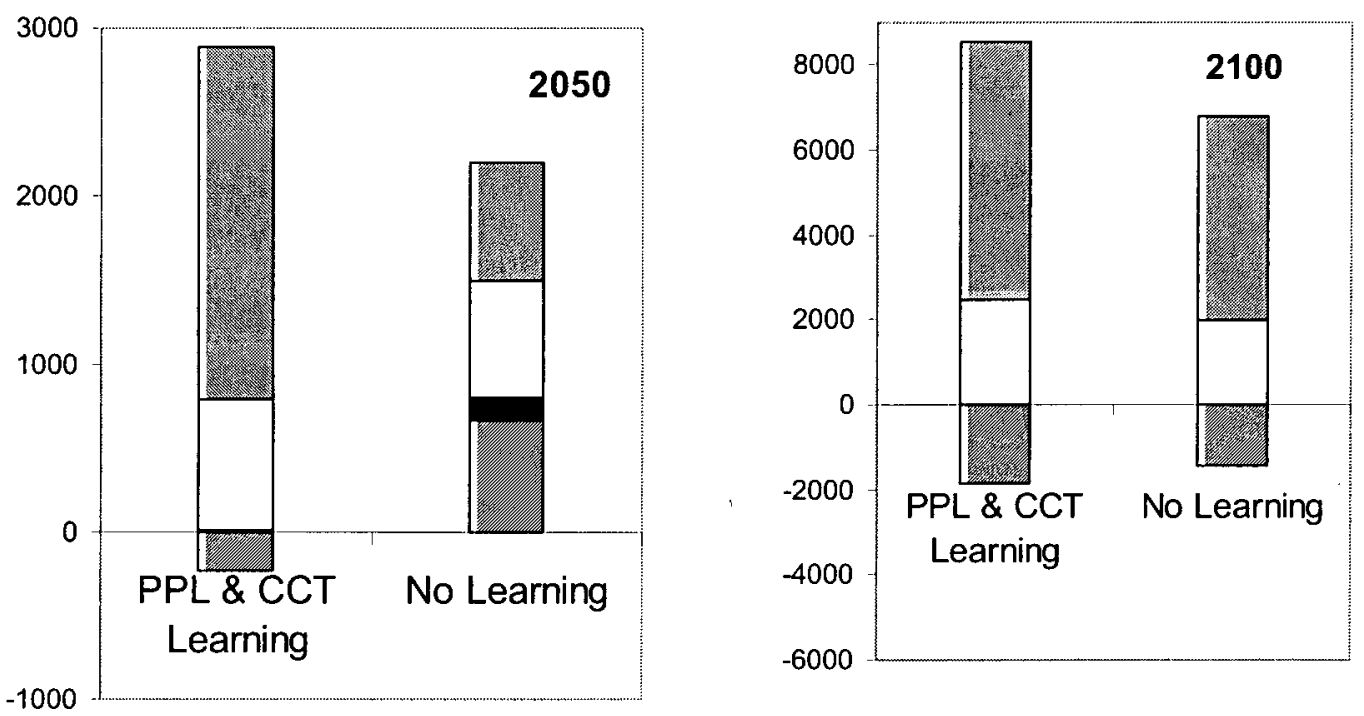

S Structural change $\mathrm{CCCT}$ _coal $\square$ CCT_gas $[\mathrm{CCT}$ _IGFC

Figure 68: Contribution of carbon capture and sequestration and structural changes in the energy system to the net $\mathrm{CO} 2$ emissions reduction in the A2-CCT (no learning, and PPL \& CCT learning) scenarios relative to the $\mathrm{A} 2$ scenario without learning.

Clearly, the factor with the largest influence in the emissions reduction is the capture and sequestration of $\mathrm{CO}_{2}$ from fossil-fired power plants. The amount of captured and sequestered carbon dioxide increases along the time horizon as the CCT policy becomes more stringent, amounting to approximately 8.6 Gigatons of carbon in the year 2100 in the case with full learning (PPL \& CCT). However, this emission reduction is reinforced/compensated by other structural changes in the global energy system.

Those structural changes can be separated as those occurring within the electricity sector and those outside the electricity sector. As discussed above, since the policy makes fossil-fired power plants more expensive, they lose market share against renewable-based electricity generation. As a result, an additional decarbonization of the global electricity system takes place. Since the costs of fossil electricity generation is higher in the CCT cases without learning, this additional decarbonization effect is more pronounced in the CCT scenarios without learning (see e.g., the additional decarbonization of the A2-CCT (no learning) scenario for the year 2050 in Figure 68).

There are also structural changes triggered by the CCT policy in sectors other than electricity production. Although changes are different in different sectors (see Table 19 below), the net effect is mainly one of recarbonization, since a larger consumption of more carbon-intensive fossil fuels occurs in other energy supply and end-use sectors (in the CCT scenarios as compared to the baseline). This is a consequence of two main factors. On the one hand, it is a result of the more expensive electricity production that drives the substitution of other energy carriers for electricity at the final-energy level described above. On the other hand, it is a consequence of the changes in the electricity system favoring less carbon-intensive energy carriers (i.e. biomass and natural gas), which makes their availability for other purposes (direct use in the case of natural gas and conversion to ethanol in the case of biomass) lower. In contrast, there is a higher availability of other energy carriers, which are used less in the electricity sector (i.e. coal and oil 
products). Thus, a substitution of electricity, ethanol and natural gas by coal-based methanol and oil products takes place at the final-energy level.

In the case that no learning for fossil power plants and capture technologies are assumed the increase of fossil electricity prices are more pronounced than in the case of learning. Hence, in the first half of the $21^{\text {st }}$ century, the additional decarbonization of the electricity system (due to the relatively higher contribution of renewable/nuclear power technologies) dominates over the recarbonization in other sectors. On aggregate, this leads (in the case that no leaning is assumed) to total $\mathrm{CO}_{2}$ emissions reductions in the year 2050 that are larger than the amount of captured and sequestered carbon (see Figure 68). Due to the relatively lower generation costs of fossil electricity, the additional decarbonization effect in the electricity sector is less pronounced in the scenario with PPL \& CCT learning. Hence, the recarbonization effect in the non-electric sector is dominating already in 2050 , leading to the leakage of $\mathrm{CO}_{2}$ emissions from the electricity sector to non-electric sectors.

In the second half of the century, the final result of these structural changes is in both scenarios (with \& without learning) that the decarbonization trend of the electricity sector is offset by the increased emissions in other sectors. By the end of the century, the ensuing recarbonization trend makes the CCT policy less effective. That is, the net carbon emissions reduction is lower than the amount of captured and sequestered $\mathrm{CO}_{2}$.

In order to understand better the effects of the CCT policy in other energy sectors, a more detailed examination of the contribution of different sectors to the global carbon dioxide emissions is presented in Table 19. The carbon dioxide emissions in the A2-CCT scenario (PPL \& CCT learning) are presented according to the sector where they are originated for the years $2000,2020,2050$ and 2100. In parenthesis, the changes relative to the A2 scenario (no learning) are presented (in percent). The emissions are illustrated for three main categories in the energy supply side and for the main end-use sectors where direct use of fossil fuels occurs.

Table 191: Disaggregation of CO2 emissions by sectors in the A2-CCT (PPL \& CCT learning) scenario. Changes relative to the A2 (no learning) scenario are presented in parenthesis.

\begin{tabular}{lcccc}
\hline & 2000 & 2020 & 2050 & 2100 \\
Energy SupplyITransformation, MtC & $1999(0 \%)$ & $2645(-19 \%)$ & $2566(-49 \%)$ & $989(-90 \%)$ \\
Electric Generation & $0(0 \%)$ & $356(12 \%)$ & $1964(20 \%)$ & $8985(32 \%)$ \\
Synfuels Production & $688(0 \%)$ & $952(-5 \%)$ & $1335(-25 \%)$ & $3528(-26 \%)$ \\
\hline Other conversion & & &
\end{tabular}

\begin{tabular}{lcccc} 
Direct Use of Fossil Fuels by Sector, MtC & & & & \\
Residential/Commercial & $910(0 \%)$ & $1221(0 \%)$ & $1507(-3 \%)$ & $919(0 \%)$ \\
Industry & $1191(0 \%)$ & $1461(2 \%)$ & $1259(-1 \%)$ & $1645(4 \%)$ \\
Transportation & $1597(0 \%)$ & $2507(0 \%)$ & $2868(-1 \%)$ & $5038(20 \%)$ \\
Feedstocks & $374(0 \%)$ & $739(0 \%)$ & $1315(0 \%)$ & $2084(5 \%)$ \\
\hline TOTAL emissions, MtC & $6759(0 \%)$ & $9880(-6 \%)$ & $12814(-17 \%)$ & $23187(-22 \%)$ \\
\hline
\end{tabular}

* Other conversion includes emissions from district heat production, energy transmission/distribution, oil refining, fuel extraction and other conversion-losses.

On the supply side, the main changes are noticeable in the electricity and synthetic fuels production sectors. As discussed above, emissions from the electricity generation sector are 
strongly reduced as a consequence of the carbon capture policy. In contrast, the emissions associated with synthetic fuel production increase, mainly due to the shift away from biomassbased ethanol towards fossil-based methanol. As for the emissions associated to the direct use of fossil fuels as final-energy carriers, the most pronounced changes occur in the transportation sectors, where the decline in the use of oil products becomes less steep under the A2-CCT policy.

\section{Conclusions}

This report has examined the role of fossil-fired power plants equipped with carbon capture storage systems in a coal-intensive long-term scenario of the global energy system. Assuming the introduction of a technology policy that requires over time an increasing fraction of fossil-fired power generation to incorporate carbon capture technologies, we have examined the potential contribution that this option could offer in reducing energy-related carbon emissions at the global level and highlighted some of the technologies that may play a role in achieving this goal. The analysis has been carried out with the systems engineering model MESSAGE, considering endogenous technological learning for fossil power plants and carbon capture technologies, such that they experience cost reductions as a function of accumulated capacity installations.

With the imposition of the CCT policy on the global electricity system, significant changes take place in the fossil-fired share of the generation mix. Technologies are chosen, which provide the most cost-effective combination between electricity generation and carbon capture. Specifically, integrated gasification combined cycle (IGCC) plants appear as the most attractive option in the long run. Besides them, coal-fired high temperature fuel cells and natural gas combined cycle plants with high conversion efficiencies, also play an important role in the policy constrained A2-CCT worlds. These results, of course, remain dependent, among others, on our assumptions about the learning characteristics of both carbon capture technologies and power plants and the methodological treatment of technology learning in the model.

The CCT policy has additional effects within the electricity system and in other energy sectors. Within the power generation sector, the policy makes fossil-fired power plants less competitive and leads to an additional penetration of non-fossil generation technologies (additional decarbonization). In the non-electric sectors, the imposition of the CCT policy leads to an increased use of more carbon-intensive fossil fuels (recarbonization). This is predominantly due to (1) the higher costs for electricity production, which drive the substitution of electricity by other carbon-intensive energy carriers at the final energy level, and (2) the changes in the electricity system favoring less carbon-intensive energy carriers (e.g. biomass and natural gas), reducing their availability, and hence, also their use in other non-electric sectors. On aggregate, the decarbonization trend in the electricity sector is offset in the long term by the increased emissions in other sectors. This in turn leads to the leakage of $\mathrm{CO}_{2}$ emissions from the electric to non-electric sectors, making the CCT policy less effective.

Clearly, carbon capture and sequestration is but one of many possible alternatives for reducing the carbon-intensity of the global electricity generation system. These technologies will have to prove effective and competitive with other options such as, renewables, nuclear power, and efficiency improvements, if they are to become part of an integrated GHG mitigation strategy. Nevertheless, fossil-based power plants are going to play a significant role well into the future, 
even if a transition to a post-fossil energy system takes place at very high pace. Given this fact, it appears worth ensuring that the fossil-based systems that would bridge such transition are as clean as possible, as to minimize their environmental effects.

Often carbon capture and other zero-carbon technologies are seen as competing and mutually excluding options. We believe, however, that in a carbon constraint world the penetration of both technologies could play complementary roles, permitting to achieve carbon mitigation in a more effective and efficient manner. Carbon capture and sequestration could operate as a "bridging" option during the transformation towards a post-fossil energy system, where renewable and nuclear (fission and/or fusion) technologies could play an important role in the long-term. Stimulating the learning process of both options simultaneously could contribute in hedging the risk that the introduction of carbon capture technologies reinforce the current fossil "lock-in" of the global energy system.

The results of the A2-CCT scenarios portrayed here highlight the importance of stimulating the development and deployment of fossil-fired electricity generation technologies able to capture carbon dioxide in a convenient and efficient way. Our analysis shows that the introduction of a policy for carbon capture and storage would foster the penetration of advanced and more efficient power generation technologies. In particular, coal gasification systems such as, IGCC power plants and high temperature fuel cells, and in addition gas-fired combined cycle power plants appear as the most attractive fossil-fired electricity generation options.

A decisive factor for the choice of the future power generation technology (in a carbonconstrained world) is the cost and efficiency of the associated carbon capture process. The important role played by the various possible combinations of fossil-based power plants and carbon capture technologies highlights also the importance of exploring ways to fully integrate carbon capture systems into future generations of fossil power plants. Including carbon capture considerations directly from the conception and design stages of the power plants would help increasing the effectiveness and reducing the costs of the process. While developments in fossil power plants and carbon capture technologies may appear independent today, they could be intertwined in the long term. Requirements for carbon capture will certainly affect the design and choice of power generation technologies in the future, as carbon capture evolves from its current status of an "add-on" technology towards a "built-in" feature. In the long-term, such interconnected technology evolution could lead to the deployment of new generations of clean and more versatile fossil-based technologies.

Carbon-capture technologies, and the electricity generation technologies most compatible with them, however, still require significant performance and costs improvements as to become a viable and competitive option. Among others, the energy requirements of the capture processes must be substantially lowered and more convenient ways for generating a concentrated stream of $\mathrm{CO}_{2}$ are required. Also, in order to attain effective pre-combustion carbon capture in the long run, IGCC power plants (and high temperature fuel cells) have to overcome a number of current technical barriers and reduce costs as to become competitive in the marketplace.

In order to achieve the necessary improvements, the technologies within a "carbon capture cluster" in the power sector would require policy measures to support their learning processes, i.e. to cover the "learning investments". Sustained efforts in Research, Development, Demonstration and Deployment activities (summarized as RD3, following PCAST, 1999) are required. Research and development needs have been identified in a number of areas 
(IEA/CERT, 2002). However, "demand pull" actions will also be necessary. While some demonstration projects are already in place, additional efforts are required, in particular concerning large-scale demonstration facilities where the different technologies can be adequately integrated. In this respect, business-government partnerships would constitute a very valuable instrument. In addition, niche markets for carbon capture and sequestration systems exist, for instance, in connection with the injection of captured $\mathrm{CO}_{2}$ to enhance the recovery of fossil resources (Socolow, 1997), and it would be worth exploring and tapping them.

As illustrated by the scenarios presented in this report, the decarbonization of the electricity sector through carbon capture and sequestration would lead to significant $\mathrm{CO}_{2}$ emissions reductions in the order of magnitude of about one fifth of total emissions. These emissions reductions, however, will not be sufficient for the stabilization of $\mathrm{CO}_{2}$ concentrations. In all policy cases the long-term emissions path is dominated by increasing contributions from nonelectric sectors, leading to continuous growth of emissions particularly in the second half of the century. Thus, we conclude that the long-term stabilization of $\mathrm{CO}_{2}$ concentrations needs additional measures and a broad portfolio of technologies, ranging from energy efficiency improvements to structural changes in both the energy supply and the demand side.

Still, the contribution of carbon capture and sequestration systems to a greenhouse gases mitigation strategy could be significant, provided a number of issues related to the process of capturing, transporting and sequestering carbon could be resolved. As mentioned above, carbon capture technologies must become less energy-intensive, more cost-effective and allow a more efficient capture of $\mathrm{CO}_{2}$. In addition, a better assessment of the sequestration potential of different reservoirs, their leakage characteristics and associated risks and costs is required. In other words, possible environmental impacts of sequestration and leakage must be quantified and the effectiveness of the overall storage schemes will have to be evaluated. Instrumental in this process will be the development of methods for Measurement, Monitoring and Verification (MMV), providing a better understanding of the long-term fate of stored $\mathrm{CO}_{2}$, thus rising public confidence in carbon capture and sequestration (NCCTI, 2002).

\section{References}

Argote, L., Epple, D., 1990. Learning Curves in Manufacturing. Science 247, 920-924.

Audus, H., Jackson, A.J., 2000. $\mathrm{CO}_{2}$ Abatement by the Combustion of $\mathrm{H}_{2}$-rich Fuels in Gas Turbines. Paper presented to the Fifth International Conference on Greenhouse Gas Control Technologies (GHGT-5). Cairns, Australia, August 13 - 16 (2000).

Barreto, L., 2001. Technological Learning in Energy Optimisation Models and the Deployment of Emerging Technologies. Ph.D. Thesis No 14151. Swiss Federal Institute of Technology Zurich.

David, J., Herzog, H., 2000. The Cost of Carbon Capture. Paper presented to the Fifth International Conference on Greenhouse Gas Control Technologies (GHGT-5), Cairns, Australia, August 13-16, (2000).

DOE, 1999a. Carbon Sequestration. Research and Development. U.S Department of Energy. December, 1999. http://www.fe.doe.gov/coal_power/sequestration/reports/rd/index.shtml 
DOE, 1999b. Clean Energy Plants for the $21^{\text {st }}$ Century. Vision 21 Program Plan. Federal Energy Technology Center. Office of Fossil Energy. U.S. Department of Energy.

Freund, P., Thambimuthu, K., Davison, J., 2002. Sequestering $\mathrm{CO}_{2}$. Chapter 6. In Technology Options for Achieving Significant Greenhouse Gas Emissions Reductions from Energy over the Long Term. Committee for Energy Research and Technology (CERT). International Energy Agency (IEA). Paris, France. Forthcoming.

Gritsevskyi, A., Nakićenović, N., 2000. Modelling Uncertainty of Induced Technological Change. Energy Policy 28, 907-921.

Grübler, A., 1996. Time for a Change: On the Patterns of Diffusion of Innovation. Daedalus 125 (3), 19-42.

Grübler, A., Nakićenović, N.,Victor, D., 1999. Dynamics of Energy Technologies and Global Change. Energy Policy 27, 247-280.

Herzog, H., 2001. What Future for Carbon Capture and Sequestration?. Environmental Science and Technology, 35:7, pp $148 \mathrm{~A}-153 \mathrm{~A}$, April 1, 2001.

Herzog, H., K. Caldeira, and J. Reilly, "An Issue of Permanence: Assessing the Effectiveness of Temporary Carbon Storage," Climatic Change (59), 2003.

IEA (International Energy Agency), 2000. Experience Curves for Energy Technology Policy, IEA Publications, France, Paris, ISBN 92-64-17650-0.

IEA (International Energy Agency), 2001. Putting Carbon back into the Ground. IEA Greenhouse Gas R\&D Programme, Gloucestershire, U.K.

IEA (International Energy Agency), 2002a. Ocean Storage of $\mathrm{CO}_{2}$. IEA Greenhouse Gas R\&D Programme, Gloucestershire, U.K.

IEA (International Energy Agency), 2002b. Key World Energy Statistics 2002. International Energy Agency.

IEA/CERT, 2002: Solutions for the $21^{\text {st }}$ Century. Zero Emissions Technologies for Fossil Fuels. Technology Status Report. Working Party on Fossil Fuels. Committee on Energy Research and Technology. International Energy Agency.

IPCC (Intergovernmental Panel on Climate Change), 2001: Summary for Policymakers (SPM): Climate Change 2001: The Scientific Basis. IPCC, Geneva, Switzerland.

Keller, K., Hall, M., Bradford, D., 2002. Carbon Dioxide Sequestration: When and How Much? Working Paper. Carbon Mitigation Initiative. Princeton University.

Kordesch, K. and G., Simander, 1996, Fuel Cells and their Applications, John Wiley \& Sons, NY, ISBN 3527285792.

Lovins, A., Lovins, H., Hawken, P., 1999. A Road Map for Natural Capitalism. Harvard Business Review, 145-158. May-June, 1999.

Lutz, W. (ed.), 1996: The Future Population of the World: What can we assume today? $2^{\text {nd }}$ Edition, Earthscan, London. 
Mattsson, N., 1997. Internalizing Technological Development in Energy Systems Models. Thesis for the Degree of Licentiate of Engineering. Chalmers University of Technology. Göteborg, Sweden.

Messner, S., 1997. Endogenised Technological Learning in an Energy Systems Model. Journal of Evolutionary Economics 7, 291-313.

Messner, S., Schrattenholzer, L., 2000. MESSAGE-MACRO: Linking an energy supply model with a macroeconomic module and solving it iteratively, Energy 25, 267-282.

Messner, S., Strubegger, M., 1995. User's Manual of MESSAGE III. WP-95-69. International Institute for Applied Systems Analysis (IIASA). Laxenburg, Austria.

Nakićenović, N., 1997. Technological Change as a Learning Process. IIASA Induced Technology Workshop. International Institute for Applied Systems Analysis. Laxenburg, Austria.

Nakićenović, N., A. Grübler, and A. McDonald (eds.), 1998: Global Energy Perspectives. Cambridge University Press, Cambridge, UK.

Nakićenović, N., and Riahi, K., 2001: An assessment of technological change across selected energy scenarios. In: Energy Technologies for the Twenty-First Century, World Energy Council (WEC), London, UK.

NCCTI (National Climate Change Technology Initiative), 2002. $\mathrm{CO}_{2}$ Capture and Storage in Geological Formations. Draft. $\mathrm{CO}_{2}$ Capture and Storage Working Group. NCCTI Energy Technologies Group. Office of Fossil Energy. U.S. Department of Energy.

NETL (National Energy Technology Laboratory), 2000. Developing Power Systems for the $2 I^{\text {st }}$ Century-Fuel Cell/ATS Hybrid Systems. Project Fact Sheet. National Energy Technology Laboratory. U.S Department of Energy.

NETL (National Energy Technology Laboratory), 2001. Coproduction of Power, Fuels and Chemicals. Topical Report \#21. September, 2001. National Energy Technology Laboratory. U.S Department of Energy. http:/www.netl.doe.gov/publications/others/topicals/topical21.pdf

PCAST (President's Committee of Advisors on Science and Technology), 1999. Powerful Partnerships: The Federal Role in International Co-operation on Energy Innovation. President's Committee of Advisors on Science and Technology. Panel on International Cooperation in Energy Research, Development, Demonstration and Deployment. Washington, USA.

Rabitsch, H., 2001, Energy technologies for the 21 st century, Thesis, Graz University of Technology, Graz, Austria.

Rao, A.D., Samuelsen, G.S., Robson, F.L., Geisbrecht, R.A., 2002. Power Plant System Configurations for the $21^{\text {st }}$ Century. Paper presented to the ASME Turbo Expo 2002: Land, Sea and Air. June 3-7, 2002. Amsterdam, The Netherlands.

Reiner, D.M., Herzog, H.J, 2003: A search for regulatory analogs to carbon sequestration. In: J. Gale and Y. Kaya (eds.), Greenhouse Gas Control Technologies: Proceedings of the Sixth International Conference on Greenhouse Gas Control Technologies, Kyoto, Japan, Elsevier Science, Oxford, UK. 
Riahi, K., Barreto, L., Rao, S., 2003, Long-term Perspectives for Carbon Capture in Power Plants: A Scenario for the 21st Century, IIASA Interim Report submitted to the Carnegie Mellon University, Laxenburg, Austria

Riahi, K., Roehrl, R.A., 2000. Energy Technology Strategies for Carbon Dioxide Mitigation and Sustainable Development. Environmental Economics and Policy Studies 3(2), 89-123.

Riahi, K., Roehrl, R.A., Schrattenholzer, L., Miketa, A., 2001. Technology Clusters in Sustainable Development Scenarios. Progress Reports of Environmental Issue Groups, International Forum of the Collaboration Projects. Spring 2001, Tokyo.

Riahi, K., Rubin, E., Taylor, M., Schrattenholzer, L., Hounshell, D., 2002. Technological Learning for Carbon Capture and Sequestration Technologies. Paper submitted to Energy Economics.

Rogner, H. H., 1997: An Assessment of World Hydrocarbon Resources. Annual Review of Energy and the Environment 22, 217-262.

Rubin, E., Hounshell, D., Taylor, M,. Yeh, S., Riahi, K., Schrattenholzer, L., Zhu, B., Roehrl, A., 2001. The Effect of Government Actions on Environmental Technology Innovation: Applications to the Integrated Assessment of Carbon Sequestration Technologies. A Progress Report submitted to the Office of Biological and Environmental Research of the U.S. Department of Energy. Carnegie Mellon University and International Institute for Applied Systems Analysis.

Schaeffer, G.J., 1998: Fuel Cells for the Future. University of Twente, the Netherlands, ISBN 90 36512301 .

Seebregts, A., Bos, S., Kram, T., Schaeffer, G., 2000. Endogenous Learning and Technology Clustering: Analysis with MARKAL Model of the Western European Energy System. Int. J. of Global Energy Issues 14 (1/2/3/4), 289-319.

Simbeck, D., 2001. $\mathrm{CO}_{2}$ Mitigation Economics for existing Coal-fired Power Plants. Paper presented at the First National Conference on Carbon Sequestration. National Energy technology Laboratory (NETL). U.S. Department of Energy. Washington D.C, May-17, 2001.

Socolow, R. (Editor), 1997. Fuels Decarbonization and Carbon Sequestration : Report of a Workshop. PU/CEES Report No 302. September, 1997. Princeton University. Princeton, NJ.

SRES (Special Report on Emission Scenarios), 2000: A Special Report on Emissions Scenarios for Working Group III of the Intergovernmental Panel on Climate Change (IPCC), Cambridge University Press, Cambridge, UK.

Srinivasan, S., Mosdale, R., Stevens, P., Yang, C., 1999. Fuel Cells: Reaching the Era of Clean and Efficient Power Generation in the $21^{\text {st }}$ Century. Annual Review of Energy and Environment 24, 281-328.

Stiegel, G., 1998. A New IGCC Program Strategy to Meet Future Energy Market Requirements. Federal Energy Technology Center. U.S Department of Energy.

Taylor, M., 2001. The Influence of Government Actions on Innovative Activities in the Development of Environmental Technologies to Control Sulfur Dioxide Emissions from Stationary Sources. Ph.D. Thesis, Carnegie Mellon University, Pittsburgh, PA, Jan 2001. 
Whitacker, R., 1998, Investment in Volume Building: "Virtous Cycle" in PAFC, Journal of Power Sources, 71.

Williams, R.H., Bunn, M., Consonni, S., Gunter, W., Holloway, S., Moore, R., Simbeck, D., 2000. Advanced Energy Supply Technologies. In: World Energy Assessment: Energy and the Challenge of Sustainability, Chapter 5 of the World Energy Assessment.

UNDP/WEC/UNDESA (United Nations Development Programme, World Energy Council, UN Department of Economic and Social Affairs), Washington/New York, US (ISBN: 92-1126126-0). 


\section{Appendix C1. Aggregate technologies in the electricity generation sector}

\begin{tabular}{|c|c|}
\hline \multicolumn{2}{|c|}{ Abbreviations: Technology Description } \\
\hline Coal_Stdu & $\begin{array}{l}\text { Aggregation of various types of traditional (single steam cycle) coal power plants } \\
\text { without FGD and DENOX. Some potential for district heat co-generation. } \\
\text { Efficiencies for the model base year (1990) range between } 38 \text { and } 40 \text { percent. Plant } \\
\text { life is } 30 \text { years and plant factor (availability of utilization) } 65 \text { percent. }\end{array}$ \\
\hline Coal_Stda & $\begin{array}{l}\text { Aggregation of various types of traditional (single steam cycle) coal power plants } \\
\text { with FGD up to } 90 \text { percent and DENOX up to } 50 \text { percent. Some potential for district } \\
\text { heat co-generation. Efficiencies for the model base year (1990) range between } 38 \text { and } \\
40 \text { percent. Plant life is } 30 \text { years and plant factor (availability of utilization) } 65 \\
\text { percent. }\end{array}$ \\
\hline Coal_Adv & $\begin{array}{l}\text { Supercritical coal plant. Efficiencies for the model base year (1990) range between } 40 \\
\text { and } 42 \text { percent. Plant life is } 30 \text { years and plant factor (availability of utilization) } 65 \\
\text { percent. }\end{array}$ \\
\hline CoallGCC & $\begin{array}{l}\text { Integrated (coal) gasification combined cycle with } 99 \text { percent FGD and DENOX. } \\
\text { Some potential for co-generation. Initial efficiency in the base year (1990) is } 43 \\
\text { percent plant life is } 30 \text { years and plant factor } 65 \text { percent }\end{array}$ \\
\hline Oil & $\begin{array}{l}\text { Aggregation of various types of oil power plants (includes e.g., Rrankine cycle with } \\
\text { low NOx emissions and } 90 \text { percent DENOX, but also light oil fueled engine plants). } \\
\text { Some potential for co-generation. Initial efficiency in the base year (1990) ranges } \\
\text { between } 40 \text { and } 46 \text { percent, plant life is } 30 \text { years, plant factor } 65 \text { percent. }\end{array}$ \\
\hline GasStd & $\begin{array}{l}\text { Standard natural gas power plant (Rankine cycle) with district heat co-generation. } \\
\text { Initial efficiency in the base year (1990) is } 40 \text { percent, plant life is } 30 \text { years and, plant } \\
\text { factor } 65 \text { percent. }\end{array}$ \\
\hline GasCC & $\begin{array}{l}\text { Natural gas combined cycle power plant including some potential for co-generation. } \\
\text { Initial efficiency in the base year (1990) is } 50 \text { percent, plant life is } 30 \text { years and plant } \\
\text { factor } 65 \text { percent. }\end{array}$ \\
\hline GasReinj & $\begin{array}{l}\text { Natural gas combined cycle power plant with zero carbon emissions. } \mathrm{CO}_{2} \text { is assumed } \\
\text { to be re-injected in gas or oil fields (e.g., for enhanced recovery). Efficiency loss due } \\
\text { to re-injection (compared to GCC) about } 1 \text { percent. Plant life is } 30 \text { years and plant } \\
\text { factor } 65 \text { percent. }\end{array}$ \\
\hline Fossil FC & $\begin{array}{l}\text { Coal- and gas-based high temperature fuel cell. Efficiency is } 50 \text { percent, plant life } 25 \\
\text { years and plant factor } 65 \text { percent. It is assumed in most of the scenarios that this } \\
\text { technology will be available commercially after } 2010 \text {. }\end{array}$ \\
\hline Waste & $\begin{array}{l}\text { Standard municipal waste power plant (Rankine cycle) with } 90 \text { percent FGD and } 50 \\
\text { percent DENOX. Initial efficiency in the base year }(1990) \text { is } 29 \text { percent, plant life is } \\
30 \text { years and plant factor } 65 \text { percent. }\end{array}$ \\
\hline BioSTC & $\begin{array}{l}\text { Biomass power plant (single steam cycle) with some potential for district heat co- } \\
\text { generation. Initial efficiency in the base year (1990) is } 29 \text { percent, plant life is } 30 \\
\text { years and plant factor } 65 \text { percent. }\end{array}$ \\
\hline Bio_GTC & $\begin{array}{l}\text { Biomass gasification power plant. Initial efficiency in the base year (1990) is } 46 \\
\text { percent, plant life is } 25 \text { years and plant factor } 65 \text { percent. }\end{array}$ \\
\hline Nuc_LC & $\begin{array}{l}\text { Low-cost conventional nuclear power plant (light and heavy water reactor). Initial } \\
\text { efficiency in the base year (1990) is } 30 \text { percent, plant life is } 30 \text { years and plant factor } \\
70 \text { percent. }\end{array}$ \\
\hline
\end{tabular}




\begin{tabular}{|c|c|}
\hline Nuc_HC & $\begin{array}{l}\text { High-cost conventional nuclear power plant (light and heavy water reactor). Initial } \\
\text { efficiency in the base year (1990) is } 35 \text { percent, plant life is } 30 \text { years and plant factor } \\
75 \text { percent. }\end{array}$ \\
\hline Nuc\&0_carb & $\begin{array}{l}\text { Aggregation of various types of advanced nuclear power plants including high } \\
\text { temperature and fast breeder reactors with some potential for district heat and } \\
\text { hydrogen co-generation. Initial efficiency ranges between } 40 \text { and } 45 \text { percent. Plant life } \\
\text { is } 30 \text { years and plant factor } 75 \text { percent. }\end{array}$ \\
\hline Hydro & $\begin{array}{l}\text { Aggregation of various types of hydroelectric power plants. Low and high cost plants } \\
\text { are distinguished in all scenarios in order to reflect the influence of different sites and } \\
\text { other factors on the plant costs. Plant life is } 60 \text { years and plant factor } 50 \text { percent. }\end{array}$ \\
\hline SolarTh & $\begin{array}{l}\text { Solar thermal power plant with storage and some potential for district heat and } \\
\text { hydrogen co-generation. Plant life is } 25 \text { years and plant factors differ significantly } \\
\text { across world regions ranging from } 10 \text { to } 50 \text { percent. }\end{array}$ \\
\hline SolarPV & $\begin{array}{l}\text { Solar photovoltaic power generation excluding onsite electricity production } \\
\text { (predominantly large scale power plants). Plant life is } 25 \text { years and plant factors differ } \\
\text { significantly across world regions ranging from } 10 \text { to } 50 \text { percent. }\end{array}$ \\
\hline Wind & Wind turbine power plant. Plant life is 25 years and plant factor 25 percent. \\
\hline Geothrm & Geothermal power plant. Plant life is 30 years and plant factor 70 percent. \\
\hline $\mathrm{H} 2 \mathrm{FC}$ & $\begin{array}{l}\text { Aggregation of types of hydrogen fuel cells for industrial and residential use with } \\
\text { some potential for district heat co-generation. (Note that explicit assumptions for } \\
\text { investment costs are not part of the MESSAGE model for all end-use technologies } \\
\text { including these types of hydrogen fuel cells. Consequently, it was not possible to } \\
\text { include the H2FC fuel cells in the comparison of investment costs.) }\end{array}$ \\
\hline PV-onsite & Photovoltaic onsite electricity production \\
\hline
\end{tabular}


Appendix $\mathrm{C} 2$. Electricity generation and associated $\mathrm{CO} 2$ emissions in industrialized and developing regions
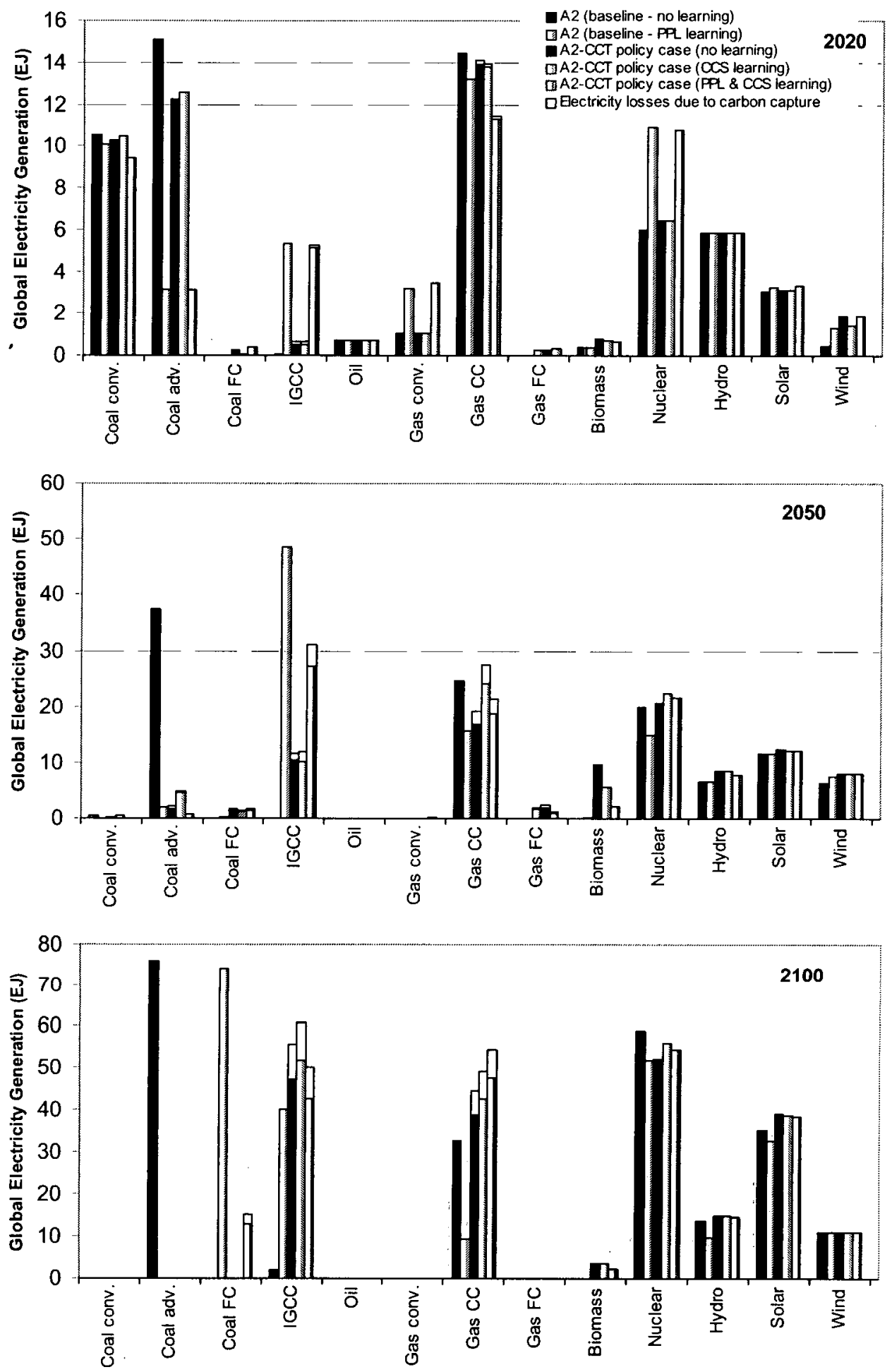

Figure 69: Electricity generation in the industrialized regions for the A2 and A2-CCT scenarios in the years 2020, 2050 and 2100. For the A2-CCT cases, electricity losses due to the carbon capture process are shown as white bars. 

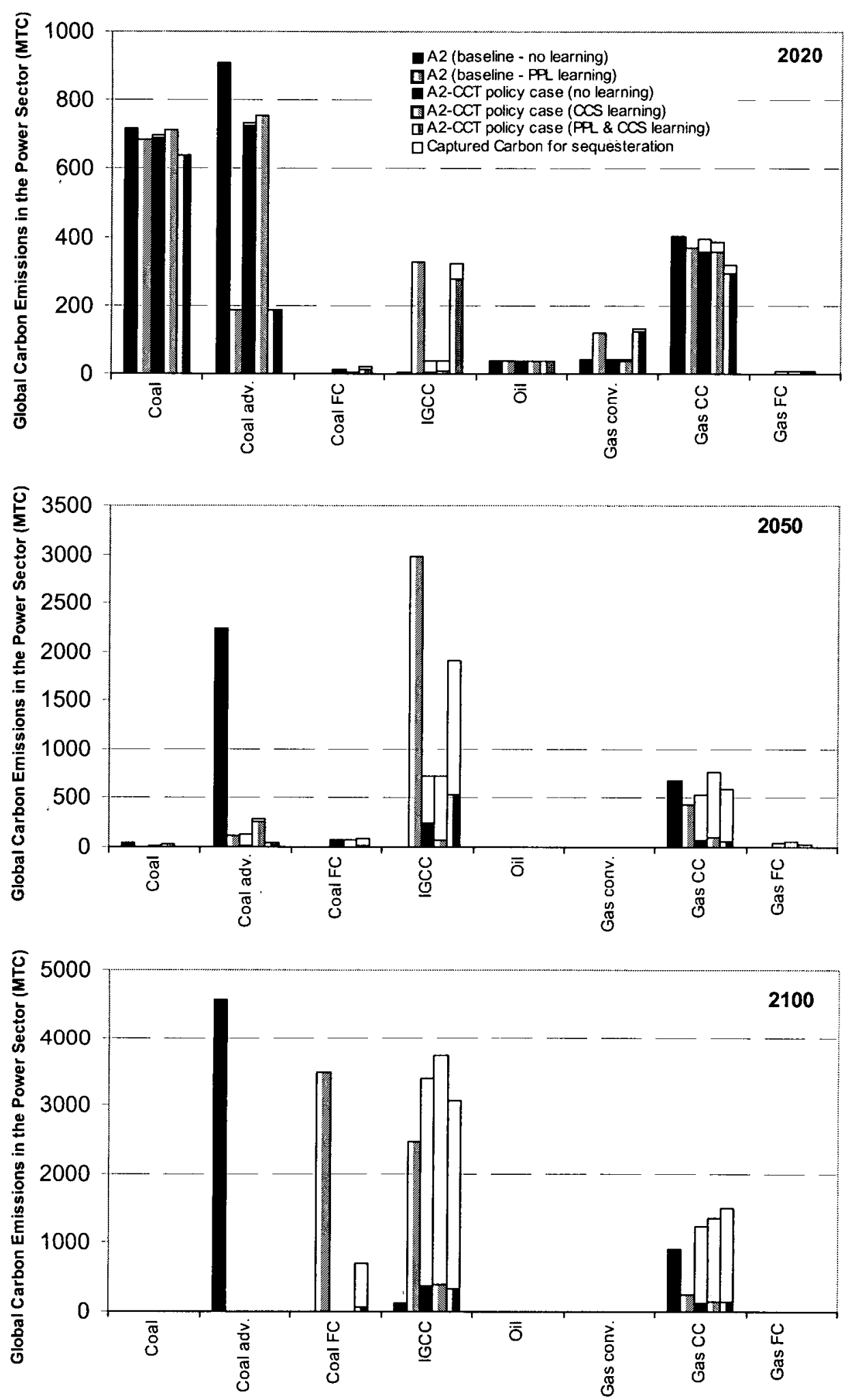

Figure 70: $\mathrm{CO}_{2}$ emissions from the electricity generation in the industrialized regions for the $\mathrm{A} 2$ and A2-CCT scenarios in the years 2020, 2050 and 2100. 

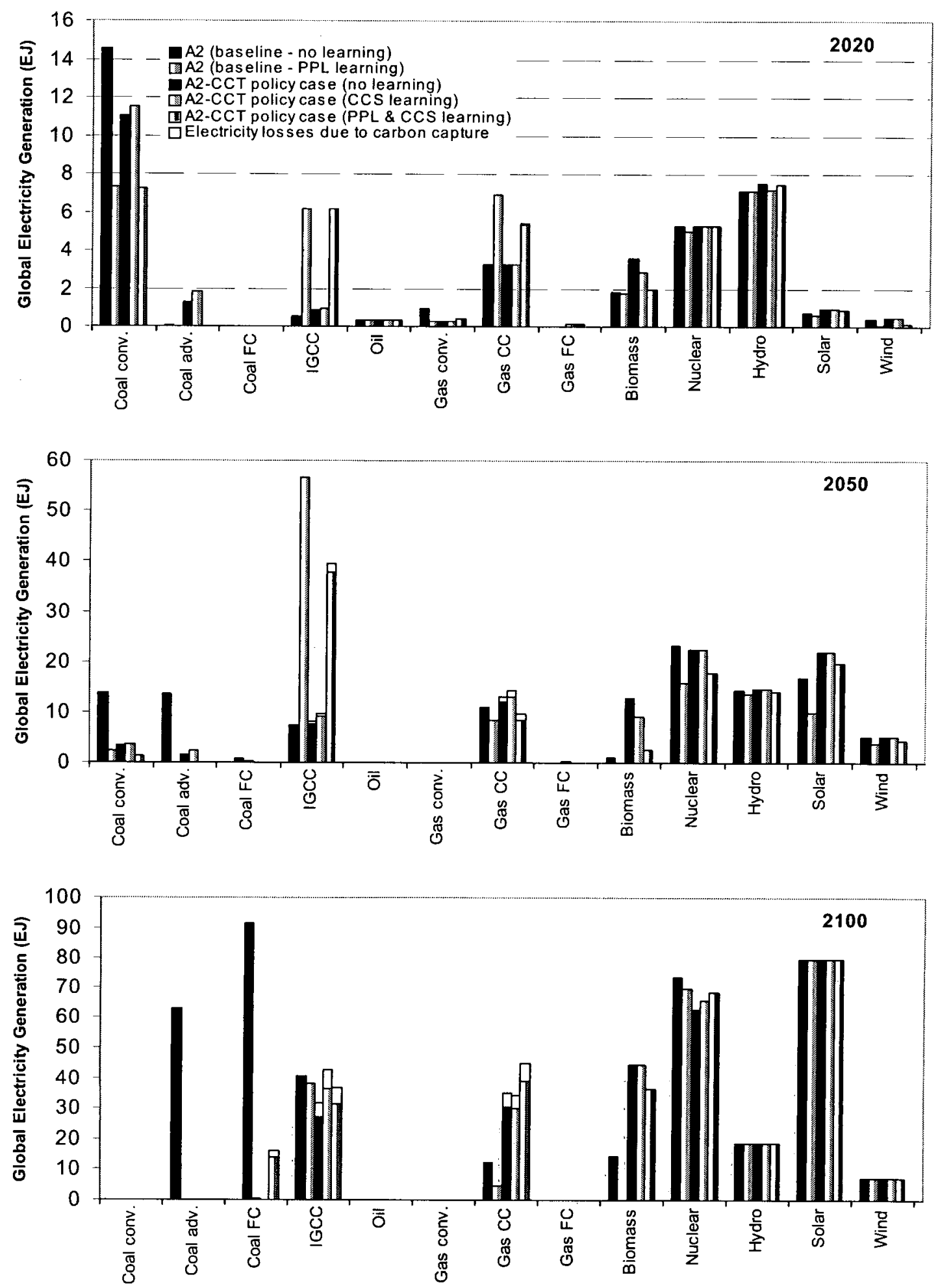

Figure 71: Electricity generation in the developing regions for the A2 and A2-CCT scenarios in the years 2020, 2050 and 2100. For the A2-CCT cases, electricity losses due to the carbon capture process are shown as white bars. 

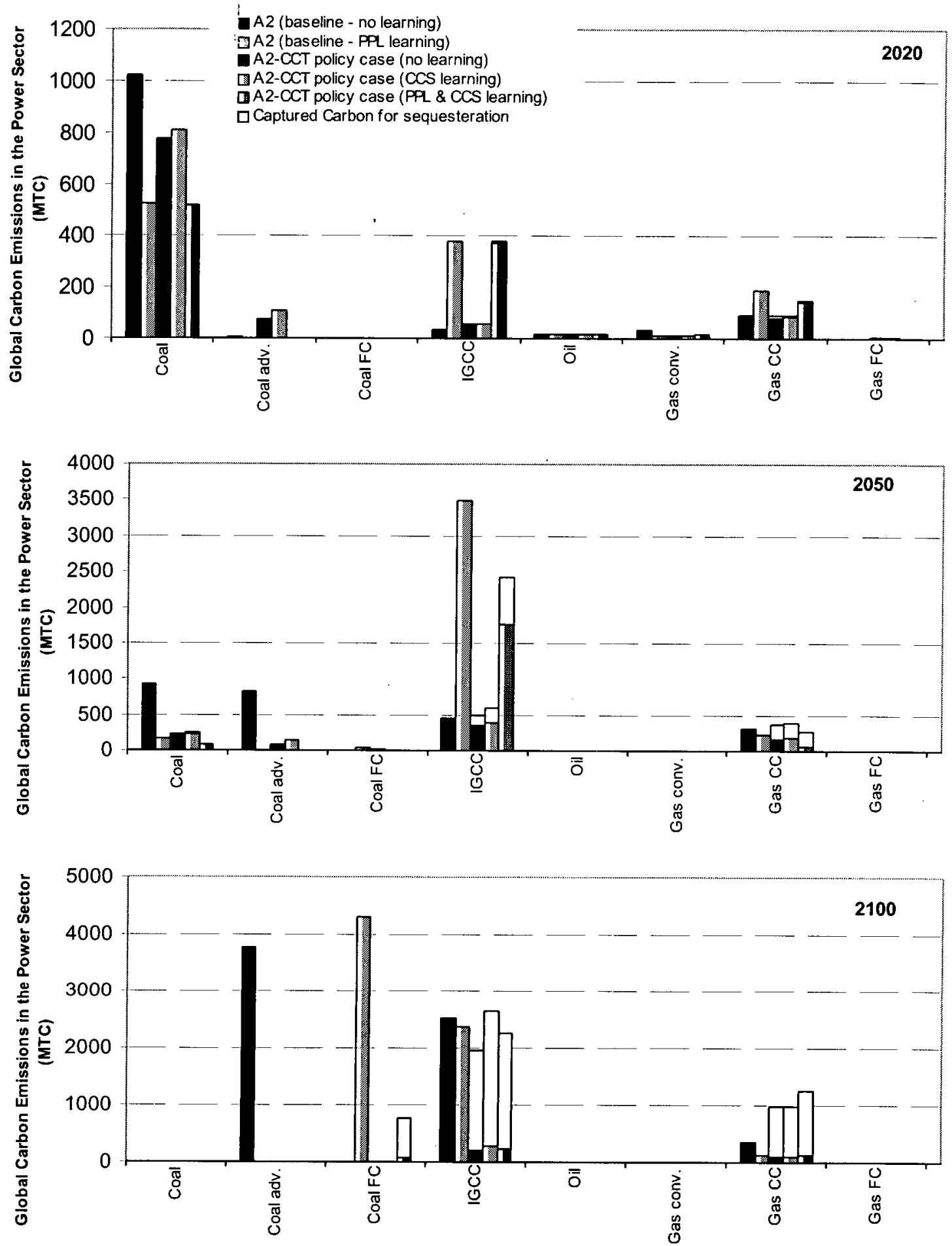

Figure 72: $\mathrm{CO}_{2}$ emissions from the electricity generation in the developing regions for the $\mathrm{A} 2$ and A2-CCT scenarios in the years 2020, 2050 and 2100. 